US Army Corps

of Engineers ${ }_{\circledast}$

Engineer Research and

Development Center

Houston Ship Channel and Vicinity ThreeDimensional Adaptive Hydraulics (AdH) Numerical Model Calibration/Validation Report

Jennifer McAlpin, Cassandra Ross, and Jared McKnight

June 2019 
The U.S. Army Engineer Research and Development Center (ERDC) solves the nation's toughest engineering and environmental challenges. ERDC develops innovative solutions in civil and military engineering, geospatial sciences, water resources, and environmental sciences for the Army, the Department of Defense, civilian agencies, and our nation's public good. Find out more at www.erdc.usace.army.mil.

To search for other technical reports published by ERDC, visit the ERDC online library at http://acwc.sdp.sirsi.net/client/default. 


\section{Houston Ship Channel and Vicinity Three- Dimensional Adaptive Hydraulics (AdH) Numerical Model Calibration/Validation Report}

Jennifer McAlpin, Cassandra Ross, and Jared McKnight

Coastal and Hydraulics Laboratory

U.S. Army Engineer Research and Development Center

3909 Halls Ferry Road

Vicksburg, MS 39180-6199

Final report

Approved for public release; distribution is unlimited.

Prepared for U.S. Army Corps of Engineers, Galveston District

P.O. Box 1229

Galveston, TX 77553-1229

Under Work Unit 145745; Coastal Texas Region 1 Protect and Restore and Work Unit 451902 HSC Feasibility Study 


\section{Abstract}

The Houston Ship Channel is one of the busiest deep-draft navigation channels in the United States and must be able to accommodate larger vessels as needed. The U.S. Army Engineer District, Galveston, requested the U.S. Army Engineer Research and Development Center, Coastal and Hydraulics Laboratory, perform hydrodynamic, salinity, and sediment transport modeling of proposed modifications along the Houston Ship Channel from its connection to the Gulf of Mexico to the Port of Houston as well as alterations for storm protection. The modeling results are necessary to provide data for salinity and sediment transport analysis as well as a ship simulation investigation to determine the navigational impacts of the proposed alternatives. The model setup and validation are presented in this report. The model proved to match field data for water surface elevation, velocity, and shoaling in the ship channel over three simulation years - 2005, 2010, and 2011.

DISCLAIMER: The contents of this report are not to be used for advertising, publication, or promotional purposes. Citation of trade names does not constitute an official endorsement or approval of the use of such commercial products. All product names and trademarks cited are the property of their respective owners. The findings of this report are not to be construed as an official Department of the Army position unless so designated by other authorized documents. 


\section{Contents}

Abstract........................................................................................................................................ if

Figures and Tables......................................................................................................................................

Preface ............................................................................................................................................... vili

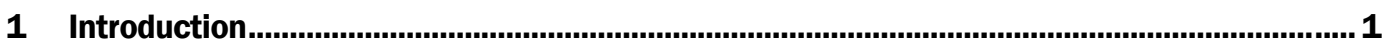

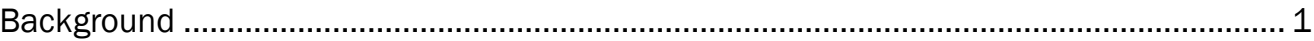

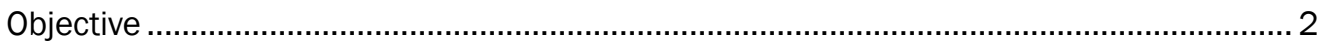

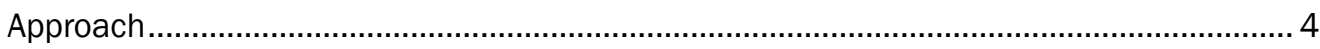

2 Model Development ............................................................................................................... 5

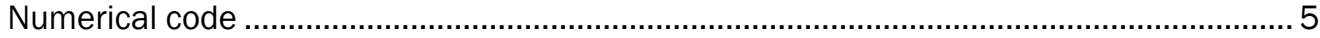

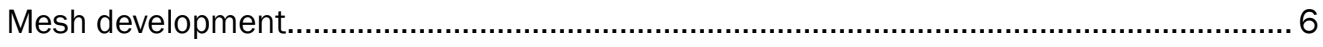

Boundary conditions ..................................................................................................... 9

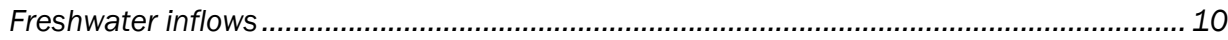

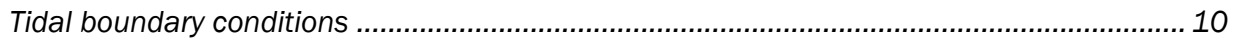

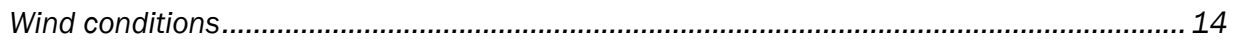

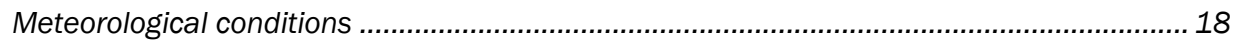

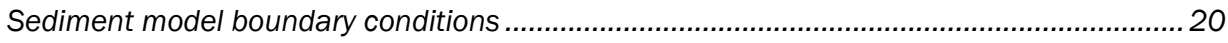

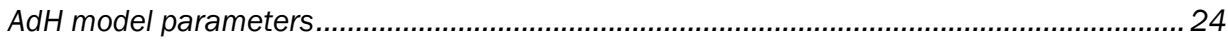

3 Model/Field Comparison - Calibration and Validation .......................................................25

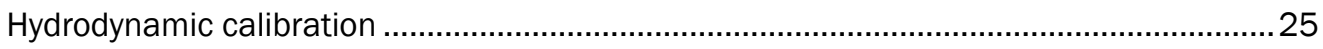

Water surface elevation....................................................................................................... 25

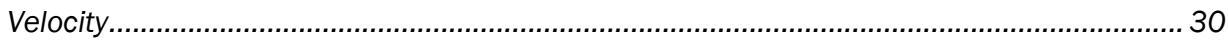

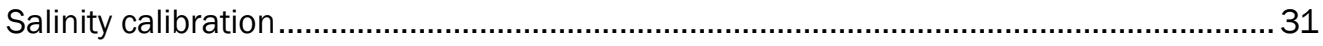

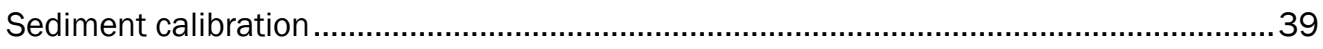

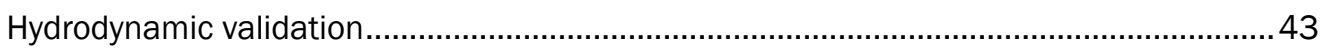

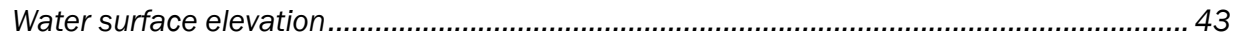

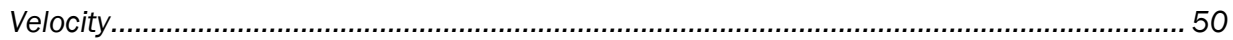

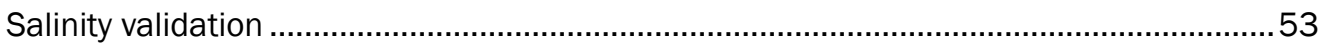

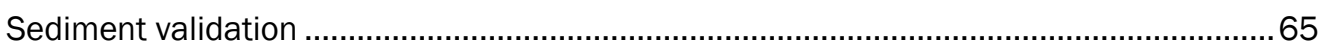

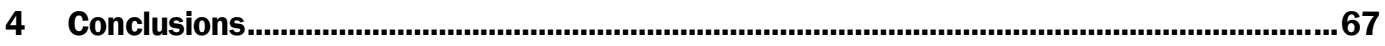

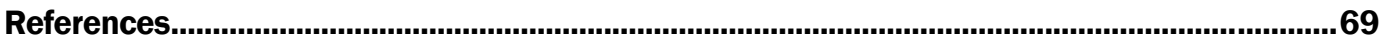

Appendix A: Water Surface Elevation Comparisons ................................................................ 72

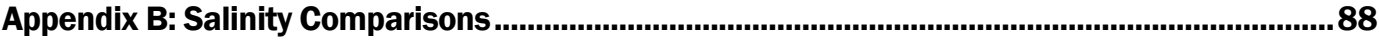

Unit Conversion Factors........................................................................................................ 119

List of Abbreviations ................................................................................................................ 120 
List of Unit Abbreviations.......................................................................................................... 121

Report Documentation Page 


\section{Figures and Tables}

\section{Figures}

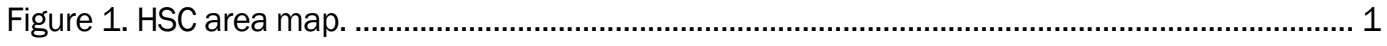

Figure 2. Proposed modifications to the HSC (figure from SWG) ..................................................... 3

Figure 3. Proposed coastal protection (figure from SWG)................................................................. 3

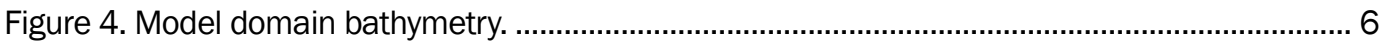

Figure 5. Vertical mesh resolution in HSC mesh. Colors represent AdH 3D material

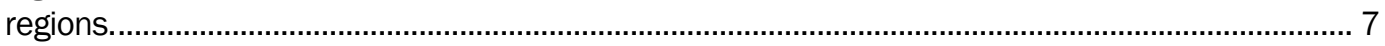

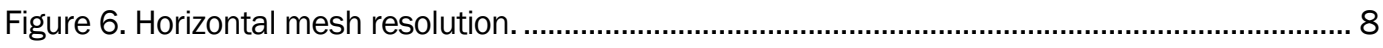

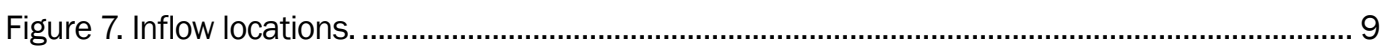

Figure 8. River and ungaged inflows for all simulation years $(2005,2010,2011)$......................... 10

Figure 9. Tidal water surface elevation data locations.................................................................... 11

Figure 10. Water surface elevation for a section of 2005............................................................. 12

Figure 11. Location of GERG_B............................................................................................ 13

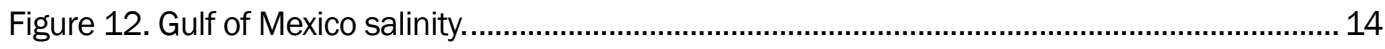

Figure 13. Wind data boundary condition locations................................................................. 15

Figure 14. 2005 wind rose for all sites. .................................................................................. 16

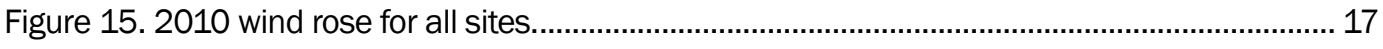

Figure 16. 2011 wind rose for all sites................................................................................ 18

Figure 17. 2005 meteorological conditions. ……................................................................... 19

Figure 18. 2010 meteorological conditions............................................................................ 19

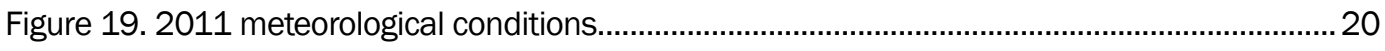

Figure 20. 2005 total sediment load for Trinity and San Jacinto Rivers.......................................... 22

Figure 21. 2010 total sediment load for the Trinity and San Jacinto Rivers.................................... 22

Figure 22. 2011 total sediment load for Trinity and San Jacinto Rivers...........................................2

Figure 23. Influences on HSC shoaling................................................................................. 23

Figure 24. Water surface elevation comparison locations.............................................................. 26

Figure 25. Water surface elevation calibration comparisons over time for Manchester. .................. 27

Figure 26. Water surface elevation calibration comparisons over time for Morgans Point.............. 27

Figure 27. Water surface elevation calibration comparisons over time for Eagle Point. .................... 28

Figure 28. Water surface elevation calibration comparison box plot for Manchester........................ 28

Figure 29. Water surface elevation calibration comparison box plot for Morgans Point. .................. 29

Figure 30. Water surface elevation calibration comparison box plot for Eagle Point........................ 29

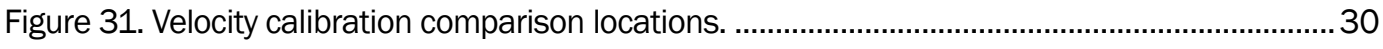

Figure 32. 2005 Morgan's Point velocity comparison (positive: flood; negative: ebb). .................... 31

Figure 33. TWDB 2005 salinity calibration sites.......................................................................... 32

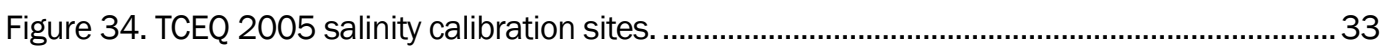

Figure 35. HARC 2005 salinity calibration sites........................................................................... 34

Figure 36. Exxon Docks salinity calibration comparison. ................................................................3 
Figure 37. Baytown Tunnel salinity calibration comparisons......................................................... 35

Figure 38. Lynchburg Ferry salinity calibration comparisons........................................................36

Figure 39. CM120 salinity calibration comparisons.................................................................... 36

Figure 40. Morgan's Point salinity calibration comparisons. ........................................................ 37

Figure 41. 2005 Mid Galveston Bay salinity calibration comparisons............................................38

Figure 42. 2005 Trinity Bay HARC salinity calibration comparisons (northwest)...............................38

Figure 43. 2005 Trinity Bay TWDB salinity calibration comparisons (southeast).............................39

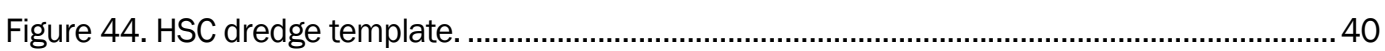

Figure 45. Annualized maintenance dredge volumes based on USACE annual reports.................. 41

Figure 46. Model/field HSC shoaling calibration comparison.......................................................... 42

Figure 47. Water surface elevation validation comparisons over time for Manchester

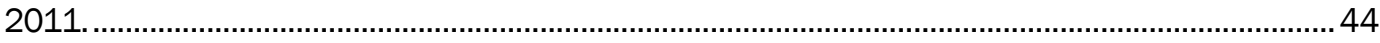

Figure 48. Water surface elevation validation comparisons over time for Morgans Point. .............. 45

Figure 49. Water surface elevation validation comparisons over time for Eagle Point..................... 46

Figure 50. Water surface elevation validation comparison box plot for Manchester........................ 47

Figure 51. Water surface elevation validation comparison box plots for Morgans Point. .................. 48

Figure 52. Water surface elevation validation comparison box plots for Eagle Point. ...................... 49

Figure 53. Velocity validation comparison locations.................................................................... 50

Figure 54. 2010 Galveston Entrance velocity comparison (positive: flood; negative: ebb).............. 51

Figure 55. 2011 CHL AWAC 1 velocity comparison (positive: flood; negative: ebb)......................... 51

Figure 56. 2011 CHL AWAC 2 velocity comparison (positive: flood; negative: ebb). ......................... 52

Figure 57. 2011 CHL AWAC 3 velocity comparison (positive: flood; negative: ebb)...........................52

Figure 58. 2011 Galveston Entrance velocity comparison (positive: flood; negative: ebb).............. 53

Figure 59. TWDB salinity validation comparison sites.................................................................... 54

Figure 60. TCEQ salinity validation comparison sites. .................................................................. 55

Figure 61. HARC salinity validation comparison sites.................................................................. 56

Figure 62. TABS salinity validation comparison site. ………………………………………...... 57

Figure 63. 2010 HSC salinity validation comparisons. ............................................................ 58

Figure 65. 2010 Scott Bay salinity validation comparisons........................................................... 59

Figure 67. 2010 Baytown salinity validation comparisons............................................................6

Figure 68. 2011 Baytown salinity validation comparisons. ........................................................... 60

Figure 69. 2010 Upper San Jacinto Bay salinity validation comparisons......................................... 61

Figure 70. 2011 Upper San Jacinto Bay salinity validation comparisons.......................................... 61

Figure 71. 2010 Mid Galveston Bay salinity validation comparisons. ............................................62

Figure 72. 2011 Mid Galveston Bay salinity validation comparisons..............................................63

Figure 73. 2010 Trinity Bay HARC salinity validation comparisons (northwest). ..............................63

Figure 74. 2010 Trinity Bay TWDB salinity validation comparisons (southeast)...............................64

Figure 75. 2011 Trinity Bay TWDB salinity validation comparisons (southeast)................................64

Figure 76. Model/field HSC shoaling validation comparison...........................................................66 


\section{Tables}

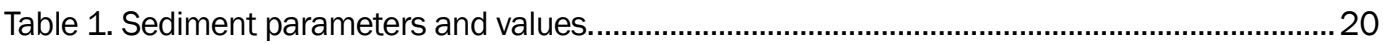

Table 2. Model parameters. ………........................................................................................ 24

Table 3. Statistical model/field calibration comparison of water surface elevation. ........................26

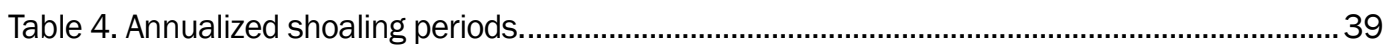

Table 5. Statistical model/field validation comparison of water surface elevation............................43 


\section{Preface}

The model investigation presented in this report was authorized and funded by the U.S. Army Corps of Engineers, Galveston District, under Work Unit 145745; Coastal Texas Region 1 Protect and Restore and Work Unit 451902 HSC Feasibility Study.

The work was performed at the U.S. Army Engineer Research and Development Center, Coastal and Hydraulics Laboratory (ERDC-CHL), Vicksburg, MS. At the time of publication of this report, Dr. Ty V. Wamsley was Director, and Mr. Jeffrey R. Eckstein was Deputy Director, ERDCCHL. Direct supervision was provided by Dr. Cary Talbot, Chief, Flood and Storm Protection Division, and Mr. Keith Flowers, Chief, River and Estuarine Engineering Branch.

COL Ivan P. Beckman was Commander of ERDC, and Dr. David W. Pittman was Director. 


\section{Introduction}

\section{Background}

Since the early 180os, vessels have transited Galveston Bay both to and from Galveston and Houston (Galveston Bay Estuary Program 2002). Galveston Bay is a tidal estuary such that the effect of the tide on the water surface elevation is observed from the Gulf of Mexico to locations near Houston, TX. The Houston Ship Channel (HSC) is a deep-draft navigation channel that allows for vessel passage from the Gulf to the city of Houston, approximately 53 miles upstream. Since 1903, Operations and Maintenance dredging has been conducted in the bay to maintain authorized channel dimensions. Figure 1 shows the HSC as it passes through Galveston Bay from its entrance at Bolivar Roads to the Port of Houston.

Figure 1. HSC area map.

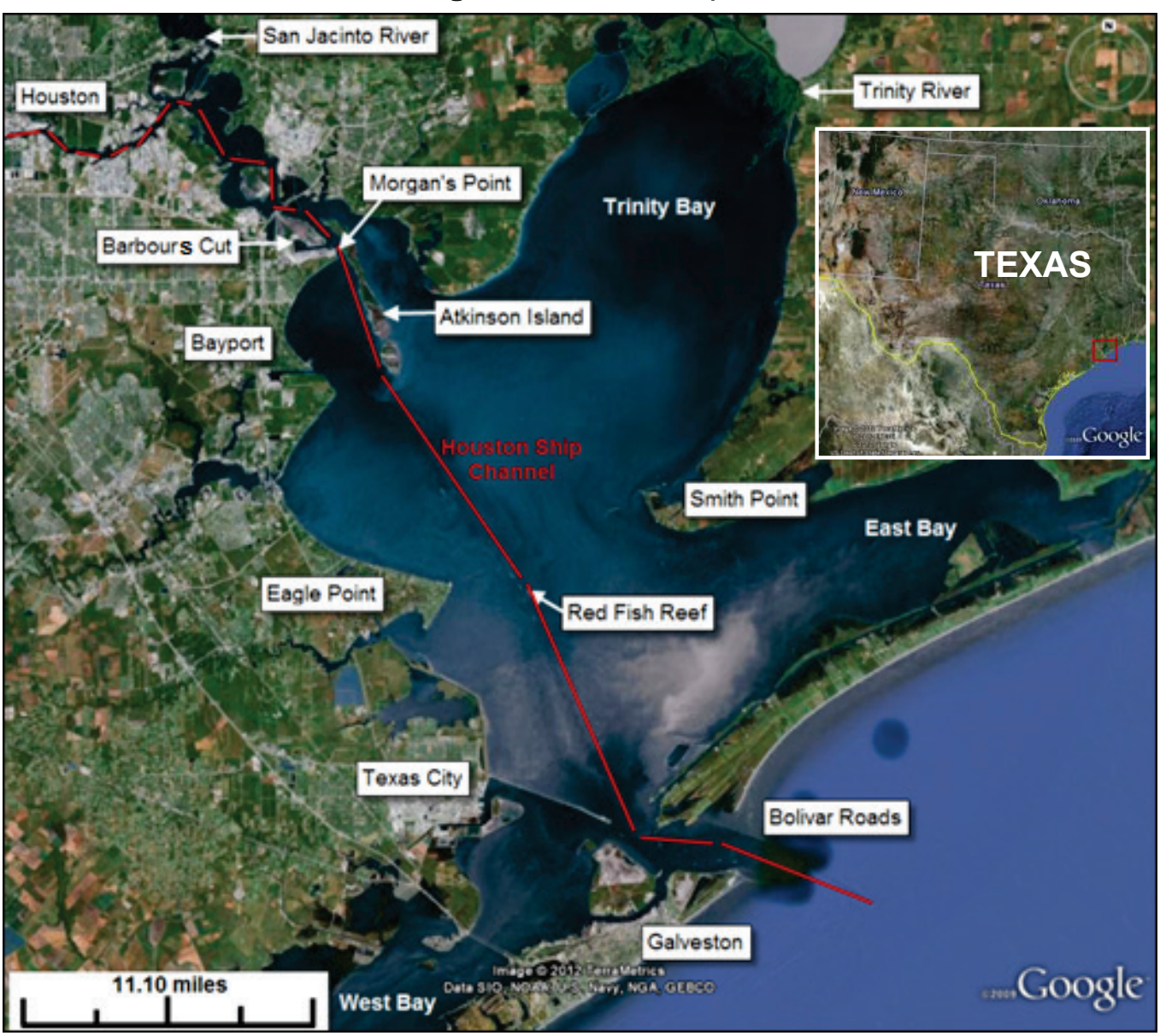


The navigation channel acts as a flow pathway for salinity to travel upstream since high-saline water is heavier than fresh water and tends to flow up-channel along the channel bottom. The net drift in the bottom of the water column is flood in much of the channel (Tate and Berger 2006) (i.e., the tendency is for suspended material to move upstream into the bay). The velocity magnitudes drop in the Atkinson Island reach due to tidal reflections from the bay boundary. The flow tends to stratify more as a result in this reach, and material from farther downstream in the estuary tends to collect near Atkinson Island.

The behavior of the salinity and hydrodynamics in Galveston Bay during May through June is different than the remainder of the year due to a salinity drop in the northern Gulf of Mexico as the Mississippi, SabineNeches, and Atchafalaya Rivers and other northern Gulf river systems provide a significant influx of fresh water. When the salinity in the Gulf of Mexico drops, the salt water tends to evacuate from the bay. A reduction in bay salinity results in different suspended concentration patterns and fresh deposit characteristics during this time period compared to data collected at other times during the year. During this period, sediment would tend to collect farther down the channel toward Red Fish Reef (Tate and Berger 2006).

The U.S. Army Corps of Engineers (USACE), Galveston District (SWG) recently enlarged the Houston Ship Channel from a 12.2-meters (m) (40-foot [ft]) depth by $122 \mathrm{~m}$ ( $400 \mathrm{ft}$ ) width to a $13.7 \mathrm{~m}$ ( $45 \mathrm{ft}$ ) depth by $162 \mathrm{~m}$ (530 ft) width. Previously, a three-dimensional (3D) numerical model study was implemented at the U.S. Army Engineer Research and Development Center, Coastal and Hydraulics Laboratory (ERDC-CHL), to evaluate the salinity and circulation impact of this enlargement.

\section{Objective}

In 2016, SWG requested the ERDC-CHL perform hydrodynamic, salinity and sediment modeling of proposed modifications along the HSC from its connection to the Gulf of Mexico to the Port of Houston for both improved navigation and storm protection (Figure 2 and Figure 3). The modeling results are necessary to provide data for salinity and sediment transport analysis as well as ship simulation studies in which pilots test the navigational effects of the modifications. The model setup and validation are presented in this report. 
Figure 2. Proposed modifications to the HSC (figure from SWG).

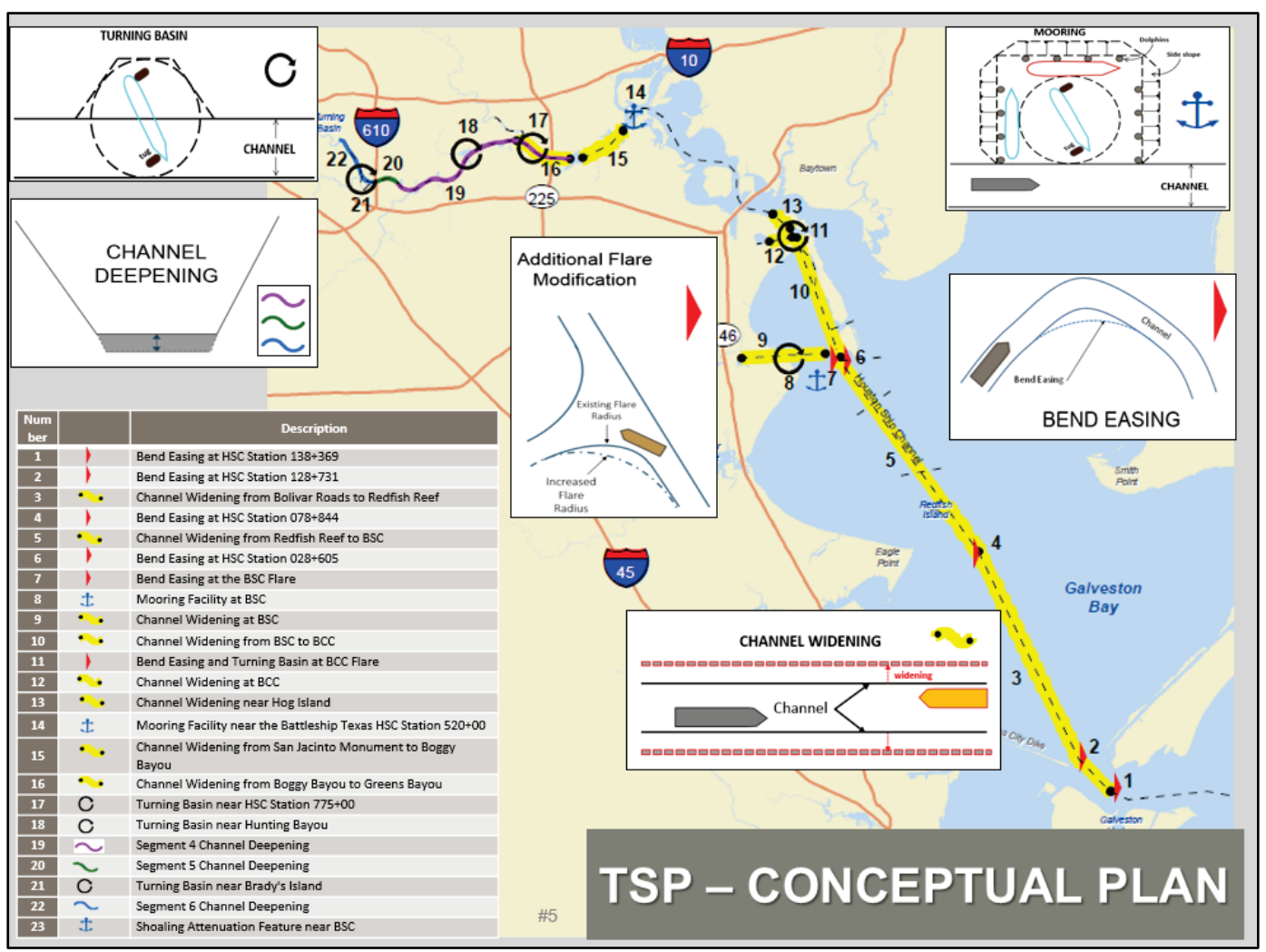

Figure 3. Proposed coastal protection (figure from SWG).

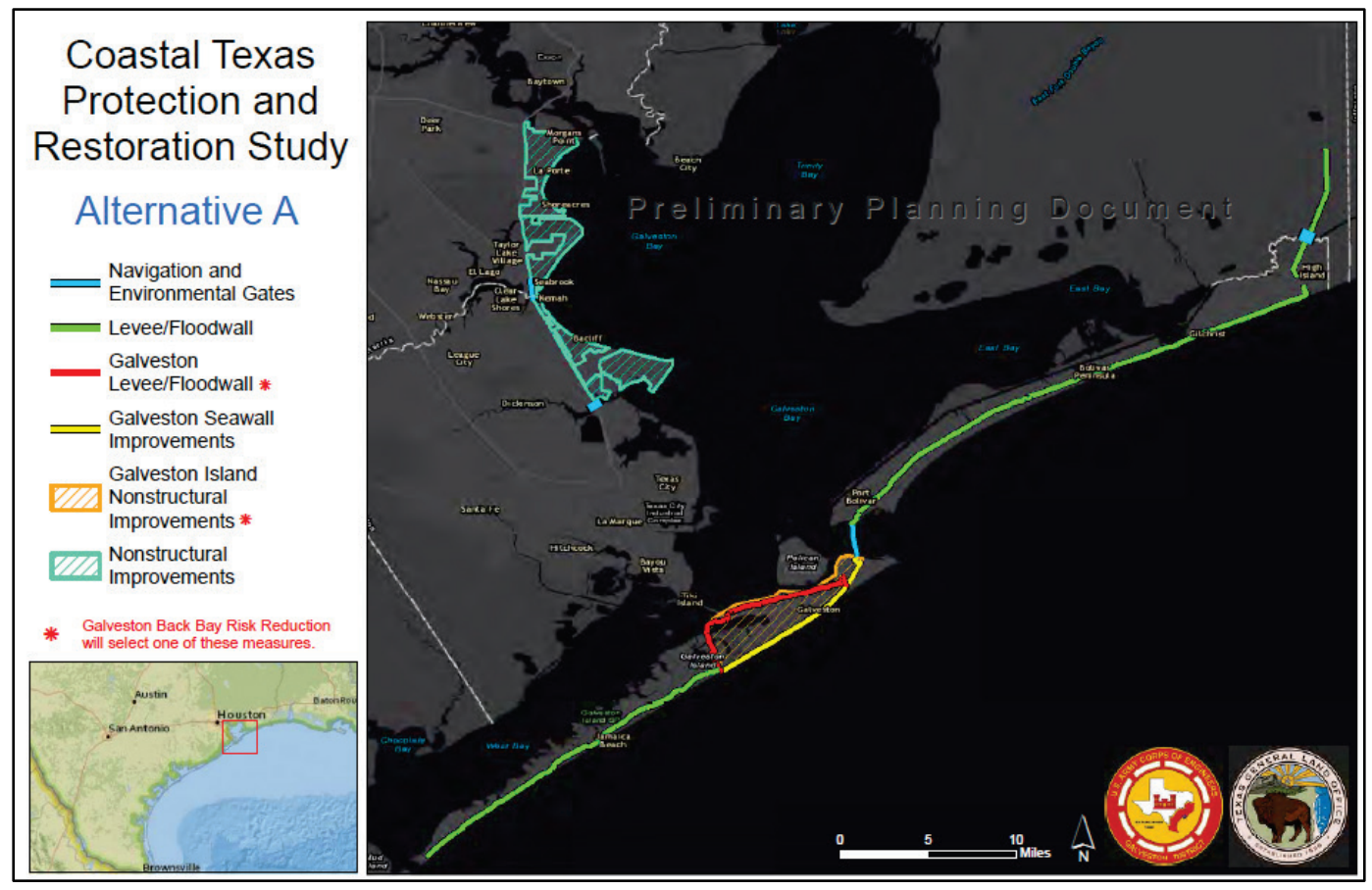




\section{Approach}

A 3D Adaptive Hydraulics (AdH) model was developed and validated for simulation of hydrodynamics, salinity, and sediment transport. Previous modeling efforts used TABS-MDS as the finite element code (Berger et al. 1995; Carrillo et al. 2002; Tate and Berger 2006; Tate et al. 2008; Tate and Ross 2012). The present effort necessitates the development of a new model utilizing the latest technology and updated to present conditions. The model was validated to available field data for all parameters and then utilized to test project alternatives for present and future conditions.

Chapter 2 discusses the model development and boundary condition definitions for the hydrodynamic, salinity, and sediment transport model. Chapter 3 documents the model to field data comparisons for hydrodynamics, salinity, and HSC dredge volumes. Chapter 4 provides the conclusions of this numerical model validation. 


\section{Model Development}

A numerical model was developed to analyze alternative plans for the HSC and to provide hydrodynamic data for ship simulation studies. The model was developed such that the natural driving forces of the system are included - winds, tides, salinity, freshwater inflows, friction effects, and sediment behavior. The model is compared to field data collected during the simulation period to ensure an accurate representation of nature. This model is validated using data from 2010 and 2011; 2005 is used as the model calibration period.

\section{Numerical code}

AdH is the numerical model code applied for the simulations in this study (Savant et al. 2014; Savant and Berger 2015). AdH is a finite element code that is capable of simulating $3 \mathrm{D}$ Navier-Stokes equations, two-dimensional (2D) and 3D shallow water equations, and groundwater equations. It can be used in a serial or multiprocessor mode on personal computers and high-performance computing systems. AdH can refine the domain mesh in areas where more resolution is needed at certain times due to changes in the flow conditions and then remove the added resolution when it is no longer needed, to minimize computational burden. The code also includes automatic time-step adaption, as needed. AdH can simulate the transport of conservative constituents, such as dye clouds, as well as simulate sediment transport, when used with SEDLIB, that is coupled to bed and hydrodynamic changes. This code has been applied to model riverine flow (Bell et al. 2017; Clifton et al. 2017) estuarine circulation (Tate et al. 2009; McAlpin et al. 2013), and sediment transport (Sharp et al. 2013; Heath et al. 2015; Letter et al. 2015).

SEDLIB is a sediment transport code that allows for the simulation of noncohesive (sand), cohesive (silt and clay), and mixed sediments. Each grain class is tracked separately yet allowed to mix as necessary in multiple bed layers. SEDLIB calculates erosion and deposition simultaneously and includes bed processes such as armoring, consolidation, and discrete depositional layer evolution.

For this study, the 3D shallow water module of AdH is applied for all simulations. This code solves for depth and velocity throughout the model domain. (More details of the $3 \mathrm{D}$ shallow water module of $\mathrm{AdH}$ and its 
computational philosophy and equations are available in Savant et al. 2014 and Savant and Berger 2015.) AdH version 4.6 was applied for this study.

\section{Mesh development}

The model domain was determined using aerial images and bathymetry/topographic data for the area. The Surface Water Modeling System was used to generate a 2D surface mesh and define material regions for applying specific model features, such as bed roughness. The domain is defined horizontally in Universal Transverse Mercator, zone 15 coordinates with units of meters. Vertically it is based on North American Vertical Datum of 1988 (NAVD88) with units of meters. All data applied to the model are shifted to this datum and coordinate system.

Bathymetry data for the model were obtained from several sources: the National Geophysical Data Center, the Coastal Relief Model, sponsor-collected hydrographic surveys, and the National Elevation Dataset. These data sets were combined such that the latest data were made a priority as well as data collected at finer resolution. The $3 \mathrm{D} \mathrm{AdH}$ code cannot include areas that wet/dry; therefore, elevations above - $2 \mathrm{~m}$ NAVD88 were set to $-2 \mathrm{~m}$ to ensure the domain remains wet throughout the simulation period. Figure 4 shows most of the model domain and bathymetry.

Figure 4. Model domain bathymetry.

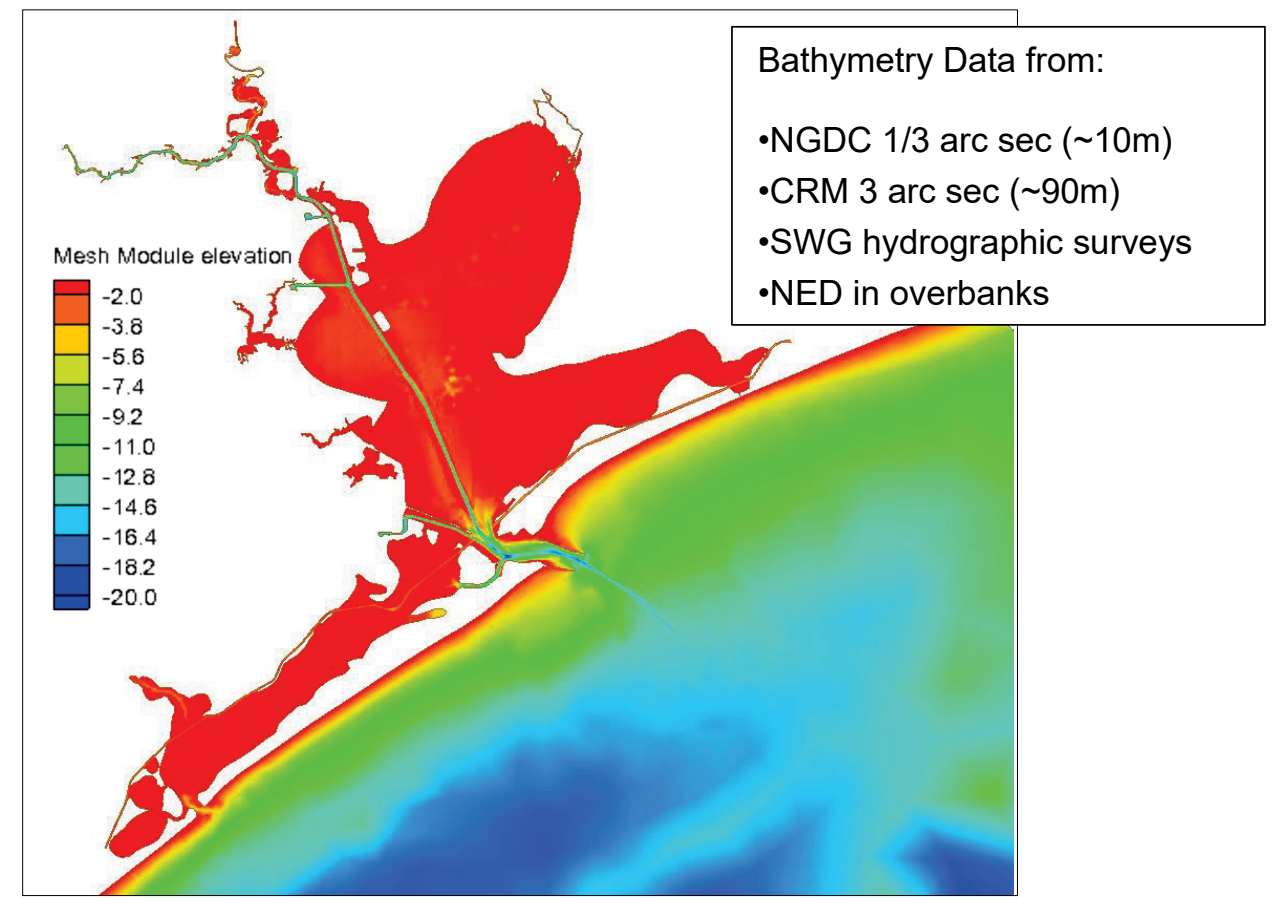


The 2D mesh was then extruded to a 3D mesh using a utility code designed specifically for use with AdH. The vertical layers are defined by elevation. All areas have at least two vertical layers with most locations having a new layer every $2 \mathrm{~m}$. The Gulf of Mexico has less vertical resolution with a new layer every $5 \mathrm{~m}$. Figure 5 shows the vertical layering in a cross section of the HSC.

Figure 5. Vertical mesh resolution in HSC mesh. Colors represent AdH 3D material regions.

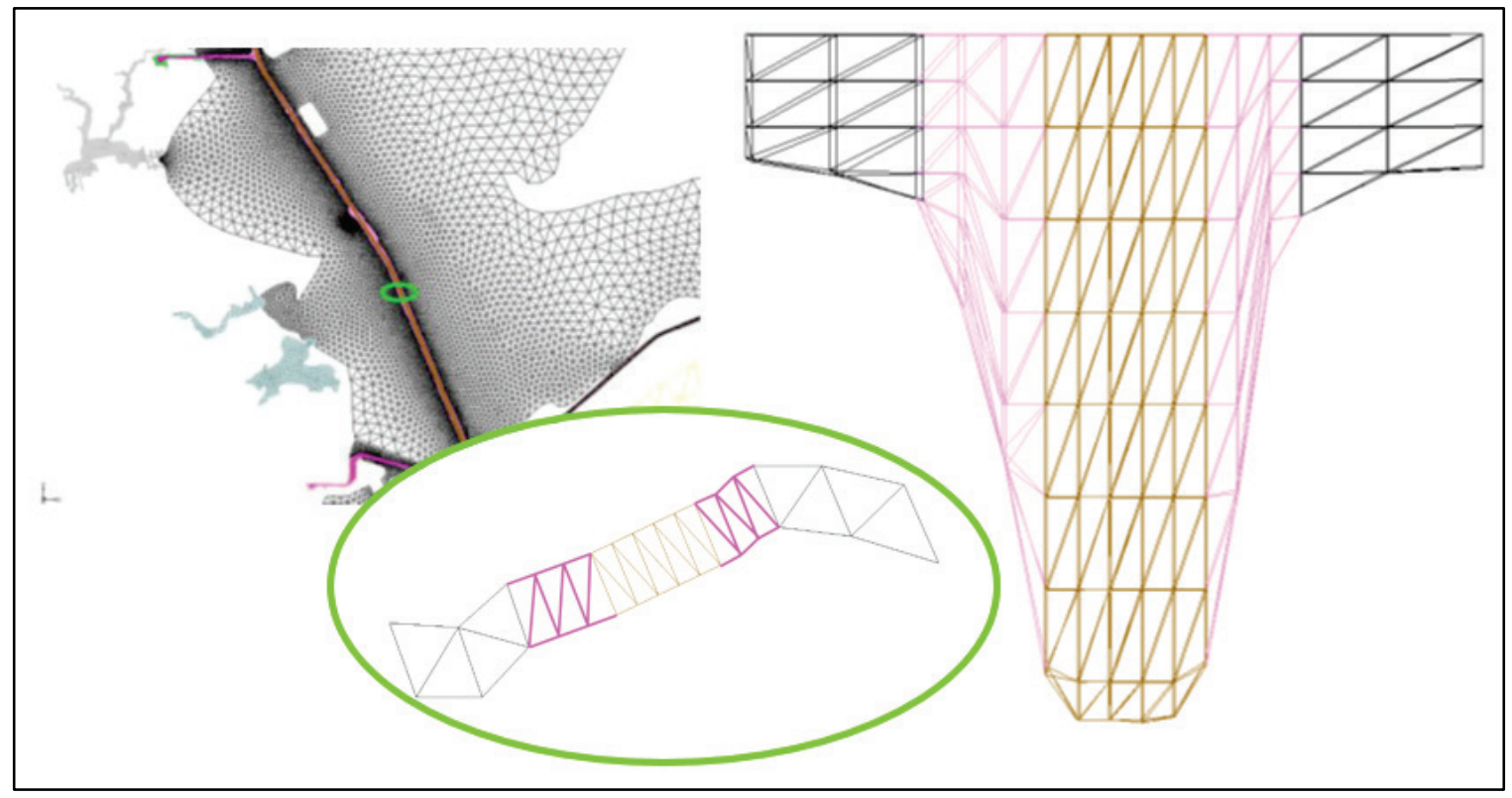

The model domain extends over 3,200 square miles from the Gulf of Mexico to Houston, TX, and includes areas from San Louis Pass on the west to Rollover Pass on the east. The 3D mesh contains over 900,000 elements and nearly 200,000 nodes. Figure 6 shows the horizontal mesh resolution for the model domain with a close-up image on the HSC at the entrance at Bolivar Roads. Resolution is finest in the HSC to accurately capture the salinity wedge that moves along the bottom of the water column in this deep channel. Finer resolution is also seen in areas where geometric features need to be defined accurately, such as in the break in the north jetty. 
Figure 6. Horizontal mesh resolution.

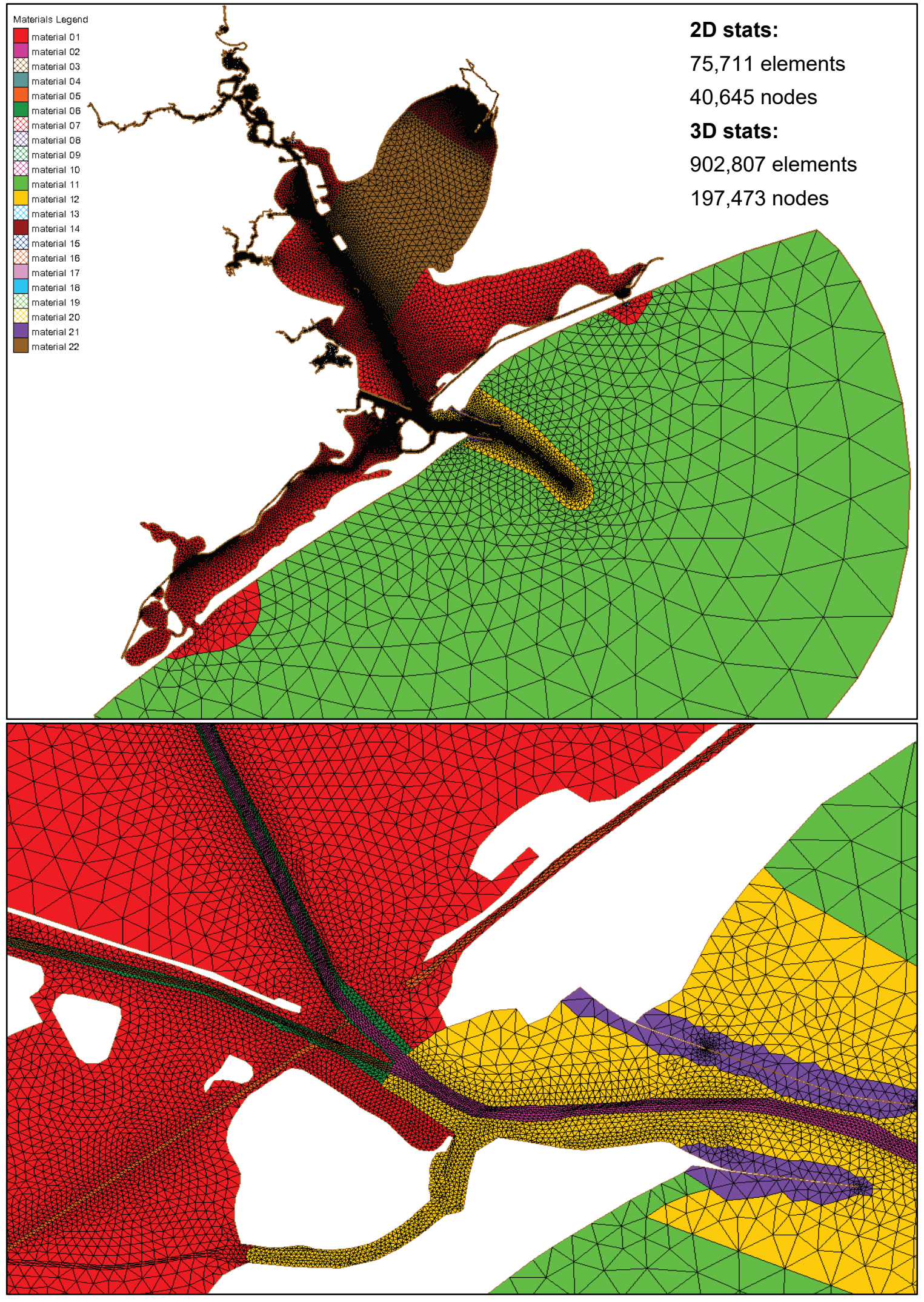




\section{Boundary conditions}

The boundary conditions for this study are set up in the same manner as the previous work performed for this model domain (Tate et al. 2008). Tidal water surface elevations and salinity are applied at the ocean boundary. Winds are included throughout the model domain. Freshwater inflow is applied for the Trinity River and the San Jacinto River, as well as at other inflow locations to account for ungaged flows in the area. All inflow locations are labeled in Figure 7.

Figure 7. Inflow locations.

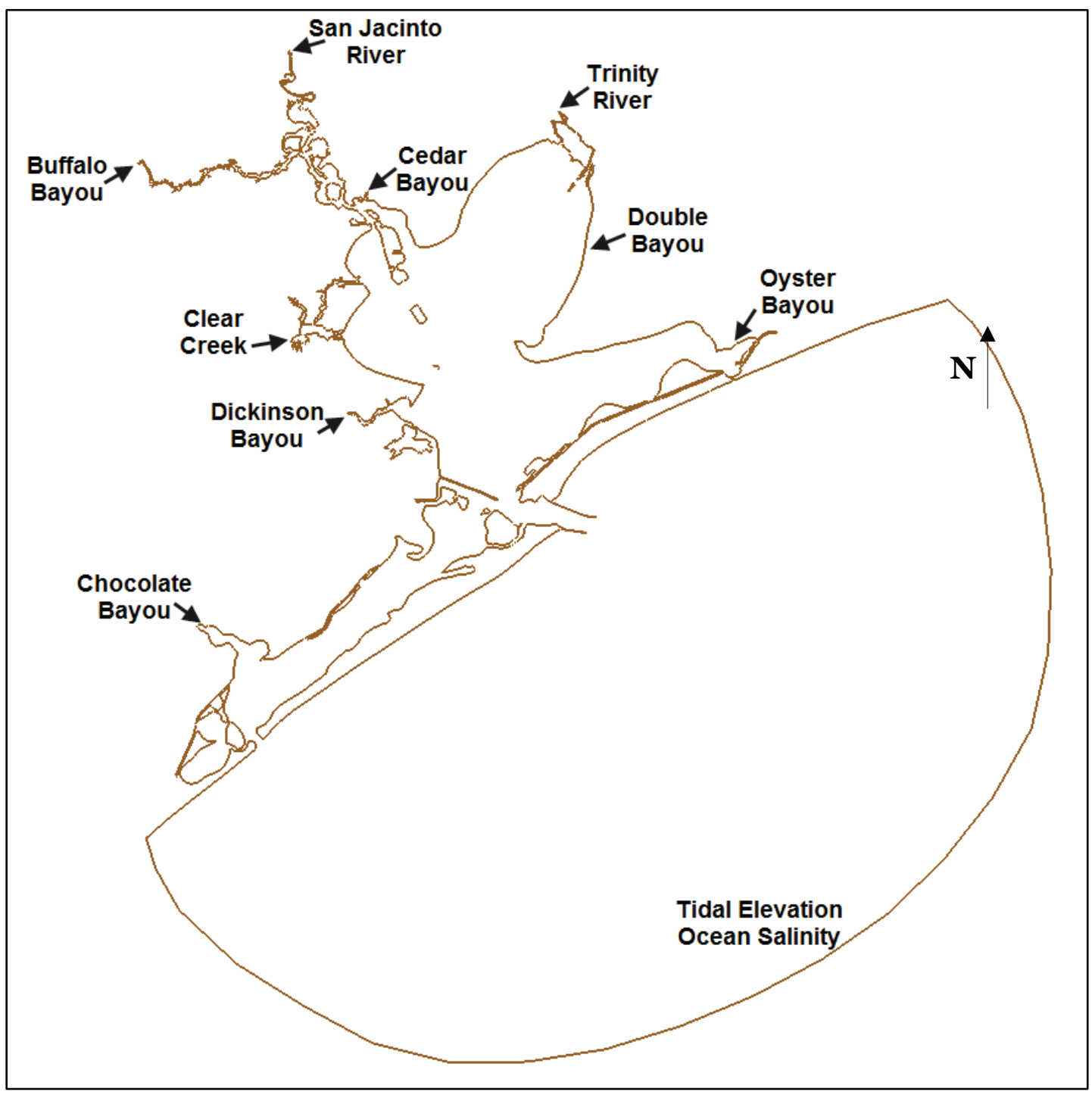




\section{Freshwater inflows}

Figure 8 shows the inflow discharge for the two major rivers entering the bay - Trinity River and San Jacinto River - as well as the ungaged inflows at the seven remaining locations specified in Figure 7. These flows are computed through a hydrology model maintained by the Texas Water Development Board (Schoenbaechler and Guthrie 2012). All data are provided for calendar years 2005 through 2014 to show how validation years compare.

Figure 8. River and ungaged inflows for all simulation years $(2005,2010,2011)$.

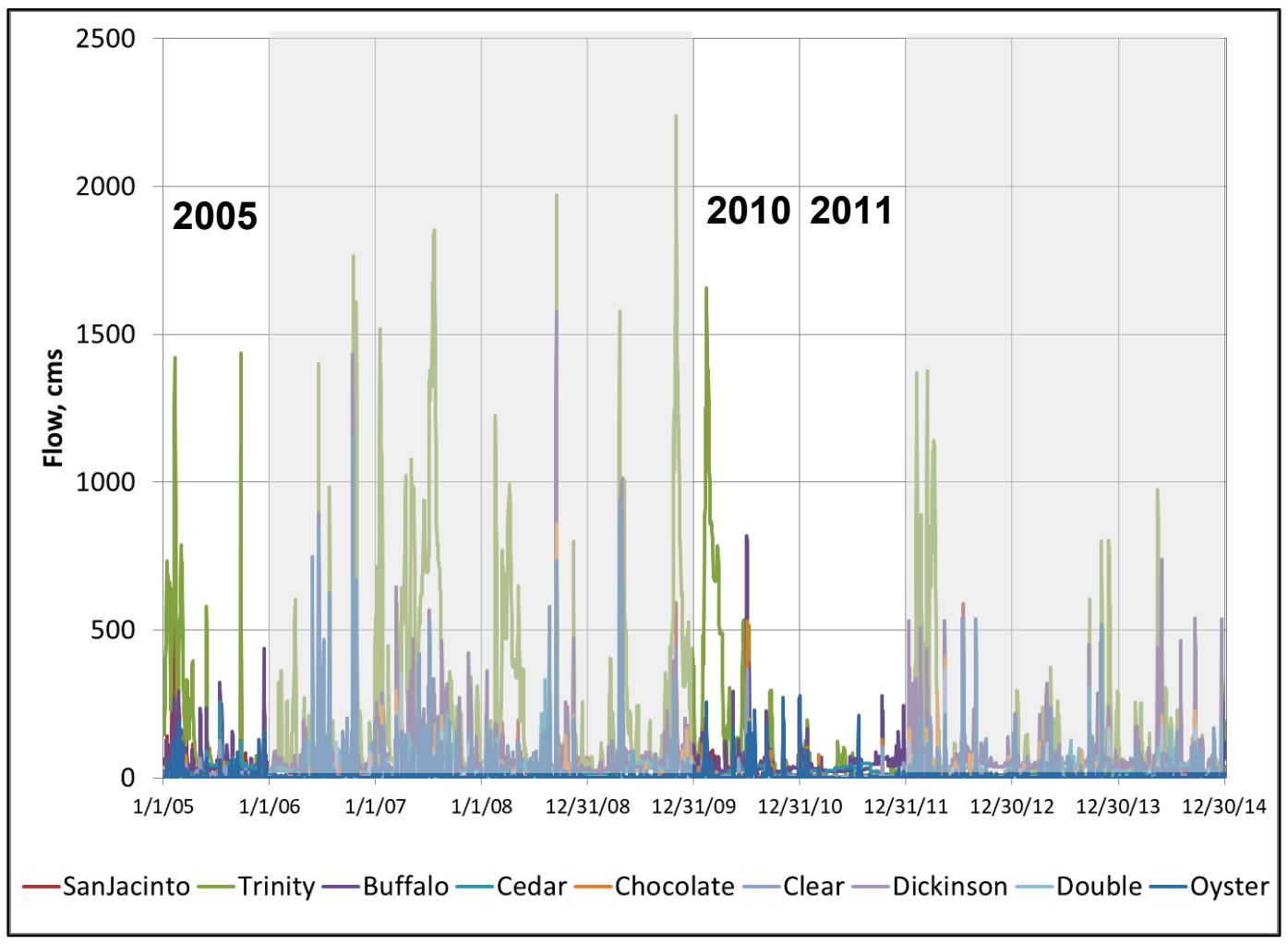

\section{Tidal boundary conditions}

Water surface elevation

In addition to freshwater inflows, a tidal boundary is applied at the ocean boundary of the mesh. The tidal water surface elevation is based on harmonics for the area and measured data from National Oceanic and Atmospheric Administration (NOAA) gages at Freeport (8772447) and Sabine Pass (8770822), Texas (Figure 9). The harmonic constituents and the nonpredicted, or subtidal, signal (the difference between the predicted value based on tidal constituents and the observed value, which includes 
winds and other factors) for each station are used to generate a tidal forcing or water surface elevation at each node along the tidal boundary for the simulation time period. The values for each node are determined by performing a linear interpolation of the gage amplitude and phase for each tidal constituent as well as for the nonpredicted signal. The tide is then reconstituted at each location along the boundary using these interpolated parameters. The time series for the east and west endpoints of the tidal boundary is shown in Figure 10 along with the tide boundary condition at the boundary midpoint. The variation along the tidal boundary is typically less than $0.1 \mathrm{~m}$.

Initially, the water surface elevation is set to the average along the tidal boundary and is a flat surface throughout the model domain. A 1-year spin-up period is executed, and the variable water surface from the end of that simulation is used as the initial condition for the analysis period model simulation.

Figure 9. Tidal water surface elevation data locations.

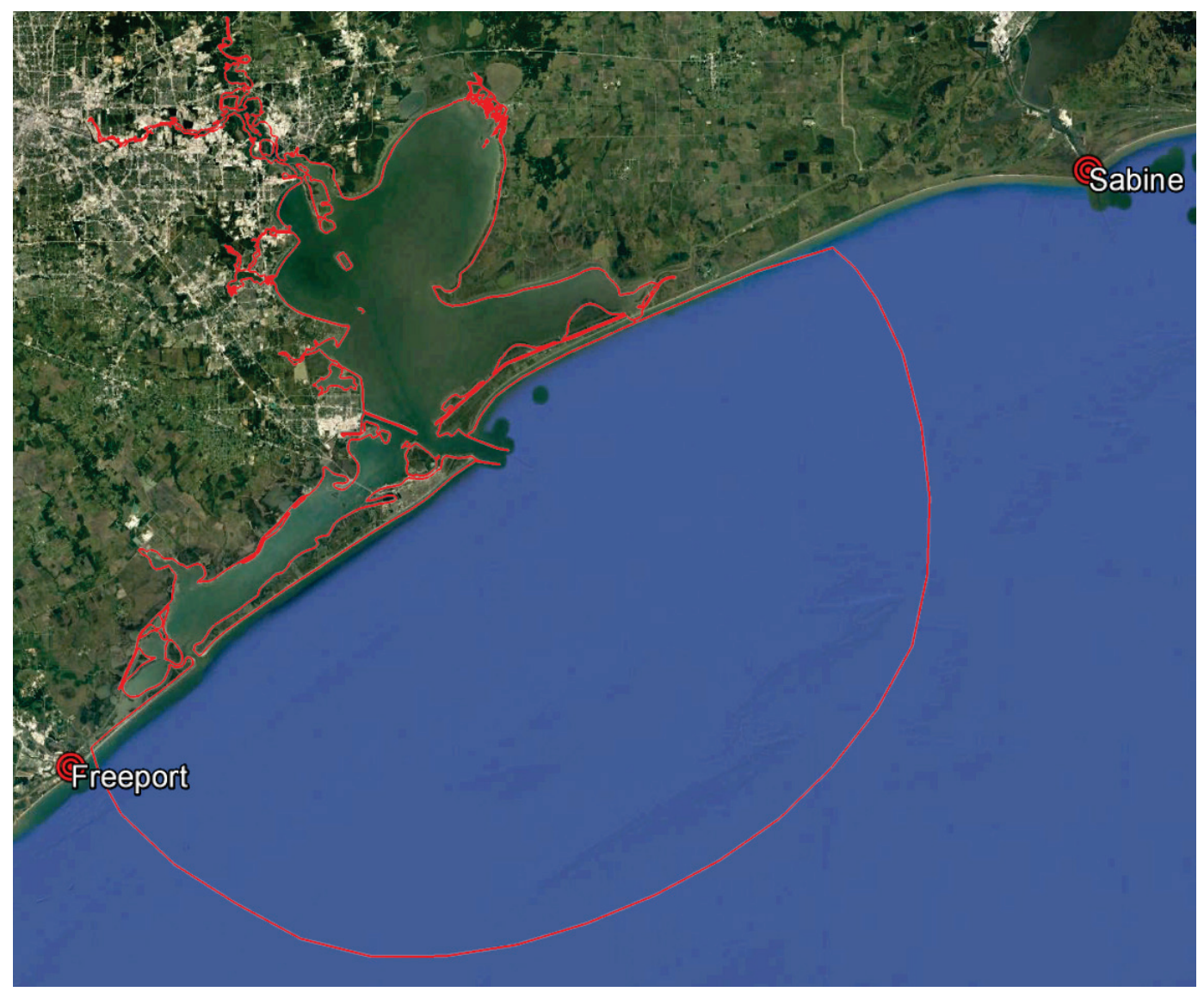


Figure 10. Water surface elevation for a section of 2005.

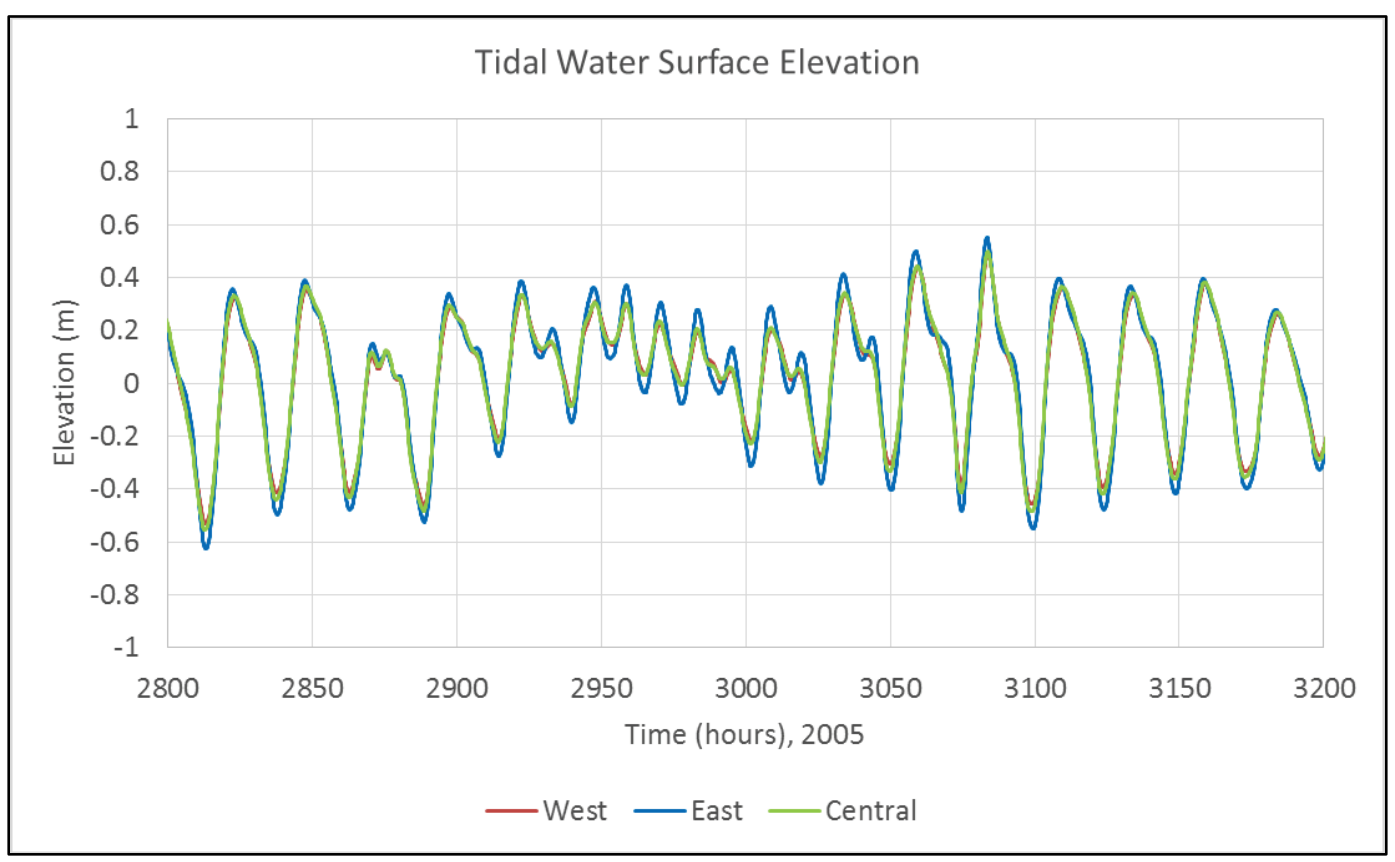

\section{Salinity}

Salinity is also applied at the model's Gulf of Mexico tidal boundary. A Texas Automated Buoy System (TABS) salinity gage (GERG_B) is maintained by the Texas General Land Office and the Geochemical and Environmental Research Group (GERG) at Texas A\&M University and shown as the red dot in Figure 11. This gage, however, experiences biofouling and malfunctions regularly making it un-usable as a model boundary condition. Figure 12 shows plots of several years of GERG_B data - 2006 and 2008-2015. Included in the plot is a data set based on monthly averages over a 15-year period (red line) (Cochrane and Kelly 1986) as well as a data set based on salinity correlations to Mississippi River and Atchafalaya River flows (yellow line). Since the monthly average data set tends to follow the GERG_B data, where it appears to be accurate, the monthly average data set (red line in Figure 12) is used as the Gulf of Mexico salinity boundary condition. This data set is used for all calibration/validation years.

Initially, the salinity is set to an average time period throughout the model domain. A 1-year spin-up period is executed for each simulation year (typically using input data for the prior calendar year), and the salinity field from the end of that simulation is used as the initial conditions for the complete model simulation. 
Figure 11. Location of GERG_B.

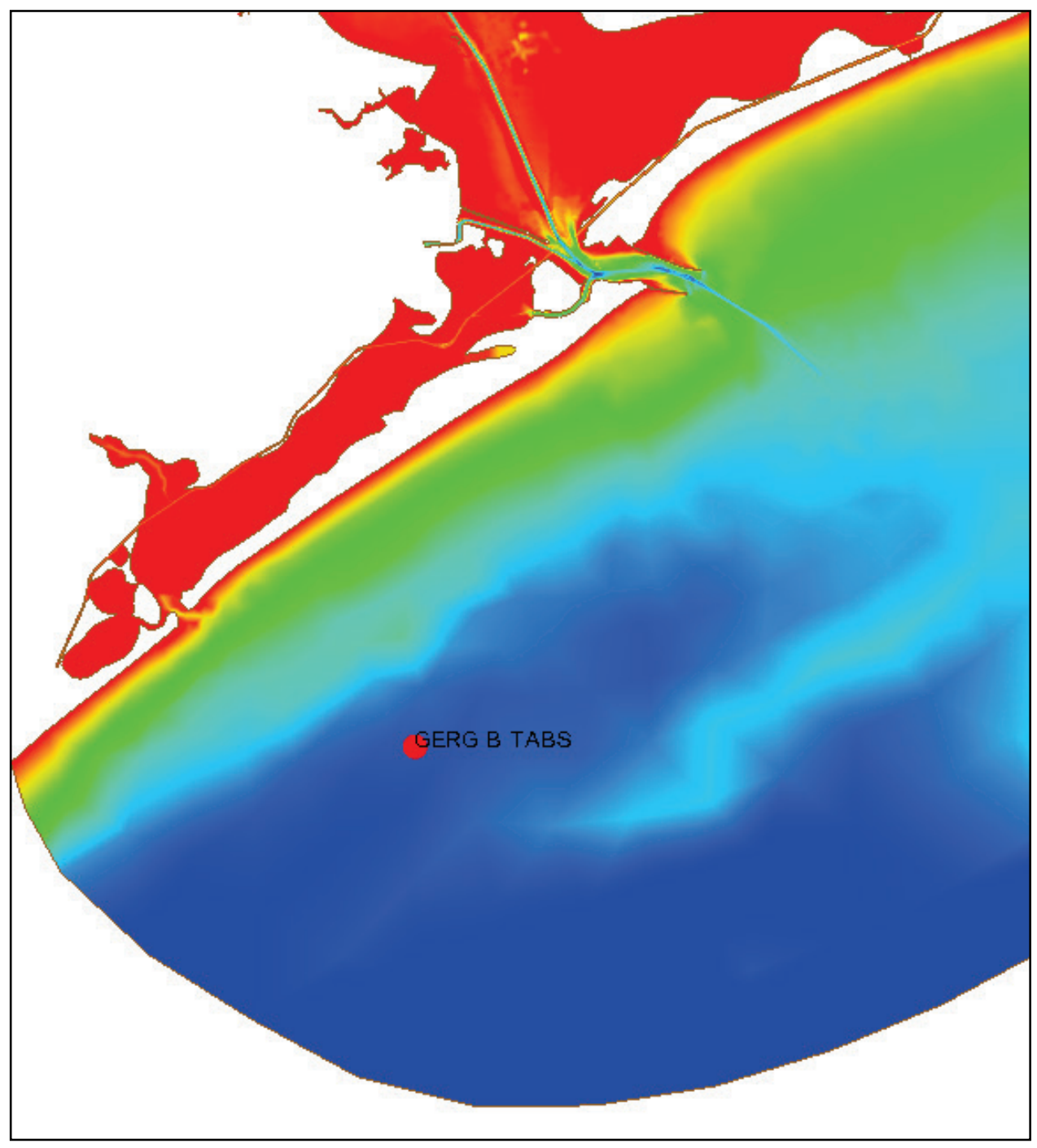


Figure 12. Gulf of Mexico salinity.

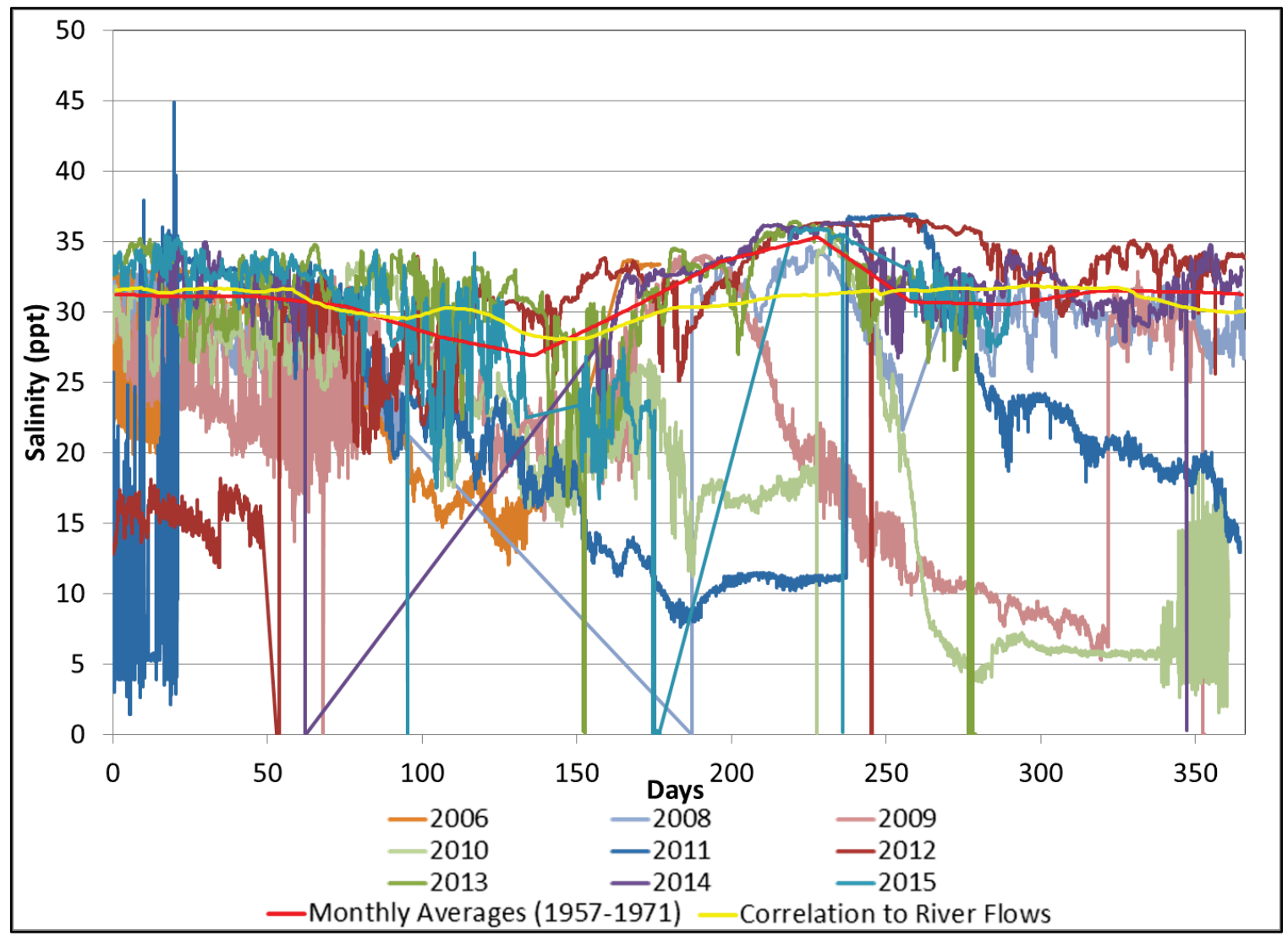

\section{Wind conditions}

The wind conditions applied to the model are obtained from the Wave Information Studies (WIS) computed wind field for points that lie in the vicinity of the model domain (Hubertz 1992). There are 26 WIS sites for this model (see Figure 13). The WIS model is validated against measurement sites where applicable, and these wind data allow for variable wind conditions across the domain. The wind data are supplied to the AdH model as time series of $x$ - and $y$-velocities. These wind components are then converted to a shear stress dependent on conditions set for each material - deeper water uses a Wu formulation (Wu 1969, 1982) and shallow regions use a Teeter formulation (Teeter 2002). The wind rose for each data site for all three calibration/validation years is shown in Figure 14 through Figure 16. 
Figure 13. Wind data boundary condition locations.

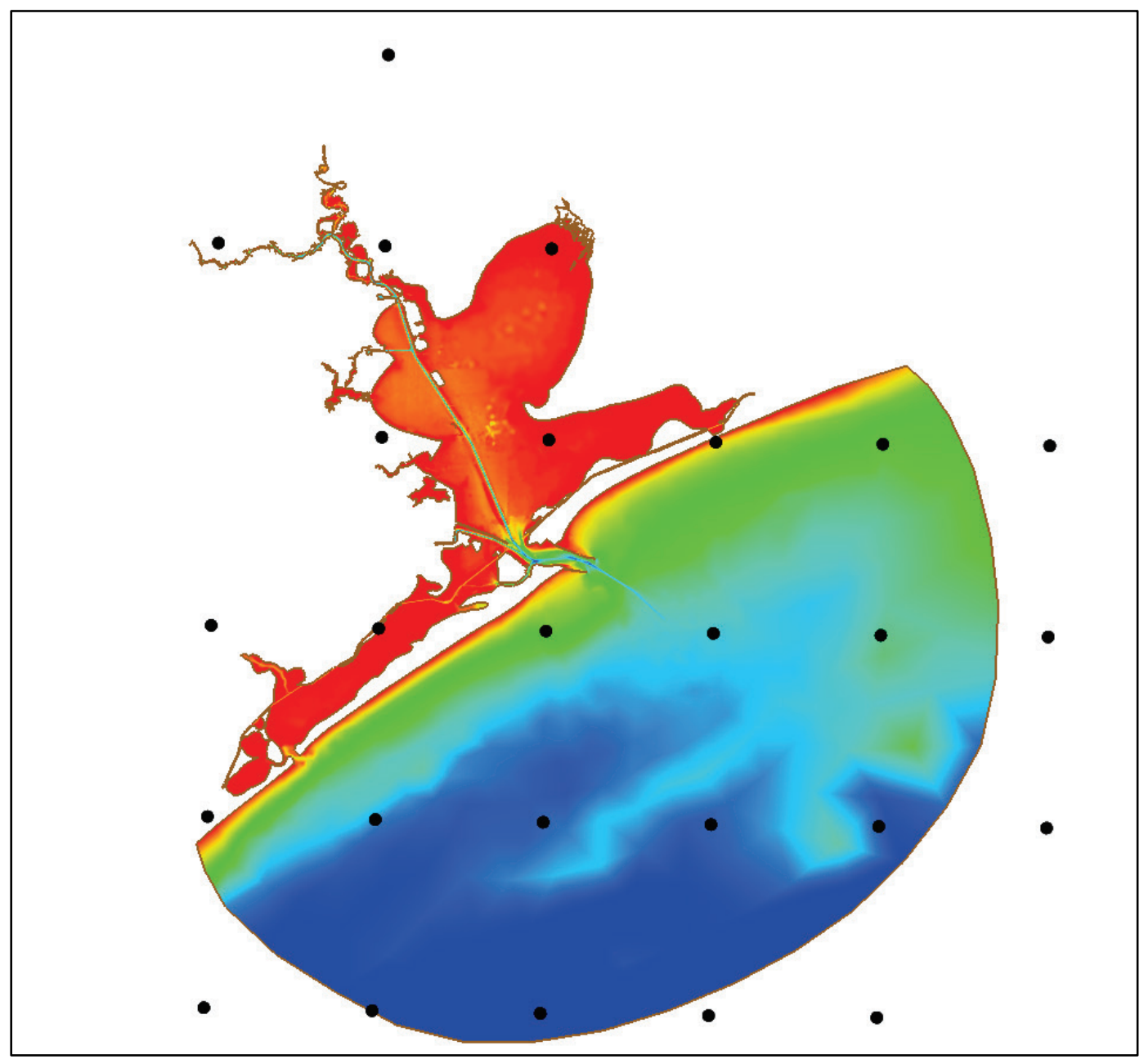


Figure 14. 2005 wind rose for all sites.

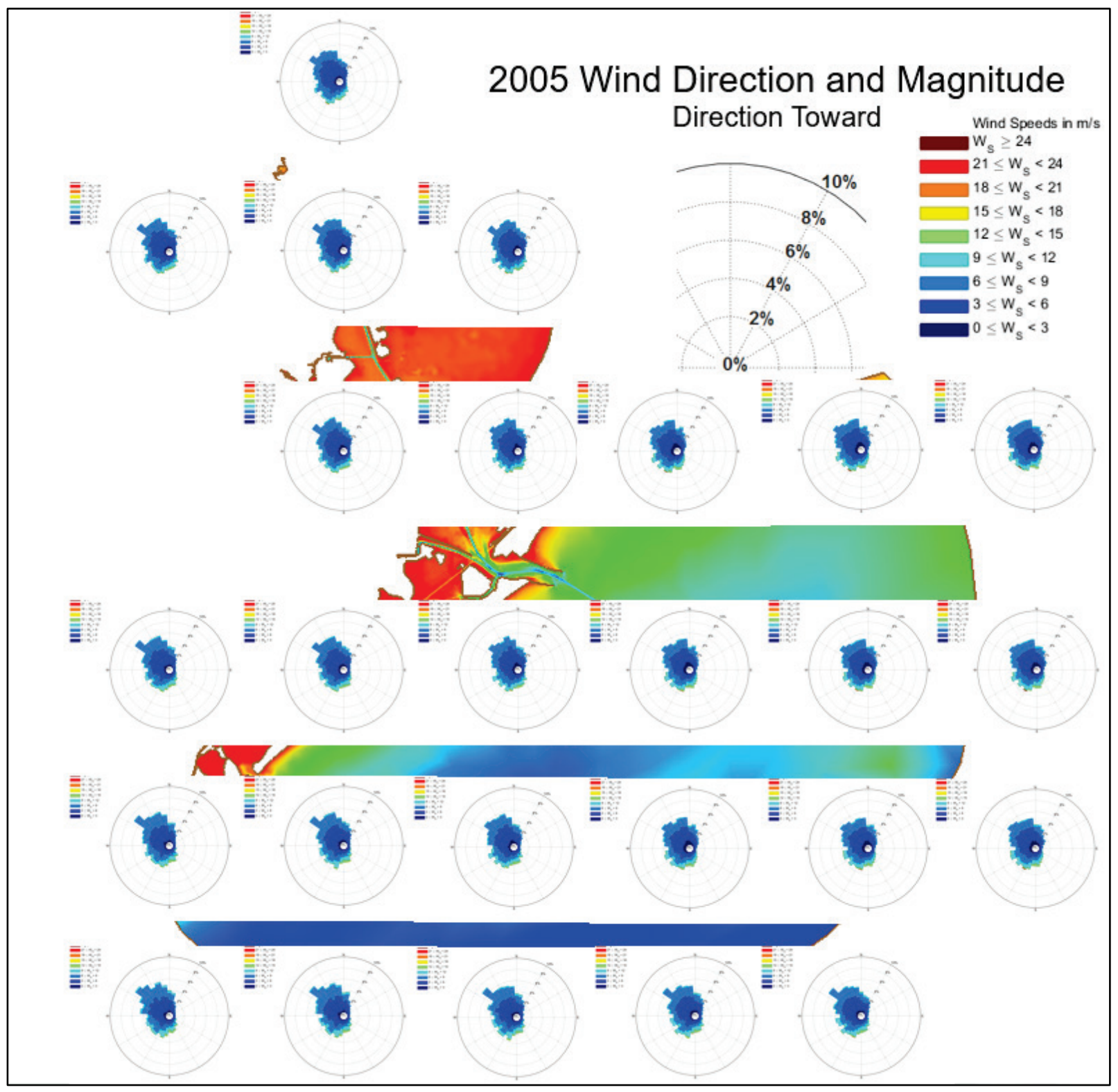


Figure 15. 2010 wind rose for all sites.

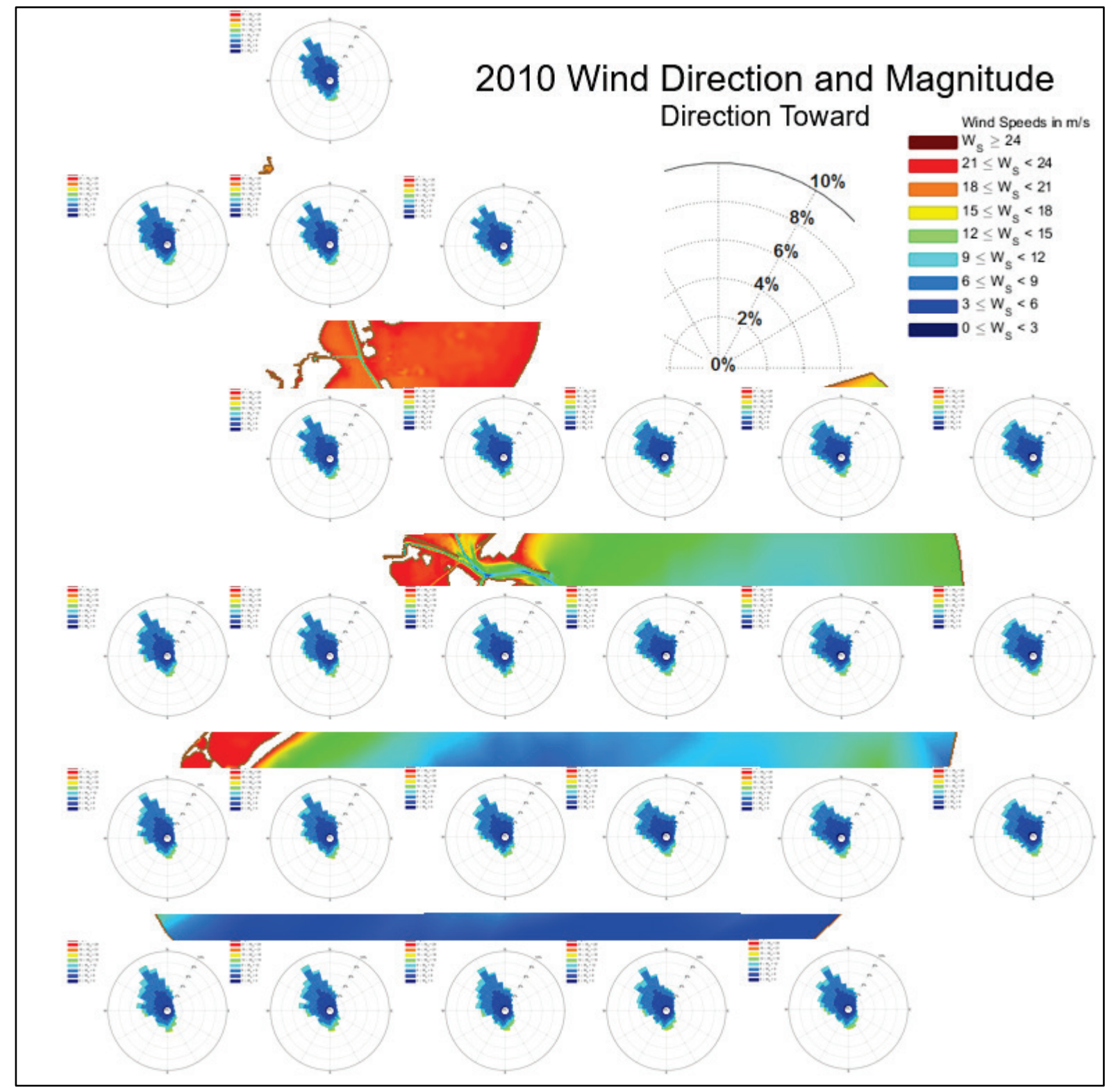


Figure 16. 2011 wind rose for all sites.

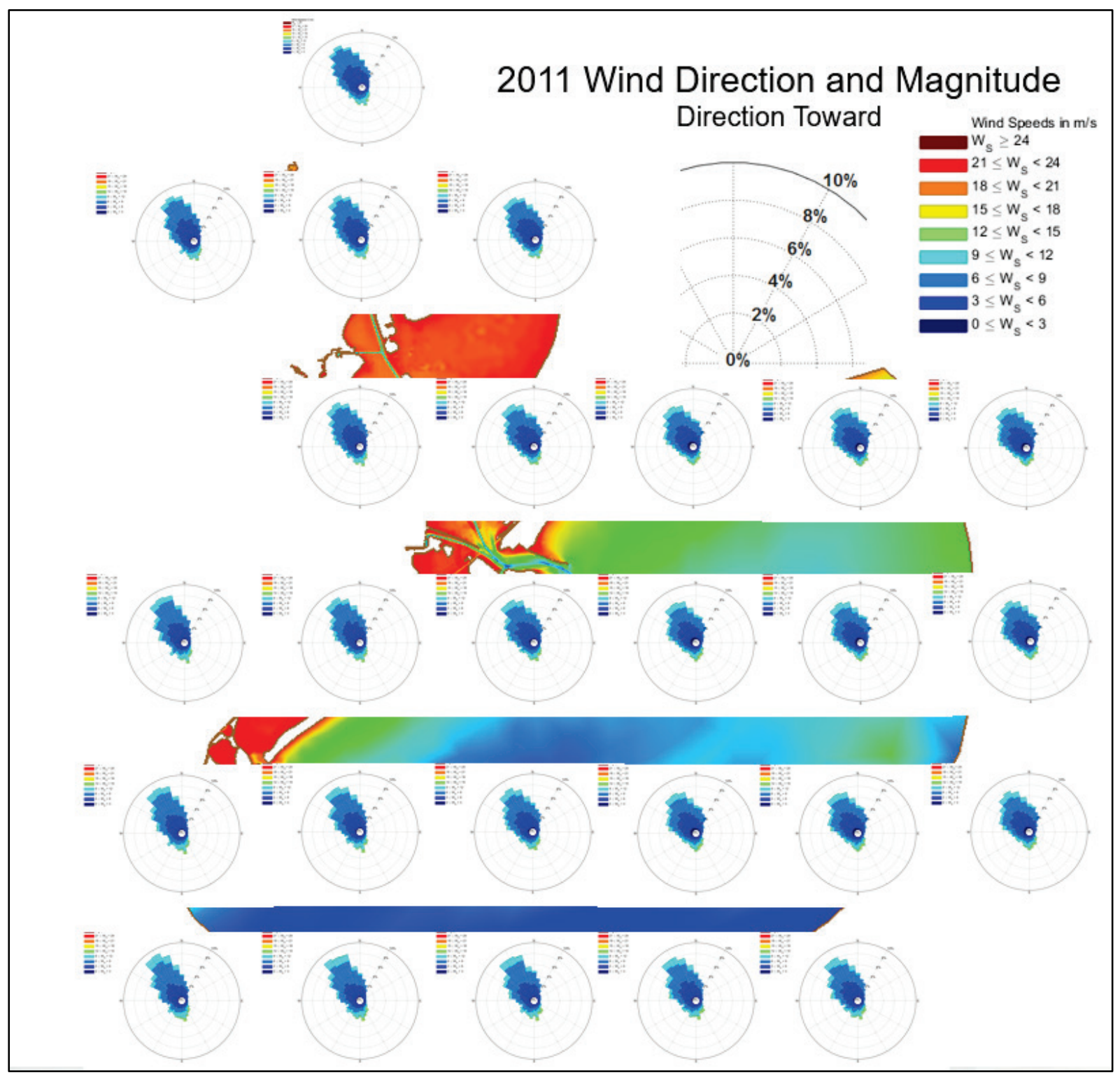

\section{Meteorological conditions}

To accurately reproduce salinity values in Trinity Bay, it was determined that rainfall and precipitation should be included in the model. These data (shown in Figure 17 through Figure 19) were also obtained from the Texas Water Development Board (TWDB), and the data are based on wind and temperature computations validated to several measurement locations using the Texas Rainfall Runoff Model. The combination of precipitation (rainfall only in south Texas) and evaporation is applied equally over the model domain. The drought conditions of 2011 are visible in the meteorological data. 
Figure 17. 2005 meteorological conditions.

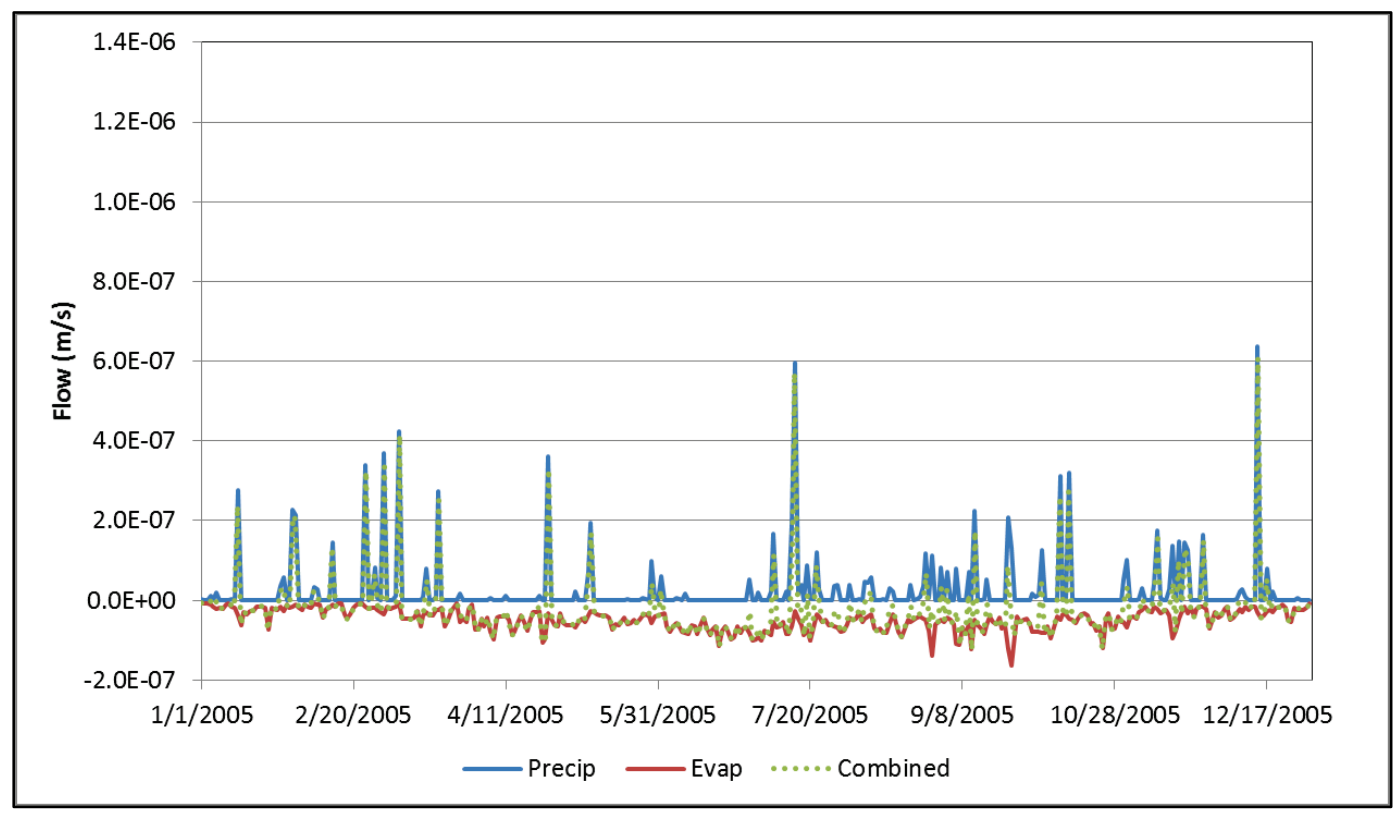

Figure 18. 2010 meteorological conditions.

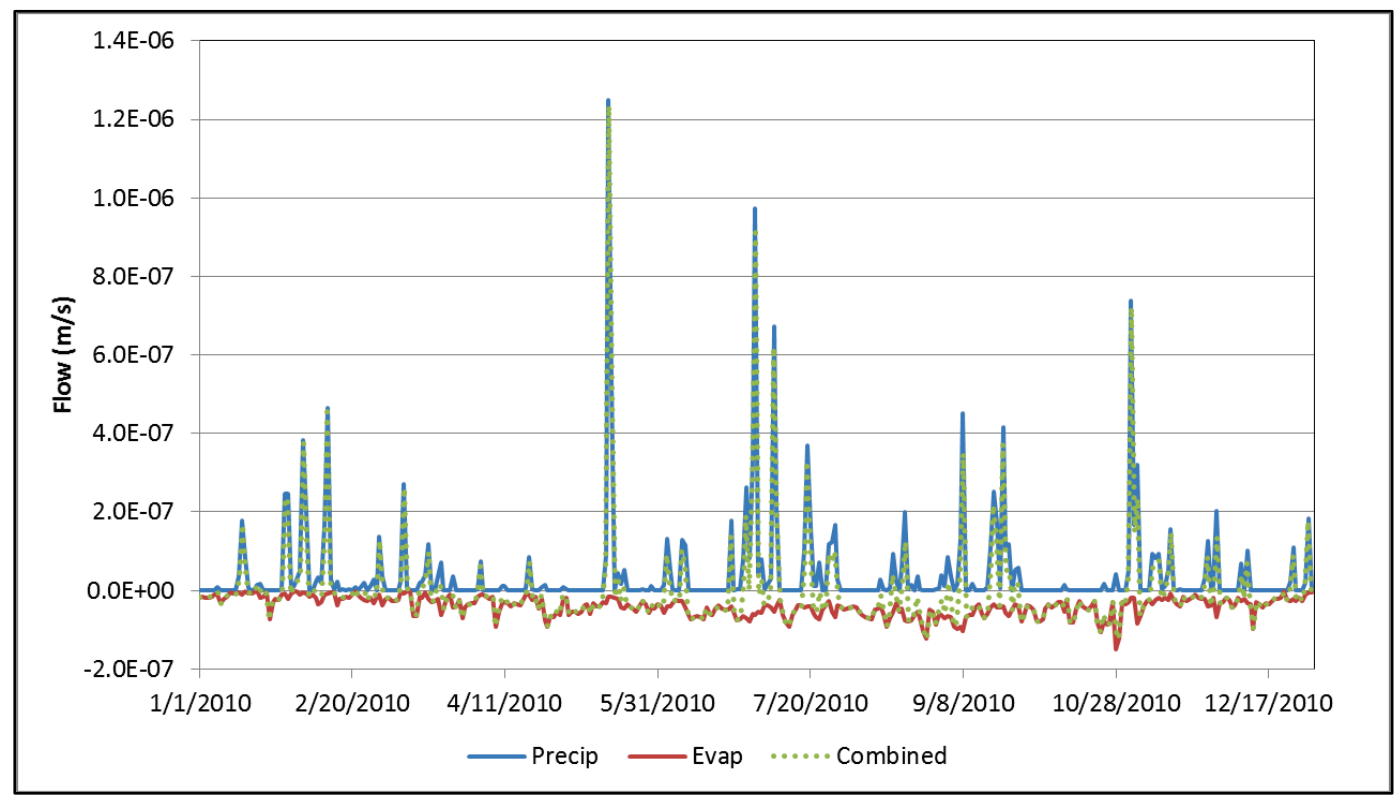


Figure 19. 2011 meteorological conditions.

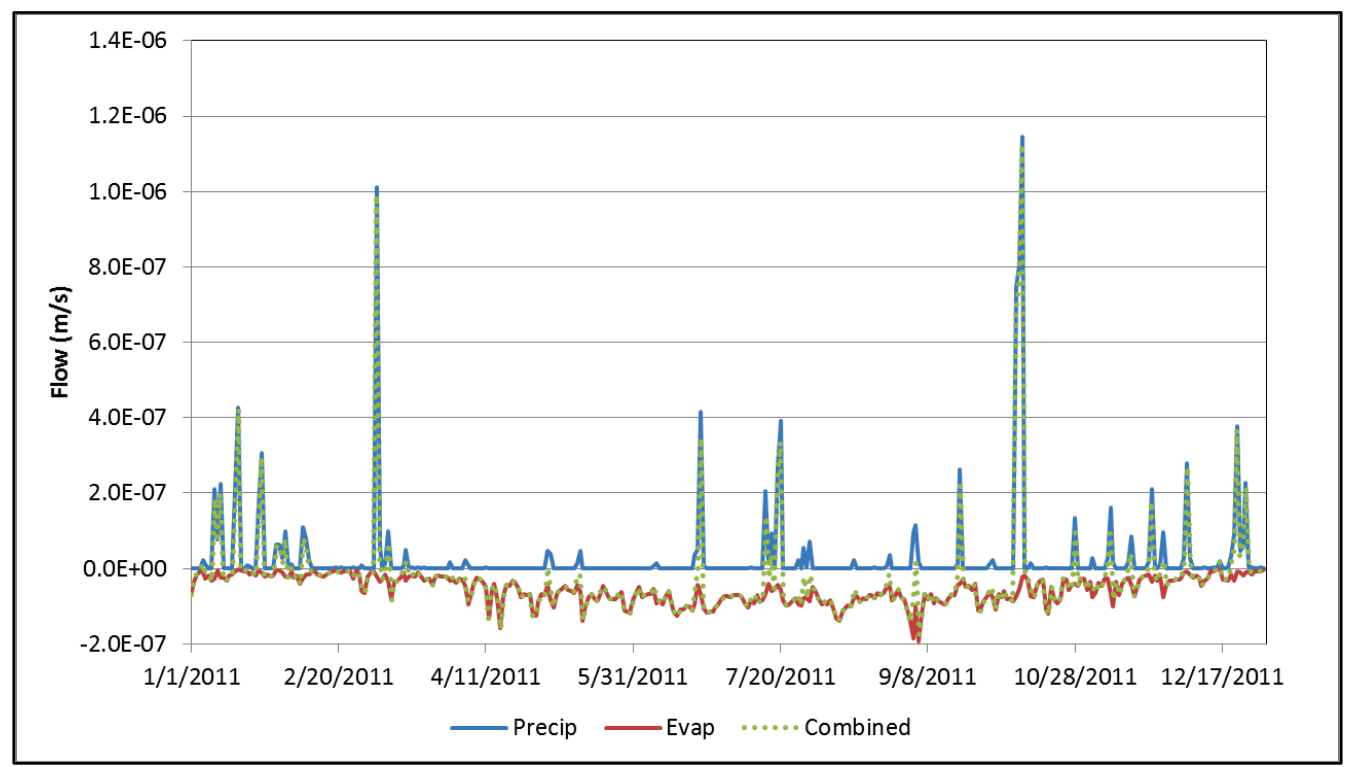

\section{Sediment model boundary conditions}

The sediment model is fully coupled with the hydrodynamic model when simulating AdH with SEDLIB. The boundary conditions for the sediment model include grain characteristics, bed definitions, and sediment loads. The conditions established from the previous sediment model validation (Tate et al. 2008) were determined from field samples (although a small sample set) in Trinity and Galveston Bays, and these parameters were used as initial parameters for the present AdH/SEDLIB sediment model. This model includes five fine sediment classes (sizes defined by the American Geophysical Union [AGU]), which encompasses the majority of the sediment present in the domain. Sand is dominant at the entrance at Bolivar Roads, but it primarily remains in that area and therefore is not included in these simulations. The sediment-specific parameters are given in Table 1. These parameters are utilized for suspended and newly deposited grains.

Table 1. Sediment parameters and values.

\begin{tabular}{|c|c|c|c|c|c|c|c|}
\hline $\begin{array}{c}\text { Grain Class } \\
(\mathrm{AGU})\end{array}$ & $\begin{array}{c}\text { Diameter } \\
(\mathrm{mm})\end{array}$ & $\begin{array}{c}\text { Specific } \\
\text { Gravity }\end{array}$ & $\begin{array}{c}\text { Density } \\
\left(\mathrm{kg} / \mathrm{m}^{3}\right)\end{array}$ & $\begin{array}{c}\text { Critical Shear } \\
\text { for Erosion } \\
(\mathbf{P a})\end{array}$ & $\begin{array}{c}\text { Erosion } \\
\text { Rate } \\
\text { Constant }\end{array}$ & $\begin{array}{c}\text { Critical Shear } \\
\text { for Deposition } \\
(\mathbf{P a})\end{array}$ & $\begin{array}{c}\text { Settling } \\
\text { Velocity } \\
(\mathrm{mm} / \mathrm{s})\end{array}$ \\
\hline Clay & 0.003 & 2.65 & 1275 & 0.1 & 0.0000384 & 0.05 & 0.009 \\
\hline Very Fine Mud & 0.006 & 2.65 & 1275 & 0.2 & 0.0000384 & 0.06 & 0.036 \\
\hline Fine Mud & 0.011 & 2.65 & 1275 & 0.3 & 0.0000384 & 0.07 & 0.121 \\
\hline Medium Mud & 0.023 & 2.65 & 1275 & 0.4 & 0.0000384 & 0.08 & 0.529 \\
\hline Coarse Mud & 0.045 & 2.65 & 1275 & 0.6 & 0.0000384 & 0.10 & 2.025 \\
\hline
\end{tabular}


Since the data available to define the sediment bed throughout the full model domain are limited (most is only in the HSC) and many years old (URS Group Inc. 2009; Buczkowski et al. 2006), the hydrodynamics of the system are used to sort the bed prior to validation and alternative simulations. This step is performed by setting the top-most defined bed layer to equal fractions for all of the grains ( 0.2 for all five grains). This layer is also defined as $0.2 \mathrm{~m}$ thick - selected because erosion beyond this value during the course of the simulation year is likely prevented due to bed armoring or nonedible material; it is known that the bay system is not eroding at a significant rate (Nichols 1989). Three additional bed layers are defined to track deposition events and help define bed features that may change the erosion/deposition potential. The cohesive bed properties that help determine erosion potential of a bed layer are defined with bulk density of 1400 kilograms per cubic meter, critical shear stress for erosion of 1.0 Pascal, erosion rate constant of 0.000062, and erosion rate exponent of 1.0.

As the model runs and the bed begins to sort and change, the bed properties vary from these initially defined parameters. An initial 1-year simulation is performed with no bed displacement allowed so that the bed can sort based on the erosion and deposition tendencies in each area. The results of this spin-up simulation are then used as the initial conditions for the analysis model run with the bed allowed to change due to computed erosion and deposition.

The sediment entrainment algorithm used in this model is Wright-Parker (Wright and Parker 2004), and the hiding factor algorithm is Egiazaroff (Egiazaroff 1965). Flocculation properties are not included in the AdH code and should be considered when defining the sediment grain properties. There is no bedload in the present 3D Shallow Water AdH code, and cohesive bed consolidation is not included in this model due to the short simulation time of 1 year for each analysis model run.

Sediment loads are applied to the two major rivers in the area: the Trinity River and the San Jacinto River. These loads are determined from a rating curve correlating discharge with concentration generated using data from the U.S. Geological Survey as documented in Tate et al. (2008). 


$$
\begin{aligned}
C_{\text {Trinity }} & =0.7704 * Q_{\text {Trinity }} 0.5716 \\
C_{\text {SanJacinto }} & =7.1547 * Q_{\text {SanJacinto }} 0.3234
\end{aligned}
$$

These load estimates are not ideal. The Trinity River load is based on 2 years of data collected at the Wallisville lock, which is the upstream model boundary for this river. The San Jacinto River load is based on limited data from Conroe, TX, which is located on the Western fork of the river and upstream of Lake Houston. The sediment loads applied at each river for each of the validation years are shown in Figure 20 through Figure 22. The total load is divided equally among the five grain classes. The load information for the ungaged inflows is unknown and therefore set to zero.

Figure 20. 2005 total sediment load for Trinity and San Jacinto Rivers.

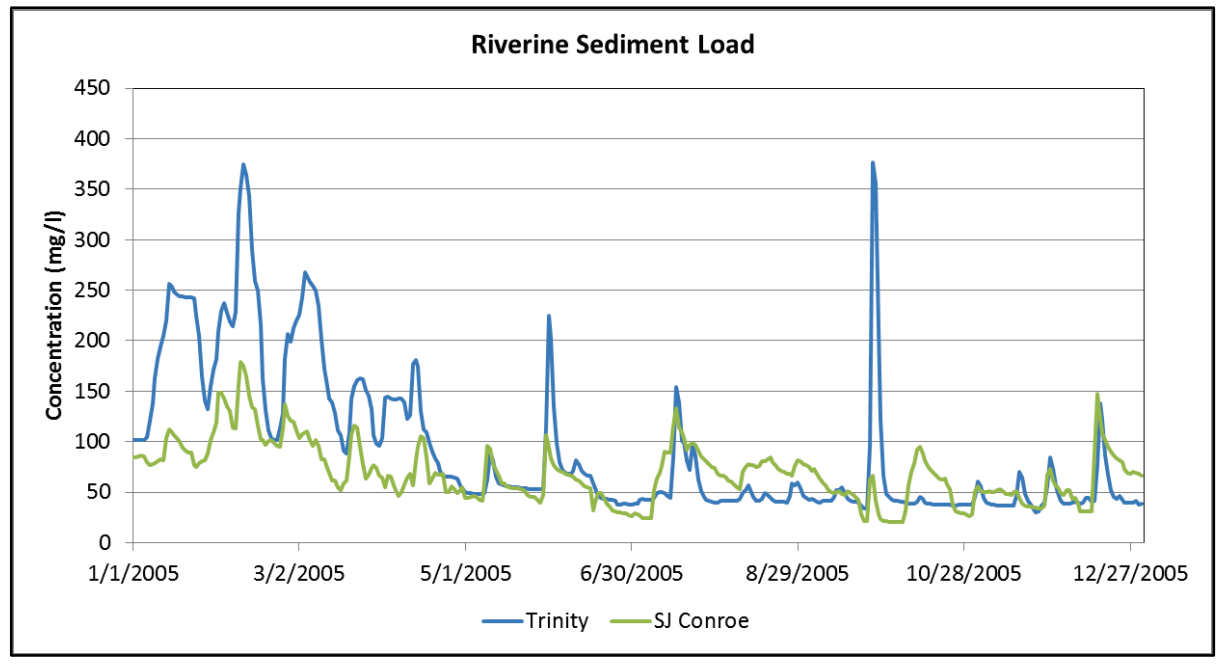

Figure 21. 2010 total sediment load for the Trinity and San Jacinto Rivers.

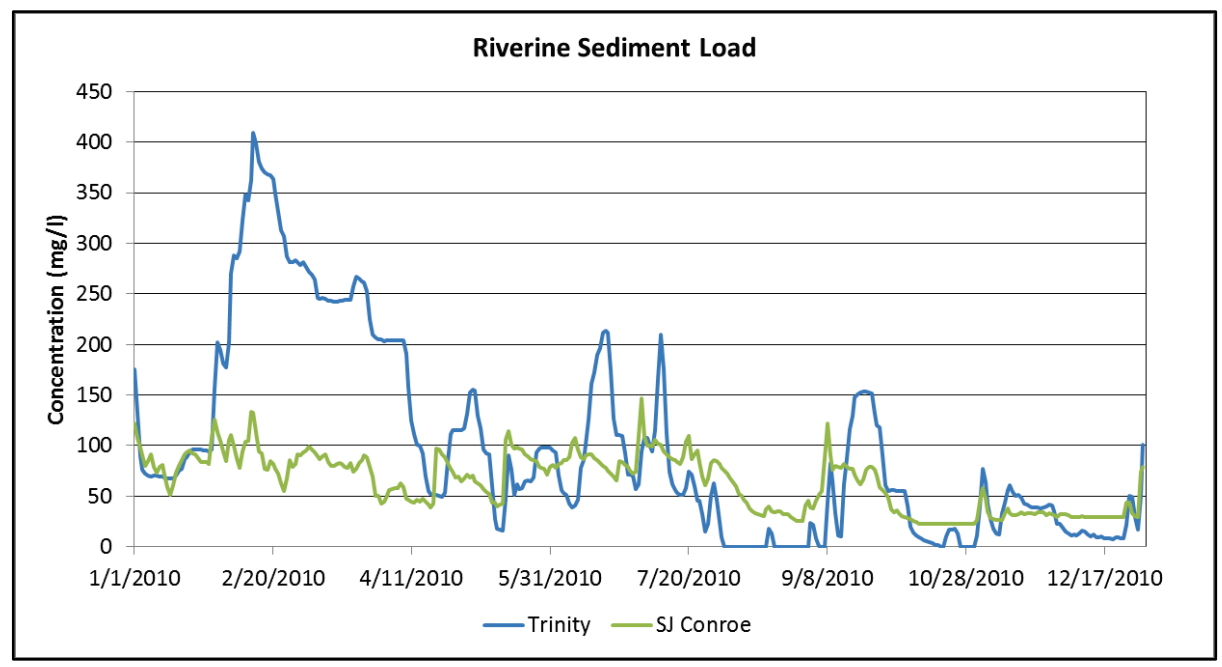


Figure 22. 2011 total sediment load for Trinity and San Jacinto Rivers.

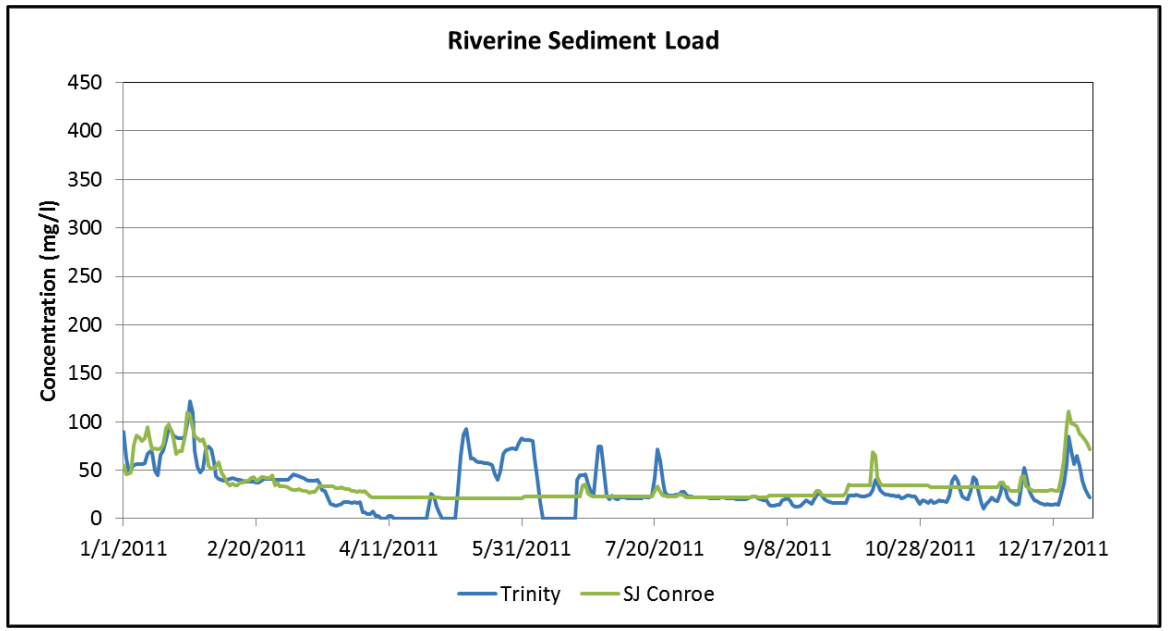

The sedimentation in the HSC and Trinity and Galveston Bays is influenced greatly by deep-draft vessel passages in the area (Tate et al. 2008 , 2014). Figure 23 shows model-computed results indicating that vessel induced shoaling can produce 4 times more shoaled volume in the HSC than other factors such as tidally driven sedimentation and river sediment loads. The model presented in this report does not include vessel impacts indicating an expectation to underpredict the sediment volumes. Shoaling drivers not specifically in the model are incorporated as part of a scaling process performed during model calibration/validation.

Figure 23. Influences on HSC shoaling.

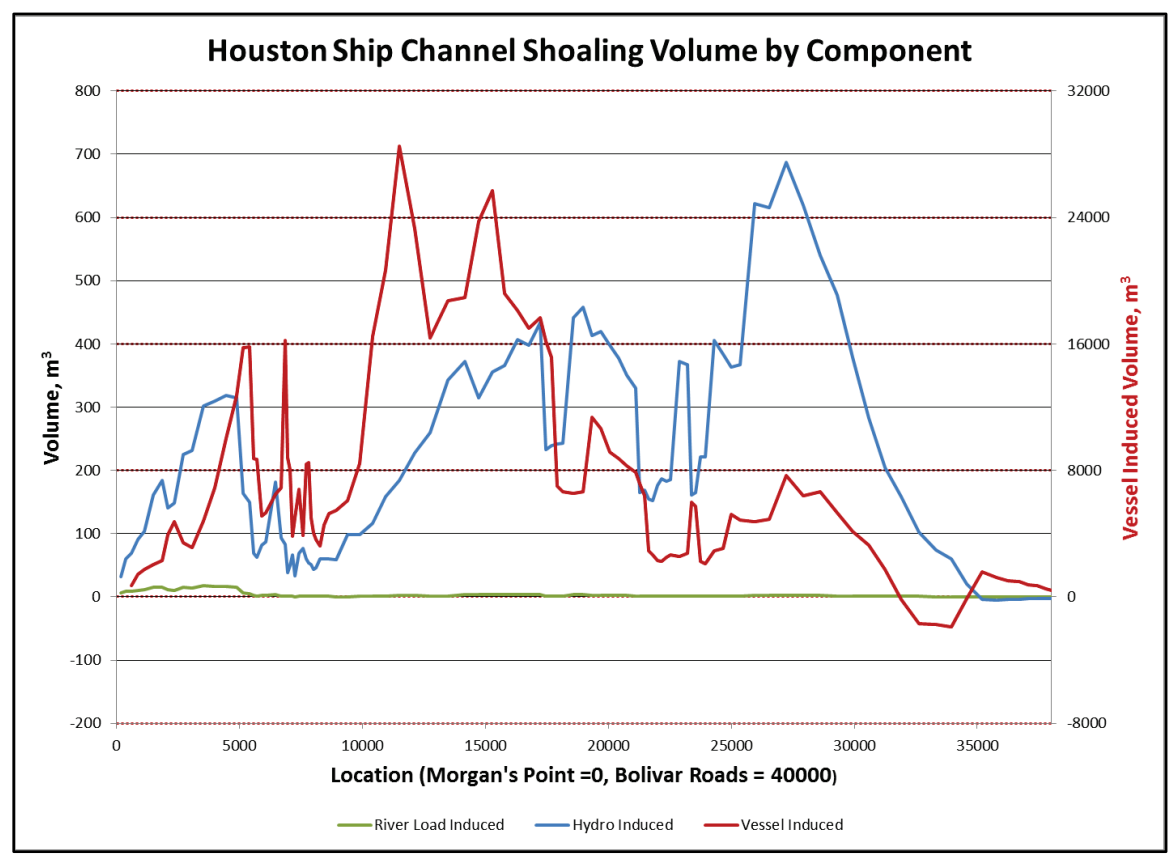




\section{AdH model parameters}

The parameters used by AdH to achieve the validated model (discussed in the following sections) are provided in Table 2. This table provides the specific or range of values used for various model properties such as bed roughness, diffusion, eddy viscosity, and turbulence. The values vary by location (material designation) and sediment grain class. Large values of diffusion, viscosity, and turbulence coefficients (increased generally to maintain model stability) are associated with larger grain sizes and locations away from the immediate study area.

Table 2. Model parameters.

\begin{tabular}{|l|l|}
\hline Parameter & Value \\
\hline Turbulent Diffusion of Salinity & $0.00005-0.1 \mathrm{~m}^{2} / \mathrm{s}$ \\
\hline Turbulent Diffusion of Cohesive Sediment & $0.001-10.0 \mathrm{~m}^{2} / \mathrm{s}$ \\
\hline Eddy Viscosity & $0.0001-1.5 \mathrm{~m}^{2} / \mathrm{s}$ \\
\hline Turbulence (Smagorinsky Coefficient) & $0.2-0.8$ \\
\hline Bed Roughness (Manning's Coefficient) & 0.015 \\
\hline Time Stepping & Second Order \\
\hline Time-Step Maximum & $150 \mathrm{~s}$ \\
\hline Convergence & 0.01 (Increment Norm) \\
\hline
\end{tabular}




\section{Model/Field Comparison - Calibration and Validation}

The model is calibrated/validated by comparing to measured field data over 3 different years $-2005,2010$, and 2011. These 3 years were used to take advantage of various data sets for hydrodynamics, salinity, and sediment transport as well as provide a wide range of conditions over which the model is considered accurate. Year 2005 served as a calibration period such that parameters - such as bed roughness, salinity diffusion, viscosity, and sediment properties - were adjusted, within a physically reasonable range, to get the best match to the field data. Those parameters were then unchanged when the model was simulated and compared to the field (validated) for 2010 and 2011. Most data were obtained from publicly accessible data websites. For all comparison types - hydrodynamic, salinity, and sediment - a subset of the sites are provided in the body of the report with all site comparisons provided in the appendices.

\section{Hydrodynamic calibration}

The model is compared to water surface elevation and velocity at several locations during the 2005 calibration period. Water surface elevation data were obtained from the NOAA Co-Ops and the National Data Buoy Center. Velocity data were obtained from NOAA PORTS.

\section{Water surface elevation}

Water surface elevation results are compared to the field at six locations. Figure 24 shows the location of the water surface elevation comparison sites. Statistical comparisons are provided in Table 3. Time history and box plot comparisons at Manchester, Morgans Point, and Eagle Point are shown in this section (see Figure 25 through Figure 27 and Figure 28 through Figure 30). The full set of comparisons is provided in Appendix A.

For the time history plots, the green line represents the measured field data, and the blue line represents the model computed values. Each comparison location also includes a box plot showing the relationship between the measured field data ( $x$-axis) and the modeled data ( $y$-axis). A perfect match would yield points on the black 1:1 line. 
Figure 24. Water surface elevation comparison locations.

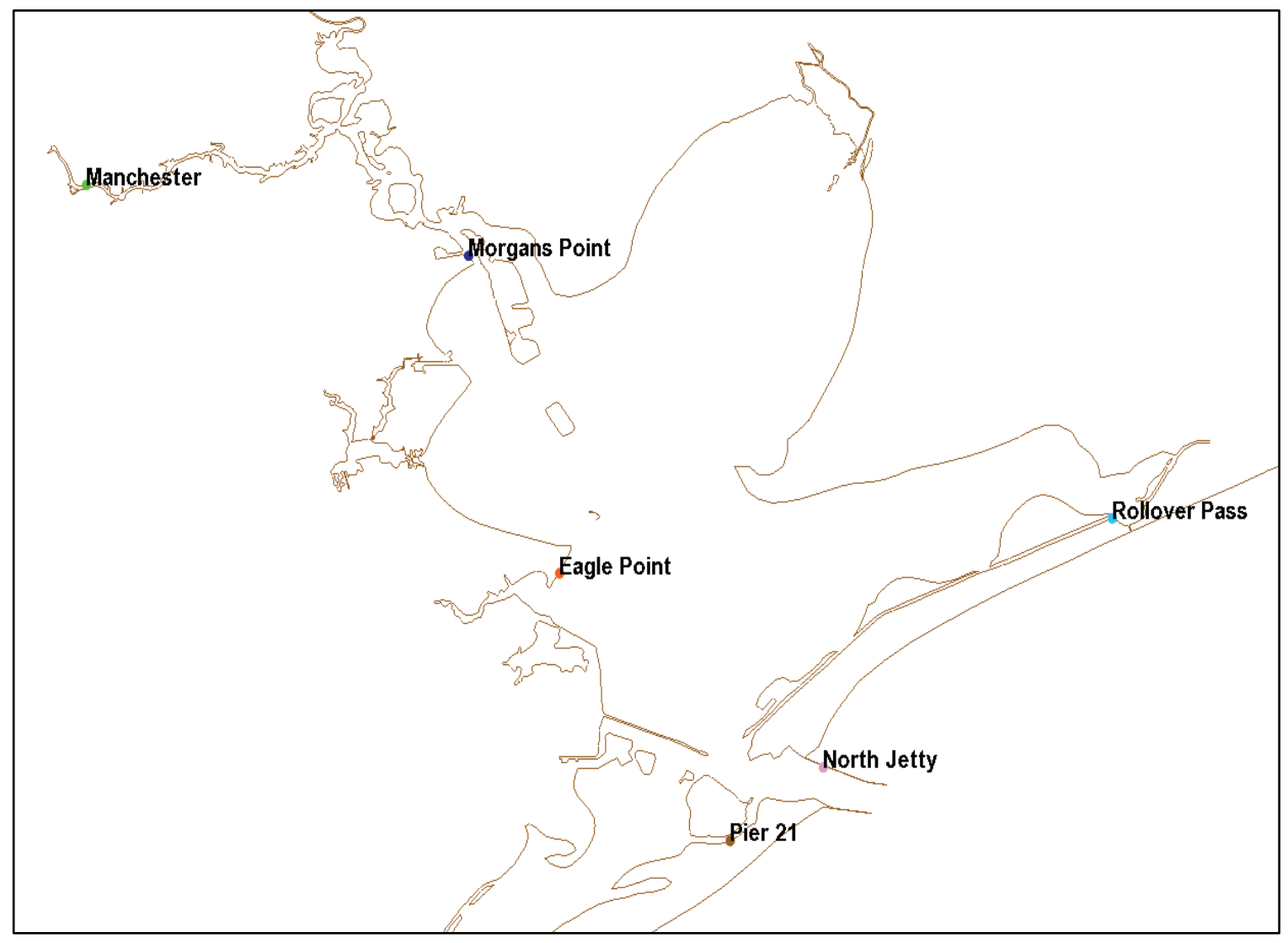

Table 3. Statistical model/field calibration comparison of water surface elevation.

\begin{tabular}{|c|c|c|}
\hline & $\begin{array}{c}2005 \\
\text { Root Mean } \\
\text { Square Error }\end{array}$ & $\begin{array}{c}2005 \\
\text { Correlation } \\
\text { Coefficient }\end{array}$ \\
\hline Manchester & 0.12 & 0.90 \\
\hline Morgan's Point & 0.07 & 0.96 \\
\hline Eagle Point & 0.06 & 0.97 \\
\hline Pier 21 & 0.07 & 0.97 \\
\hline North Jetty & 0.05 & 0.98 \\
\hline Rollover Pass & 0.12 & 0.85 \\
\hline
\end{tabular}


Figure 25. Water surface elevation calibration comparisons over time for Manchester.

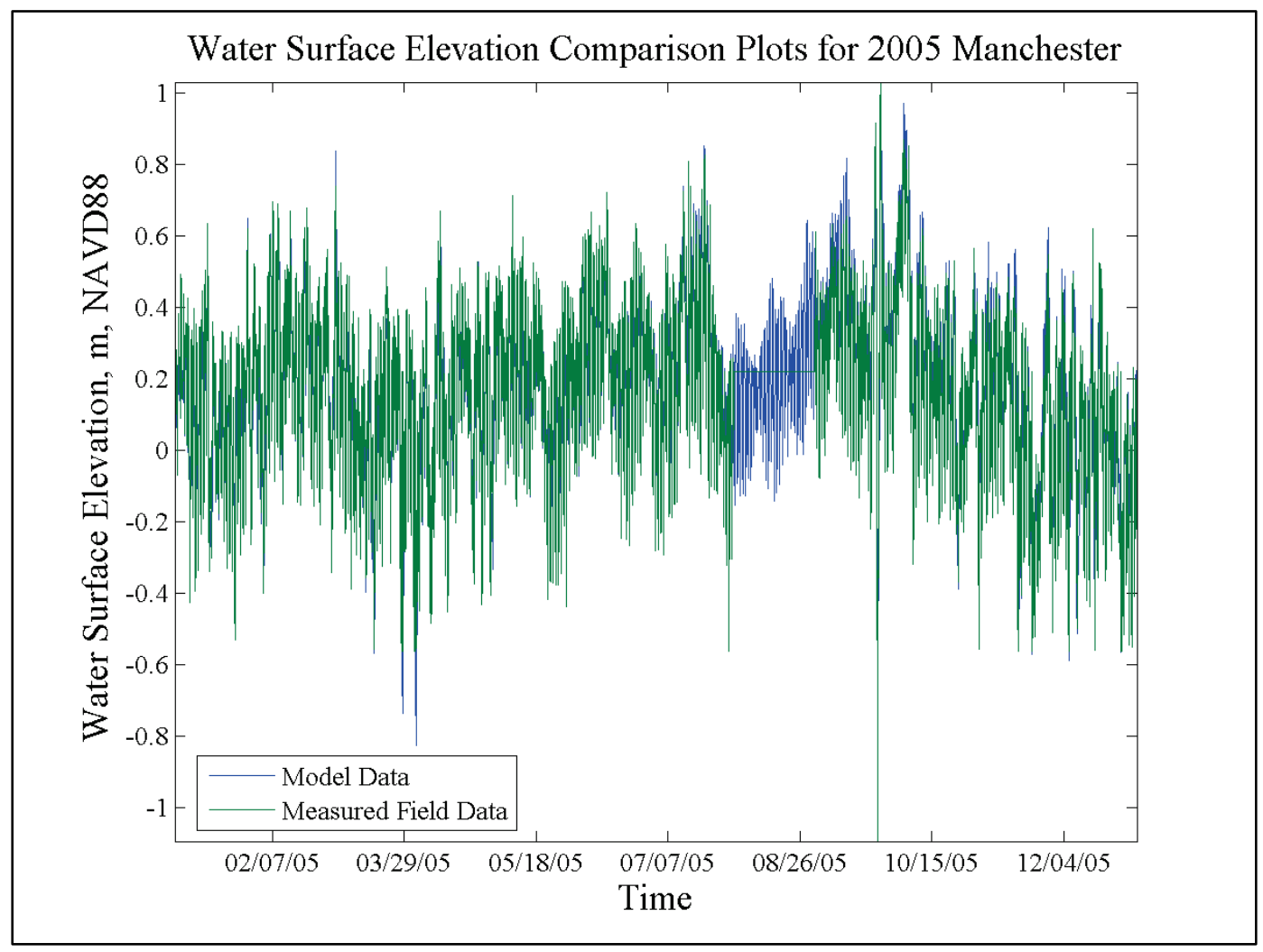

Figure 26. Water surface elevation calibration comparisons over time for Morgans Point.

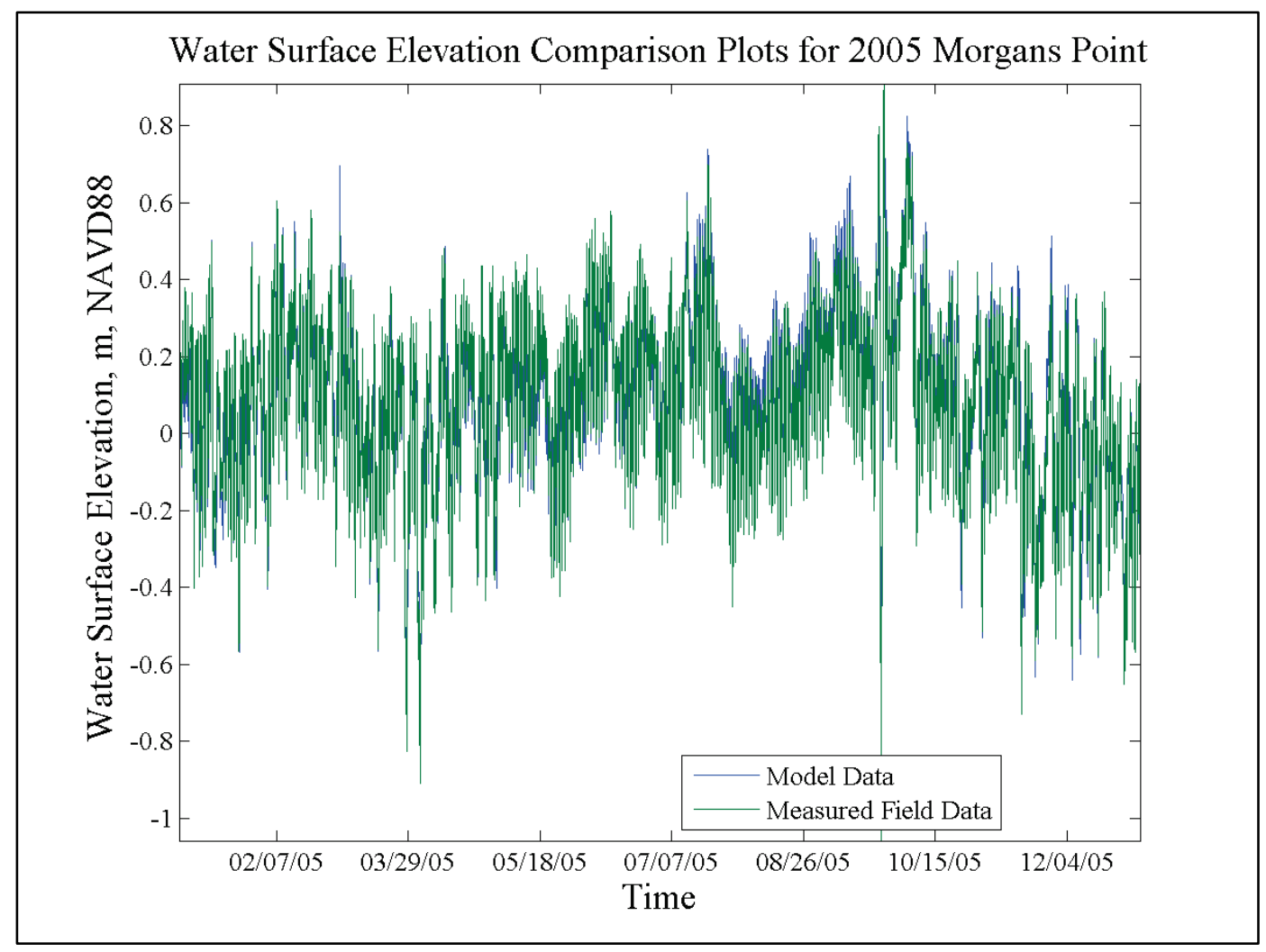


Figure 27. Water surface elevation calibration comparisons over time for Eagle Point.

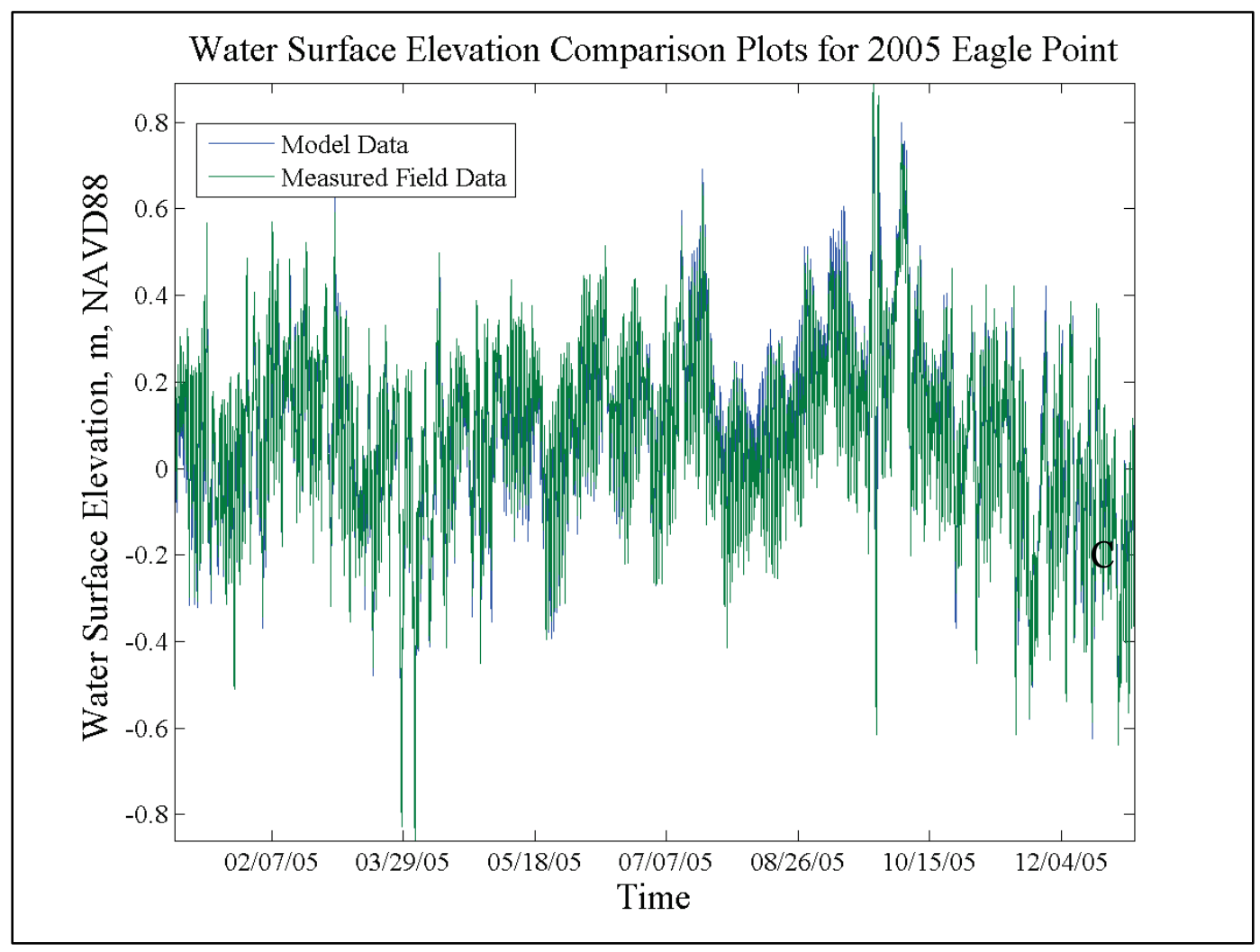

Figure 28. Water surface elevation calibration comparison box plot for Manchester.

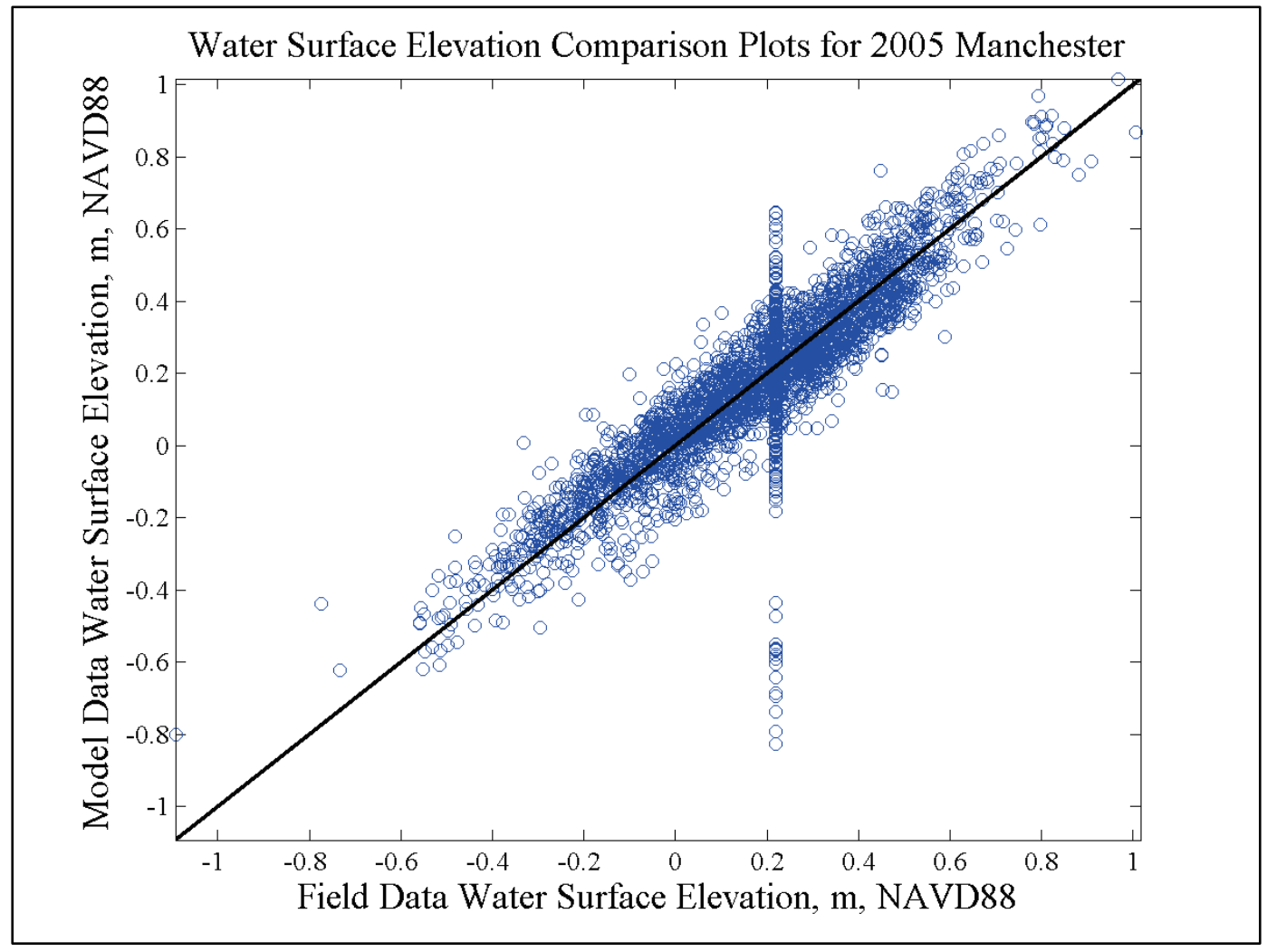


Figure 29. Water surface elevation calibration comparison box plot for Morgans Point.

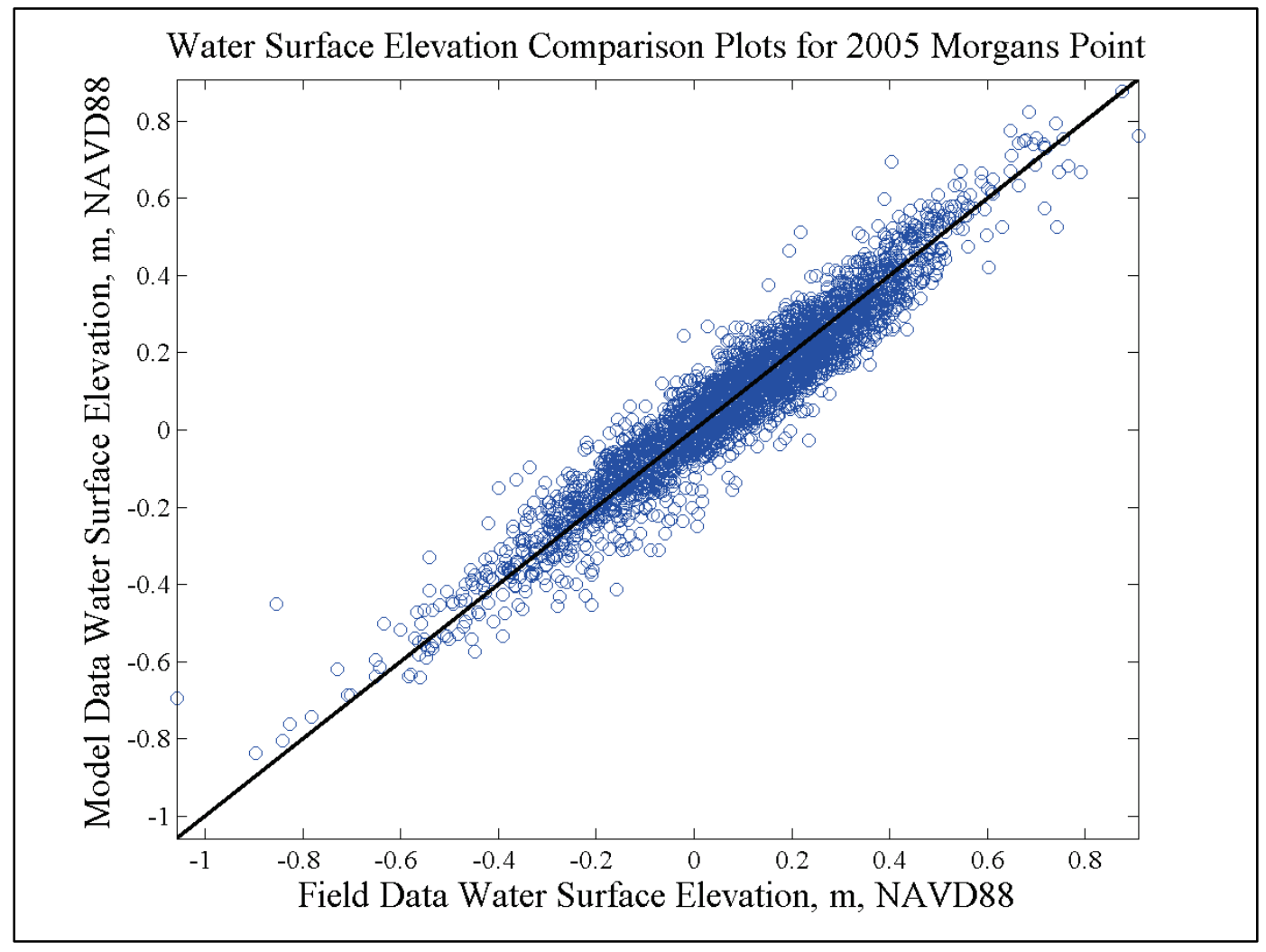

Figure 30. Water surface elevation calibration comparison box plot for Eagle Point.

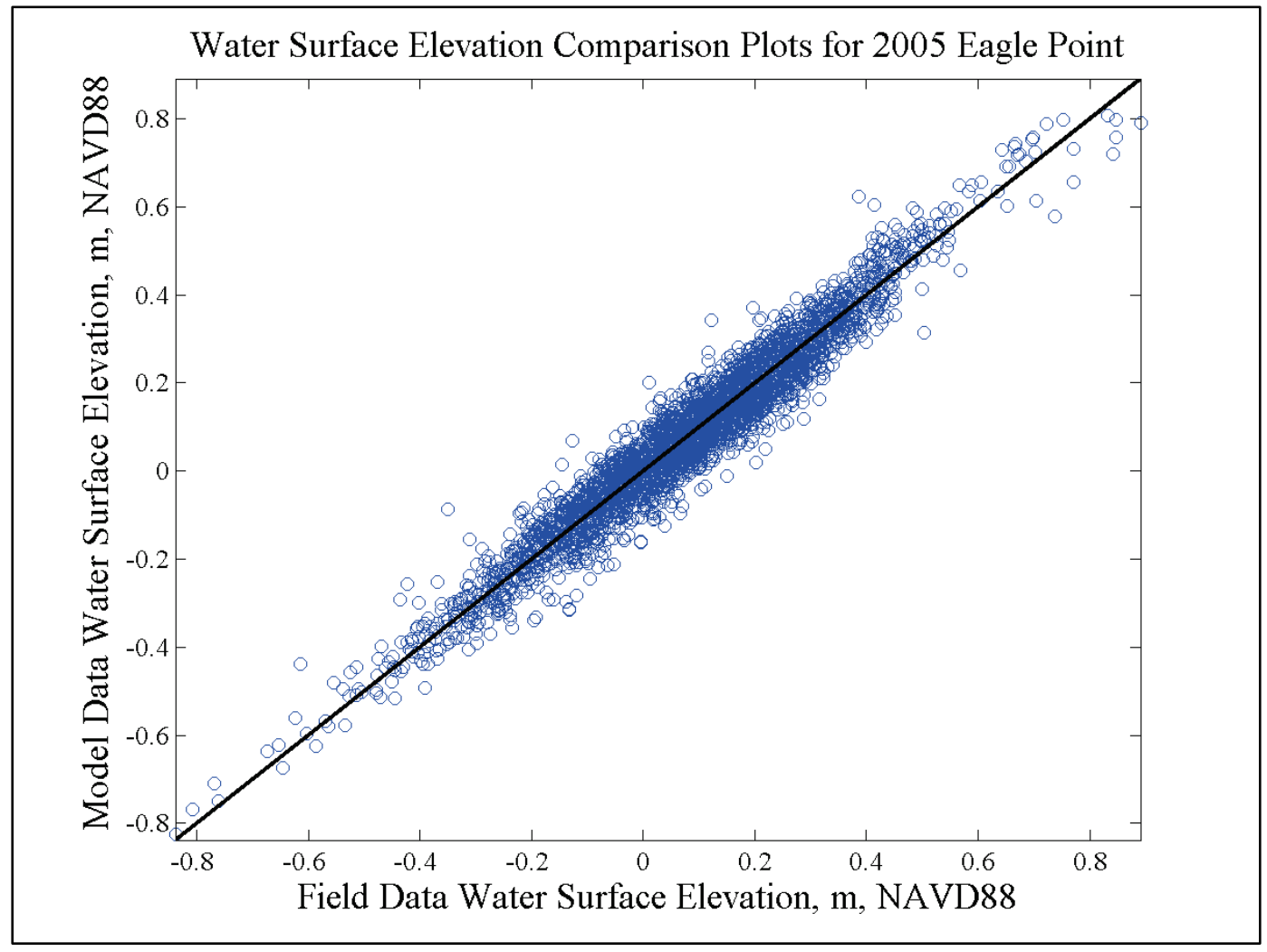




\section{Velocity}

Velocity calibration comparisons are made at one location from NOAA PORTS (Figure 31) - Morgan's Point. Additional sites are available for comparison of the validation years. Figure 32 shows the time history velocity magnitude and direction (positive: flood; negative: ebb) for this location. The overall pattern of the surface velocity signal is reproduced by the model, and the comparison of the magnitude is also good.

Figure 31. Velocity calibration comparison locations.

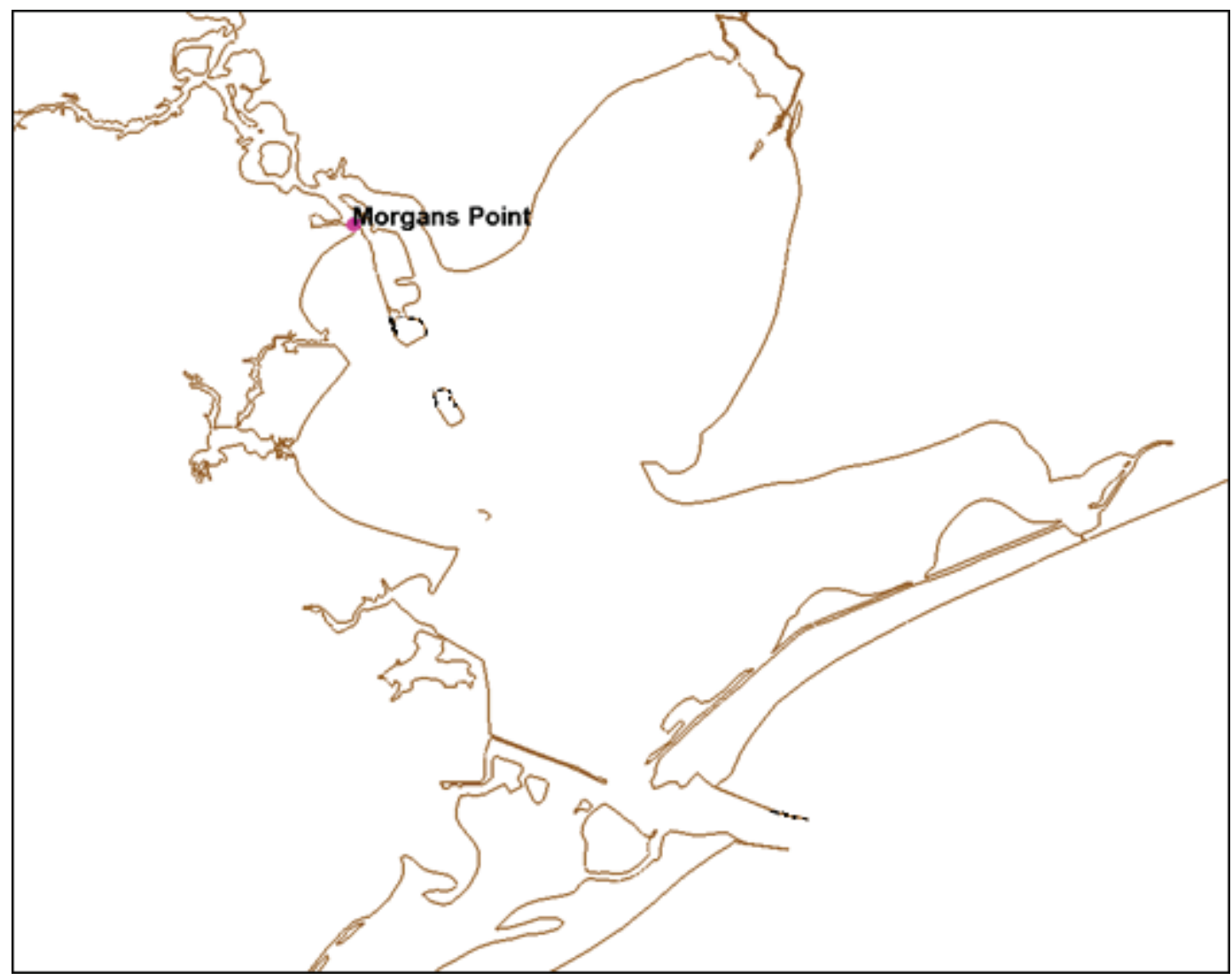


Figure 32. 2005 Morgan's Point velocity comparison (positive: flood; negative: ebb).

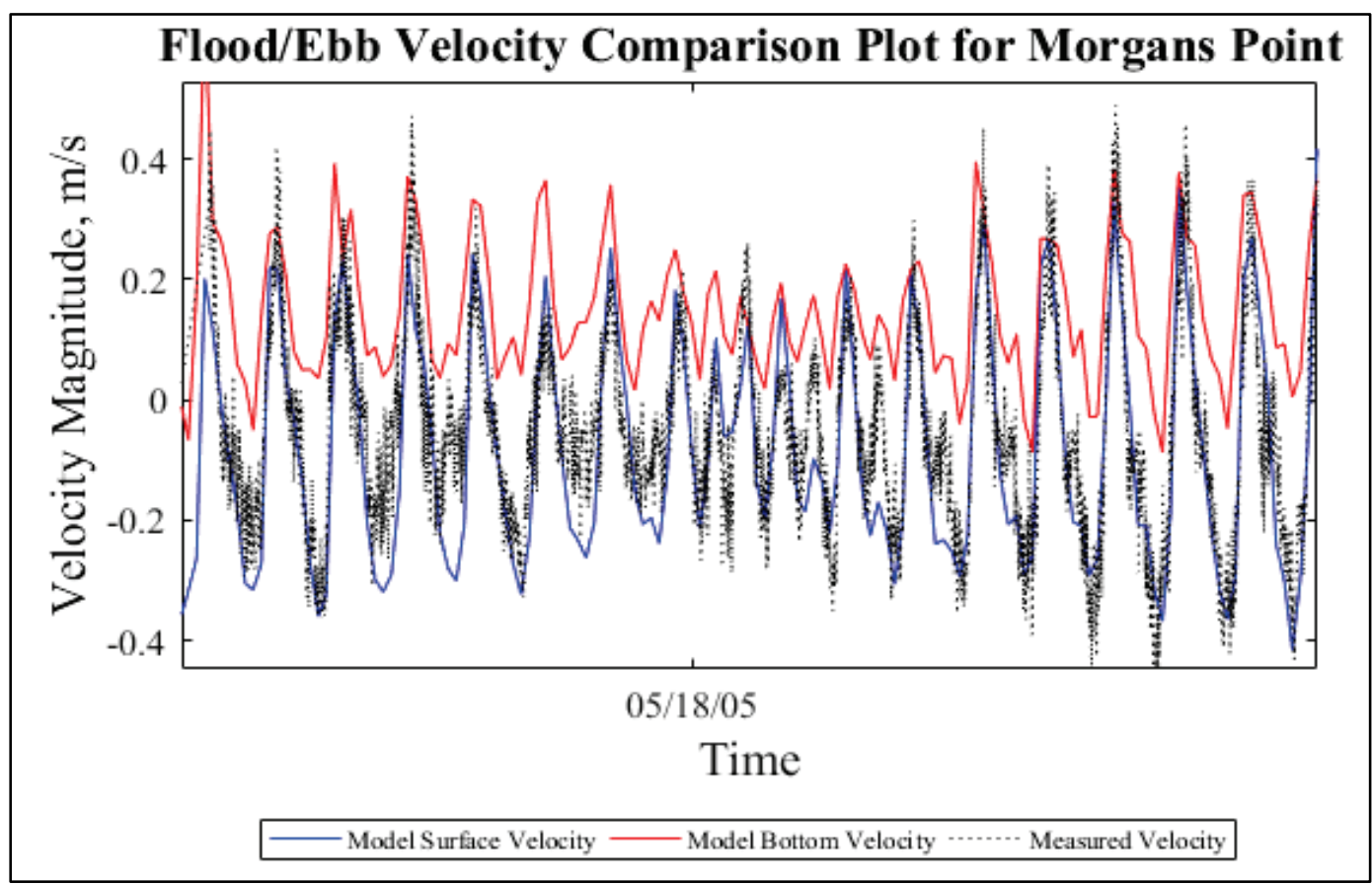

\section{Salinity calibration}

The 2005 field salinity data for model calibration were obtained from TWDB (Figure 33), Texas Commission on Environmental Quality (TCEQ) (Figure 34), and Houston Advanced Research Center (HARC) (Figure 35). There are 24 total salinity calibration sites throughout the HSC and the surrounding bays.

Time-history comparisons at selected locations are shown in this section. The field data are represented by stars where data are sparse and smaller black dots where data are numerous whereas the model data are shown in blue for surface salinity and in red for bottom salinity. In deep, stratified regions, the bottom salinity is larger than the surface salinity. In well-mixed regions the two should be approximately equal. The field-measured salinity is typically measured at the surface, but it is not specified for all data. A subset of comparisons is provided with the full set of comparisons provided in Appendix B. 
Figure 33. TWDB 2005 salinity calibration sites.

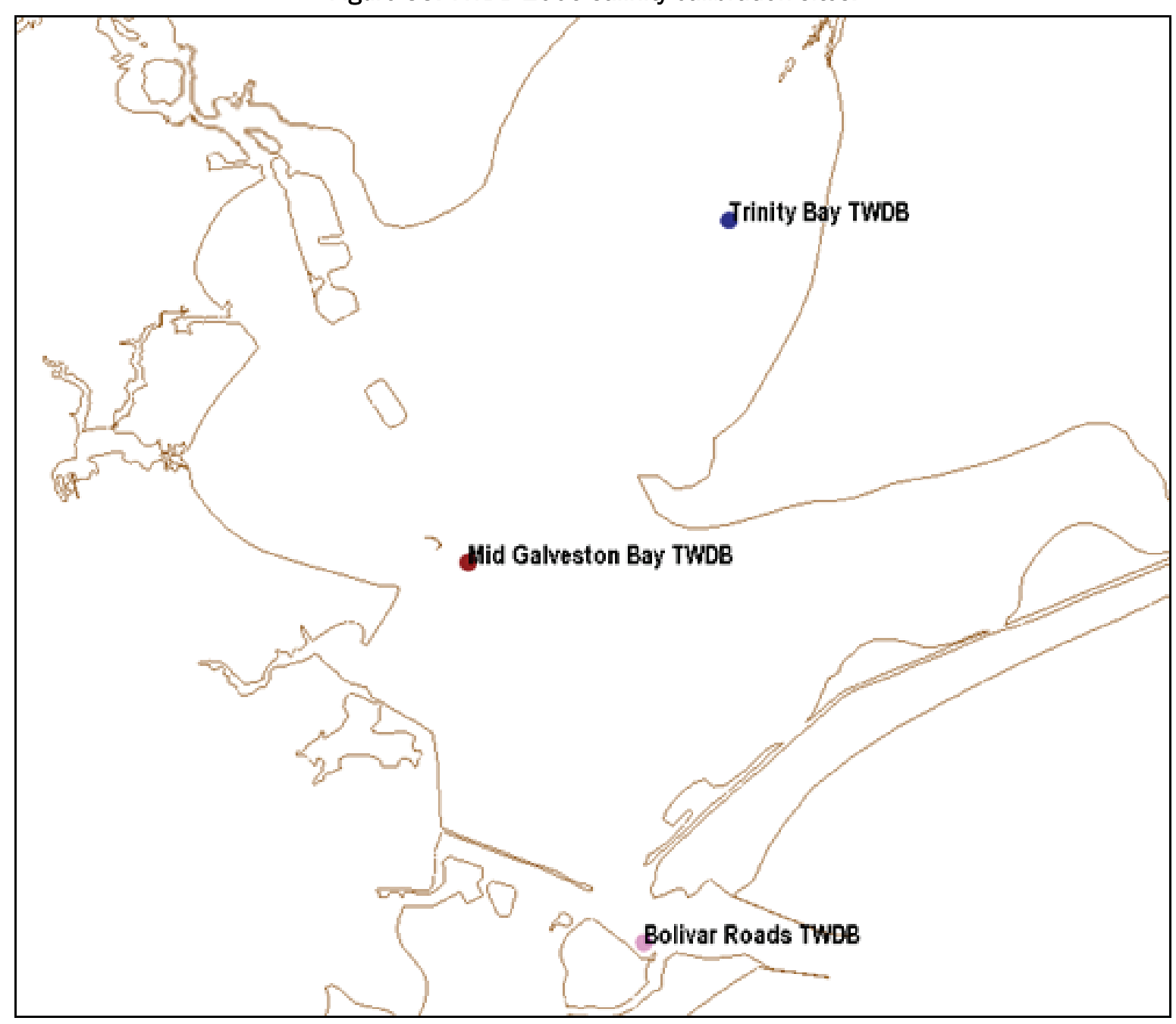


Figure 34. TCEQ 2005 salinity calibration sites.

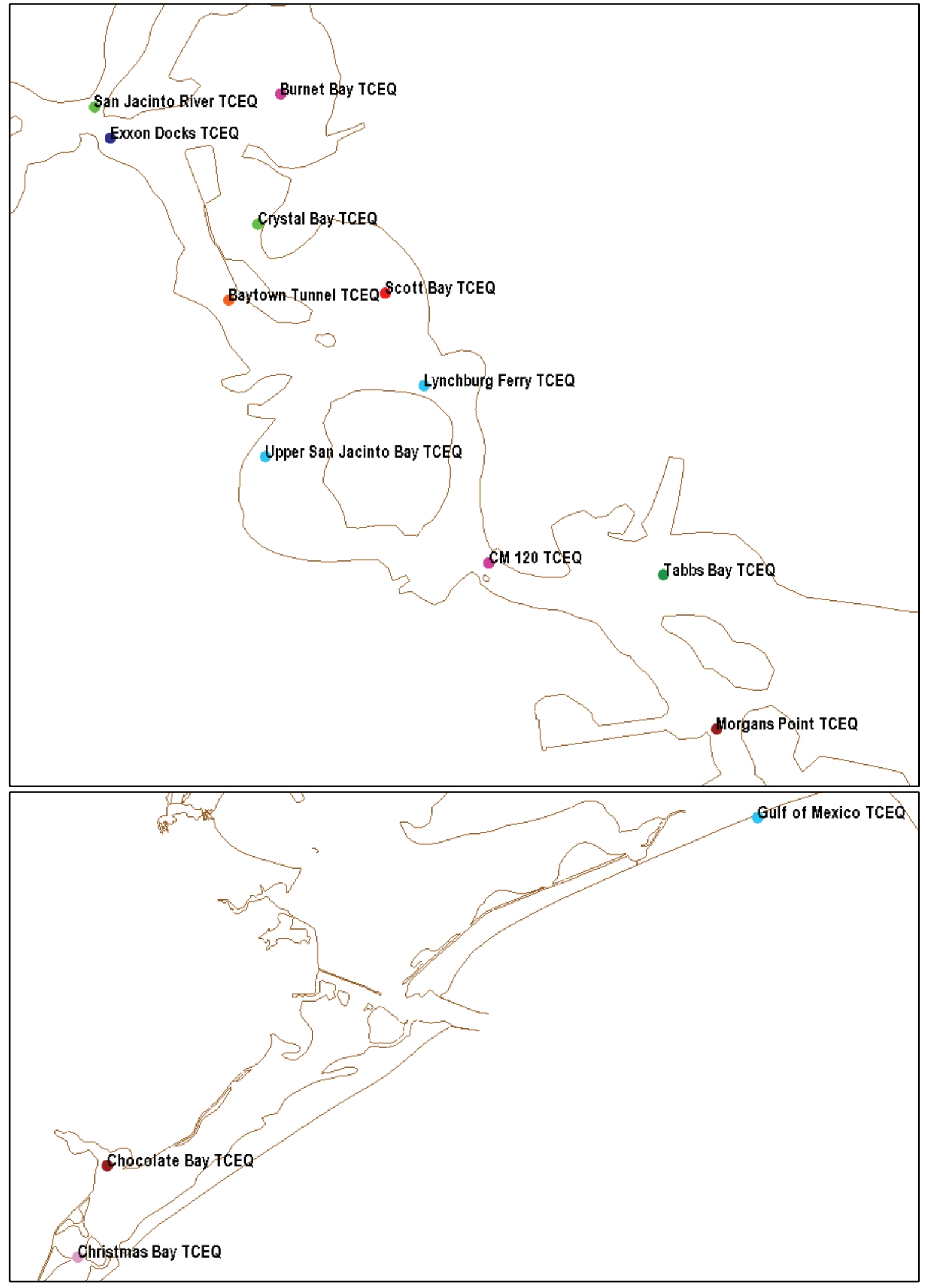


Figure 35. HARC 2005 salinity calibration sites.

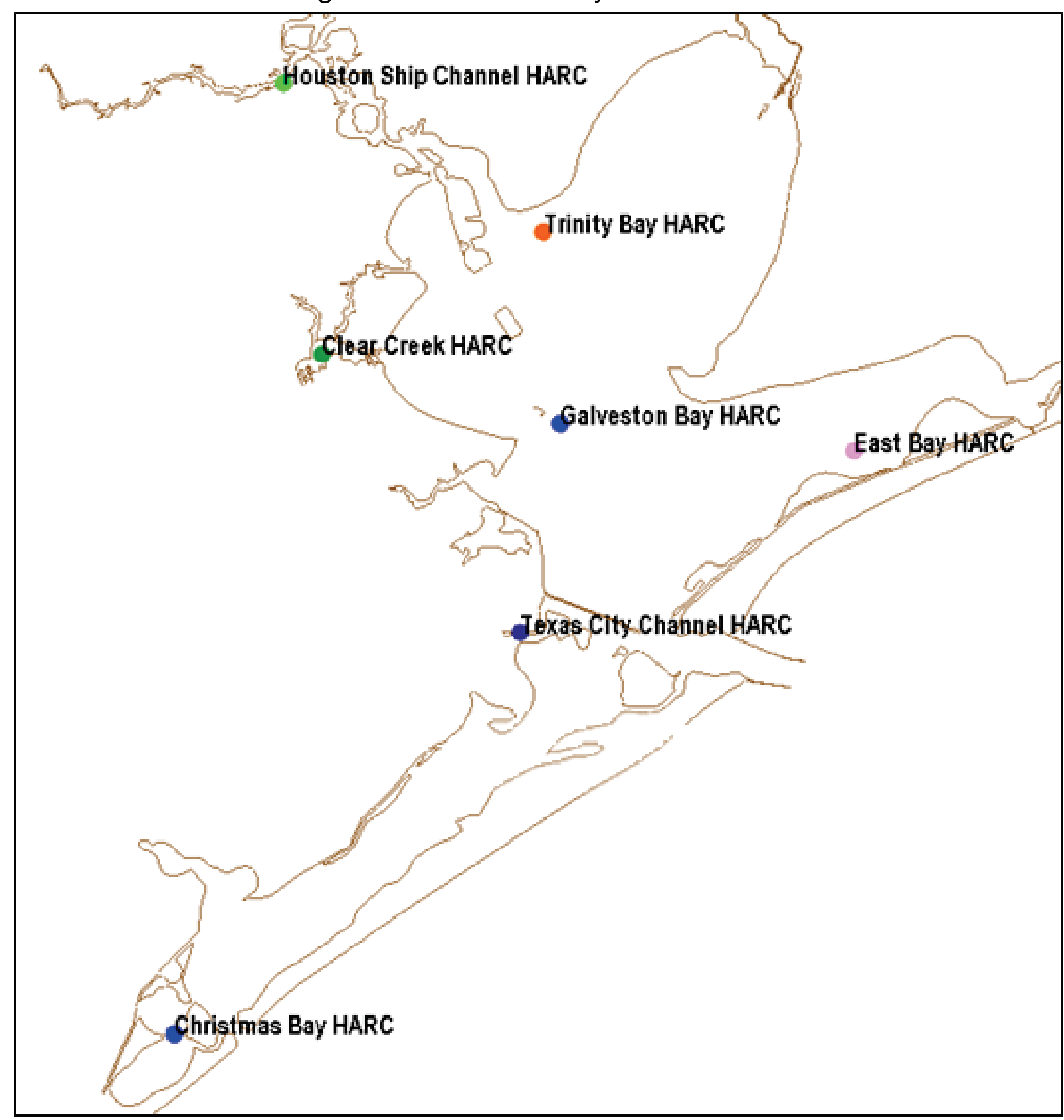

Field data for points in the upper HSC are primarily limited to 2005 in the TCEQ data set. Model/field comparisons, from upstream to downstream, at Exxon Docks, Baytown Tunnel, Lynchburg Ferry, CM120, and Morgan's Point are shown in the following plots (Figure 36 through Figure 40). 
Figure 36. Exxon Docks salinity calibration comparison.

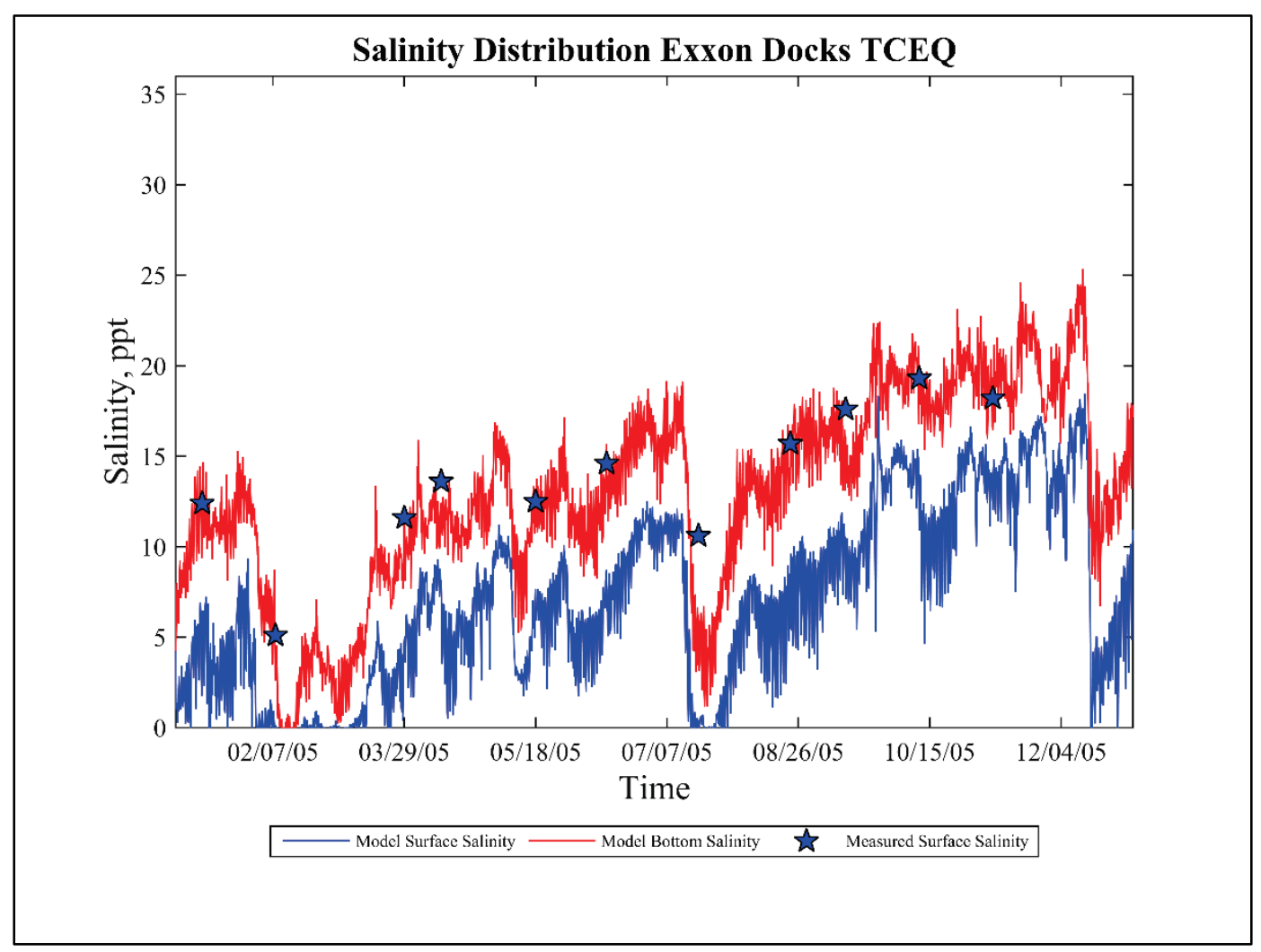

Figure 37. Baytown Tunnel salinity calibration comparisons.

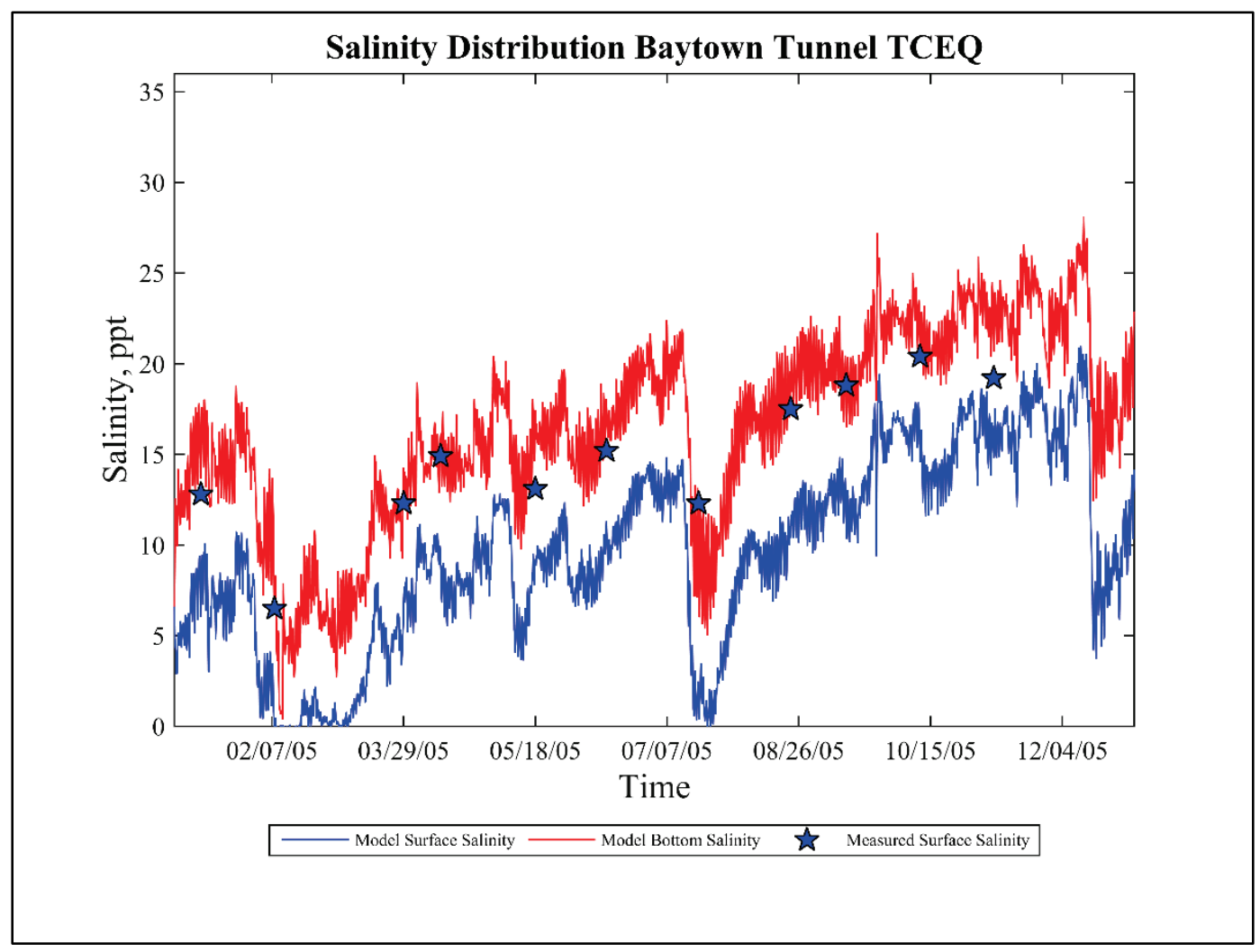


Figure 38. Lynchburg Ferry salinity calibration comparisons.

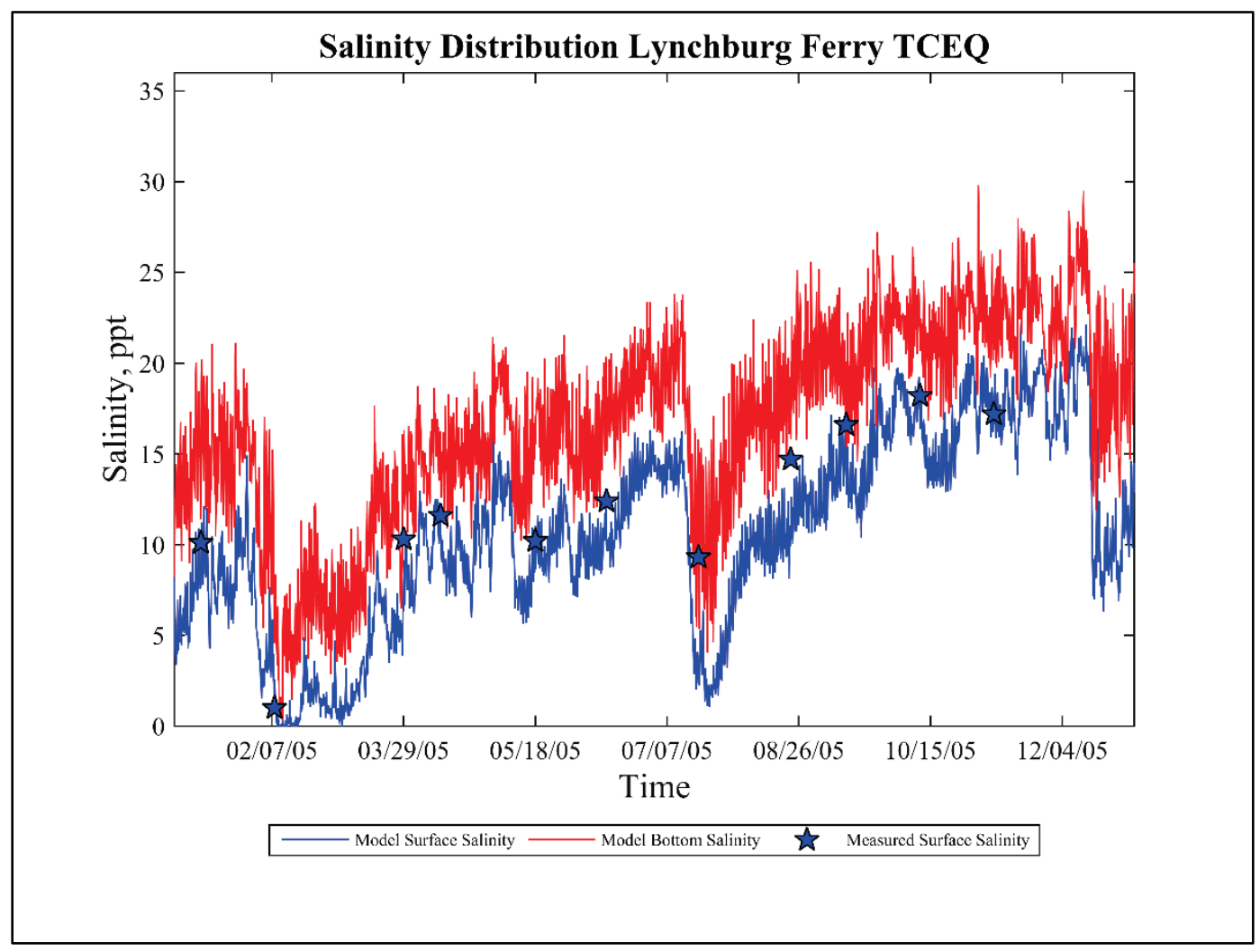

Figure 39. CM120 salinity calibration comparisons.

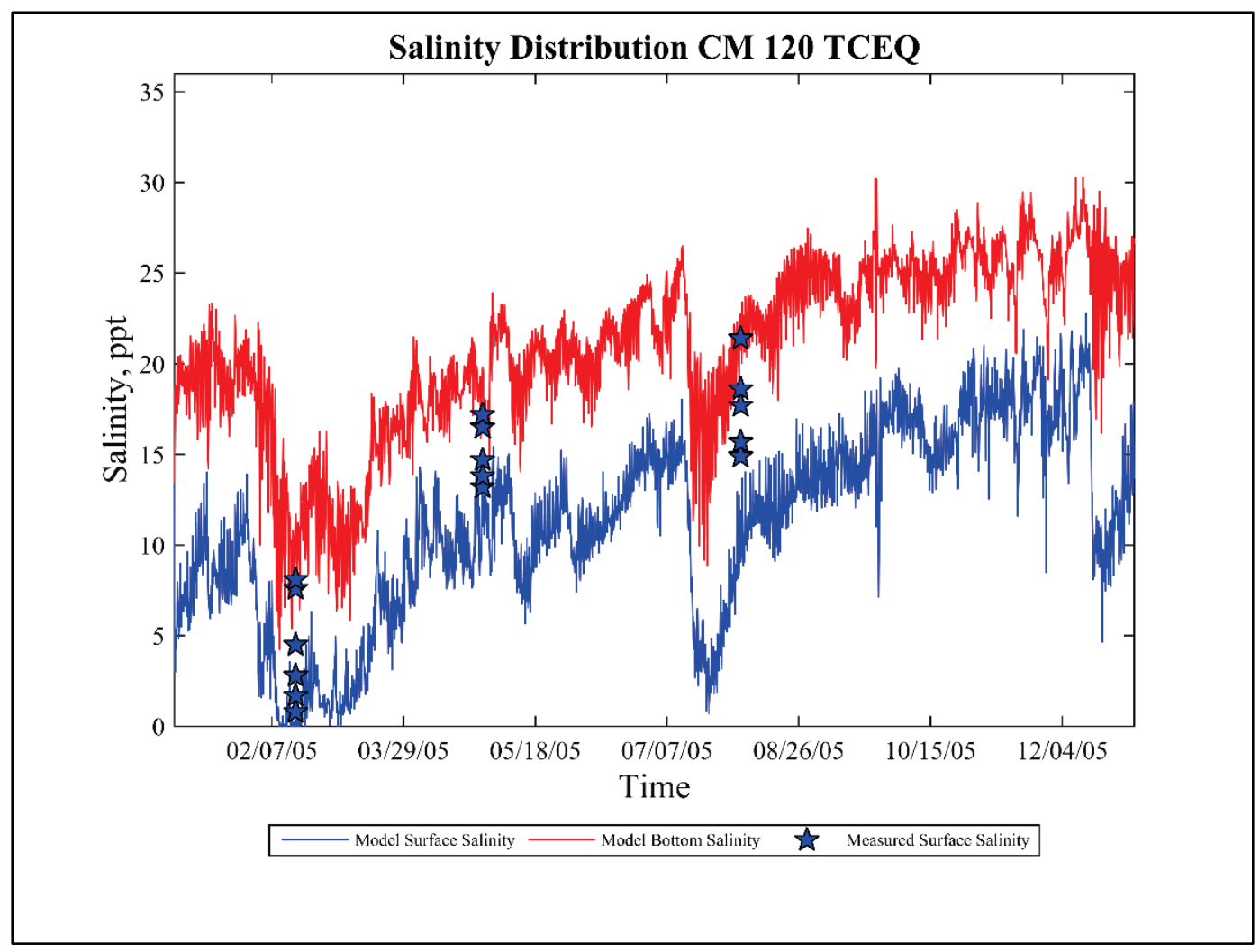


Figure 40. Morgan's Point salinity calibration comparisons.

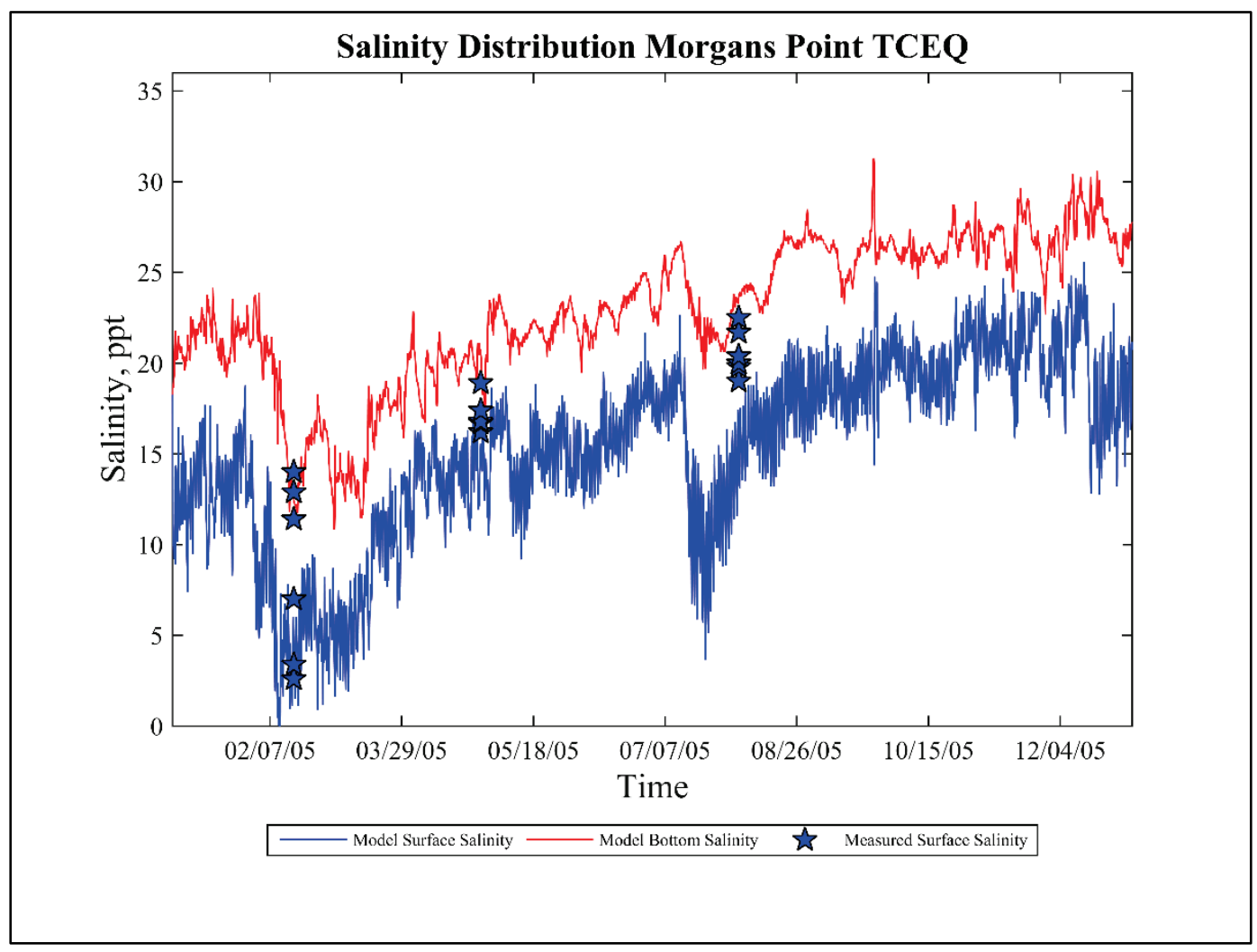

Salinity impacts in Trinity Bay are of primary concern when analyzing project changes for impacts on aquatic habitat. The model/field calibration comparisons of salinity at Mid Galveston Bay and two Trinity Bay sites - HARC on the northwest side of the bay (Figure 35) and TWDB on the southeast side of the bay (Figure 33) - are shown for 2005 in Figure 41 through Figure 43.

Overall, the salinity patterns and values are replicated in the model. There are periods in the field data where it appears the field instrument malfunctions; the model and field behavior diverges during these periods. The TWDB Trinity Bay (southeast) location comparisons indicate that the model is providing lower salinity values than the field, sometimes by as much as 8 parts per thousand (ppt). This area may be more heavily influenced by shallow depths and wind wave impacts (not included in this model) that are not impacting the salinity comparisons at the other comparison locations. Given the physics that are presently included in this AdH model and the overall good comparisons at other locations, these differences are noted but will not result in additional model calibration. 
Figure 41. 2005 Mid Galveston Bay salinity calibration comparisons.

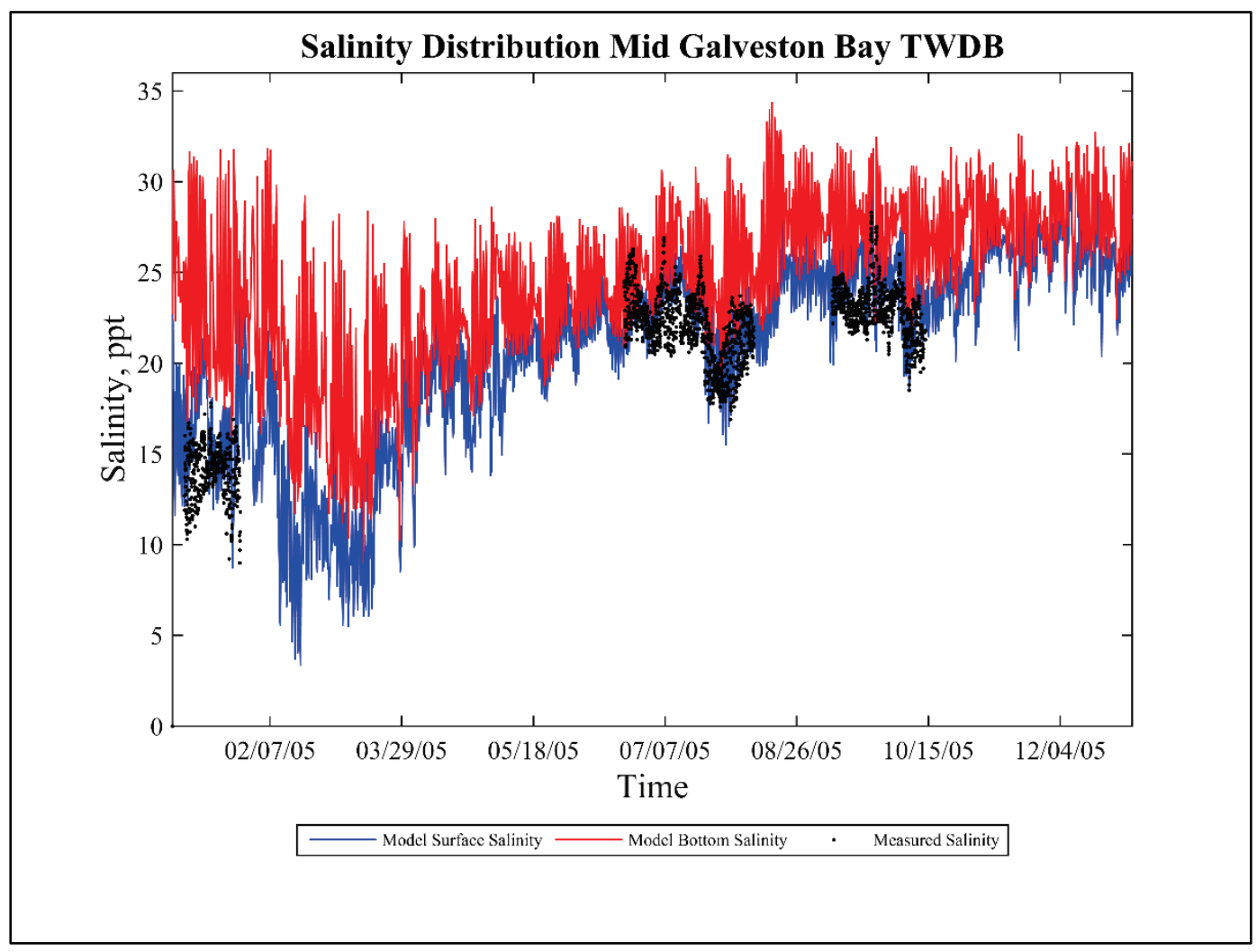

Figure 42. 2005 Trinity Bay HARC salinity calibration comparisons (northwest).

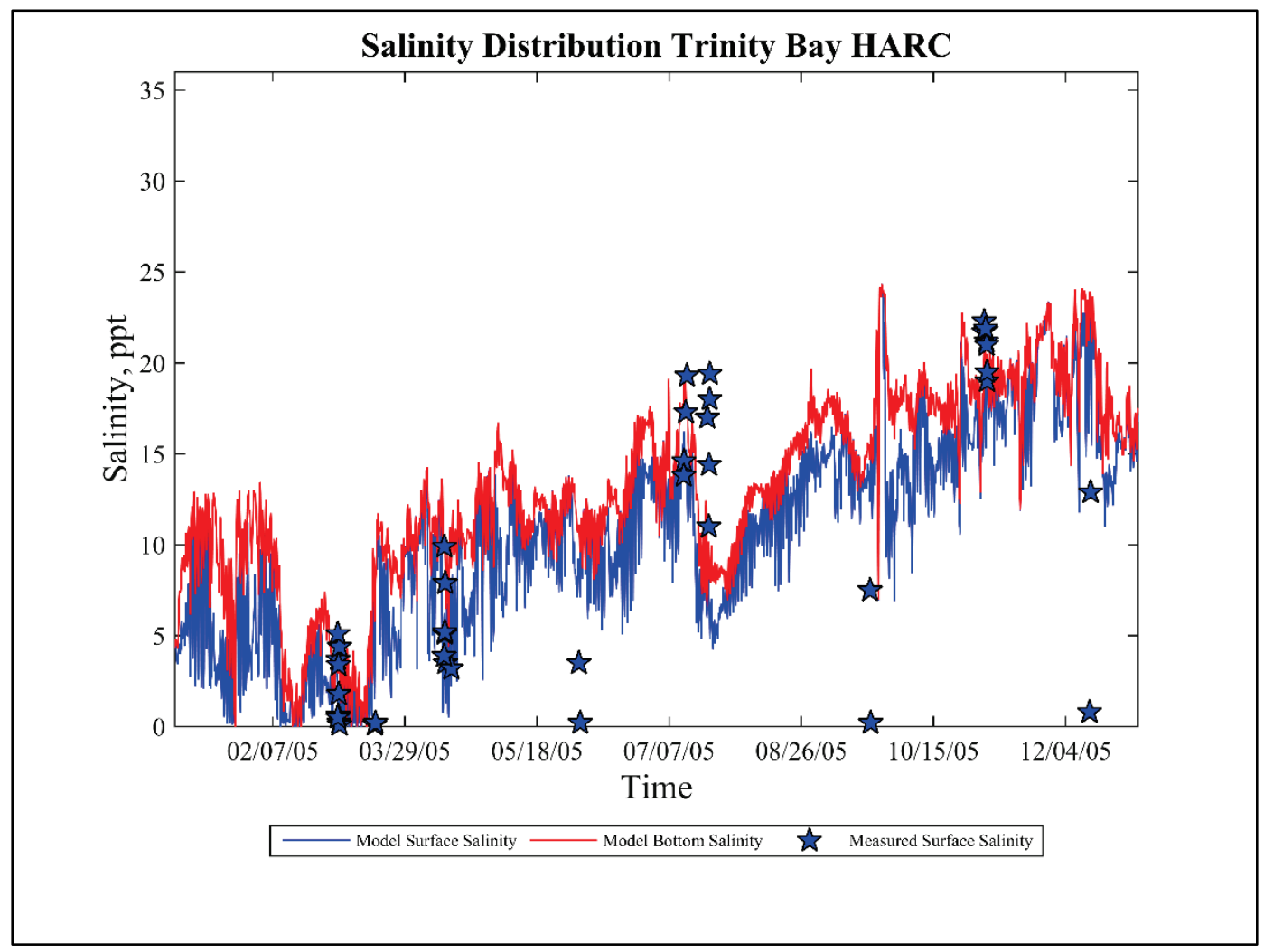


Figure 43. 2005 Trinity Bay TWDB salinity calibration comparisons (southeast).

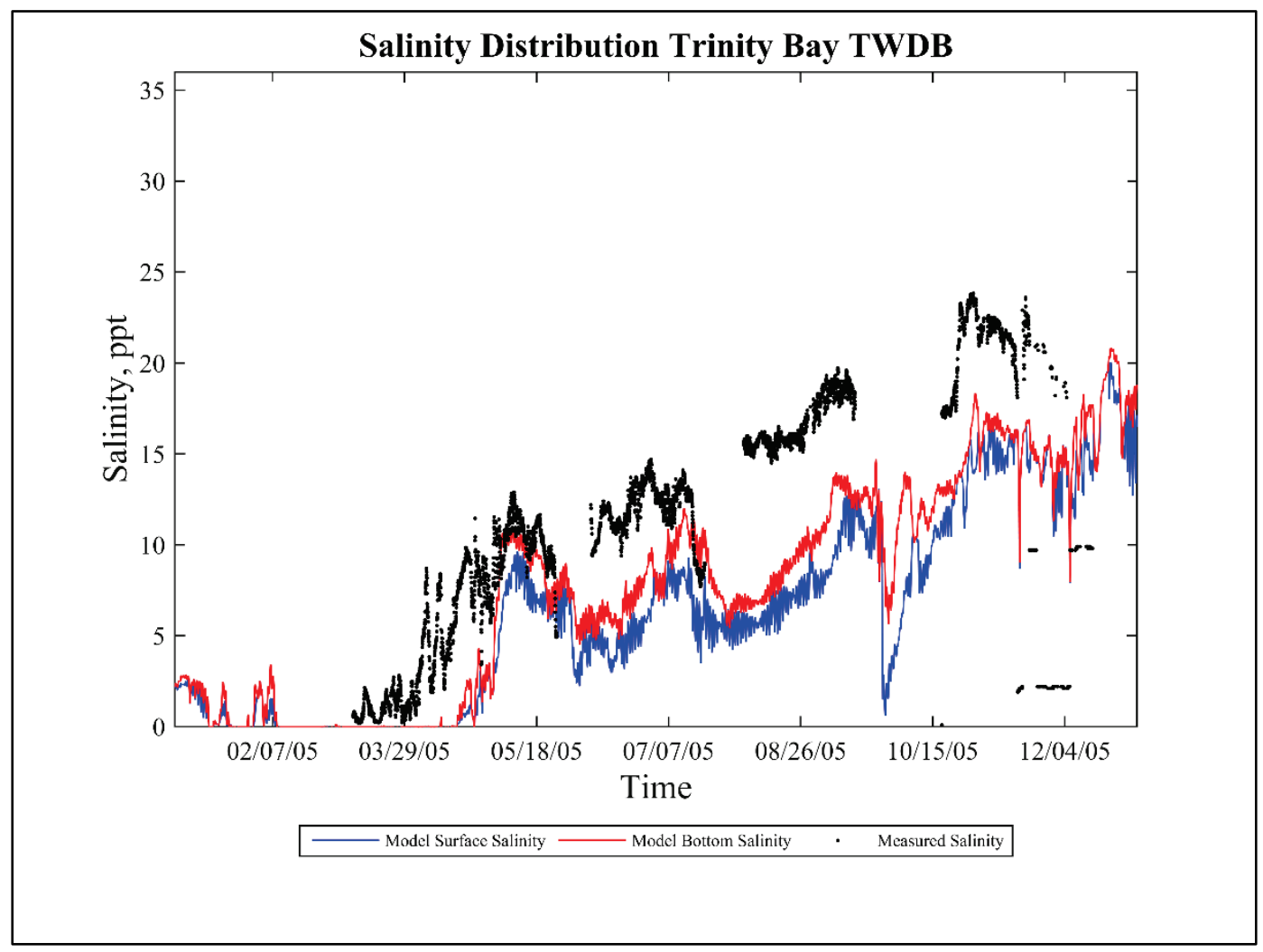

\section{Sediment calibration}

The sediment model is calibrated based on historic maintenance dredge records for the HSC. Previous research has indicated that several sources of dredge records are available - contract records, pre and post surveys, USACE annual reports, etc. - but the various sources often provide very different total volumes (Tate et al. 2014). For this study, the data provided in the USACE annual reports are used for model calibration and validation. This data set covers over 55 years and is reported by channel segments. From the data, three time periods as defined by the channel dimensions can be specified and annualized to determine an average yearly shoaling amount by reach (Table 4 ). No data were available to analyze sedimentation changes in the bay or bayou shallows over single-year time periods.

Table 4. Annualized shoaling periods.

\begin{tabular}{|c|c|}
\hline Dimensions & Years \\
\hline $40 \times 400 \mathrm{ft}$ & $1660-1997$ \\
\hline Construction & $1998-2005$ \\
\hline $45 \times 530 \mathrm{ft}$ & $2006-2016$ \\
\hline
\end{tabular}


A dredge template (Figure 44) was produced to match the HSC reaches as reported in the USACE annual report shoaling records. These sections were defined based on the HSC channel station map and the USACE channel survey sections. There is uncertainty where the Bayport and Barbours Cut channels join the HSC. Figure 45 shows the reported maintenance dredge records annualized over each time period for each channel segment.

Figure 44. HSC dredge template.

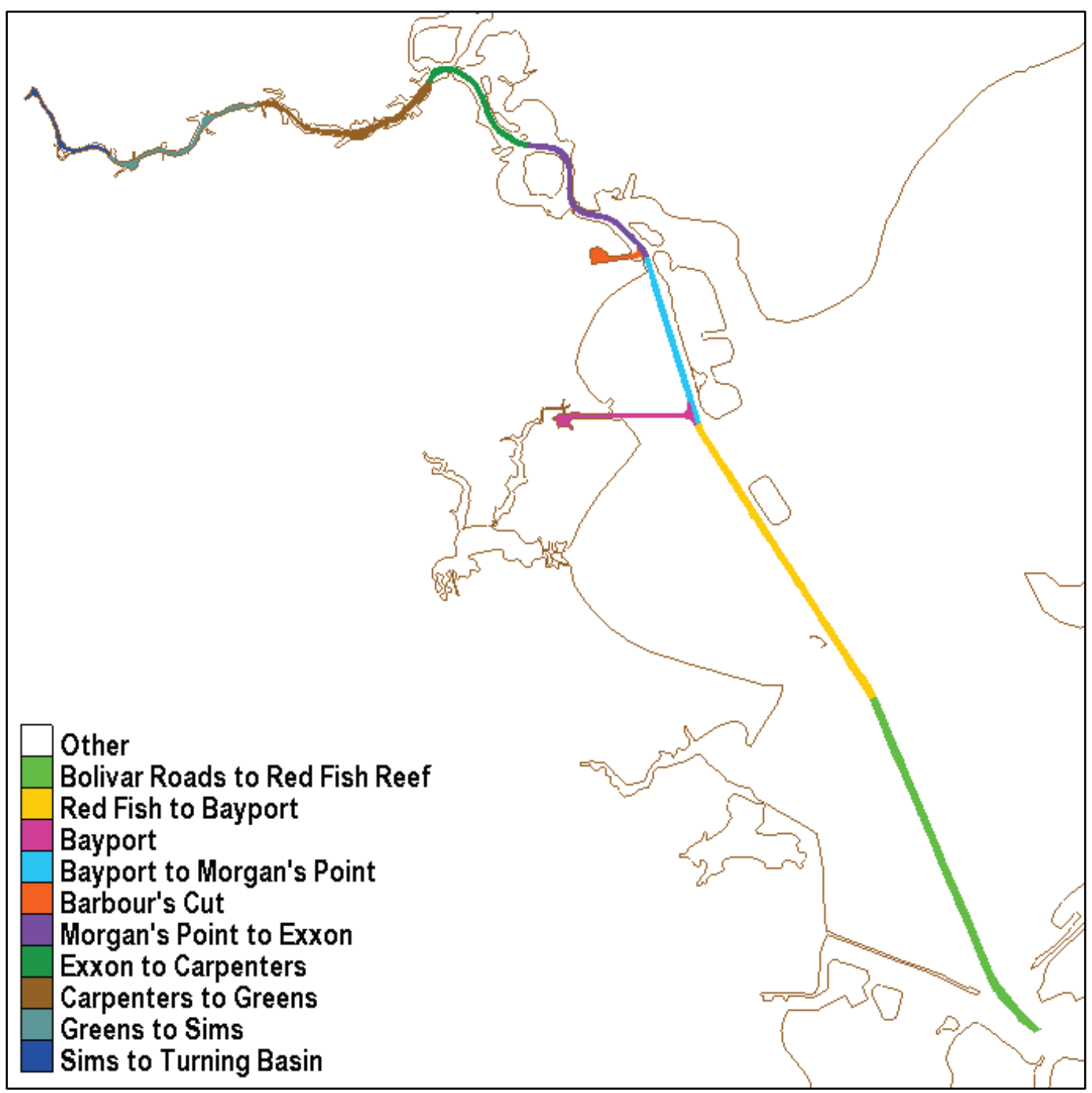


Figure 45. Annualized maintenance dredge volumes based on USACE annual reports.

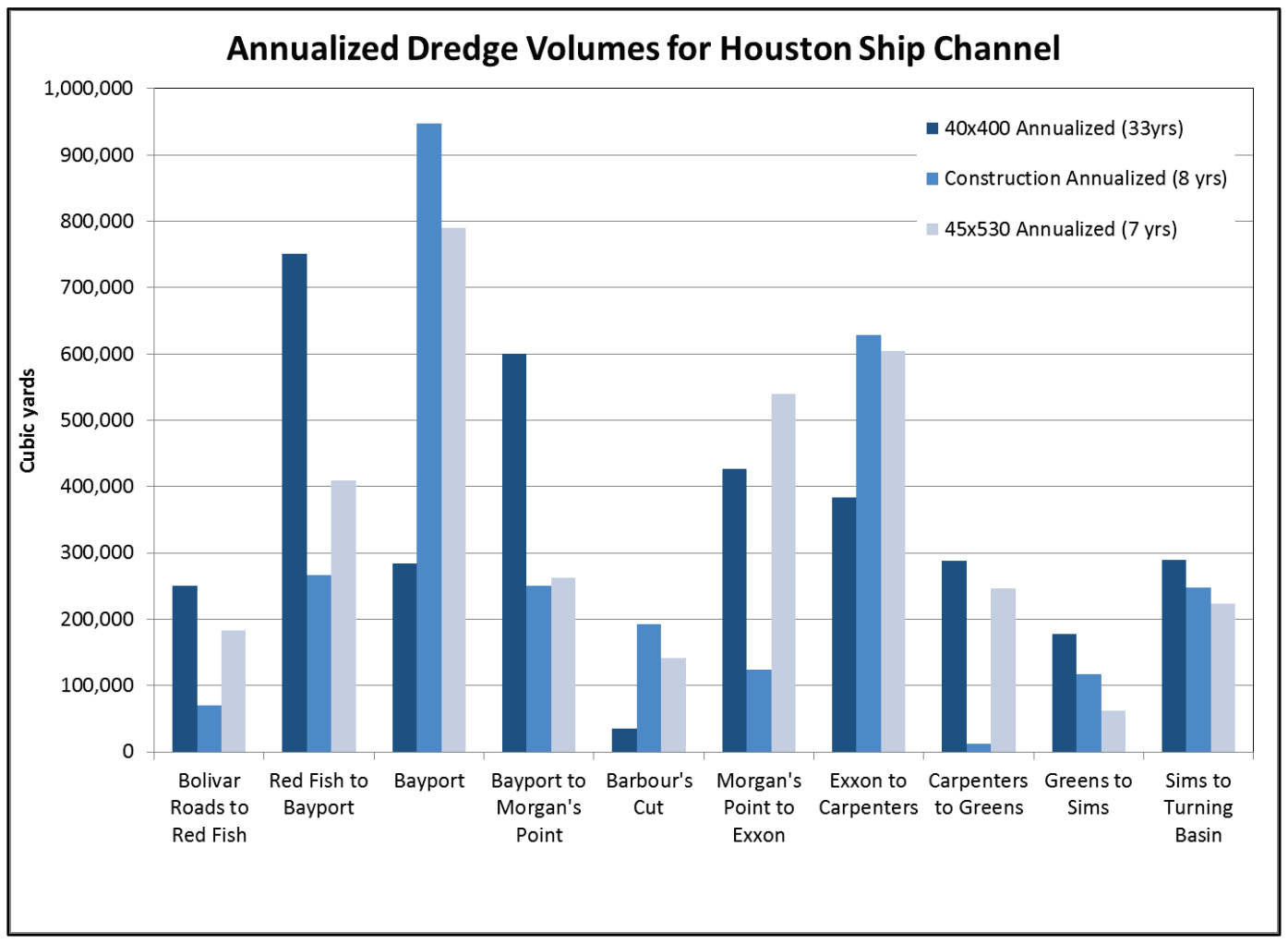

This dredge template is then used to determine the model computed shoaling volume over each 1-year simulation period. Since it is known that sediment loads are unaccounted for from the ungaged freshwater inflows, from wind-generated wave erosion along the shallows, and from vessel-induced erosion in the bays, several methods to account for these missing sources were tested. A historical scaling method for each channel segment was determined to be the best option to account for the combined effect of the various unknown loads. The 2005 model-computed shoaling for each segment was scaled to match the annualized historic records for the $45 \times 530 \mathrm{ft}$ channel as a means of calibration. A scale factor for each segment was determined and applied accordingly for the 2010 and 2011 validation years.

Figure 46 shows the shoaling calibration results for 2005 as compared to the annualized historic maintenance dredging records as well as the computed scale factor for each reach. 
Figure 46. Model/field HSC shoaling calibration comparison.

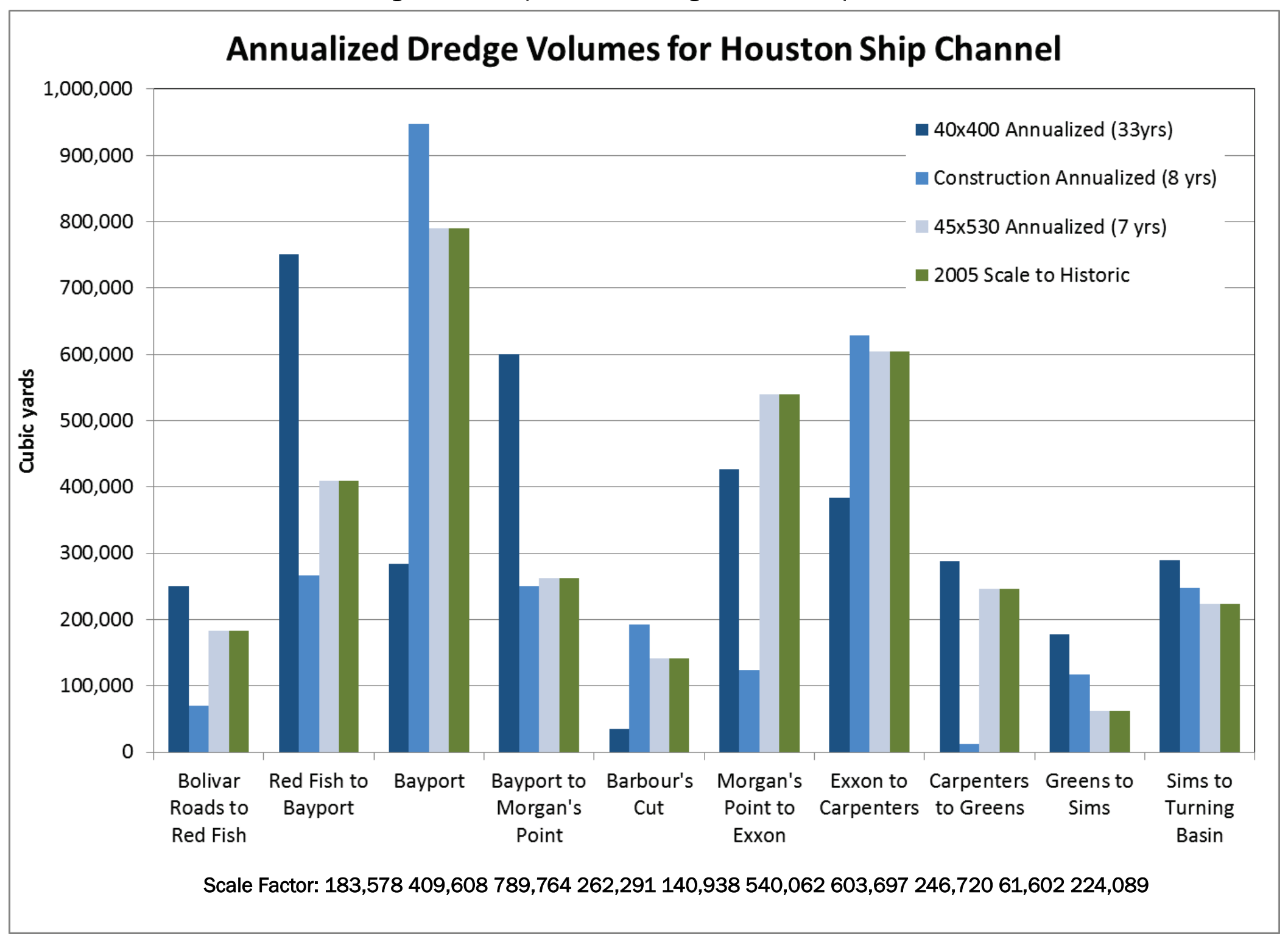




\section{Hydrodynamic validation}

The model is compared to water surface elevation and velocity at several locations during the 2010 and 2011 validation period. Water surface elevation data were obtained from the NOAA Co-Ops and the National Data Buoy Center. Velocity data were obtained from NOAA PORTS and from a 2011 CHL collection effort in Trinity Bay.

\section{Water surface elevation}

Water surface elevation validation results are compared to the field at six locations - some years have fewer locations depending on the data availability. Figure 24 shows the location of the water surface elevation comparison sites. Statistical comparisons are provided in Table 5. Time-history and box-plot comparisons at Manchester, Morgans Point, and Eagle Point are shown in his section (Figure 47 through Figure 49 and Figure 50 through Figure 52). The full set of comparisons is provided in Appendix A.

For the time-history plots, the green line represents the measured field data, and the blue line represents the model-computed values. Each comparison location also includes a box plot showing the relationship between the measured field data ( $x$-axis) and the modeled data ( $y$-axis). A perfect match would yield points on the black 1:1 line.

Table 5. Statistical model/field validation comparison of water surface elevation.

\begin{tabular}{|l|c|c|c|c|}
\hline \multirow{2}{*}{} & \multicolumn{2}{|c|}{$\begin{array}{c}\text { Root Mean } \\
\text { Square Error }\end{array}$} & \multicolumn{2}{c|}{$\begin{array}{c}\text { Correlation } \\
\text { Coefficient }\end{array}$} \\
\cline { 2 - 5 } & 2010 & 2011 & 2010 & 2011 \\
\hline Manchester & & 0.12 & & 0.89 \\
\hline Morgan's Point & 0.07 & 0.05 & 0.97 & 0.98 \\
\hline Eagle Point & 0.07 & 0.04 & 0.96 & 0.98 \\
\hline Pier 21 & 0.07 & 0.05 & 0.96 & 0.98 \\
\hline North Jetty & & 0.05 & & 0.98 \\
\hline Rollover Pass & & 0.07 & & 0.95 \\
\hline
\end{tabular}


Figure 47. Water surface elevation validation comparisons over time for Manchester 2011.

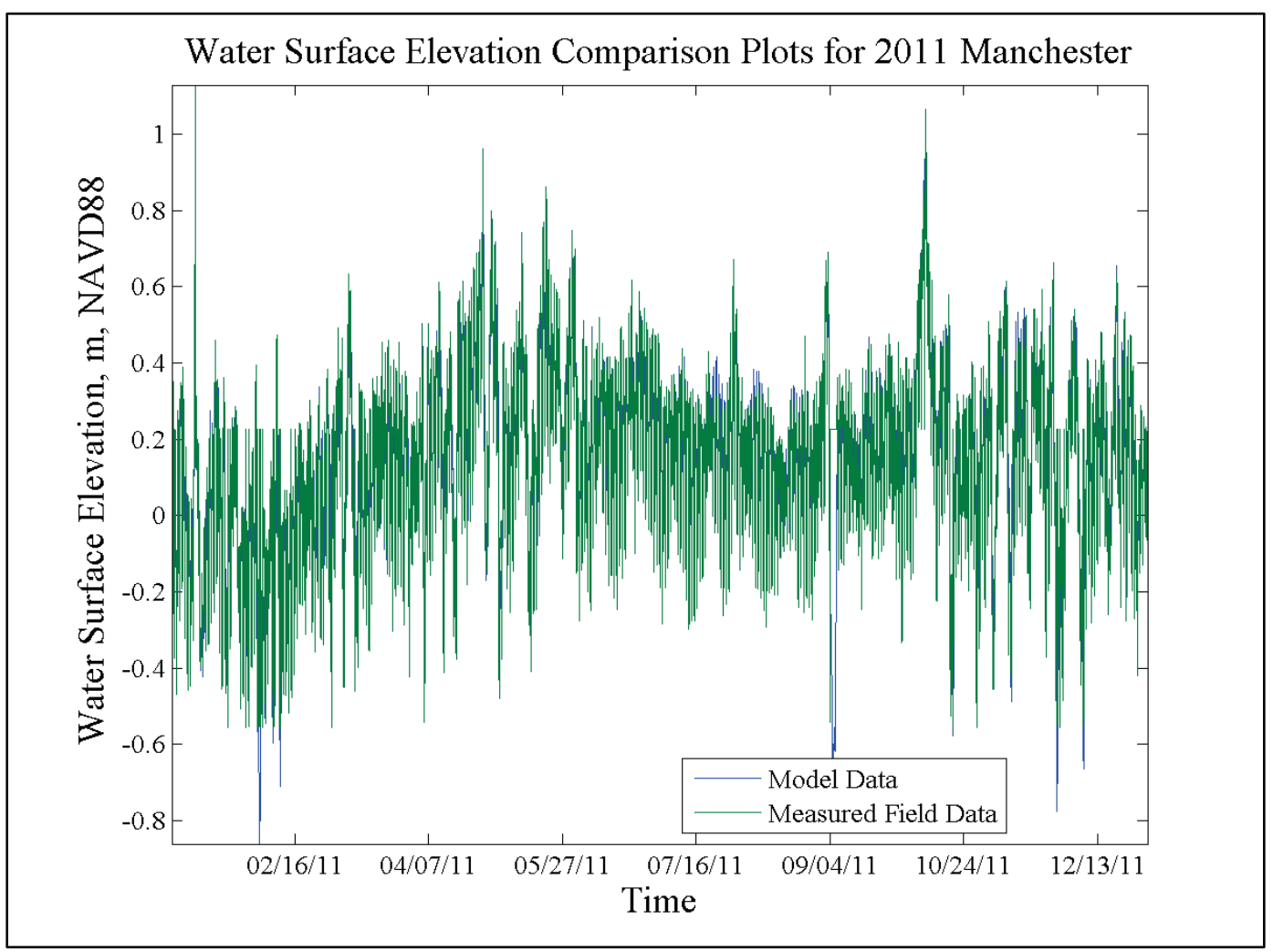


Figure 48. Water surface elevation validation comparisons over time for Morgans Point.

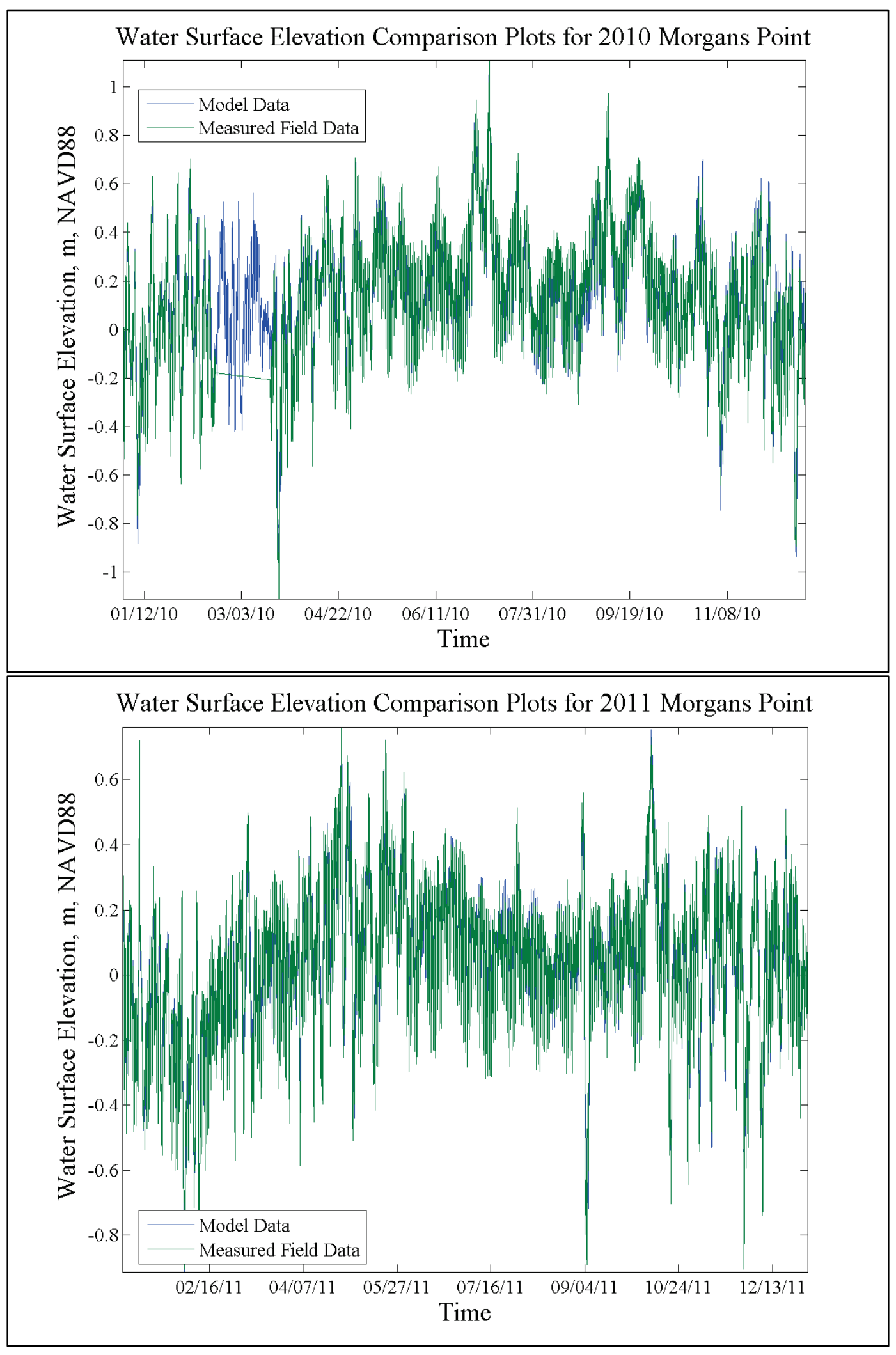


Figure 49. Water surface elevation validation comparisons over time for Eagle Point.
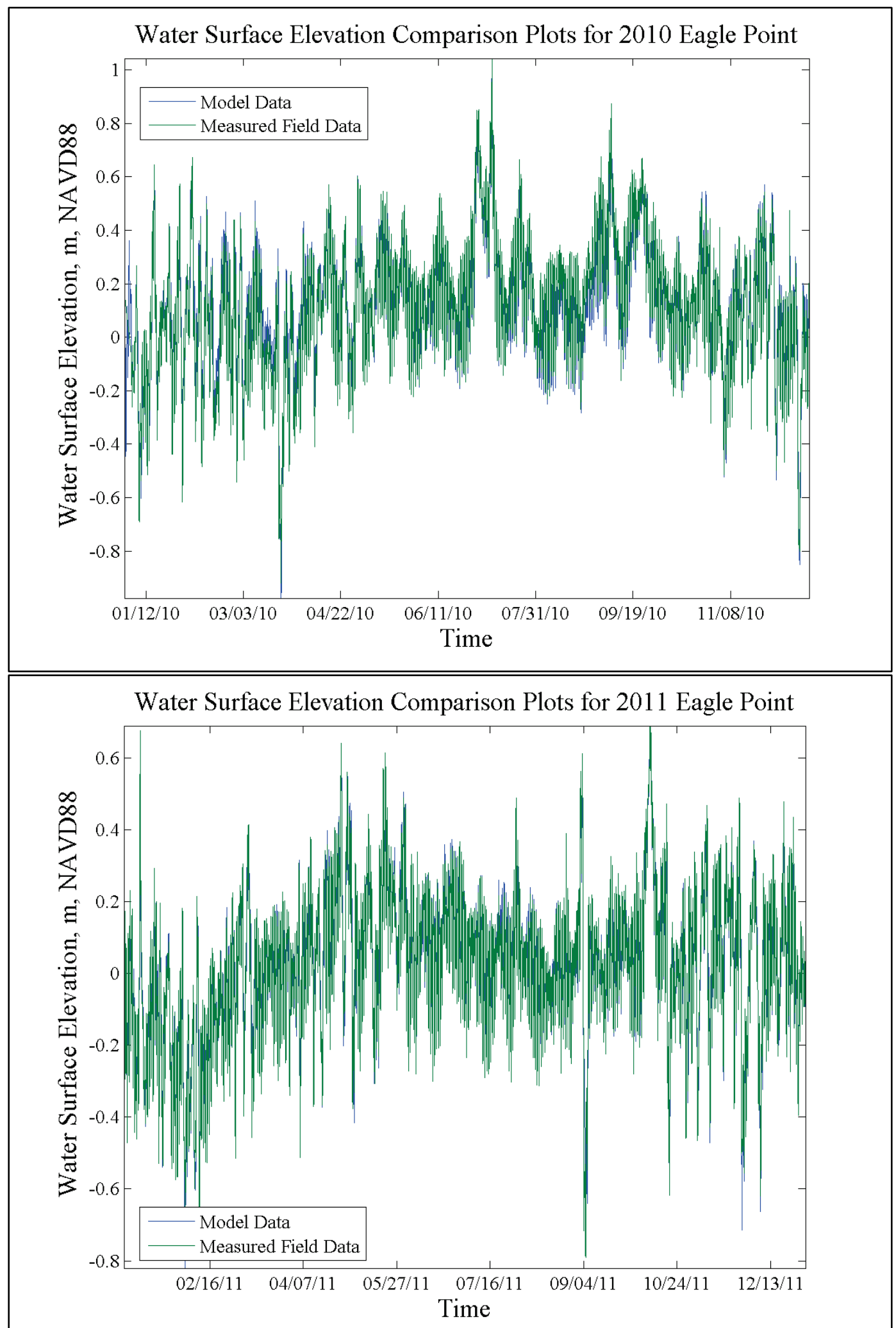
Figure 50. Water surface elevation validation comparison box plot for Manchester.

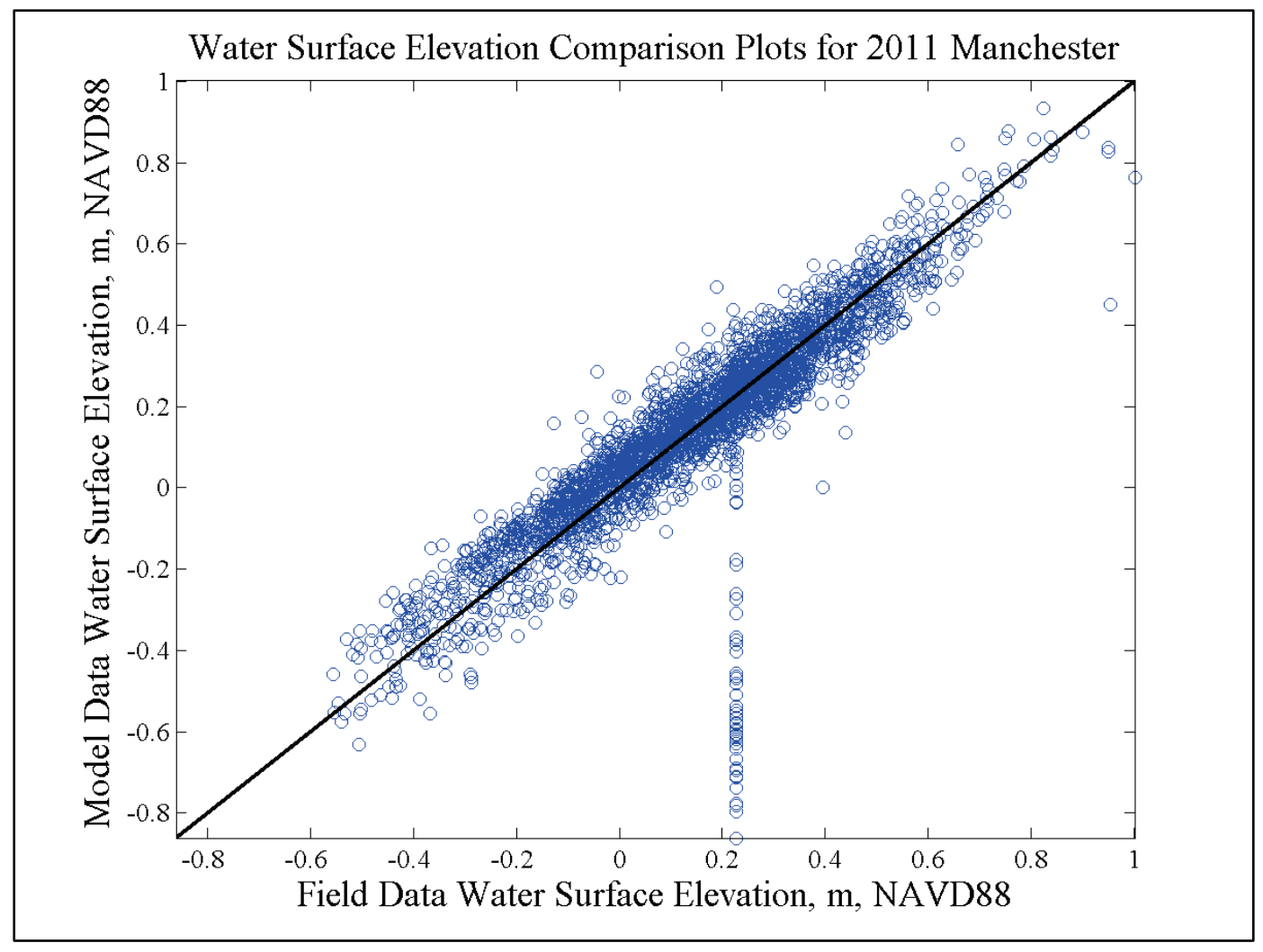


Figure 51. Water surface elevation validation comparison box plots for Morgans Point.
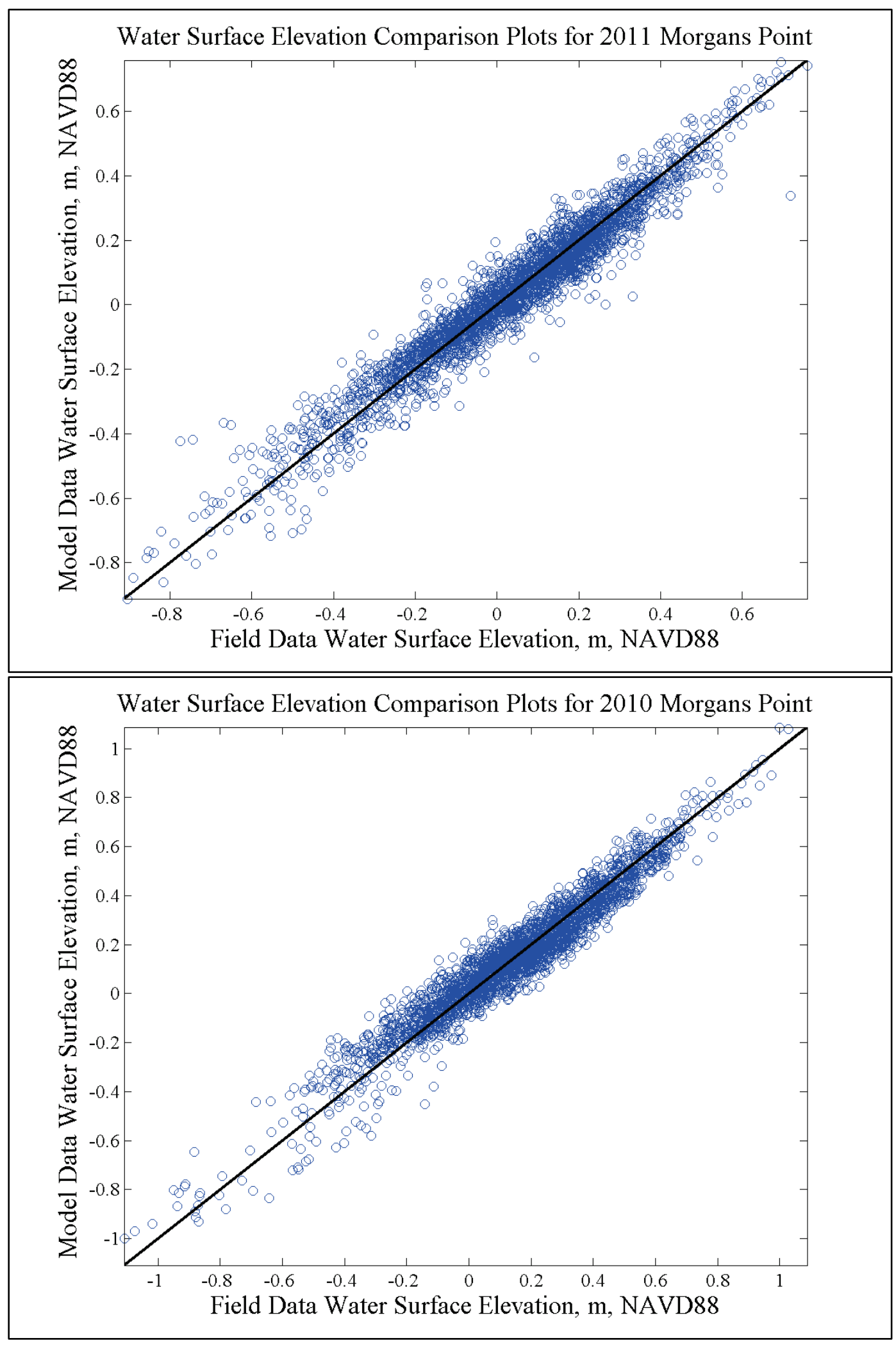
Figure 52. Water surface elevation validation comparison box plots for Eagle Point.
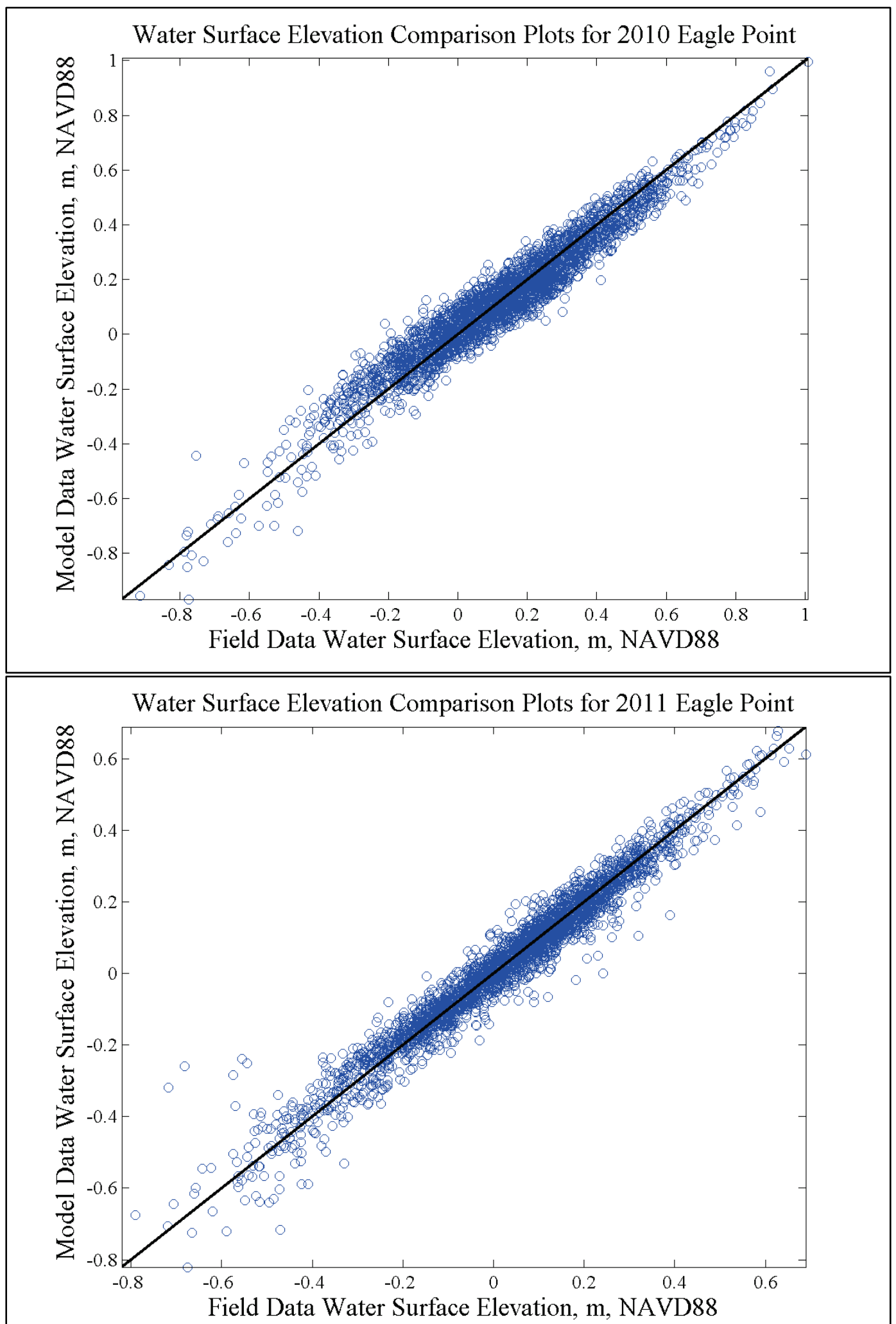


\section{Velocity}

Velocity validation comparisons are made at four locations - one from NOAA PORTS and three from a 2011 CHL data collection effort (Acoustic Wave and Current profiler [AWAC]) (Figure 53). The time available for comparison is limited for these data sets. Year 2010 only has field data for the Galveston Entrance. Year 2011 has field data for all validation locations. Figure 32 through Figure 58 show the time-history velocity magnitude and direction (positive: flood; negative: ebb) for these locations. The model/field velocity comparison is better in the ship channel locations than in the bay where there is an approximate $0.1 \mathrm{~m}$ shift in the model mean as compared to the field. The larger differences in the shallow bay are not unexpected since the velocities in the bay are impacted by smaller disturbances such as passing vessels and local winds, which can easily skew the flood/ebb magnitude. The magnitude of the velocity in the bay is also much smaller, and therefore the data can be impacted more by instrument noise. The comparisons at AWAC 1 and 2 show that the model is approximately half the magnitude of the field. This difference in magnitude may be due to the location of the gages in the barge lanes or side slope of the ship channel where the bathymetry changes rapidly and the mesh may not be most accurate. The overall pattern in the velocity signal is reproduced by the model for all locations.

Figure 53. Velocity validation comparison locations.

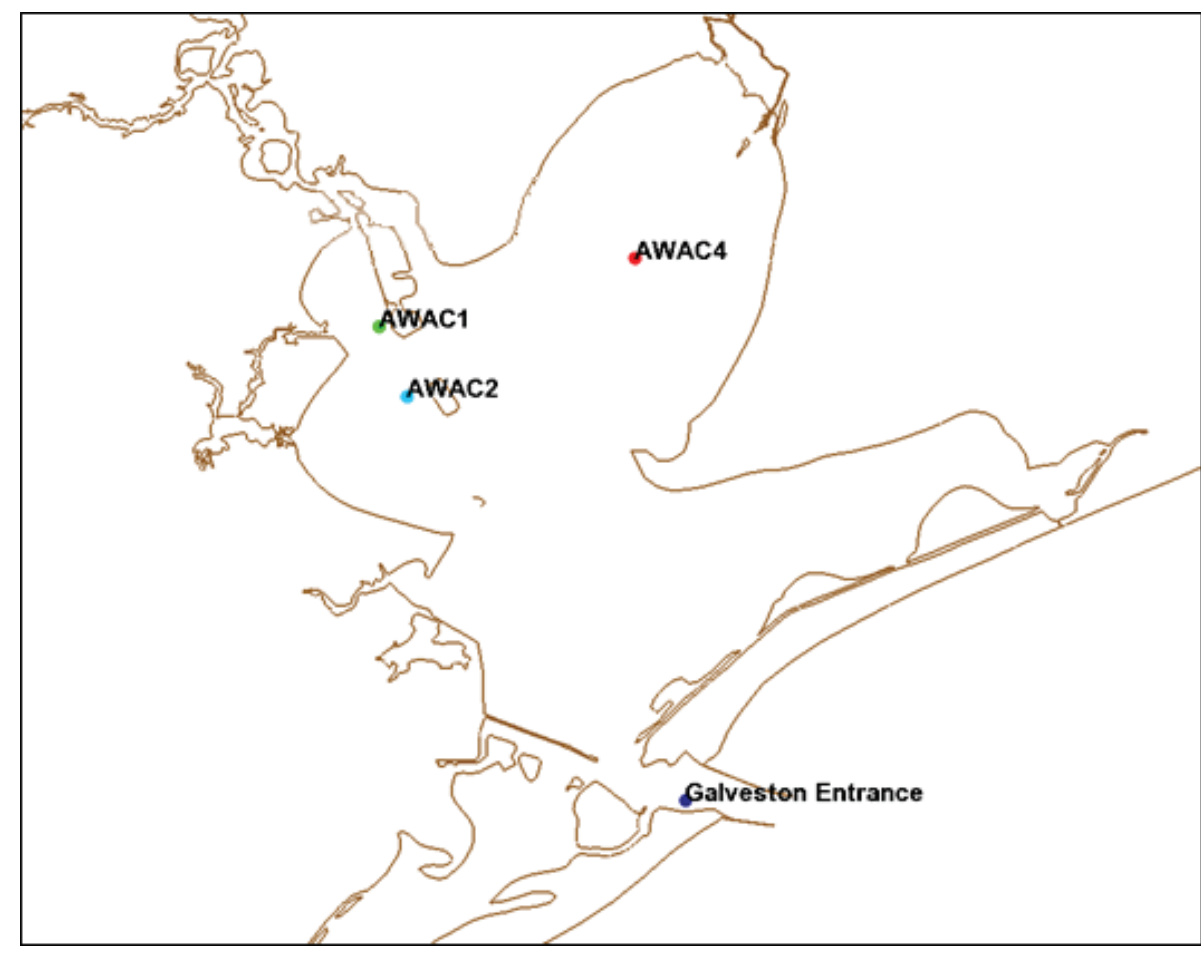


Figure 54. 2010 Galveston Entrance velocity comparison (positive: flood; negative: ebb).

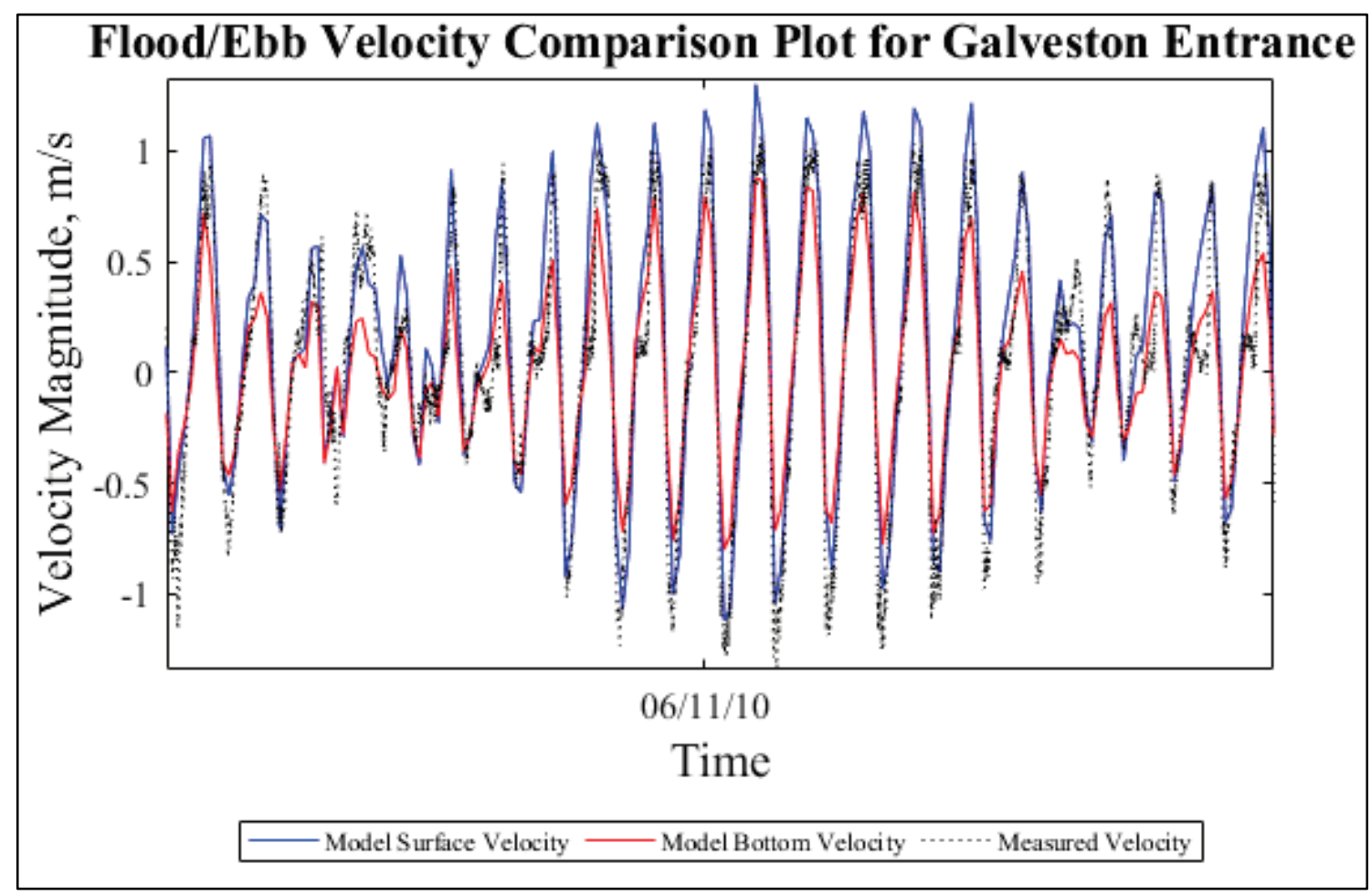

Figure 55. 2011 CHL AWAC 1 velocity comparison (positive: flood; negative: ebb).

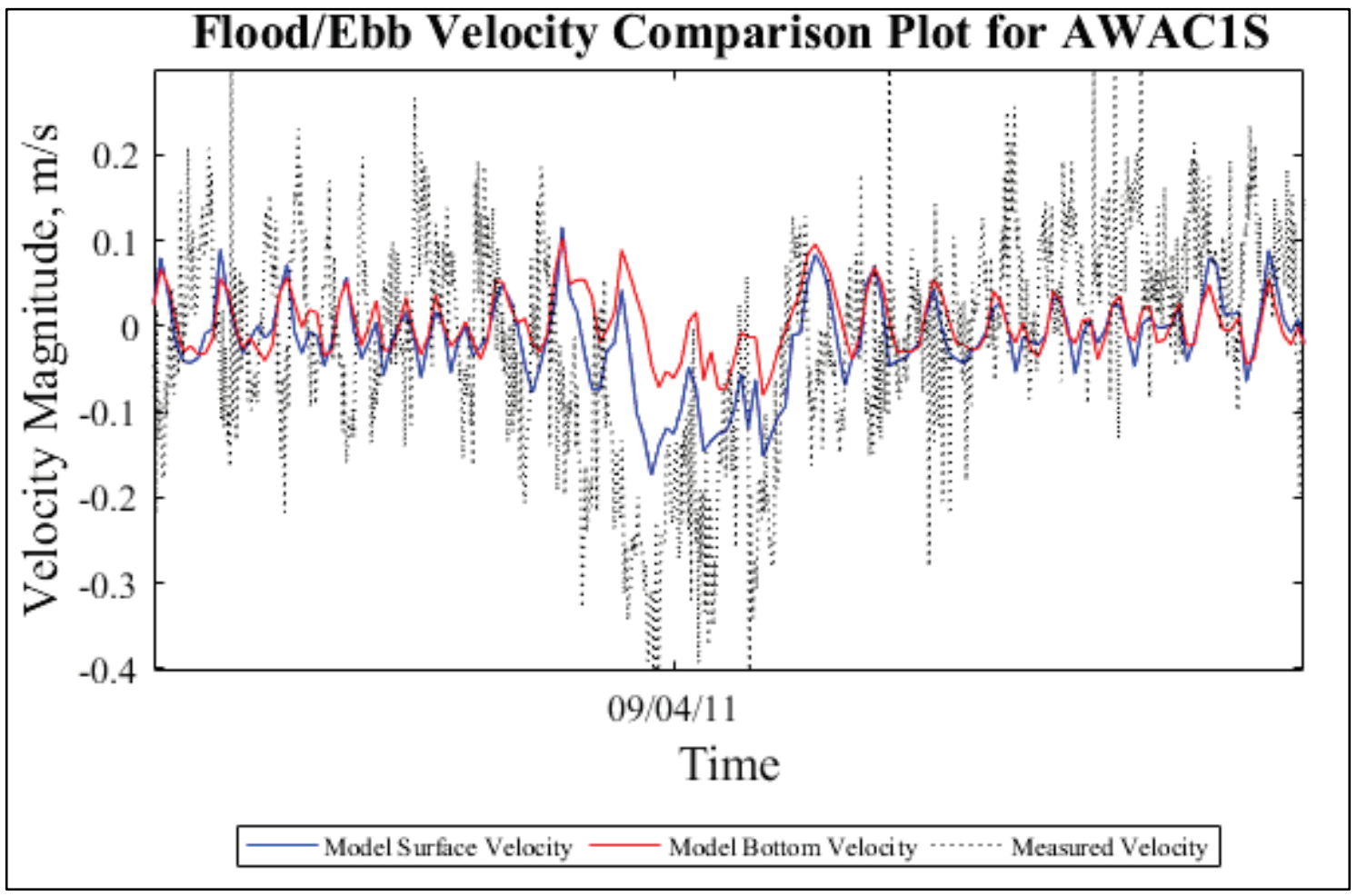


Figure 56. 2011 CHL AWAC 2 velocity comparison (positive: flood; negative: ebb).

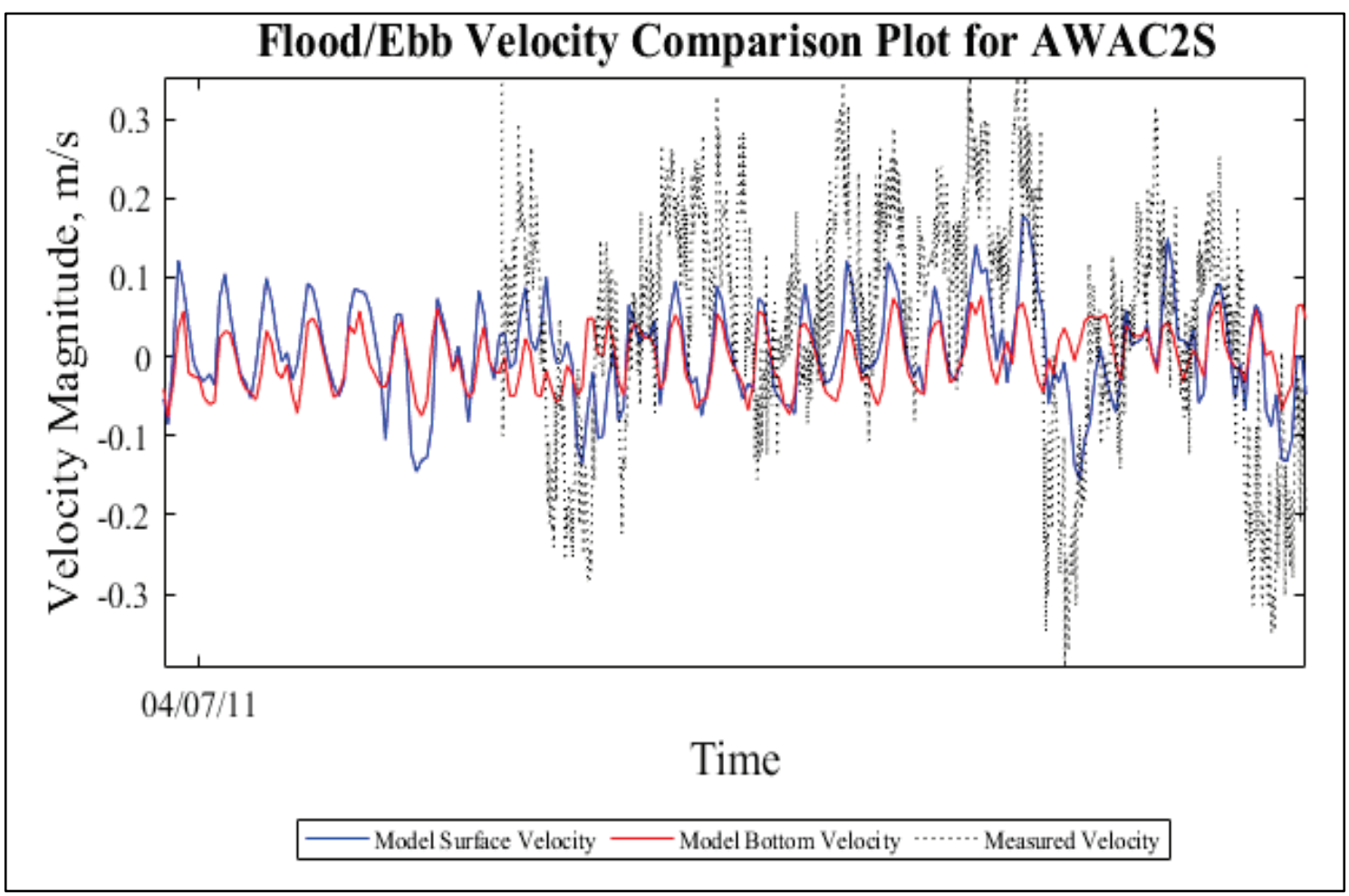

Figure 57. 2011 CHL AWAC 3 velocity comparison (positive: flood; negative: ebb).

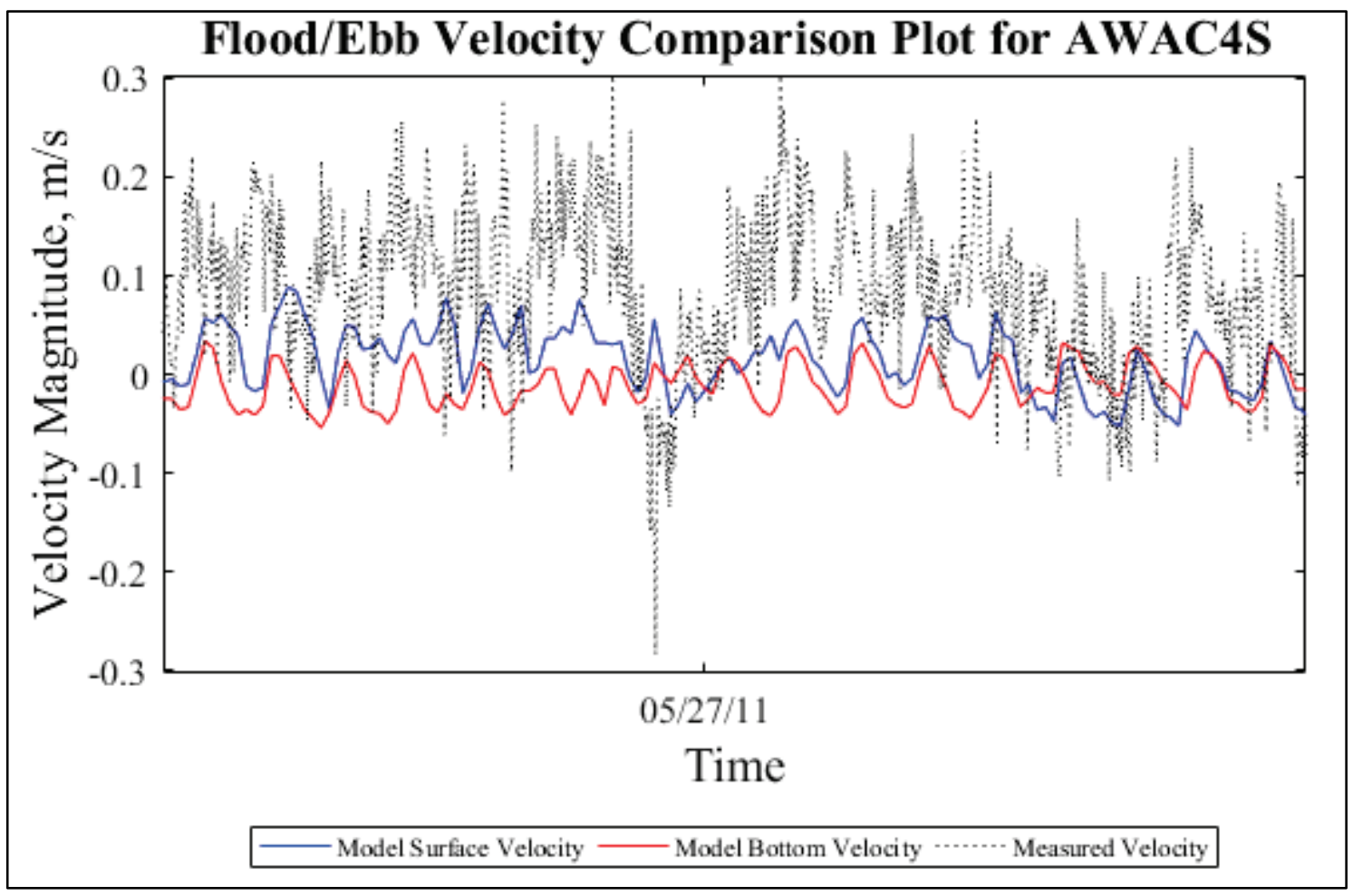


Figure 58. 2011 Galveston Entrance velocity comparison (positive: flood; negative: ebb).

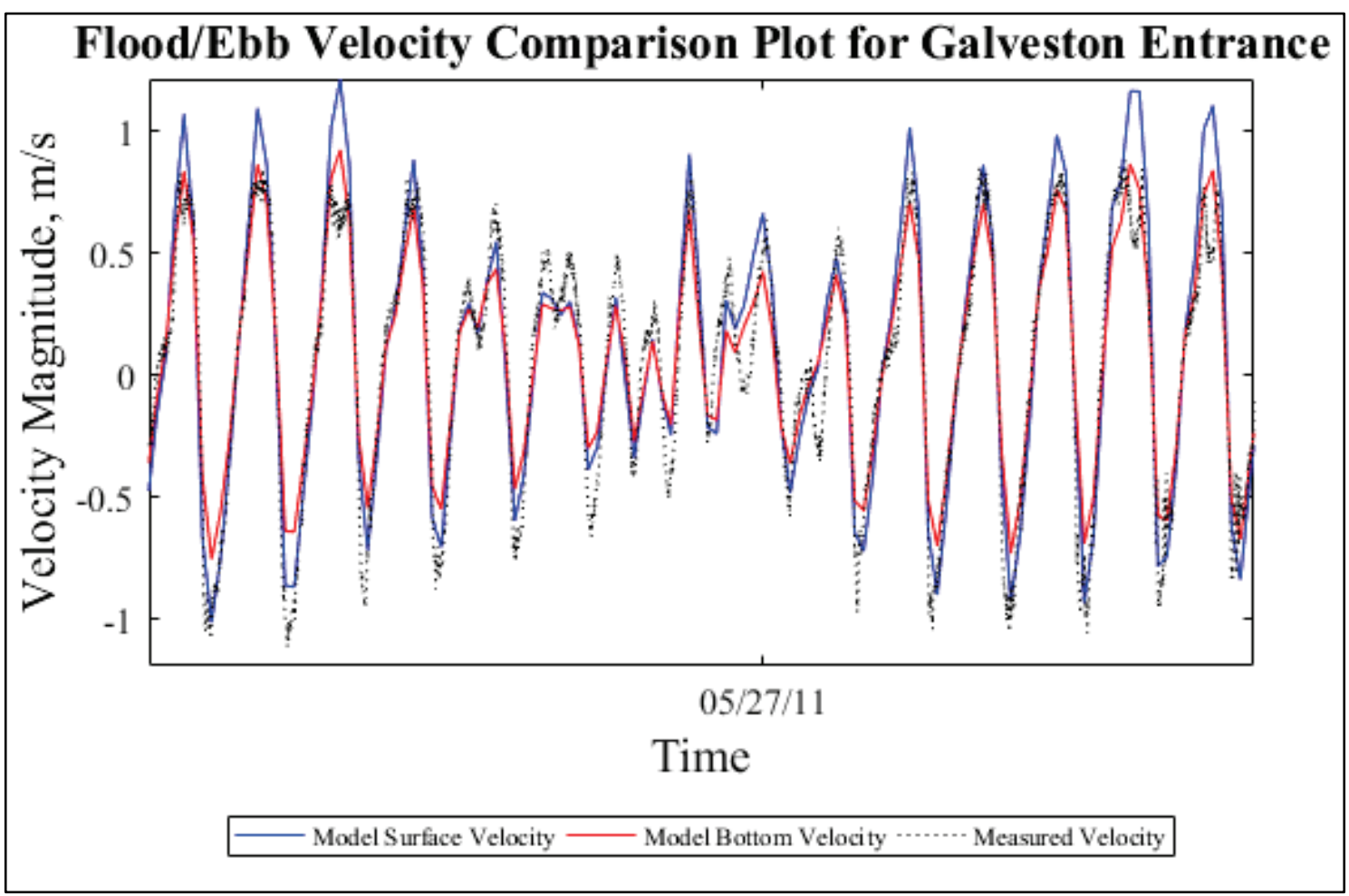

\section{Salinity validation}

Field salinity data were obtained for model validation from TWDB (Figure 59), TCEQ (Figure 60), HARC (Figure 61), and TABS (Figure 62). There are 23 total salinity validation comparison sites throughout the HSC and the surrounding bays. As with the previous data comparisons, some sites do not have data for all of the simulation periods.

Time-history comparisons at selected locations are shown in this section. The field data are represented by stars where data are sparse and smaller black dots where data are numerous whereas the model data are shown in blue for surface salinity and in red for bottom salinity. In deep, stratified regions, the bottom salinity is larger than the surface salinity. In well-mixed regions the two should be approximately equal. The field-measured salinity is typically measured at the surface, but it is not specified for all data. A subset of comparisons is provided with the full set of comparisons provided in Appendix B. 
Figure 59. TWDB salinity validation comparison sites.

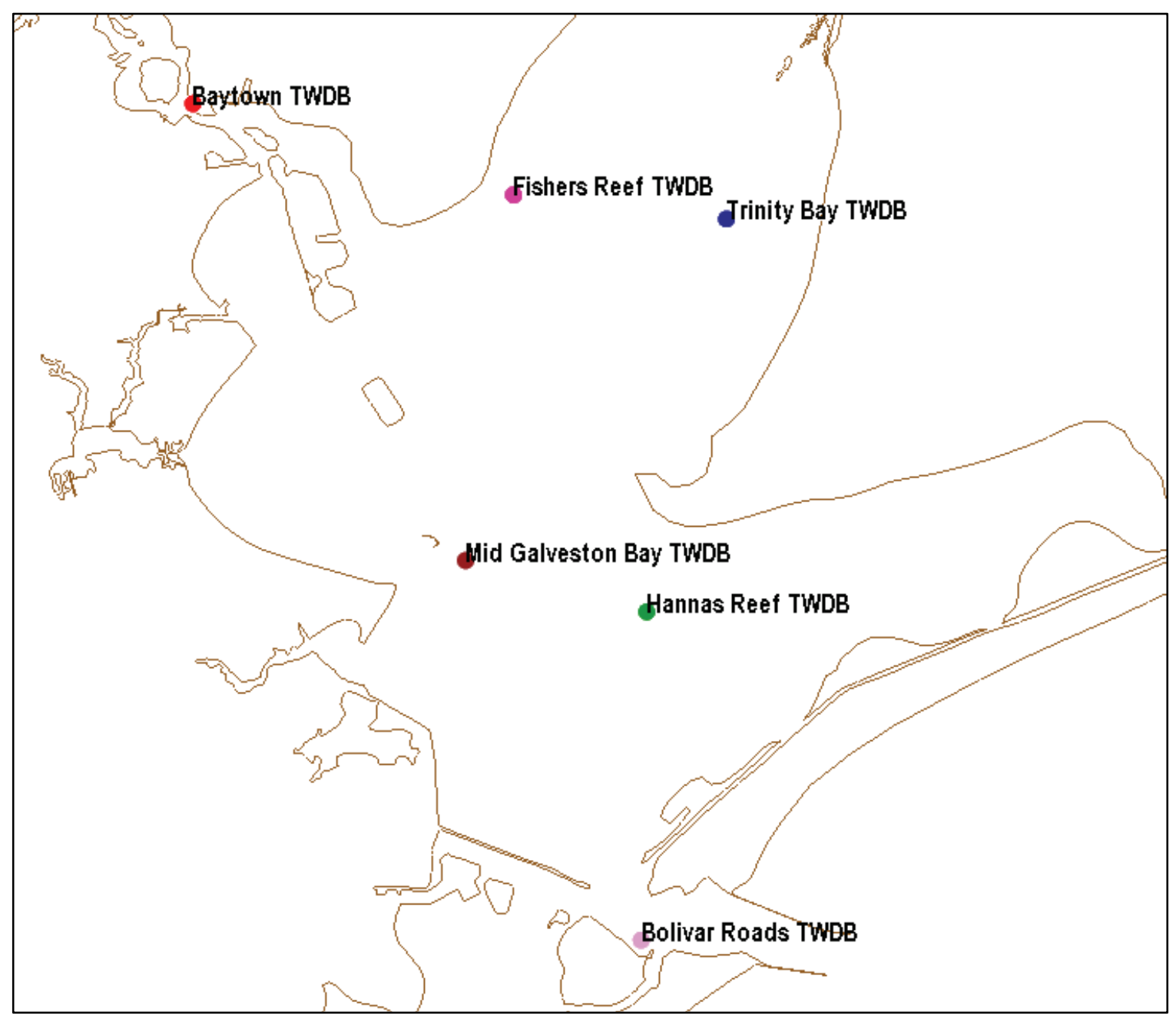


Figure 60. TCEQ salinity validation comparison sites.

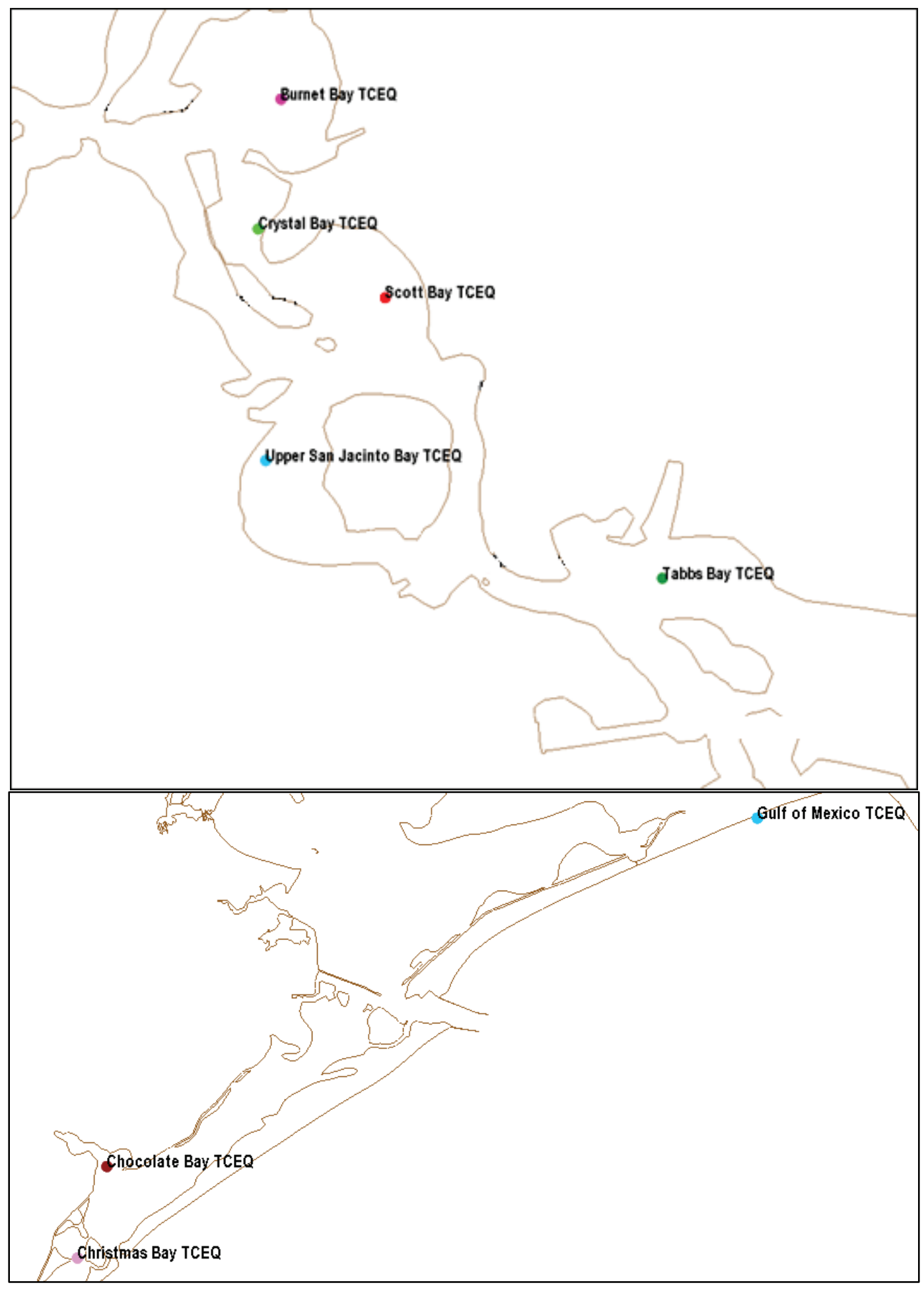


Figure 61. HARC salinity validation comparison sites.

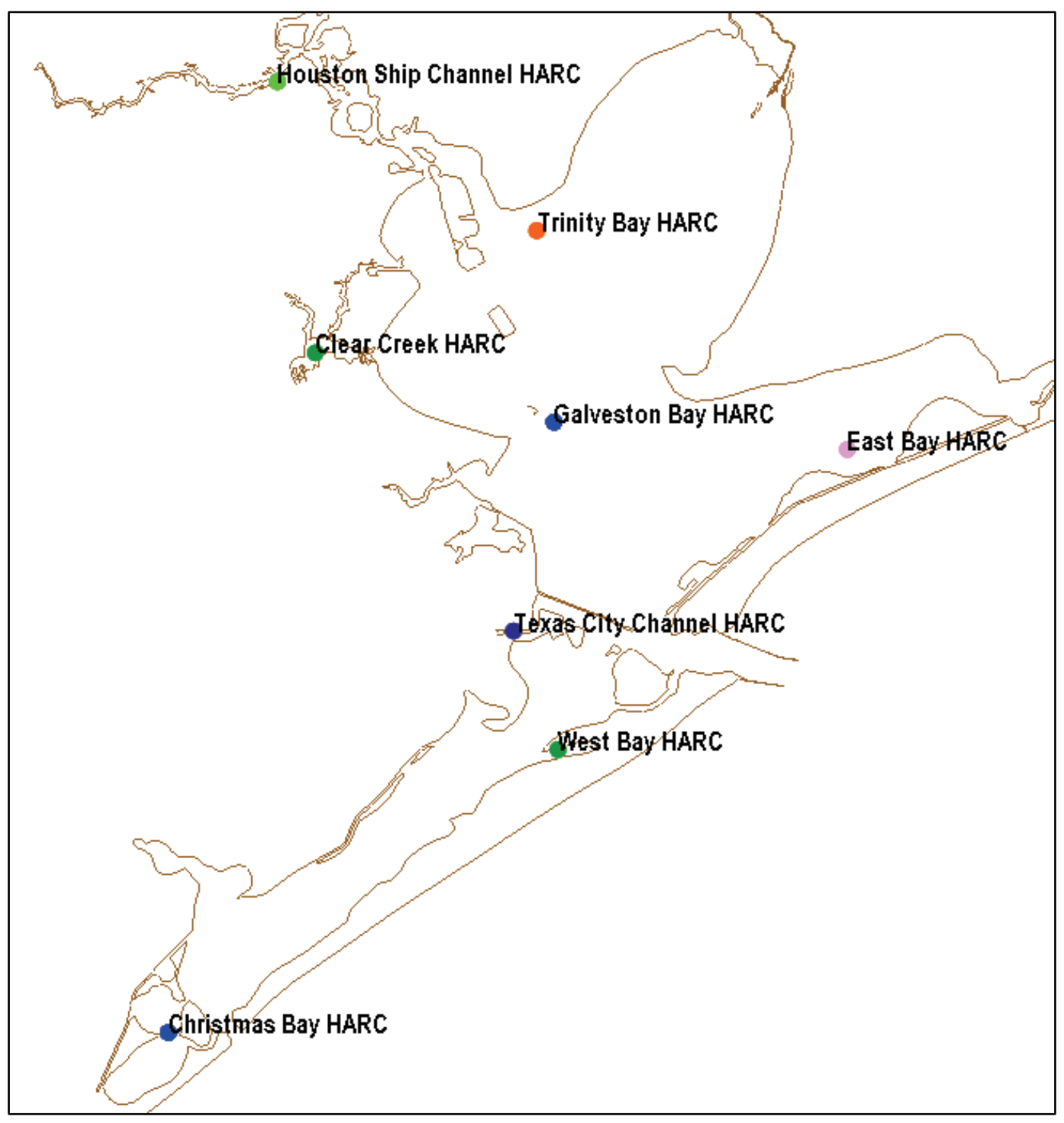


Figure 62. TABS salinity validation comparison site.

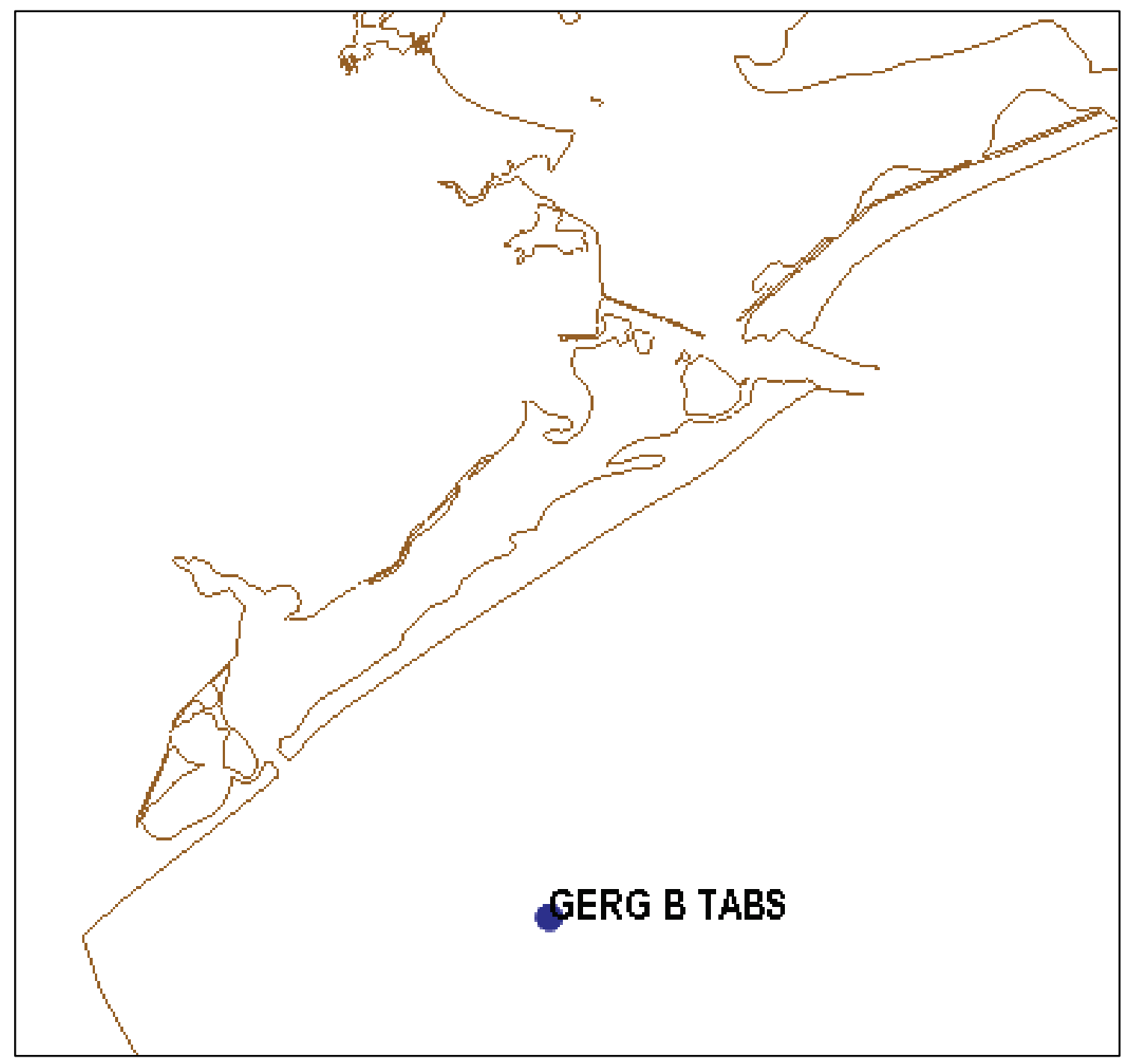

The upper HSC validation sites are primarily located in shallow regions outside of the ship channel. Model/field comparisons for the 2010 and 2011 validation period, from upstream to downstream, at HSC, Burnet Bay, Scott Bay, Baytown, and Upper San Jacinto Bay are shown in the following plots (Figure 63 through Figure 70). 
Figure 63. 2010 HSC salinity validation comparisons.

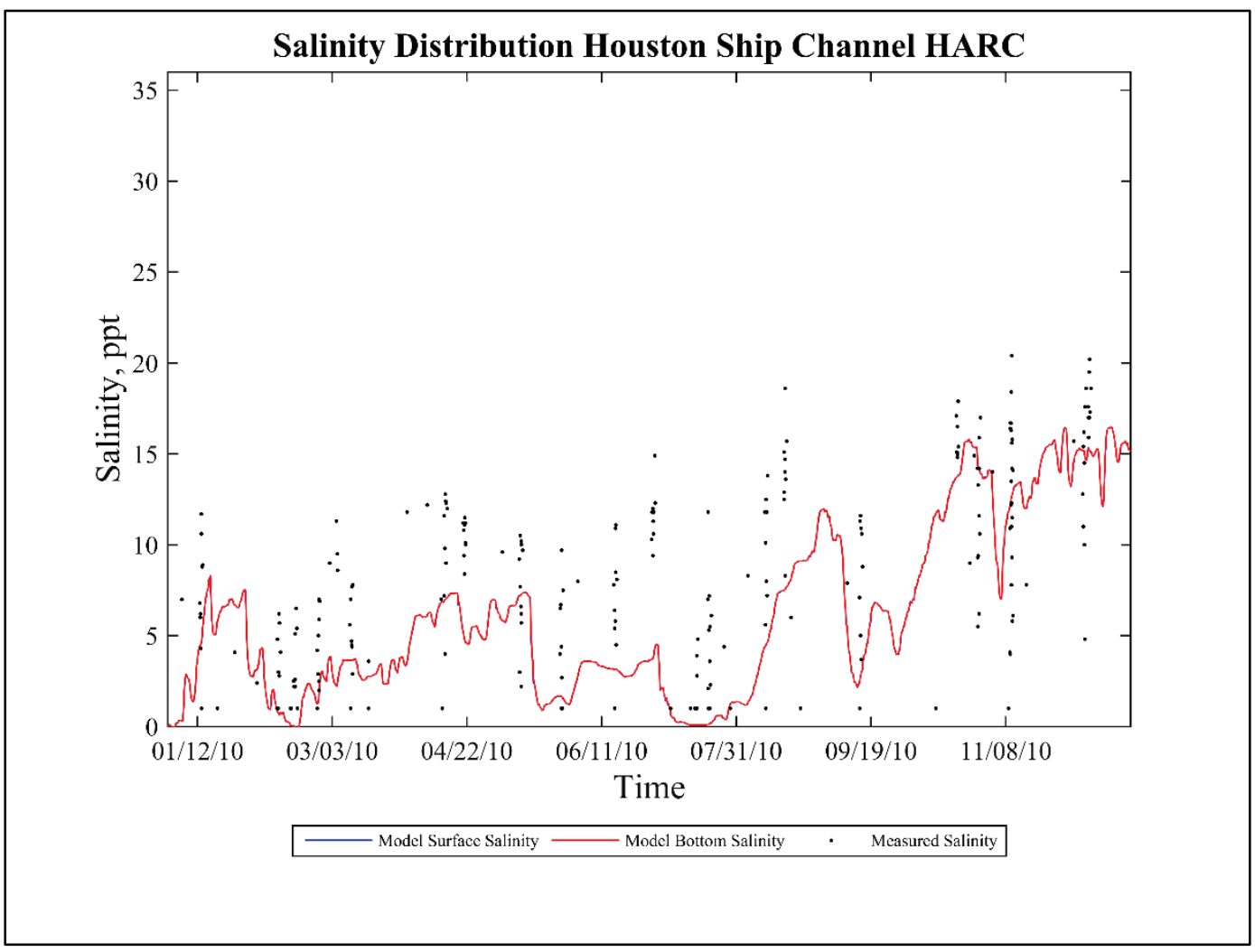

Figure 64. 2011 Burnet Bay salinity validation comparisons.

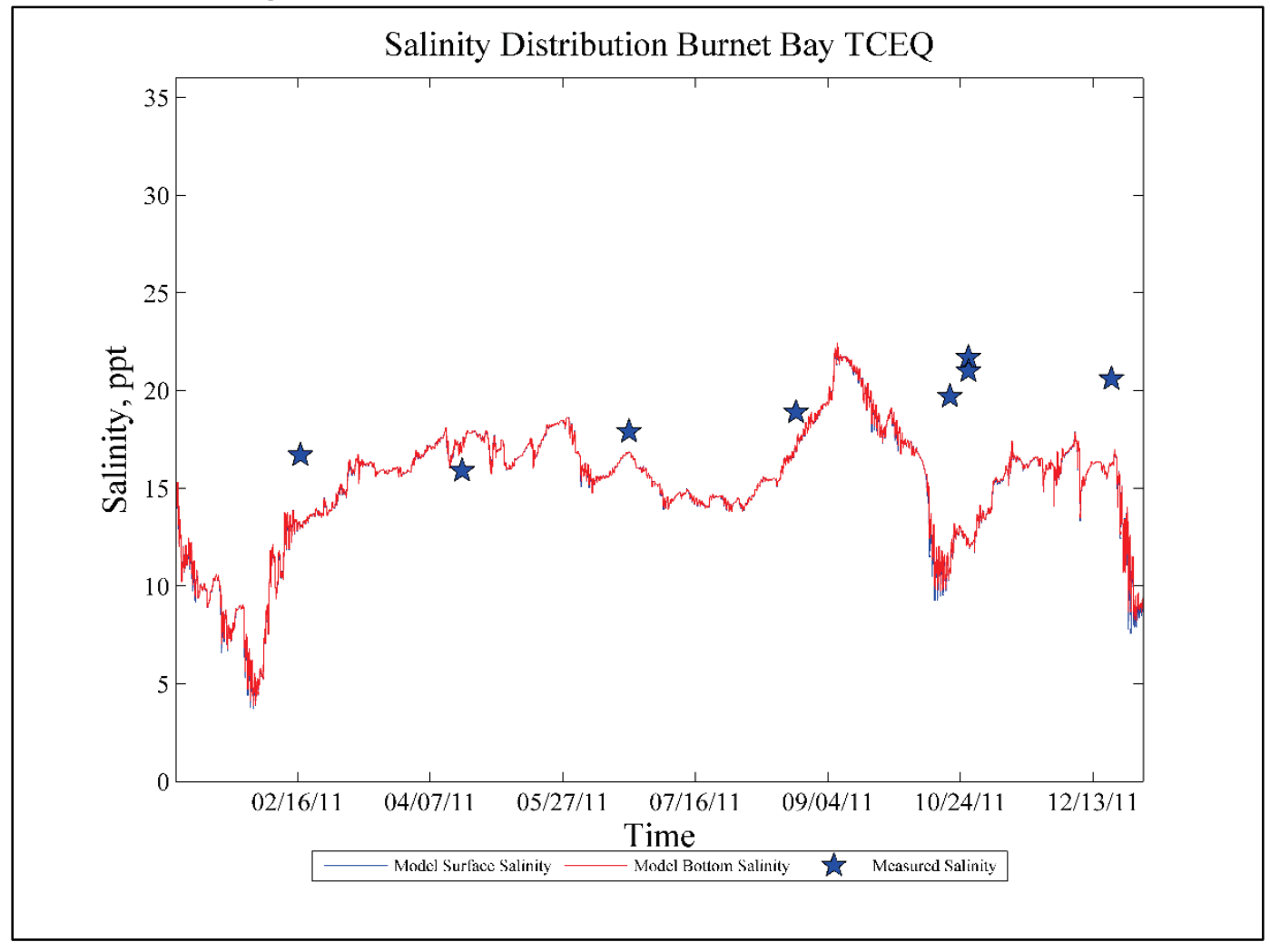


Figure 65. 2010 Scott Bay salinity validation comparisons.

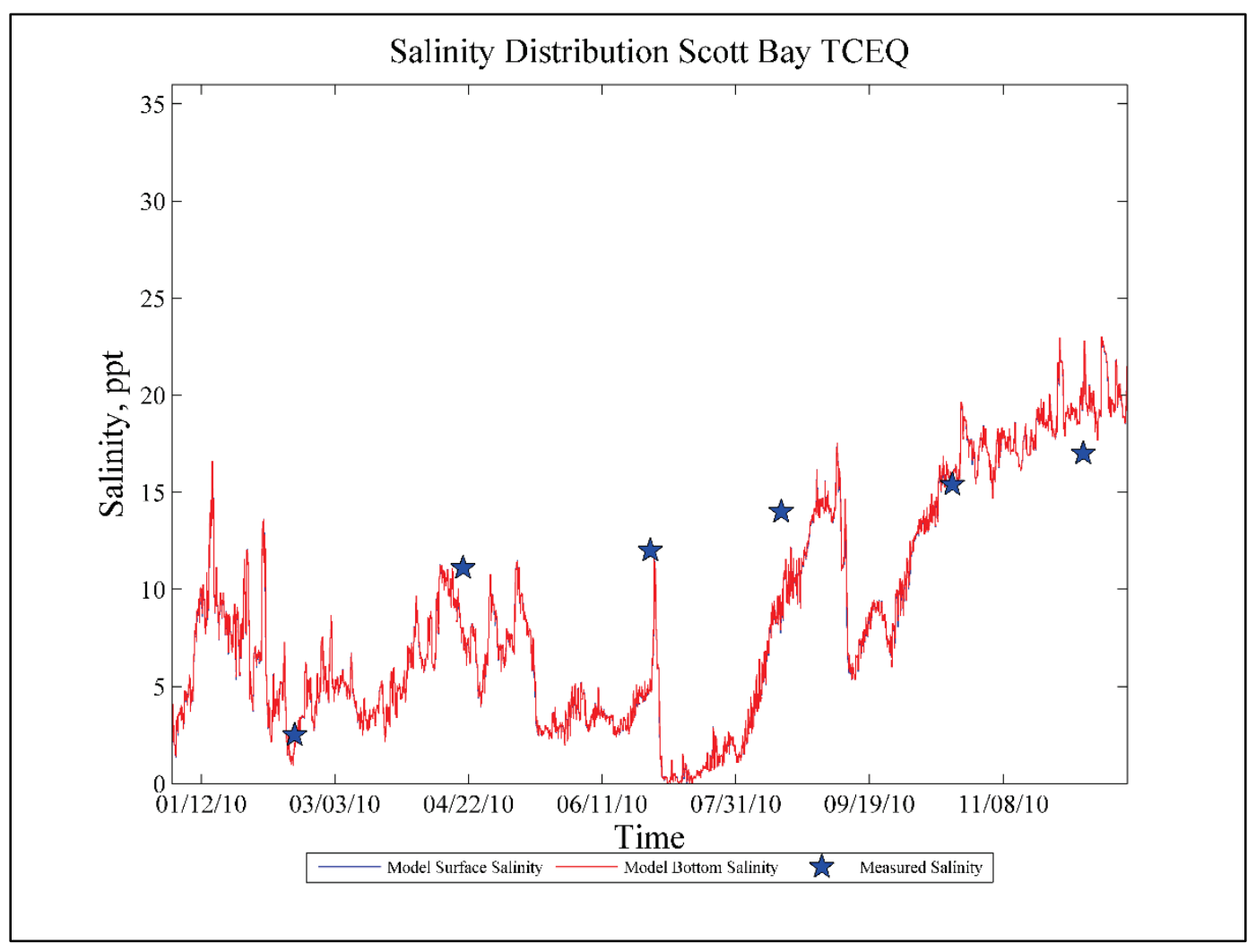

Figure 66. 2011 Scott Bay salinity validation comparisons.

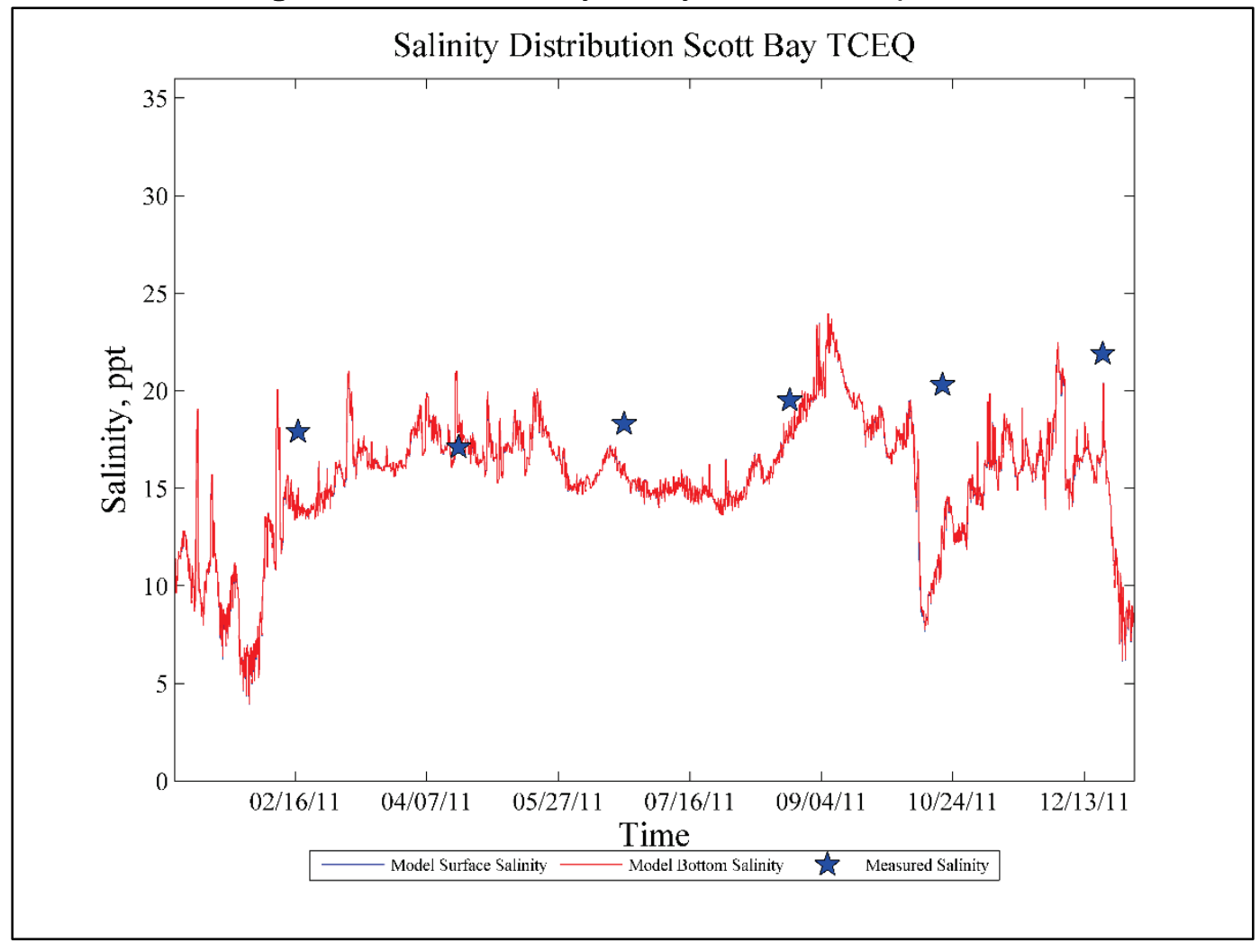


Figure 67. 2010 Baytown salinity validation comparisons.

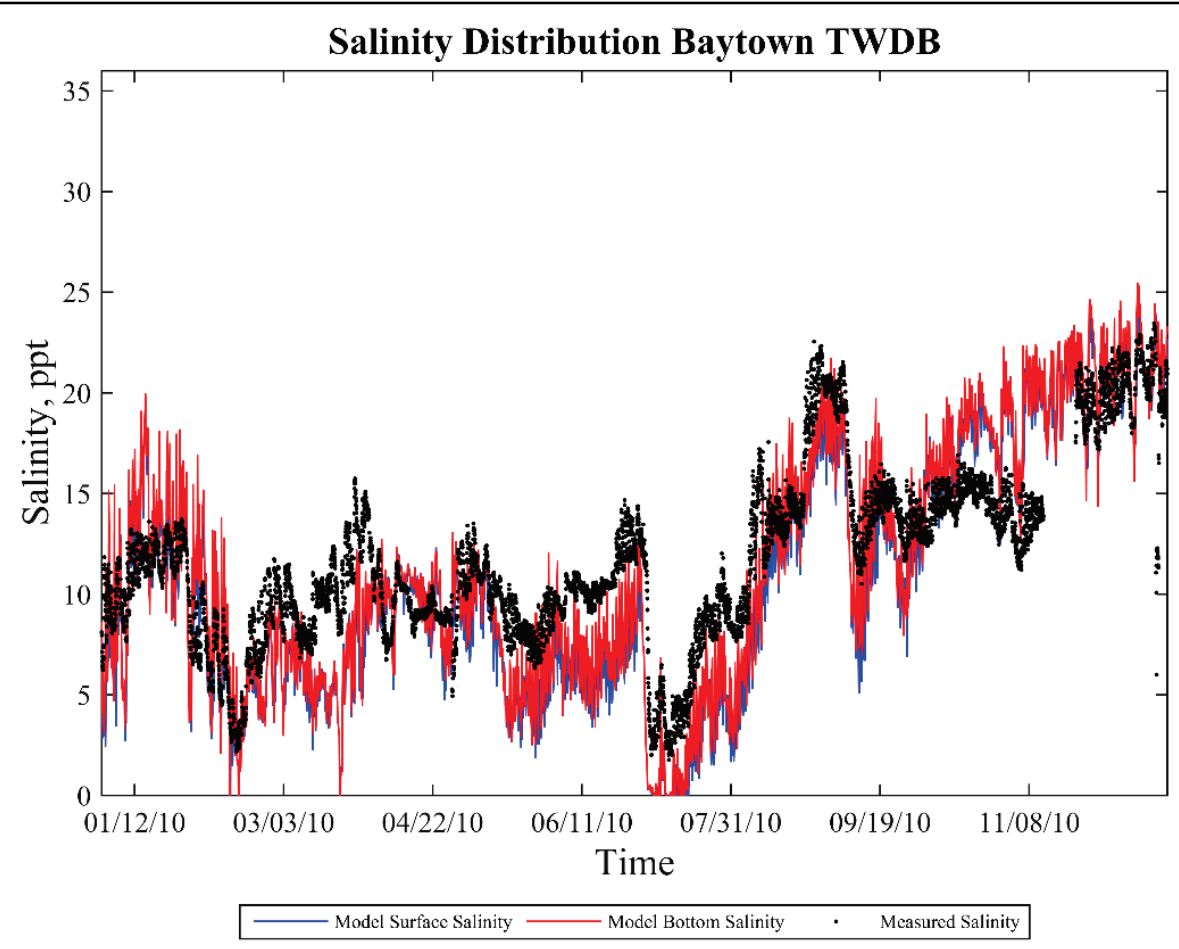

Figure 68. 2011 Baytown salinity validation comparisons.

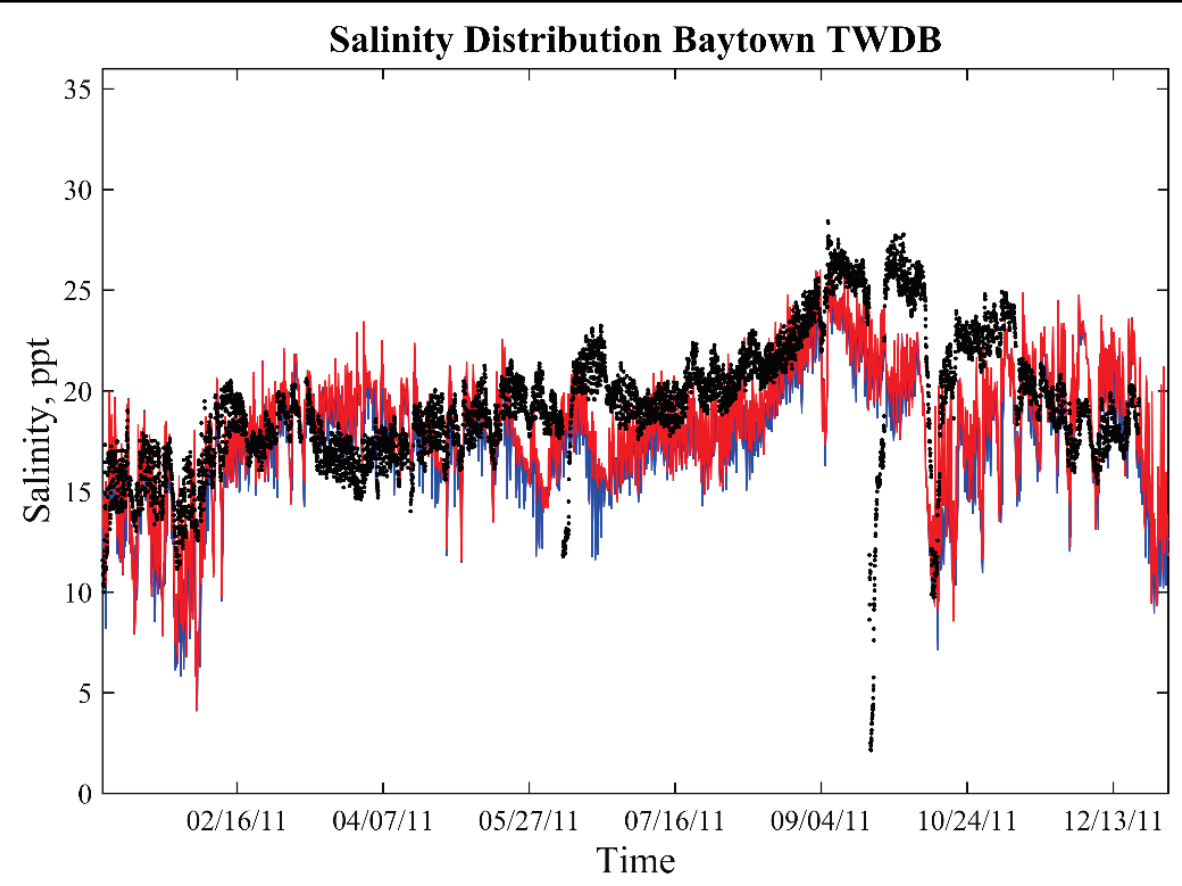


Figure 69. 2010 Upper San Jacinto Bay salinity validation comparisons.

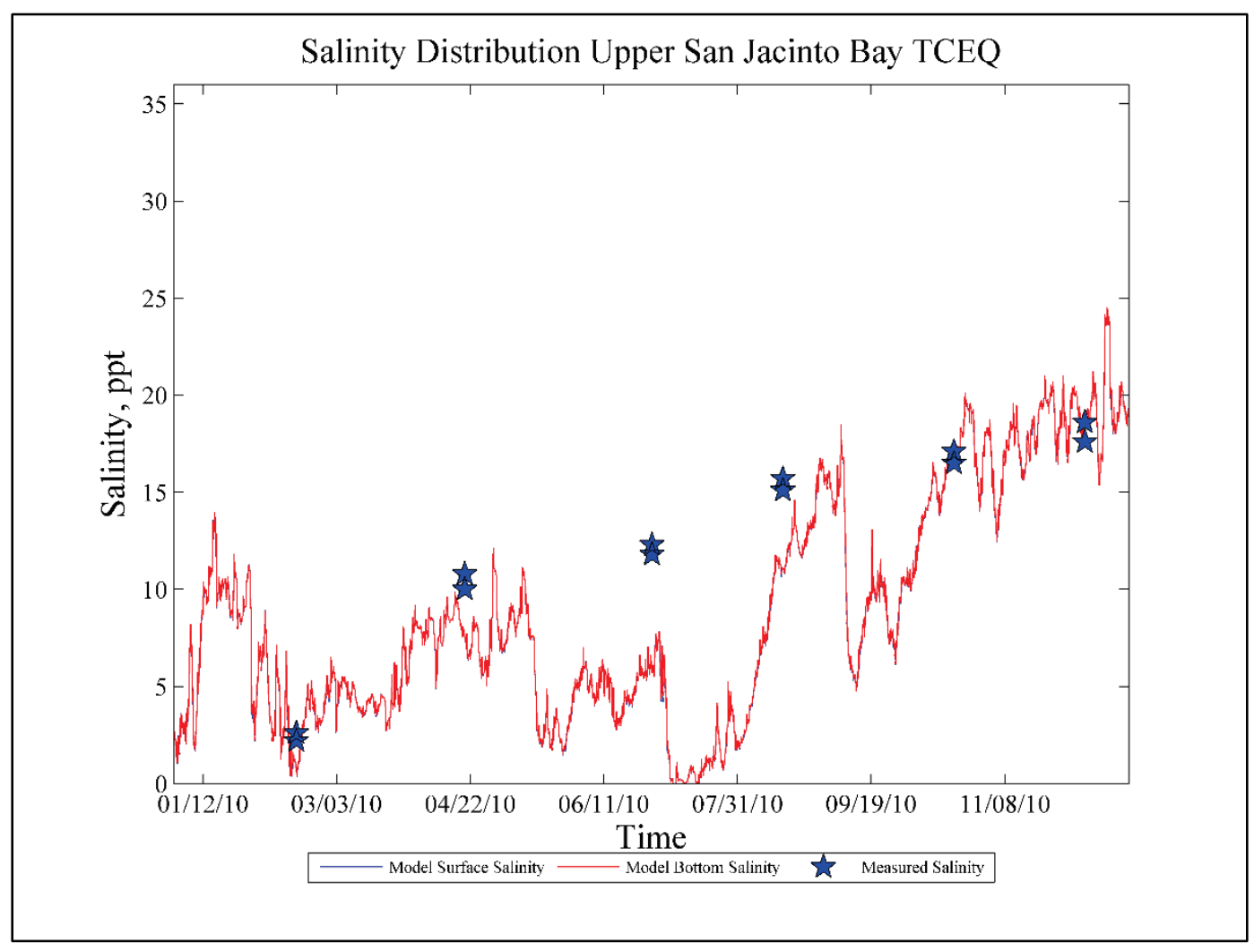

Figure 70. 2011 Upper San Jacinto Bay salinity validation comparisons.

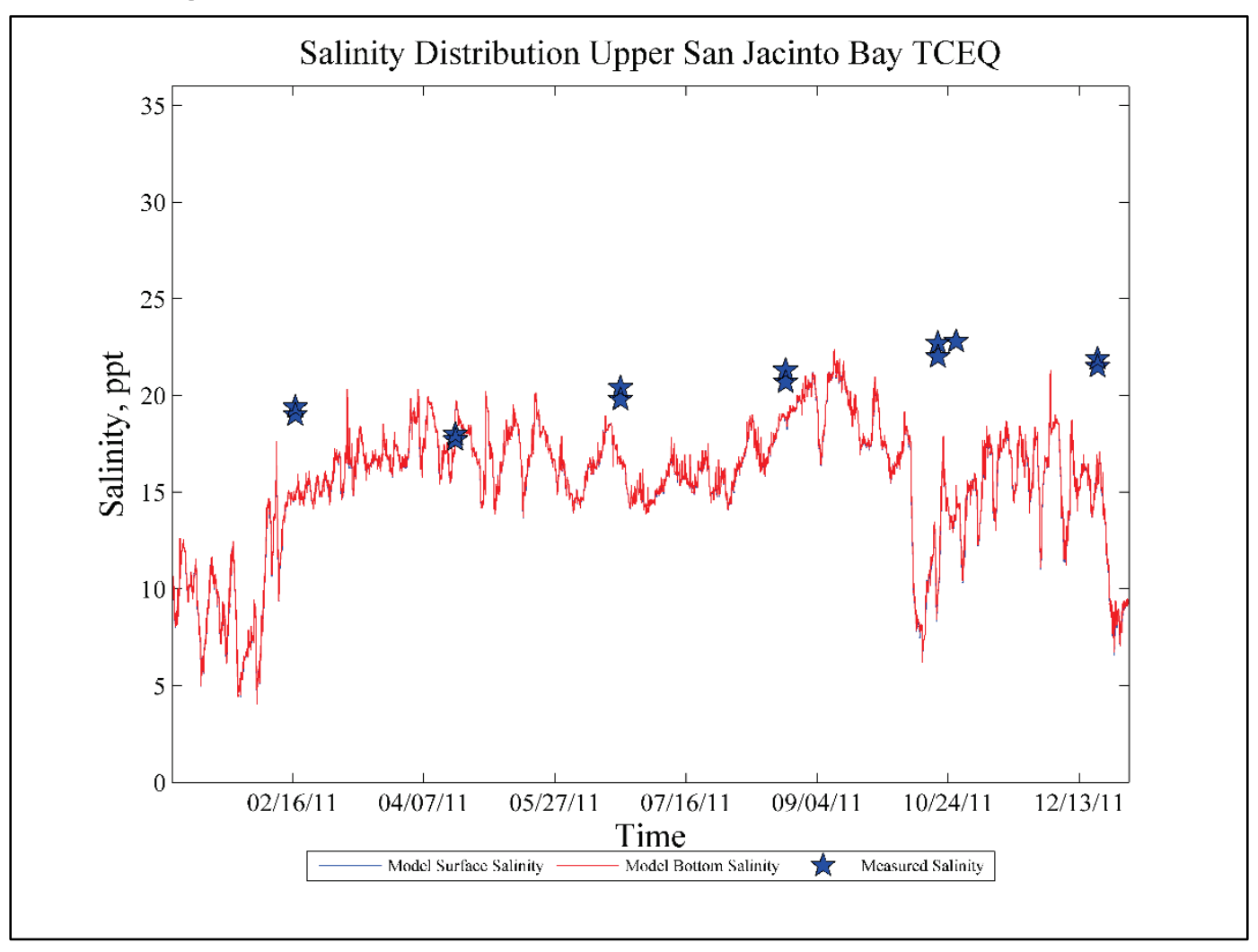


Salinity impacts in Trinity Bay are of primary concern when analyzing project changes for impacts on aquatic habitat. The model/field validation comparisons of salinity at Mid Galveston Bay and two Trinity Bay sites HARC on the northwest side of the bay (Figure 61) and TWDB on the southeast side of the bay (Figure 59) - are shown for 2010 and 2011 (except for Trinity Bay HARC) in Figure 71 through Figure 75.

Overall, the salinity patterns are replicated in the model. There are periods in the field data where it appears the field instrument malfunctions, but the general patterns are observable over the year-long simulation periods. The TWDB Trinity Bay (southeast) location comparisons indicate that the model is providing lower salinity values than the field, sometimes by as much as 8 ppt. This is expected because the model-computed velocities in these locations did not compare favorably to those observed in the field (Figure 55 through Figure 57). This area may be more heavily influenced by shallow depths and wind wave impacts (not included in this model) that are not impacting the salinity comparisons at the other comparison locations or due to neglected tidal prism due to model domain restrictions. Given the physics that are presently included in this AdH model and the overall good validation comparisons at other locations, these differences are noted but will not result in additional model calibration/validation.

Figure 71. 2010 Mid Galveston Bay salinity validation comparisons.

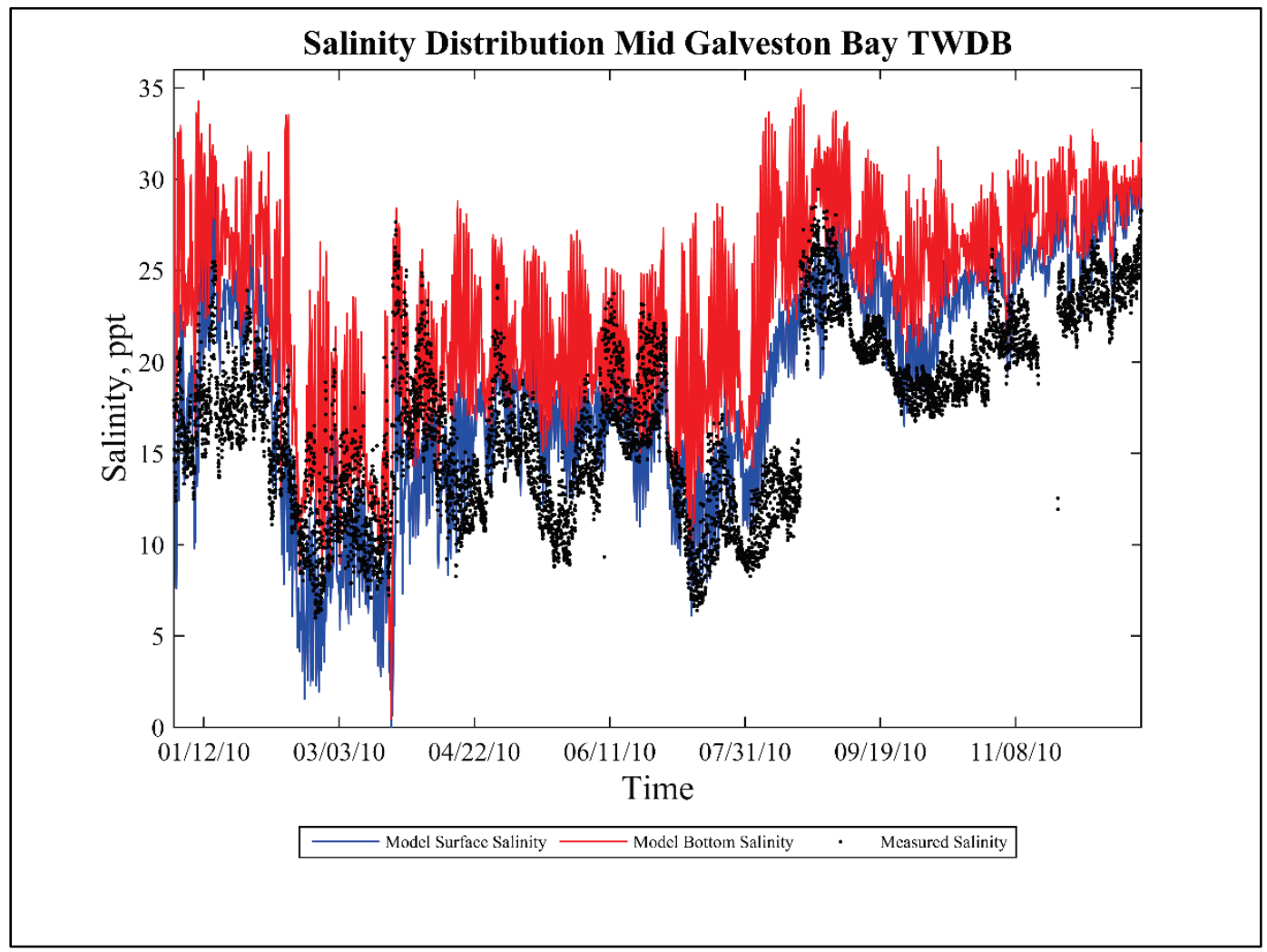


Figure 72. 2011 Mid Galveston Bay salinity validation comparisons.

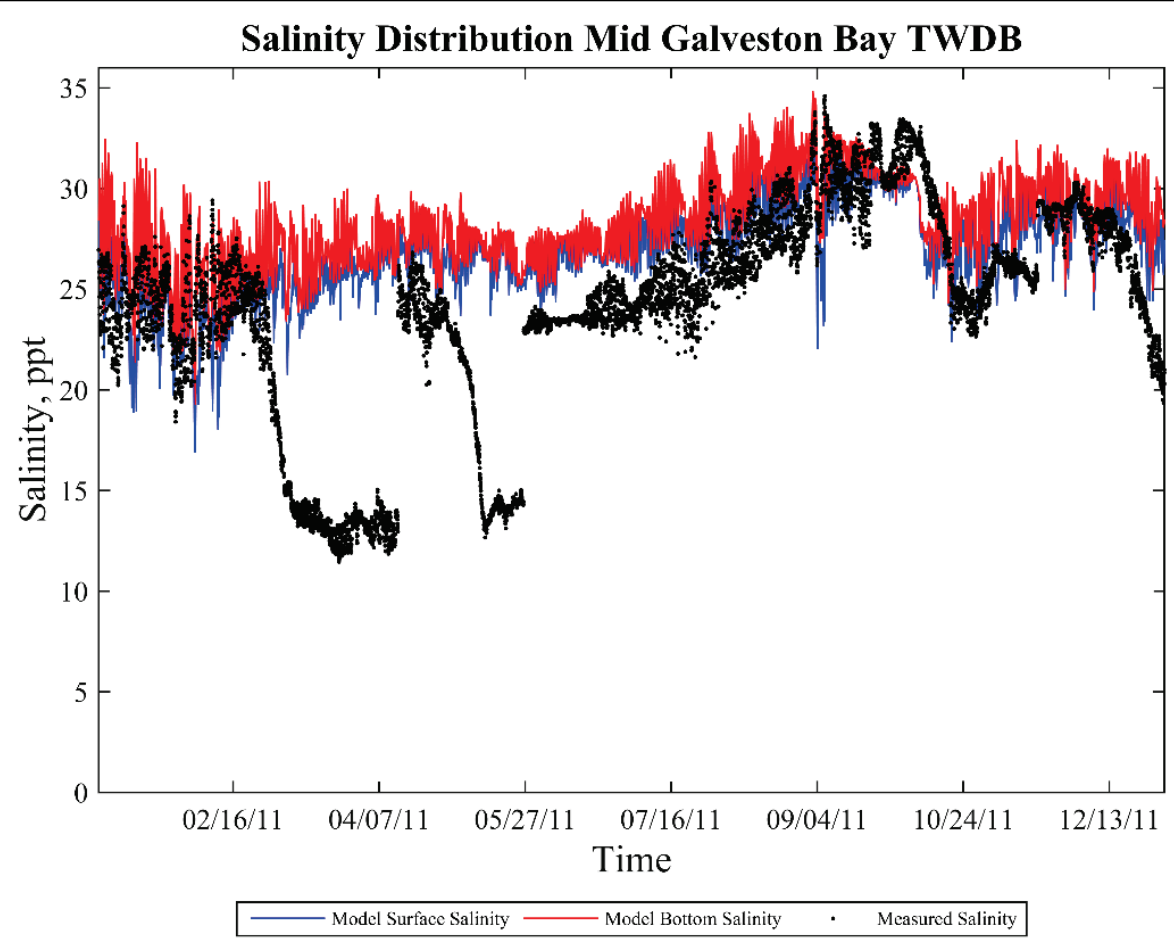

Figure 73. 2010 Trinity Bay HARC salinity validation comparisons (northwest).

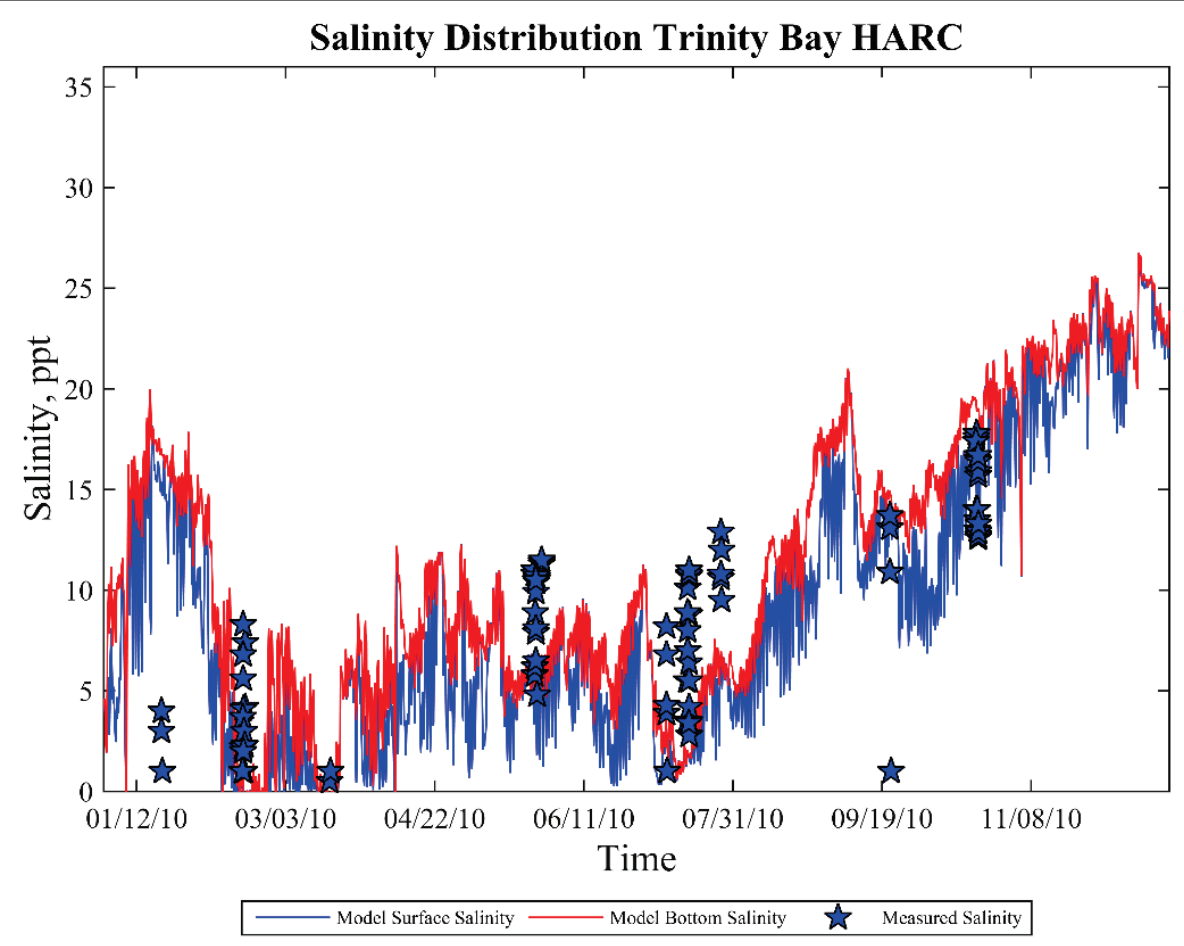


Figure 74. 2010 Trinity Bay TWDB salinity validation comparisons (southeast).

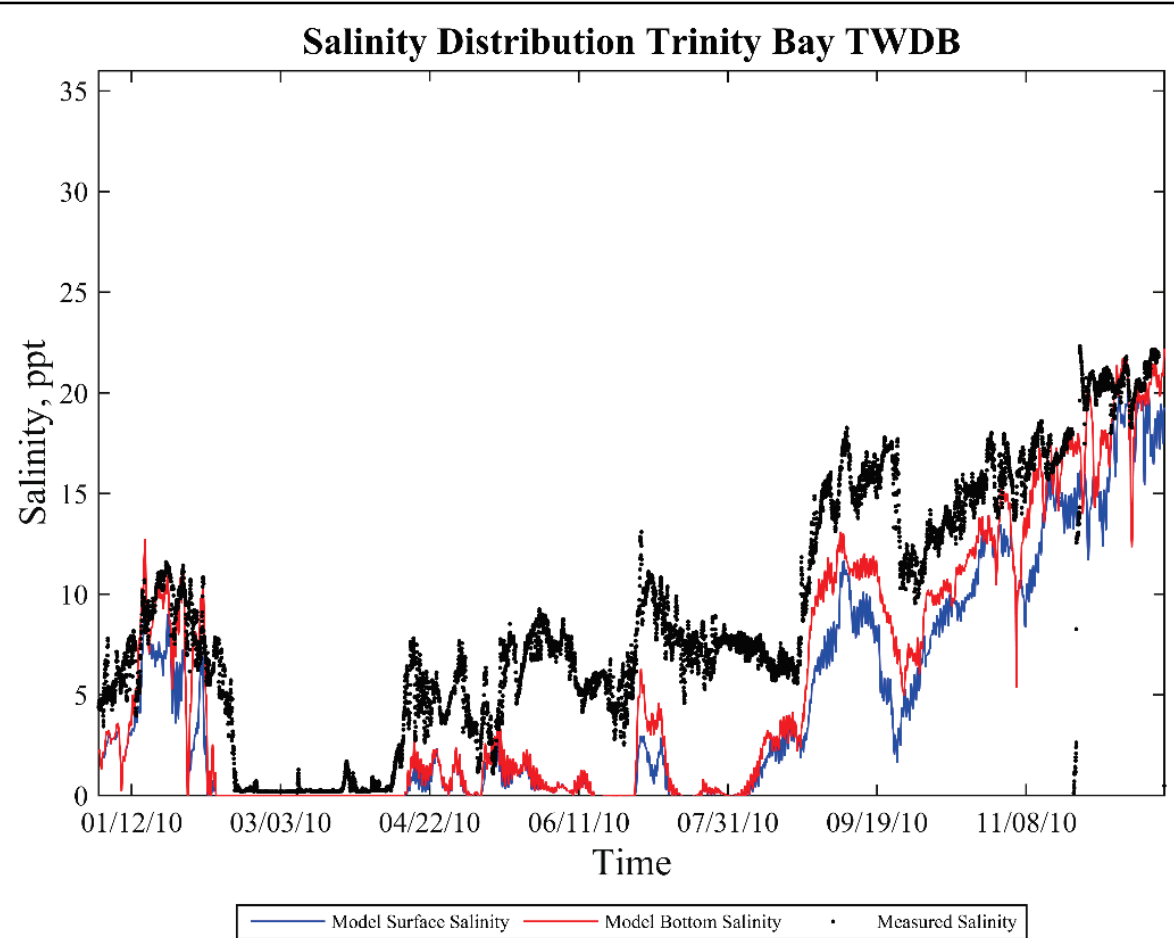

Figure 75. 2011 Trinity Bay TWDB salinity validation comparisons (southeast).

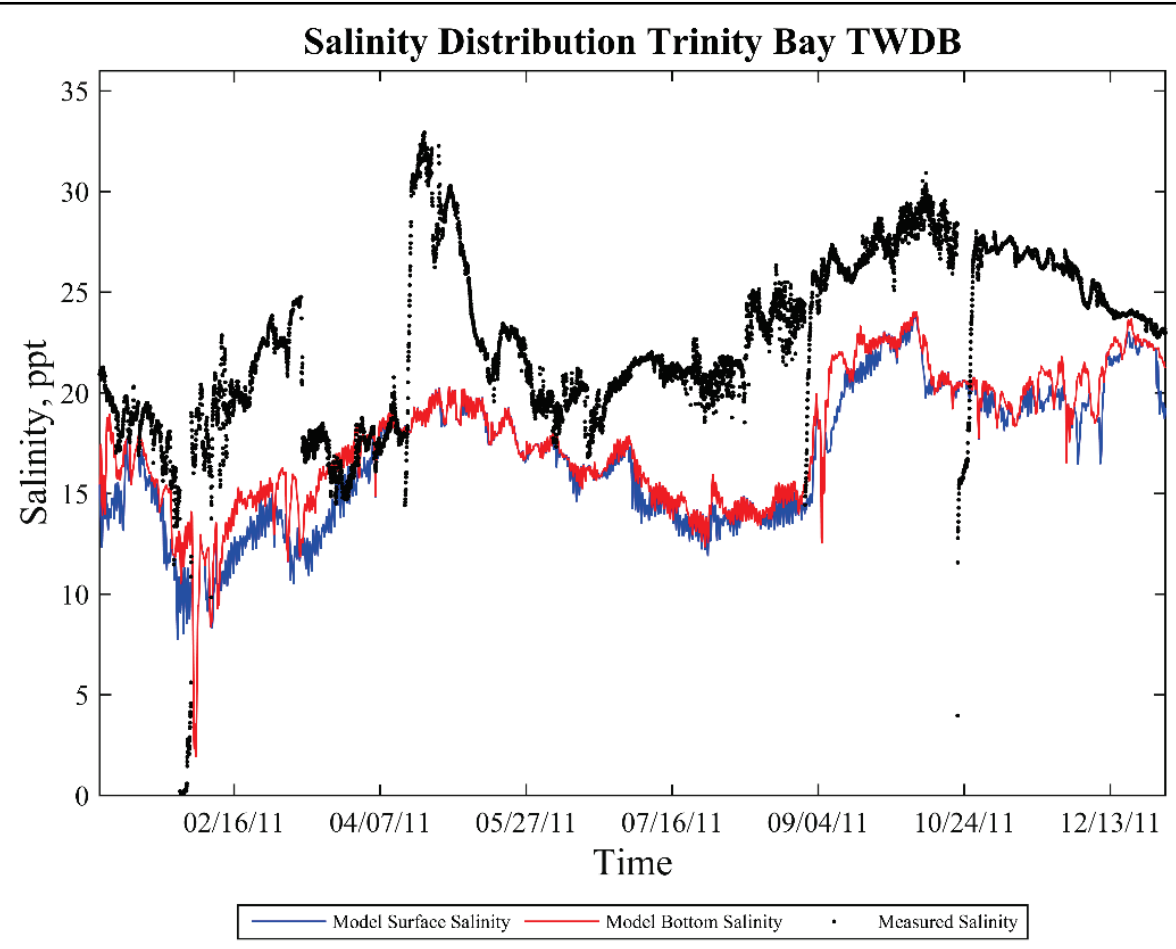




\section{Sediment validation}

The sediment model is validated based on historic maintenance dredging records for the HSC and a historic scaling method using the 2005 calibration year. The scale factor for each segment determined during the sediment model calibration was applied accordingly for the 2010 and 2011 validation years.

Figure 76 shows the shoaling validation results for 2010 and 2011 as compared to the annualized historic maintenance dredging records. The range of the shoaling results over the 2 validation years (green shades) lies within the range of the historic records (blue shades), and the large reduction in shoaling for 2011 is logical due to the drought and extremely low flow during that year. These results indicate that the model shoaling results, when scaled based on the 2005 data, should be appropriate for any base/plan comparisons made with the sediment model assuming the unaccounted for processes will not change with the plan alternative. 
Figure 76. Model/field HSC shoaling validation comparison.

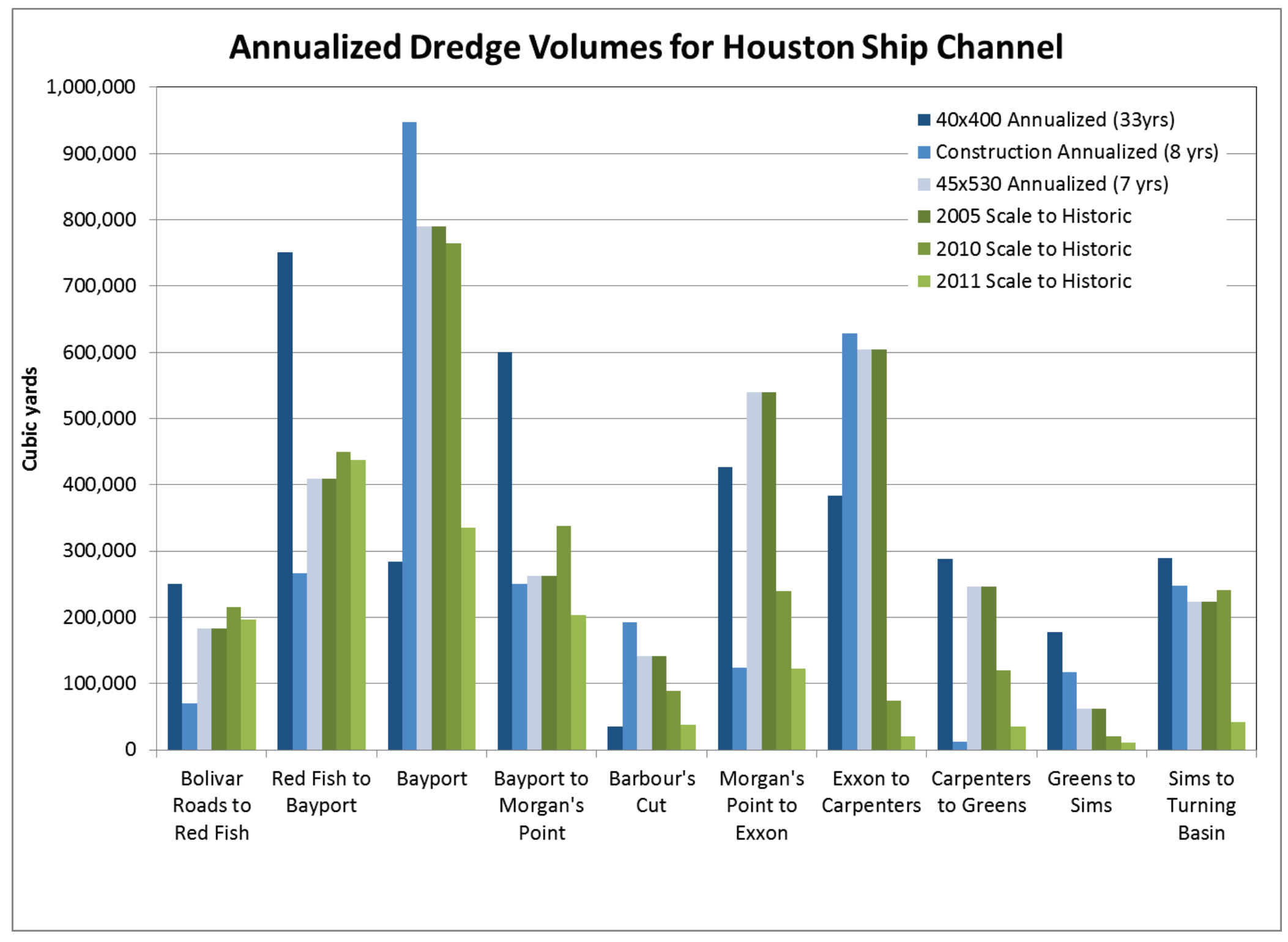




\section{Conclusions}

The $3 \mathrm{D}$ AdH model of the HSC and surrounding bays and bayous presented in this report has been developed based on the available data and known primary influences on the physics within the system. The model includes freshwater inflows, tides, salinity, wind, and sediment loads in an effort to reproduce the field for water surface elevation, velocity magnitude and direction, salinity, and HSC shoaling over a wide range of conditions. The model was compared to field data for 2005, 2010, and 2011 due to the availability of various data sets over wet and dry years. Calendar year 2005 was used for model calibration, and 2010 and 2011 were used for model validation.

Based on the AdH model definition as stated in Chapter 2 and the model/field comparisons for water surface elevation, velocity, salinity, and shoaling along the HSC as presented in Chapter 3, this model is available to simulate present and proposed future conditions, with and without project. Water surface elevation comparisons show good agreement between the model and the field over the 3 simulation years. The velocity comparisons are very good in the HSC but show much variation in Trinity Bay. It is possible that high-frequency events in the wind signal are generating some of these differences or that the field data are being influenced by local vessel traffic such as pleasure craft or fishing vessels. The model reproduces the salinity intrusion up the HSC as well as provides a reasonable representation of salinity stratification along the HSC as indicated by the available field data and historic documentation. The model also shows salinity intrusion into Trinity Bay; although comparisons in this area are not as good, the model generally replicates the salinity patterns over time.

The model does not directly include specified inputs of sediment loads from the ungaged freshwater inflows or the physics to compute wind-generated wave erosion along the shallows and vessel-induced erosion in the bays (which is known to be a significant source of HSC shoaling). Although the sediment model calibration attempts to account for these processes, there is a large range in the shoaling estimates for the validation period. This variability is also observed in the field data over time and indicates the sensitivity of the HSC shoaling to the variability of 
the forcing conditions. One-to-one comparison of the shoaling along the HSC is difficult to verify when scaling is based on a single year of data but is the only means available unless large quantities of sediment bed and load data are available for model calibration. Therefore, the modelpredicted shoaling results should be viewed only in terms of relative changes and never used to predict total volume, especially if modifications to the system cause vessel traffic to change (i.e., faster and/or larger ships will likely generate an increase in the erosion potential they create in the area causing the model to underpredict the possible increase in HSC shoaling).

Although proven to match field conditions over a range of conditions, this model is intended to be used to reasonably forecast behavior assuming events do not occur that change the physics of the system. Hurricanes, severe storms, and anthropogenic influences (among other forces) over time can generate changes to the system that will require model updates or re-validation. The model is best used for determining trends and impacts in a percentage change and range of results type of analyses. Note that this model should not be used to predict actual values for any future parameters as the future is unknown, and it is extremely unlikely that the future will mimic exactly what is modeled. 


\section{References}

Bell, Gary L., N. D. Clifton, and D. D. Abraham. 2017. Hydrodynamics in the Morganza Floodway Report 1: Phase 1-Model Development and Calibration. Mississippi River Geomorphology and Potamology Program Report No. 13. Vicksburg, MS: U.S. Army Engineer Research and Development Center.

Berger, R. C., R. T. McAdory, W. D. Martin, and J. H. Schmidt. 1995. Houston-Galveston Navigation Channels, Texas Project, Report 3, Three-Dimensional Hydrodynamic Model Verification. Technical Report HL-92-7. Vicksburg, MS: U.S. Army Engineer Waterways Experiment Station.

Buczkowski, B. J., J. A. Reid, C. J. Jenkins, J. M. Reid, S. J. Williams, and J. G. Flocks. 2006. usSEABED: Gulf of Mexico and Caribbean (Puerto Rico and U.S. Virgin Islands) Offshore Surficial Sediment Data Release. U.S. Geological Survey Data Series 146, version 1.0. https://pubs.usgs.gov/ds/2006/146/

Carrillo, A. R., M. S. Sarruff, and R. C. Berger. 2002. Effects of Adding Barge Lanes along Houston Ship Channel through Galveston Bay, Texas. ERDC/CHL TR-02-23. Vicksburg, MS: U.S. Army Engineer Research and Development Center.

Clifton, N., D.Abraham, and D. Pridal. 2017. Upper and Lower Hamburg Bend 2011 Flood Evaluation on the Missouri River near Hamburg, Iowa. ERDC/CHL TR17-1. Vicksburg, MS: U.S. Army Engineer Research and Development Center.

Cochrane, J. D., and F. J. Kelly. 1986. "Low Frequency Circulation on the TexasLouisiana Continental Shelf.” Journal of Geophysical Research 91(C9): 1064510659.

Egiazaroff, I. V. 1965. "Calculation of Non-Uniform Sediment Concentrations." Journal of Hydraulics Division, ASCE 91(HY4): 225-247.

Galveston Bay Estuary Program. 2002. The State of the Bay: A Characterization of the Galveston Bay Ecosystem, 2nd Edition. Edited by J. Lester and L. Gonzalez. Austin, TX: Texas Commission on Environmental Quality. Galveston Bay Estuary Program.

Heath, R. E., G. L. Brown, C. D. Little, T. C. Pratt, J. J. Ratcliff, D. Abraham, D. W. Perkey, N. B. Ganesh, S. K. Martin, and D. P. May. 2015. Old River Control Complex Sedimentation Investigation. ERDC/CHL TR-15-8. Vicksburg, MS: U.S. Army Engineer Research and Development Center.

Hubertz, J. M. 1992. User's Guide to the Wave Information Studies (WIS) Wave Model: Version 2.o. WIS Report 27. Vicksburg, MS: U.S. Army Engineer Waterways Experiment Station. http://wis.usace.army.mil/

Letter, J. V., G. L. Brown, R. T. McAdory, and T. C. Pratt. 2015. Numerical Modeling of Trinity River Shoaling below Wallisville, Texas. ERDC/CHL TR-15-1. Vicksburg, MS: U.S. Army Engineer Research and Development Center. 
McAlpin, T. O., G. Savant, G. L. Brown, S. J. Smith, and R. S. Chapman. 2013.

"Hydrodynamics of Knik Arm: Modeling Study." Journal of Waterway, Port, Coastal, and Ocean Engineering 139(3).

Nichols, M. M. 1989. "Sediment Accumulation Rates and Relative Sea-Level Rise in Lagoons.” Marine Geology 88(3-4): 201-219.

Savant, G., R. C. Berger, T. O. McAlpin, and C. J. Trahan. 2014. Three-Dimensional Shallow Water Adaptive Hydraulics (AdH-SW3): Hydrodynamic Verification and Validation. ERDC/CHL TR-14-7. Vicksburg, MS: U.S. Army Engineer Research and Development Center.

Savant, G., and R. C. Berger. 2015. Three-Dimensional Shallow Water Adaptive Hydraulics (AdH-SW3) Validation: Galveston Bay Hydrodynamics and Salinity Transport. ERDC/CHL TR-15-3. Vicksburg, MS: U.S. Army Engineer Research and Development Center.

Schoenbaechler, C., and C. G. Guthrie. 2012. Coastal Hydrology for the Trinity-San Jacinto Estuary. Austin, TX: Texas Water Development Board.

Sharp, J. A., C. D. Little, G. L. Brown, T. C. Pratt, R. E. Heath, L. C. Hubbard, F. Pinkard, S. K. Martin, N. D. Clifton, D. W. Perkey, and N. B. Ganesh. 2013. West Bay Sediment Diversion Effects. ERDC/CHL TR-13-15. Vicksburg, MS: U.S. Army Engineer Research and Development Center.

Tate, J. N., and R. C. Berger. 2006. Houston-Galveston Navigation Channels, Texas Project: Navigation Channel Sedimentation Study, Phase 1. ERDC/CHL TR-o68. Vicksburg, MS: U.S. Army Engineer Research and Development Center.

Tate, J. N., R. C. Berger, and C. G. Ross. 2008. Houston-Galveston Navigation Channels, Texas Project, Navigation Channel Sedimentation Study, Phase 2. ERDC/CHL TR-o8-8. Vicksburg, MS: U.S. Army Engineer Research and Development Center.

Tate, J. N., J. P. McKinney, T. C. Pratt, F. C. Carson, M. W. Tubman, G. L. Brown, K. M. Barry, R. T. McAdory, and M. J. Briggs. 2009. Salinas de San Pedro (Cabrillo) Wetland Restoration Project. Volume 1, Main Text. ERDC/CHL TR-09-14. Vicksburg, MS: U.S. Army Engineer Research and Development Center.

Tate, J. N., and C. G. Ross. 2012. Bayport Flare Hydrodynamic Study for Ship Simulation. ERDC/CHL TR-12-13. Vicksburg, MS: U.S. Army Engineer Research and Development Center.

Tate, J. N., B. Gunkel, J. Rosati, E. Wood, A. Sanchez, R. Thomas, N. Ganesh, and T. Pratt. 2014. Monitoring Completed Navigation Projects Program; HoustonGalveston Navigation Channel Shoaling Study. ERCD/CHL TR-14-14. Vicksburg, MS: U.S. Army Engineer Research and Development Center.

Teeter, A. Michael. 2002. Sediment Transport in Wind-Exposed Shallow, Vegetated Aquatic Systems. A Dissertation. Louisiana State University.

URS Group Inc. 2009. Houston-Galveston Navigation Channels Preliminary Assessment, Appendix C: Maintenance Sediment Composition. Project Number 25008848. 
Wright, S., and G. Parker. 2004. "Flow Resistance and Suspended Load in Sand-Bed Rivers: Simplified Stratification Model." Journal of Hydraulic Engineering 130(8): 796-805.

Wu, J. 1969. "Wind Stress and Surface Roughness at Air-Sea Interface." Journal of Geophysical Research 74(2): 444-455.

Wu, J. 1982. "Wind-Stress Coefficients Over Sea Surface from Breeze to Hurricane.” Journal of Geophysical Research 87(C12). 9704-9706. 


\section{Appendix A: Water Surface Elevation Comparisons}

The following plots include all of the model/field water surface elevation comparisons for the available field data during the 3 calibration/validation years $-2005,2010$, and 2011. Data are not available for all 3 years at all sites. Figure 24 in the main text shows the locations of all water surface elevation comparison sites. For the time-history plots, the green line represents the measured field data, and the blue line represents the model-computed values. Each comparison location also includes a box plot showing the relationship between the measured field data ( $x$-axis) and the modeled data ( $y$-axis). A perfect match at all times would yield points on the black 1:1 line.

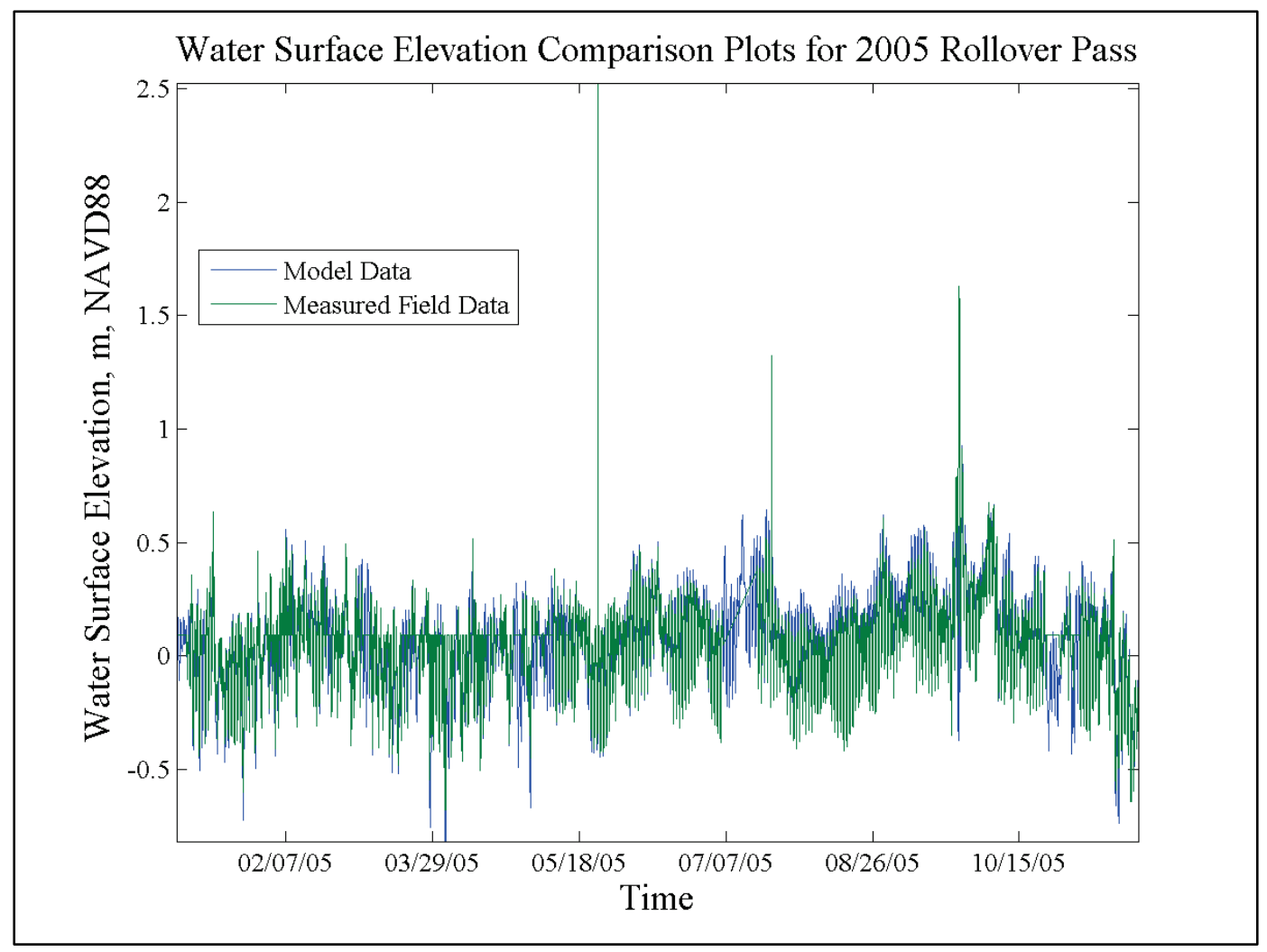



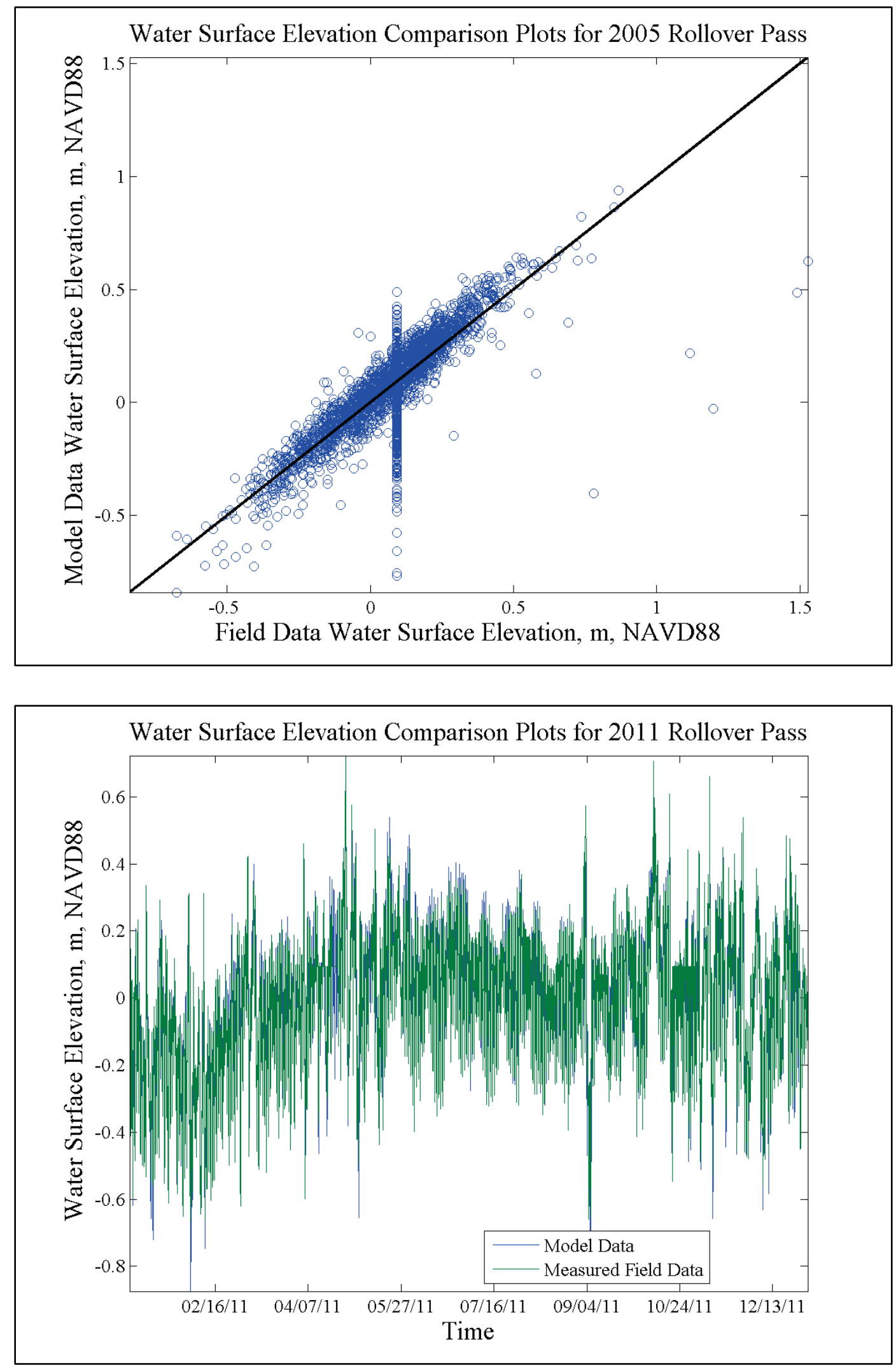

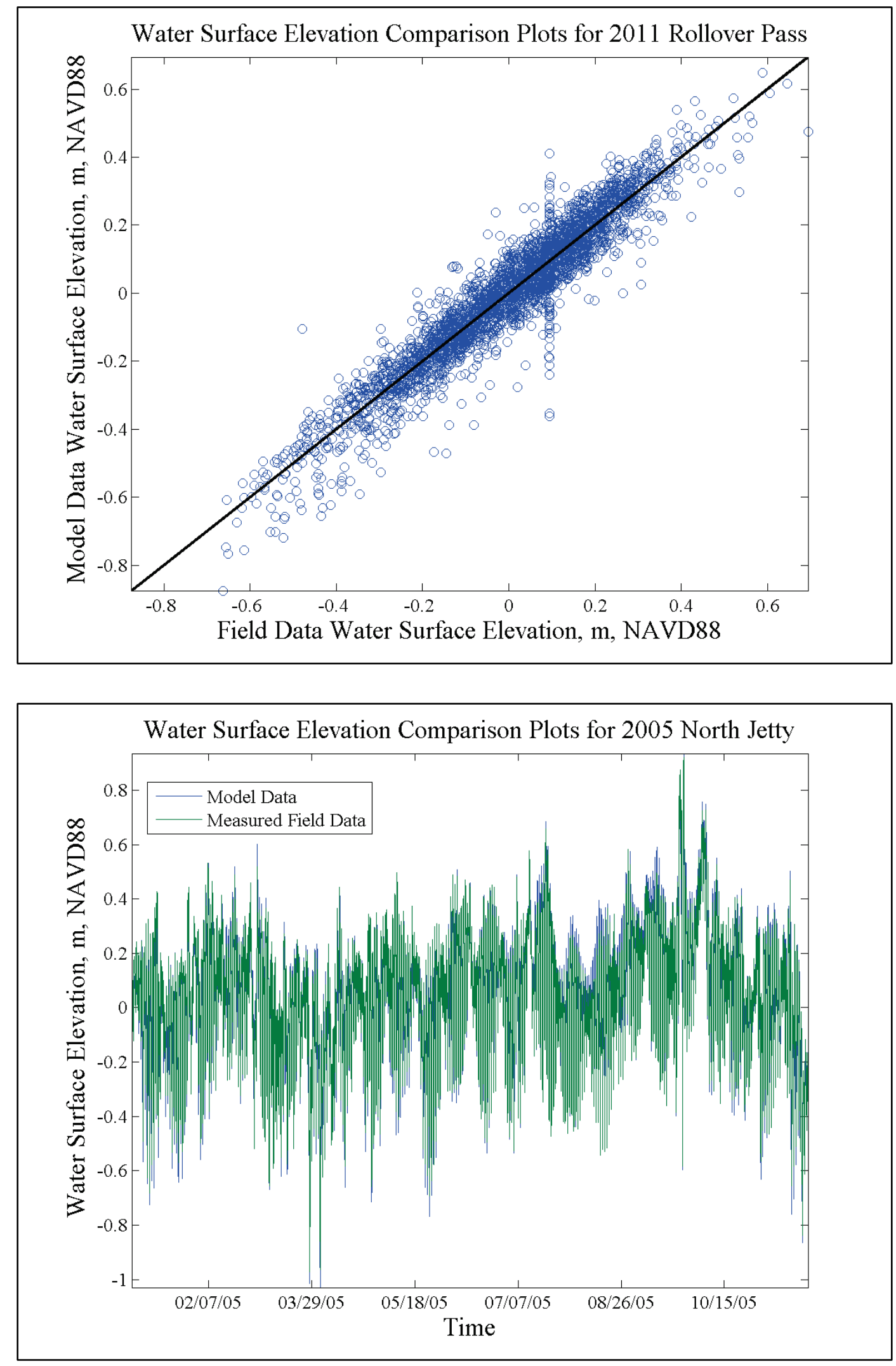

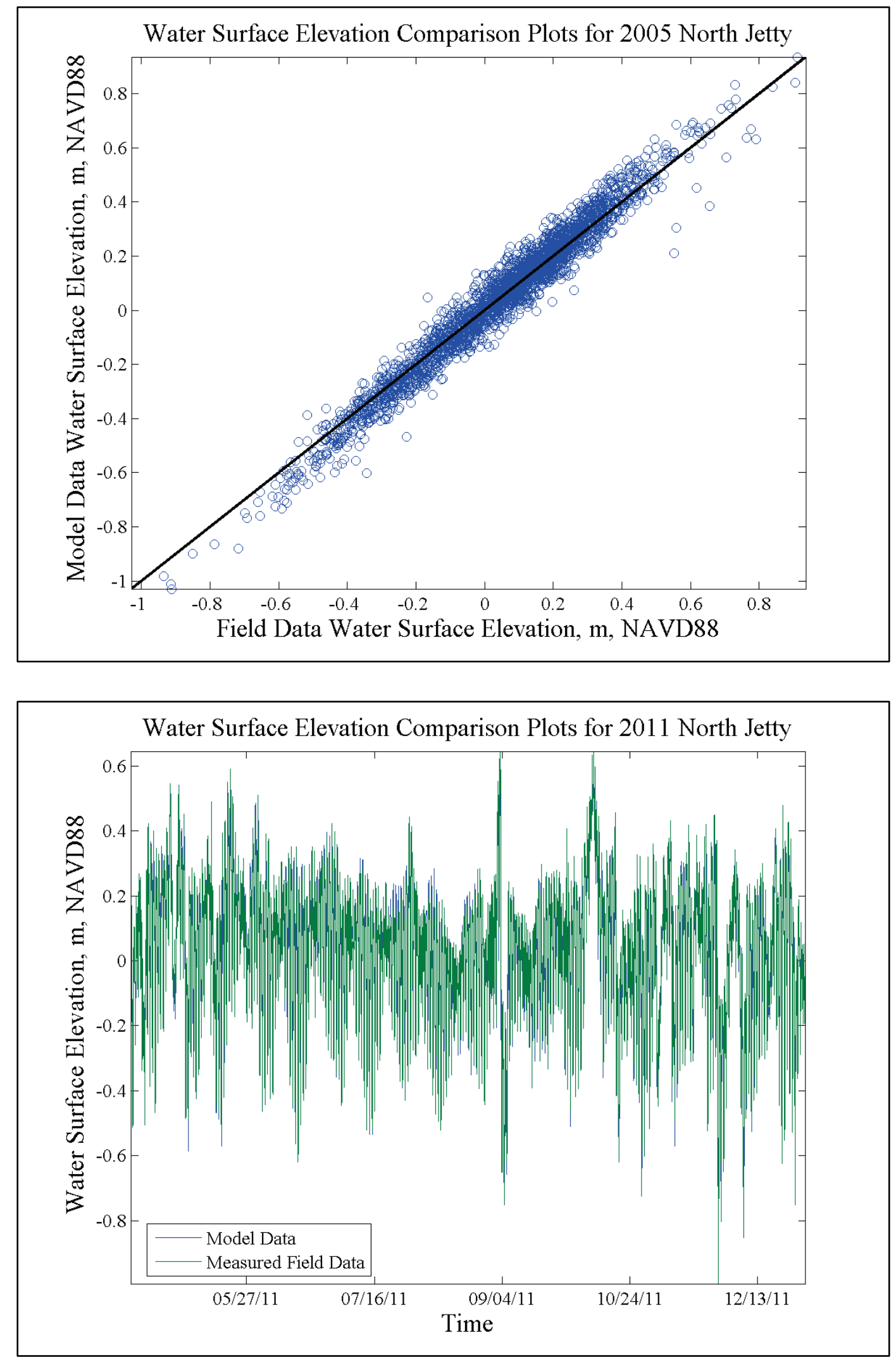

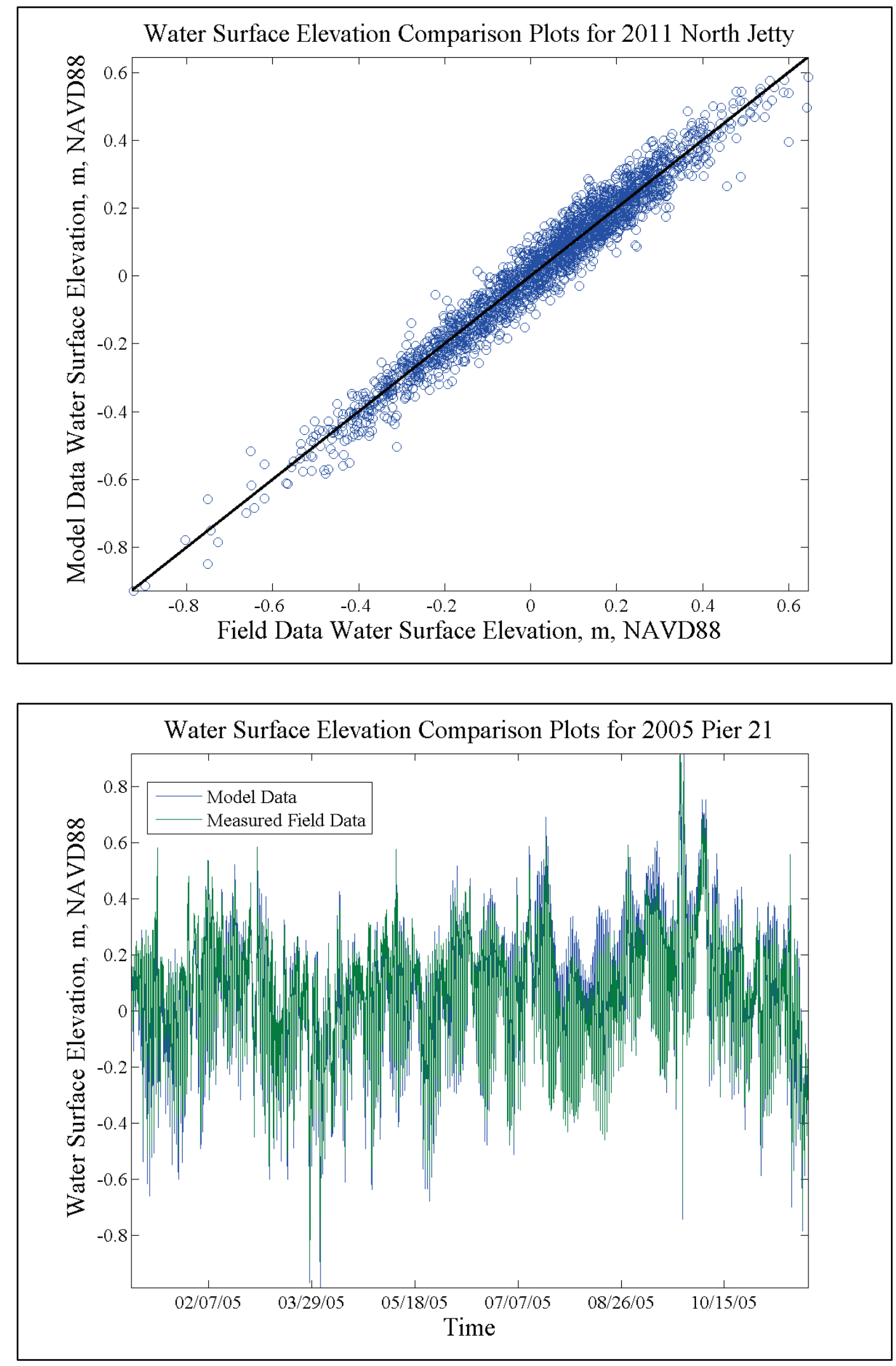

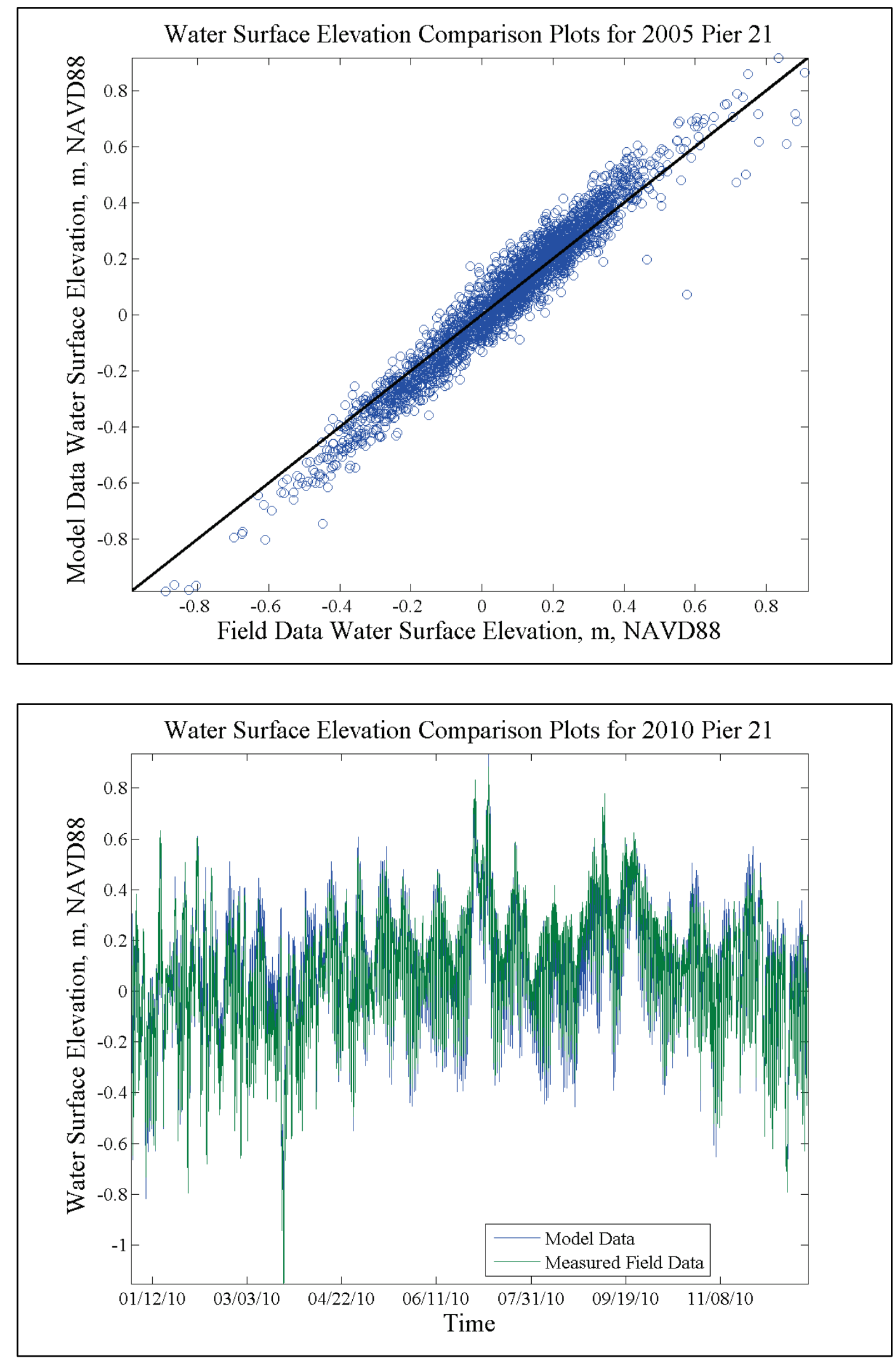

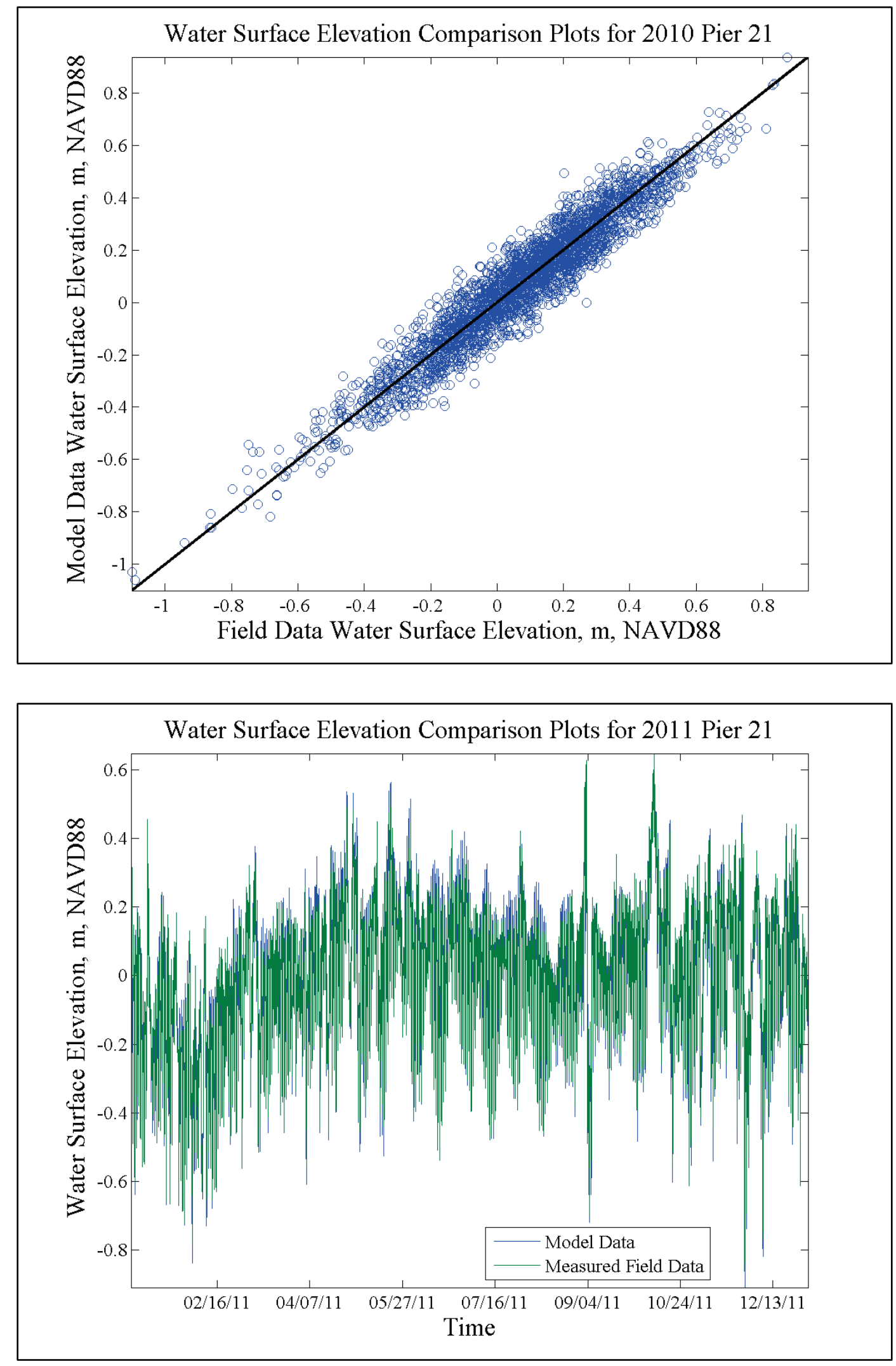

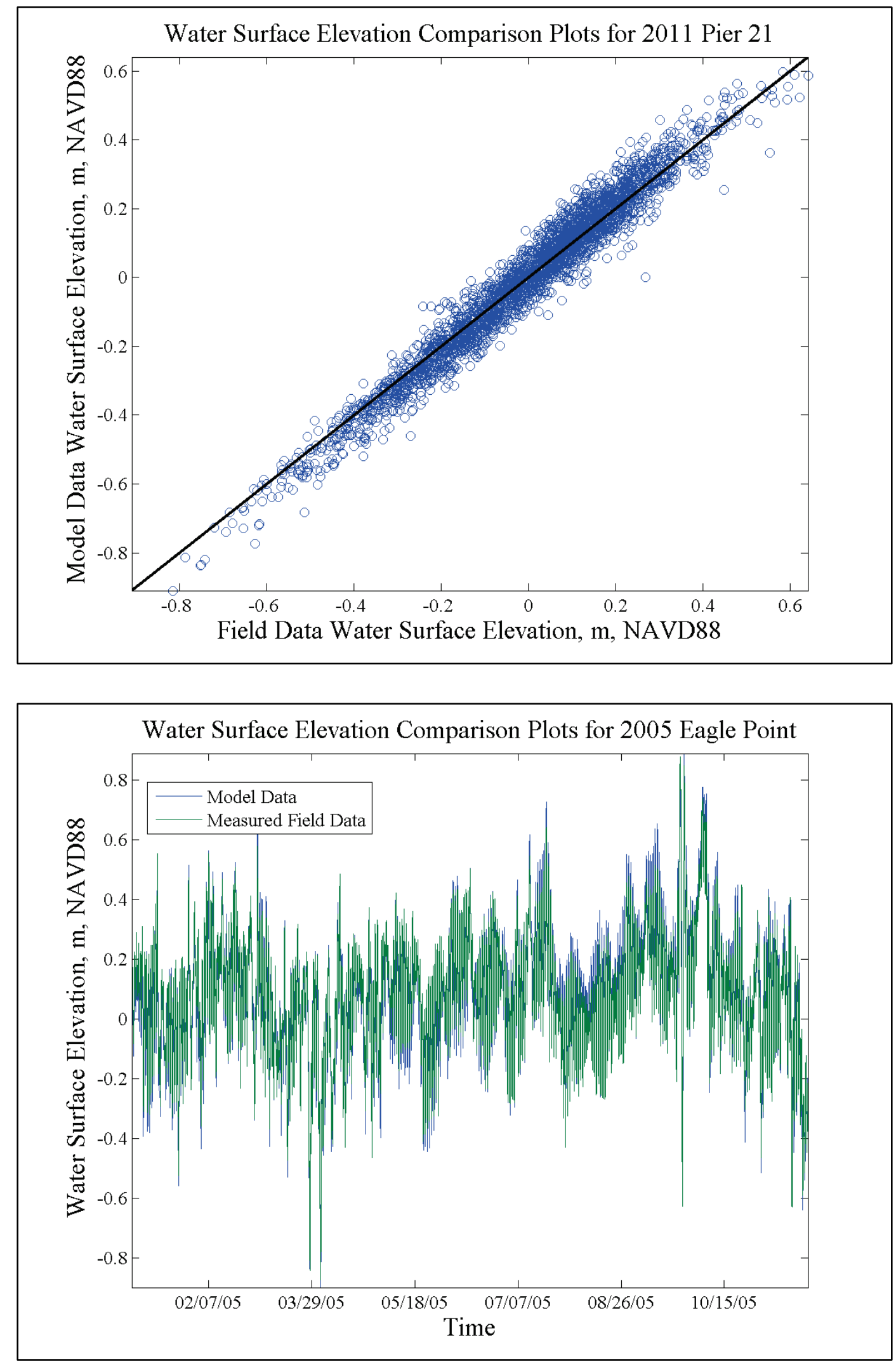

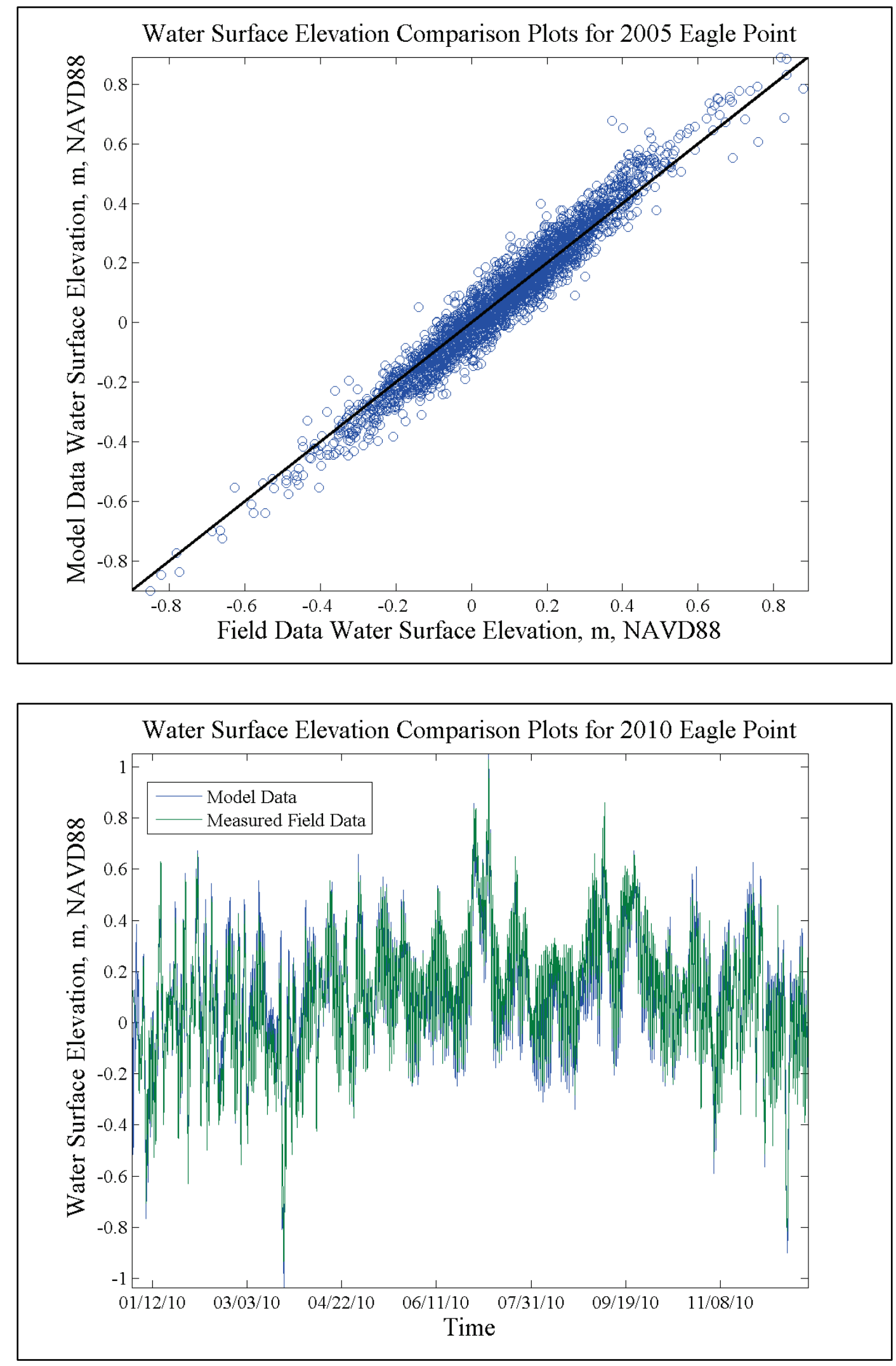

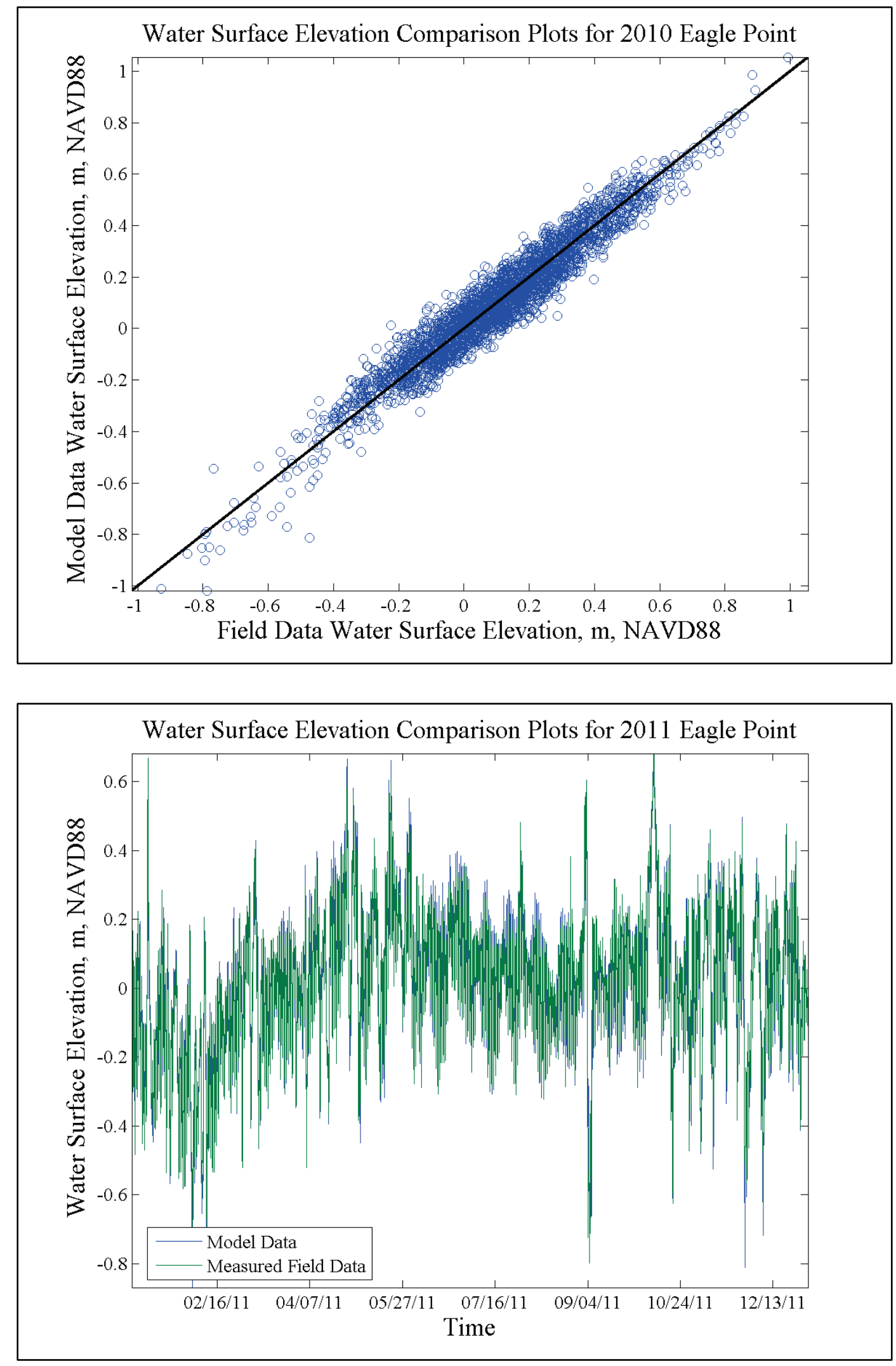

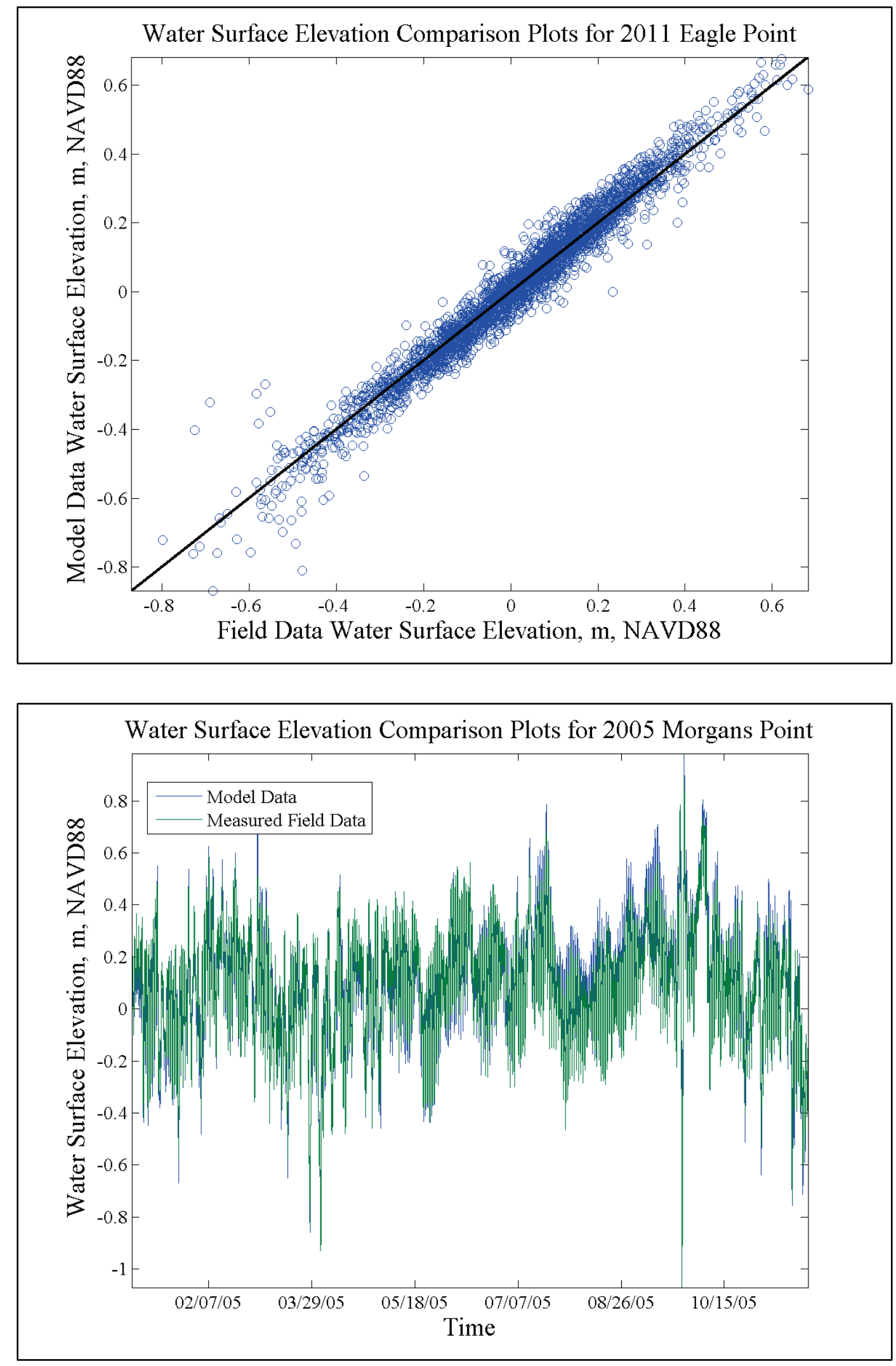

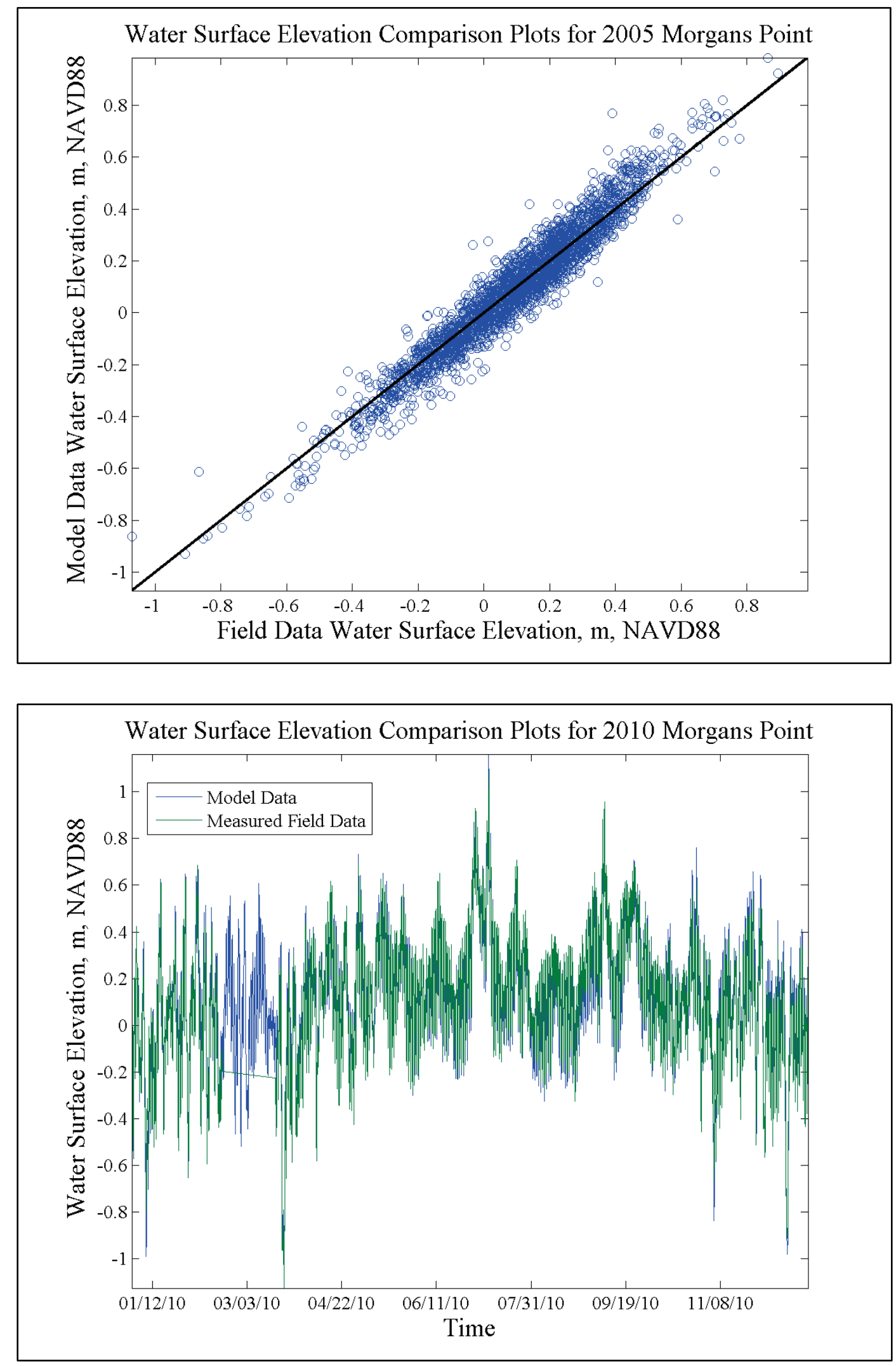

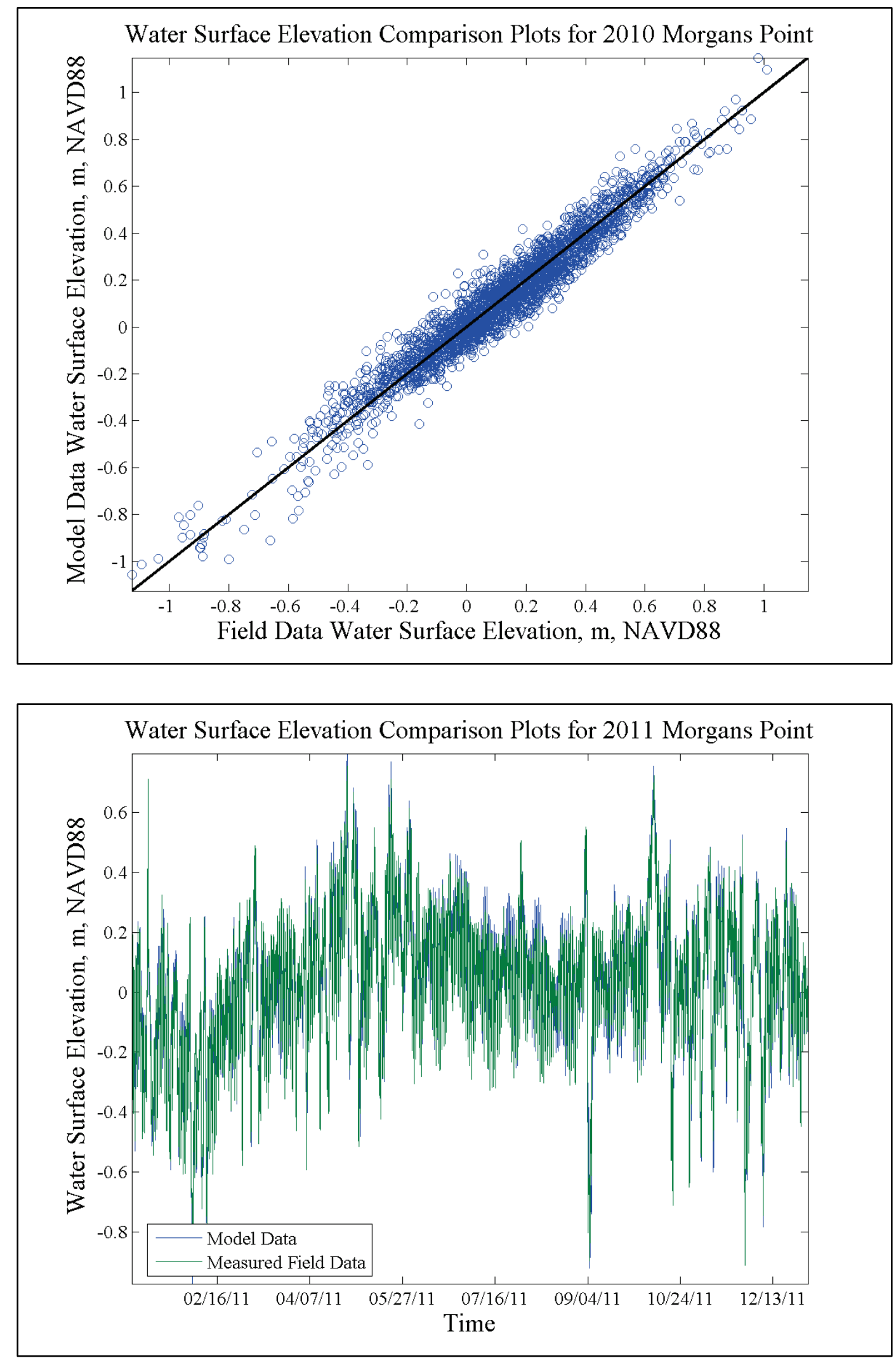

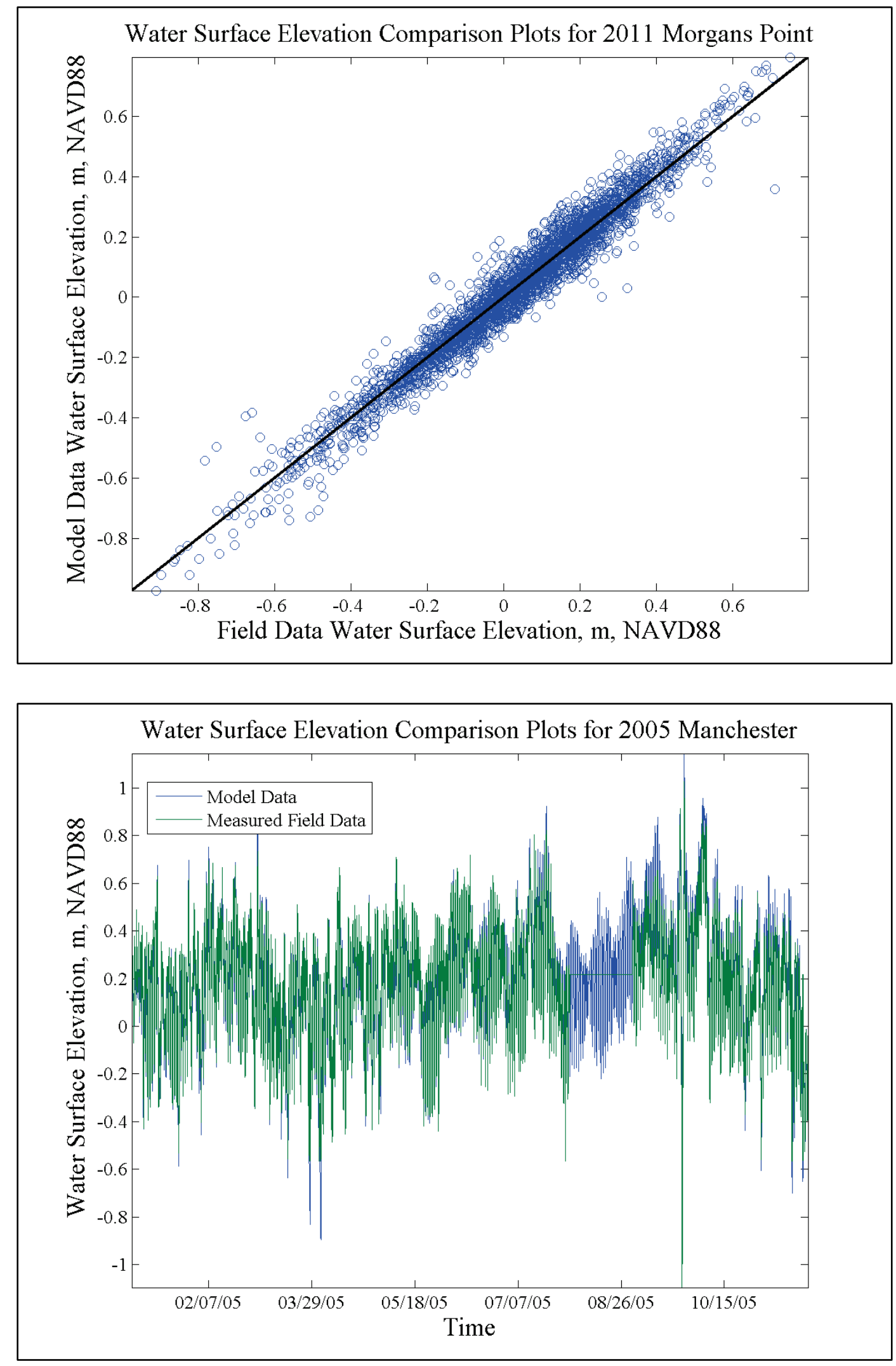

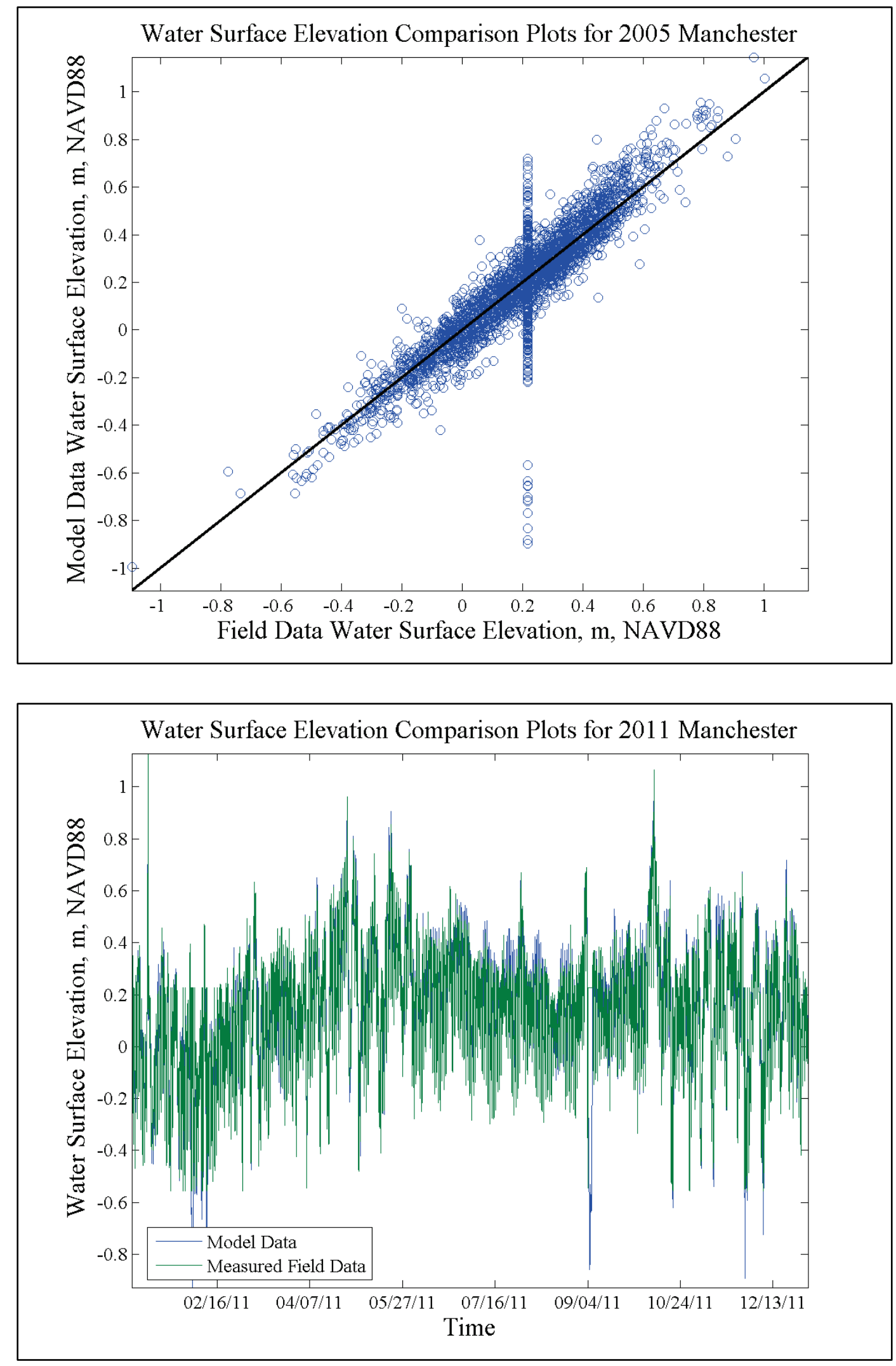


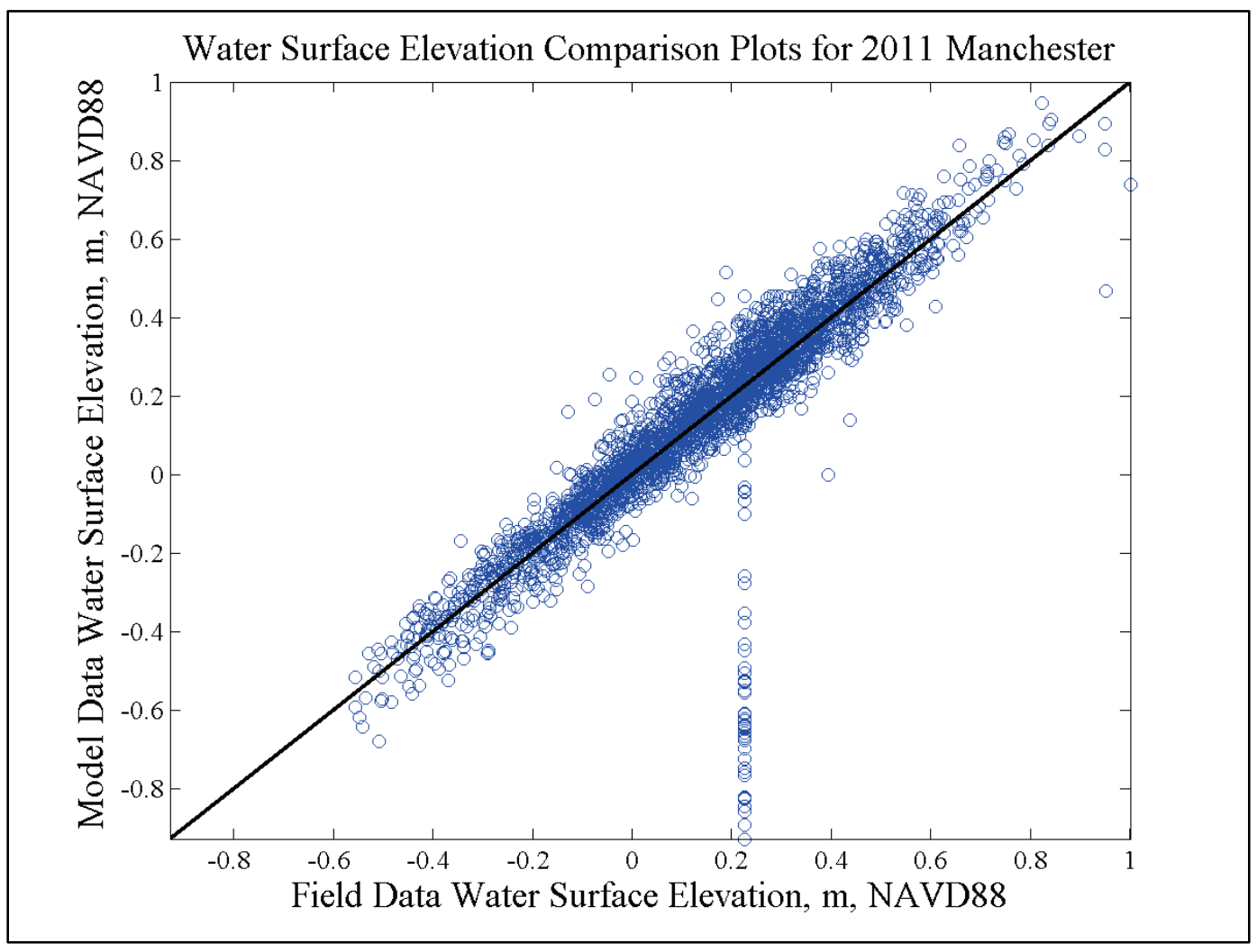




\section{Appendix B: Salinity Comparisons}

The following plots include all of the model/field comparisons for the available field data during the 3 calibration/validation years -2005 , 2010, and 2011. Data are not available for all 3 years at all sites. Figure 33 through Figure 35 and Figure 59 through Figure 62 in the main text show the locations of all salinity comparison sites. The blue stars (where data are sparse) and smaller black dots (where data are numerous) represent the measured field data. These data are defined as near surface for several of the sites, but many others do not define the vertical location of the samples. The model-computed surface salinity is given by the blue line, and the model-computed bottom salinity by the red line. In deep, stratified regions, the bottom salinity is larger than the surface salinity. In well-mixed regions, the two should be approximately equal.

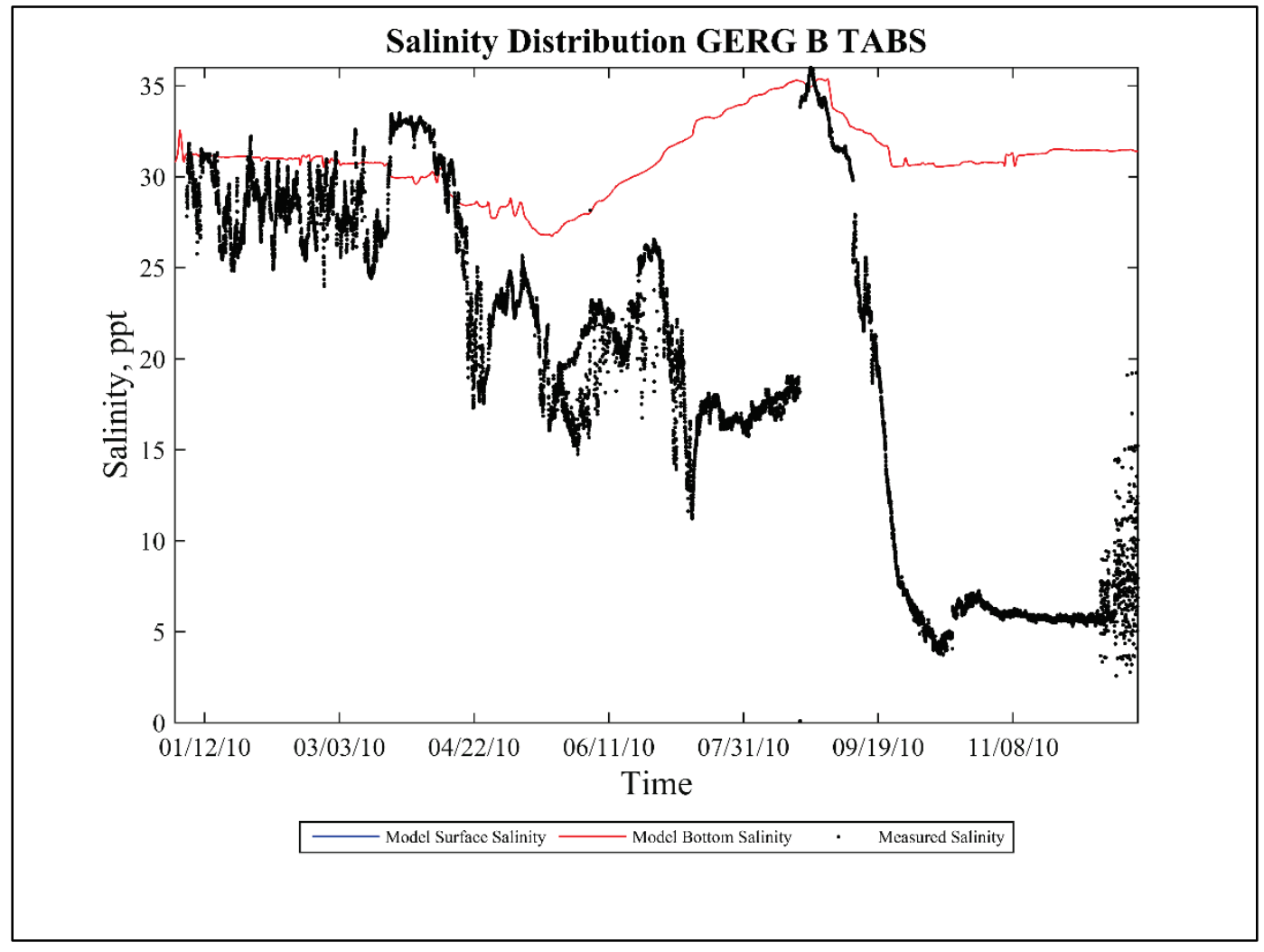



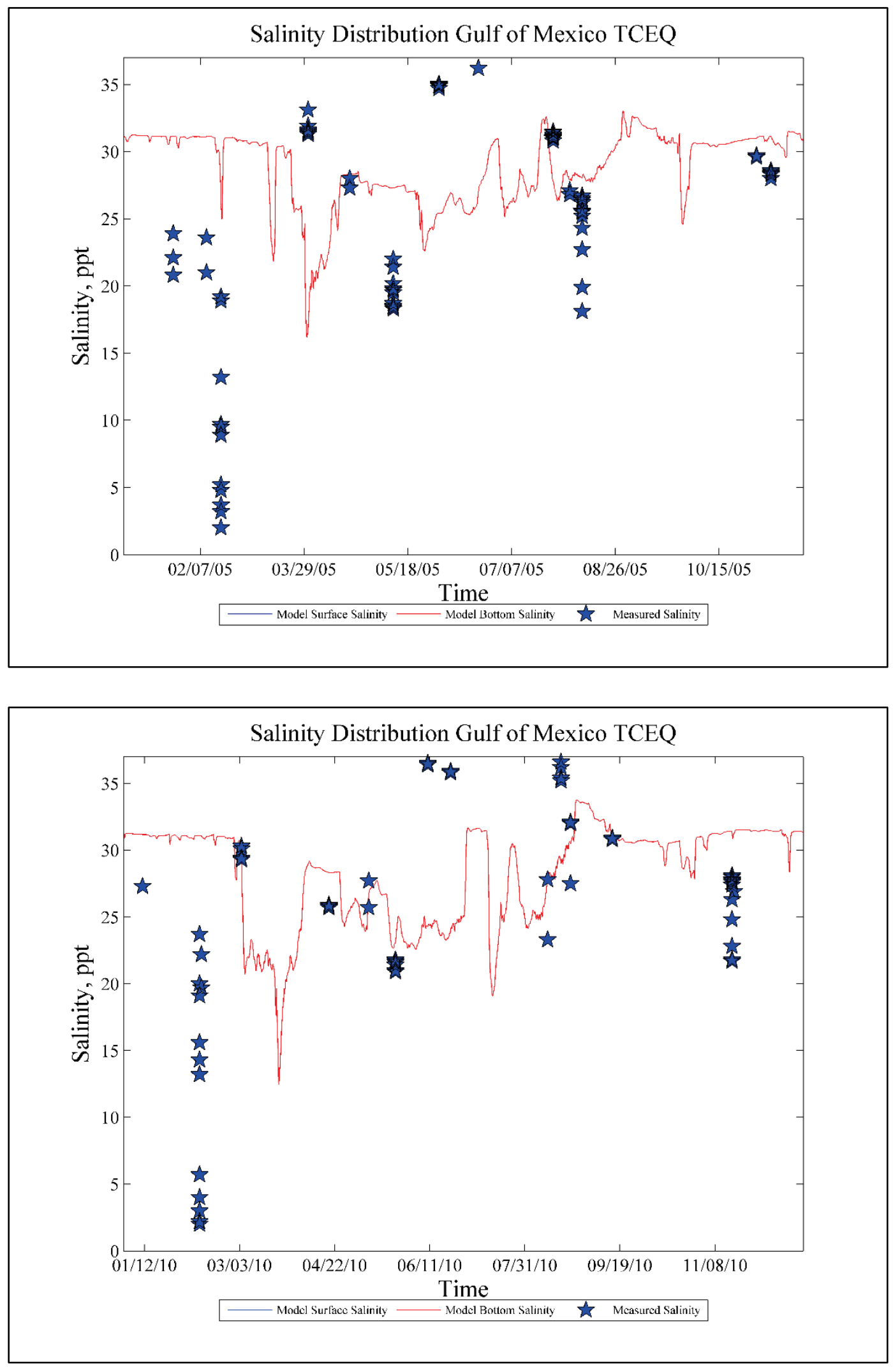

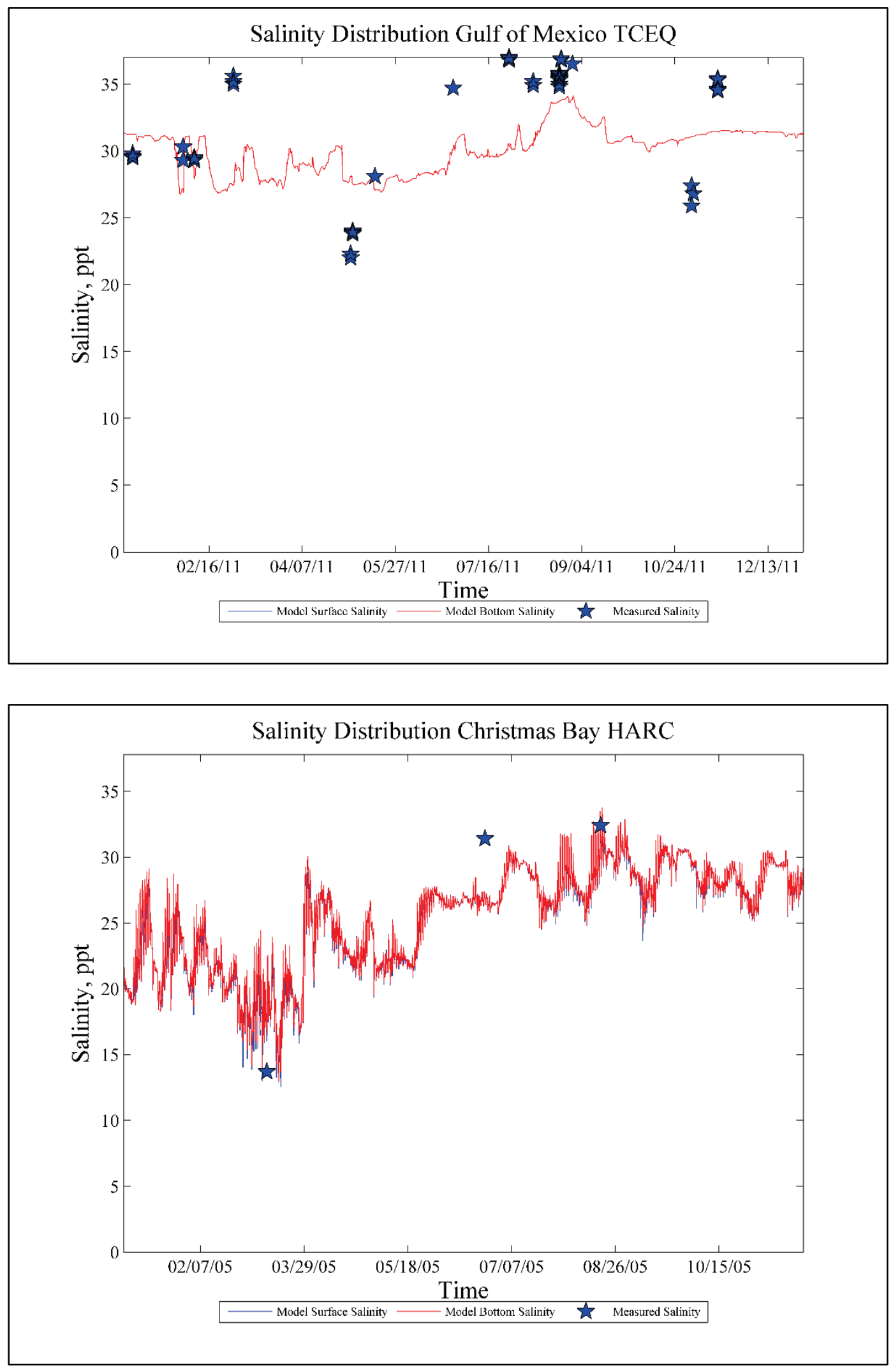

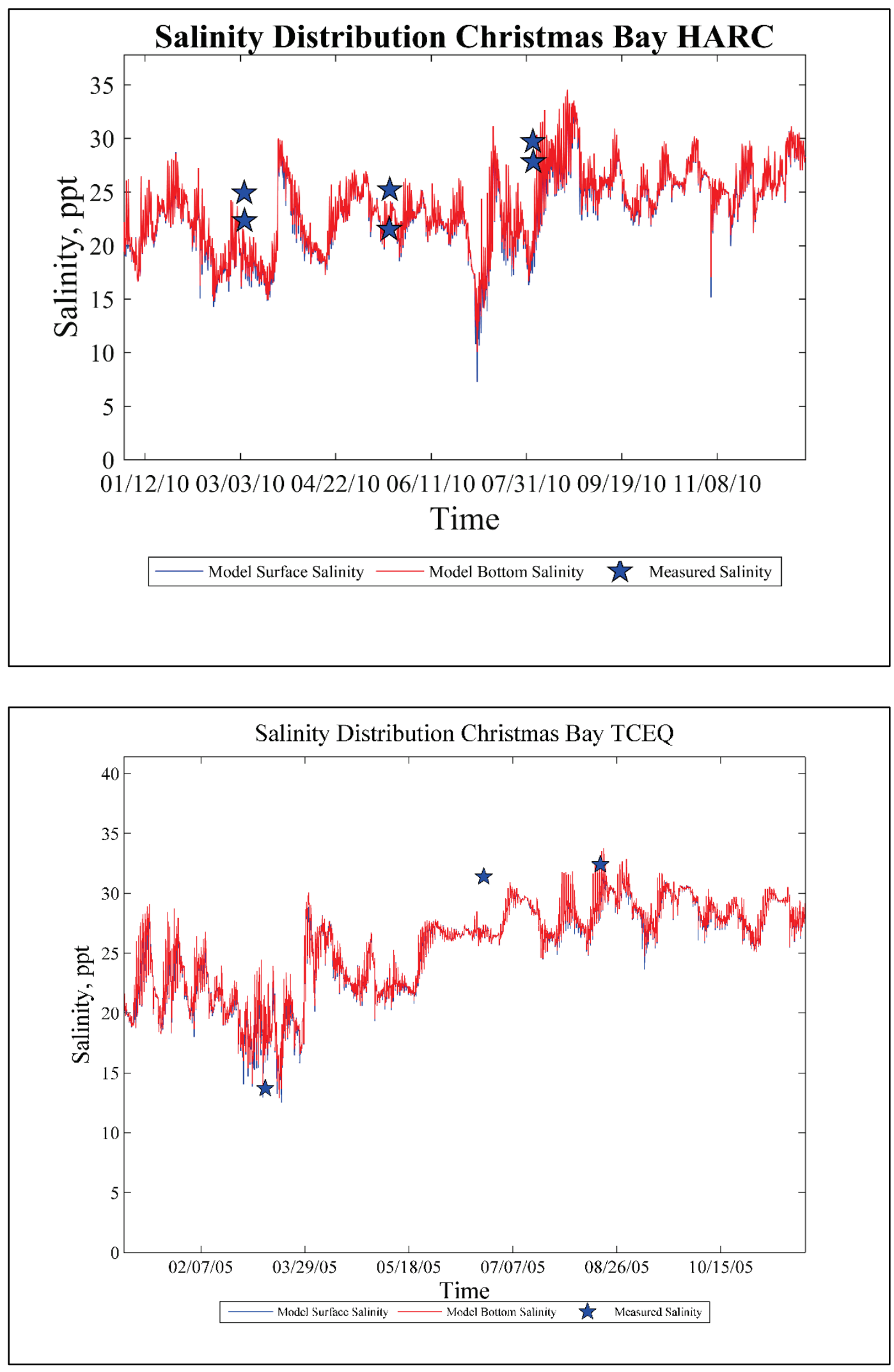

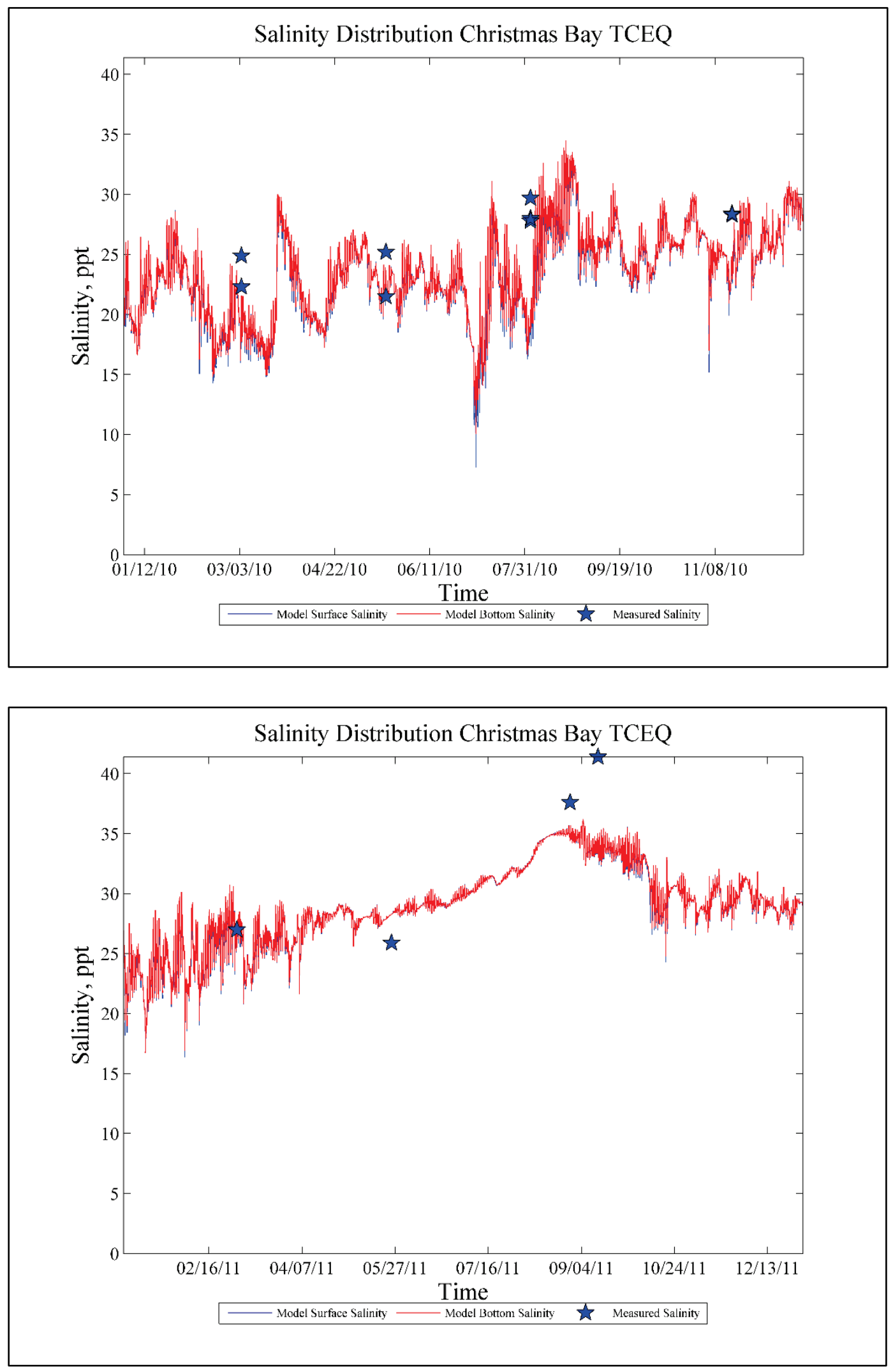

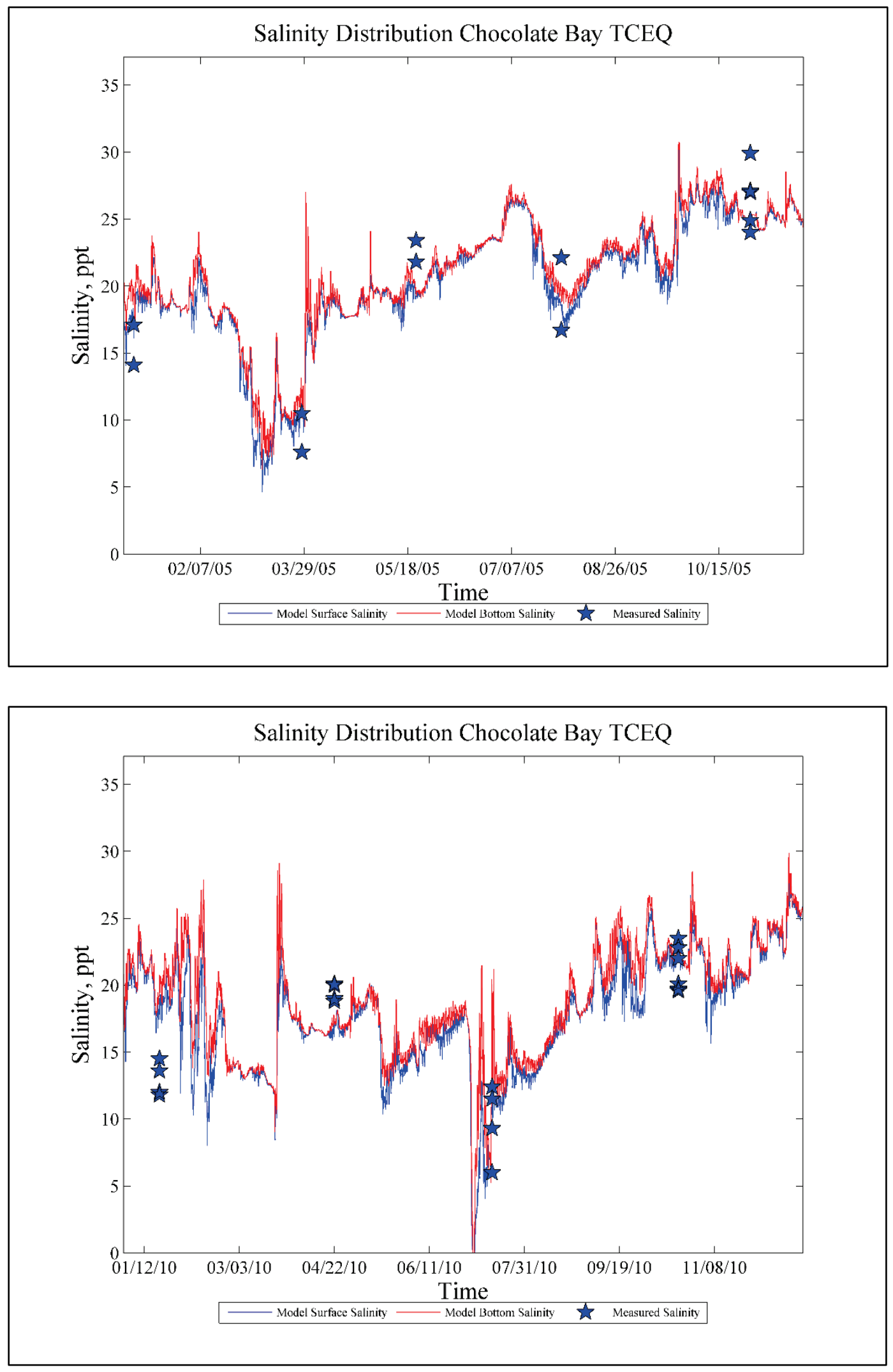

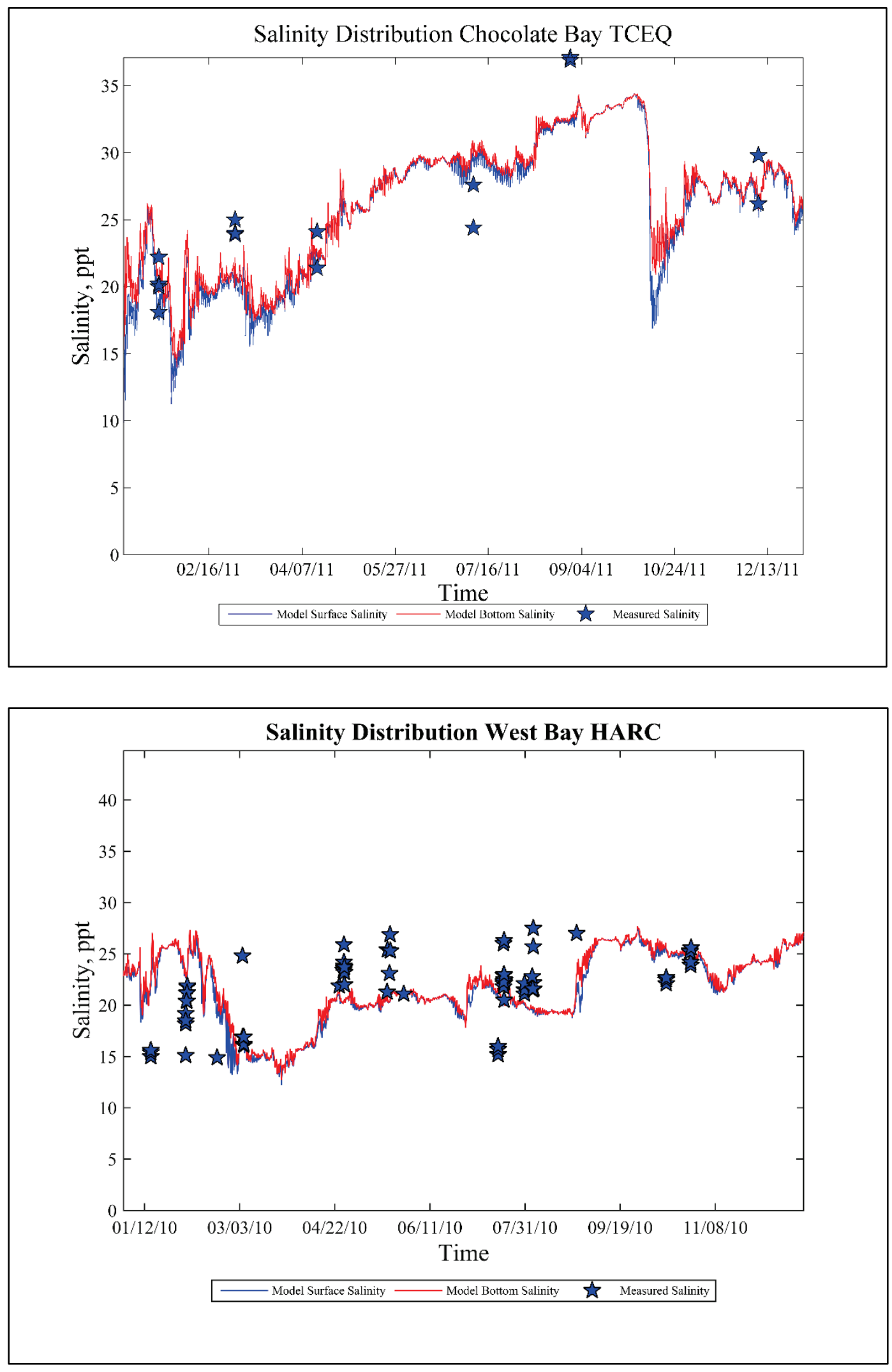

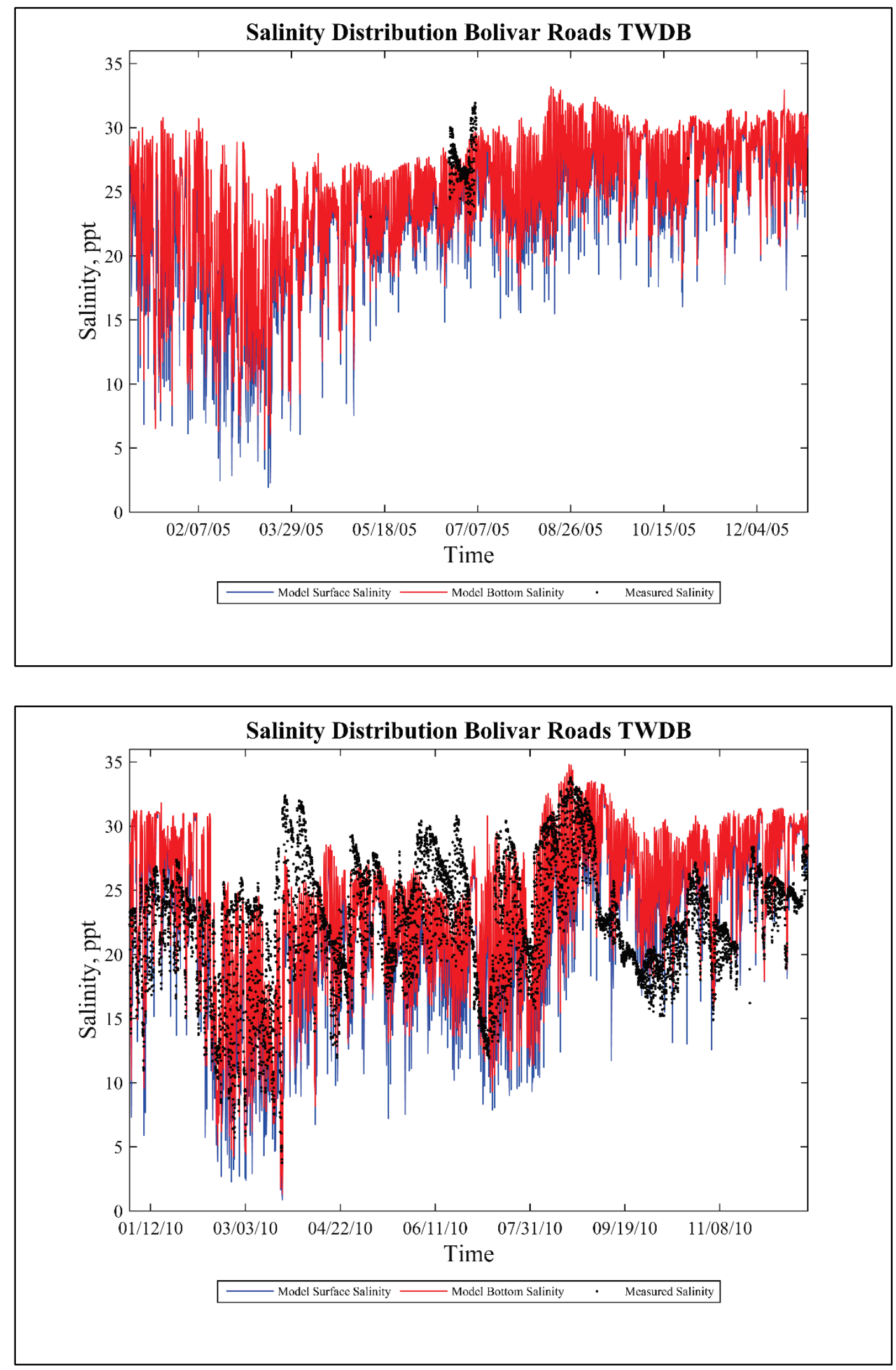

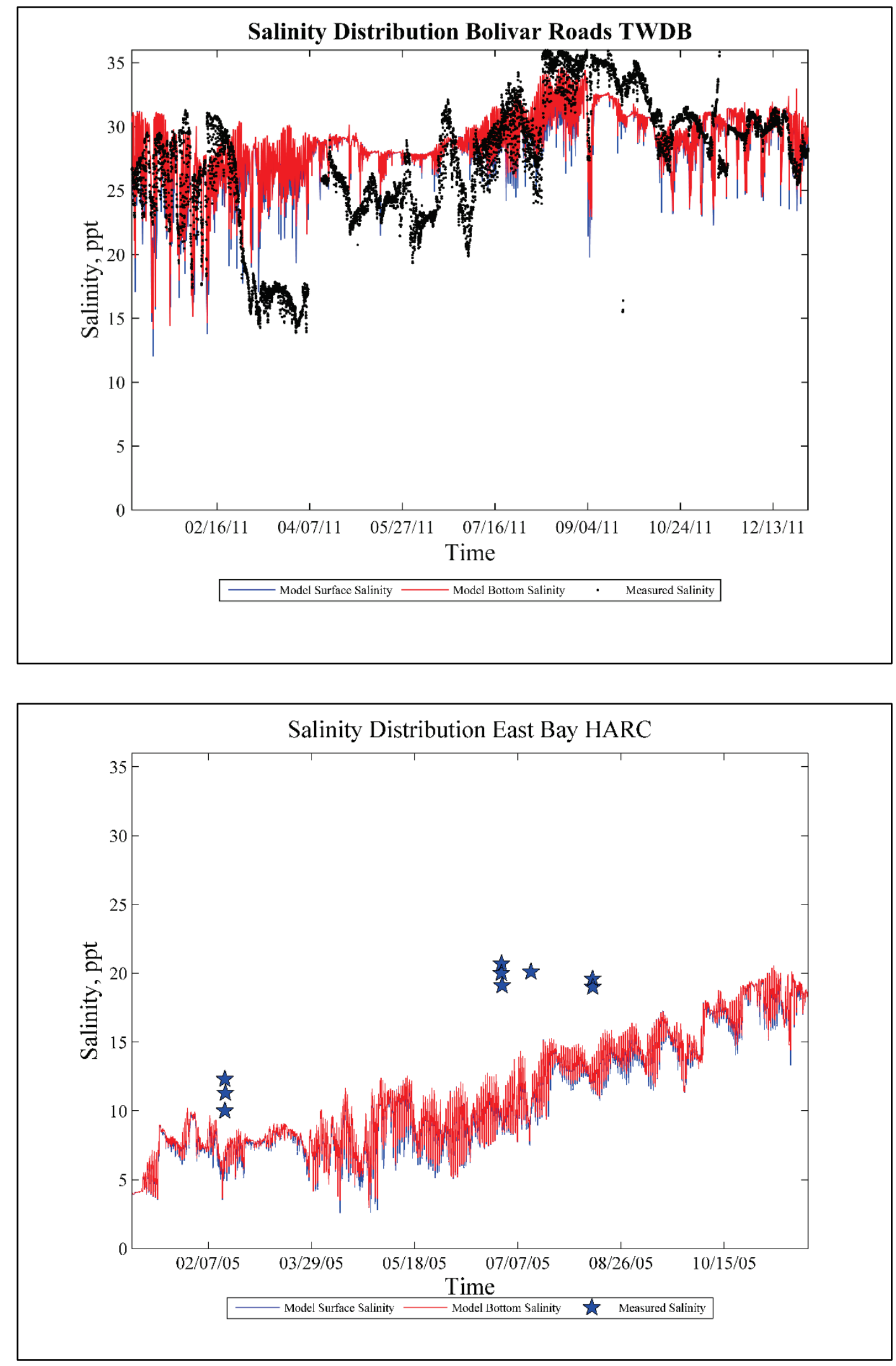

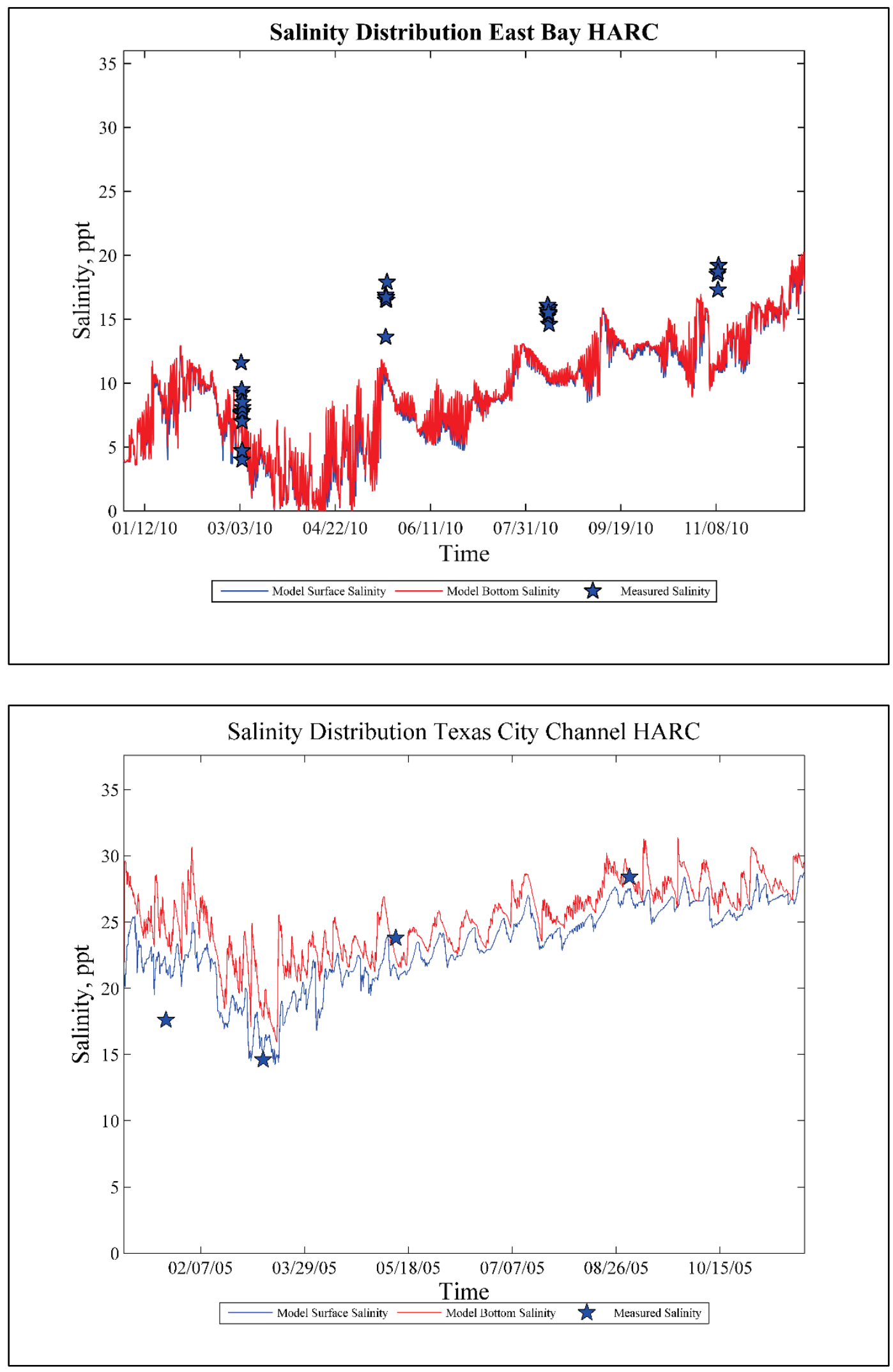

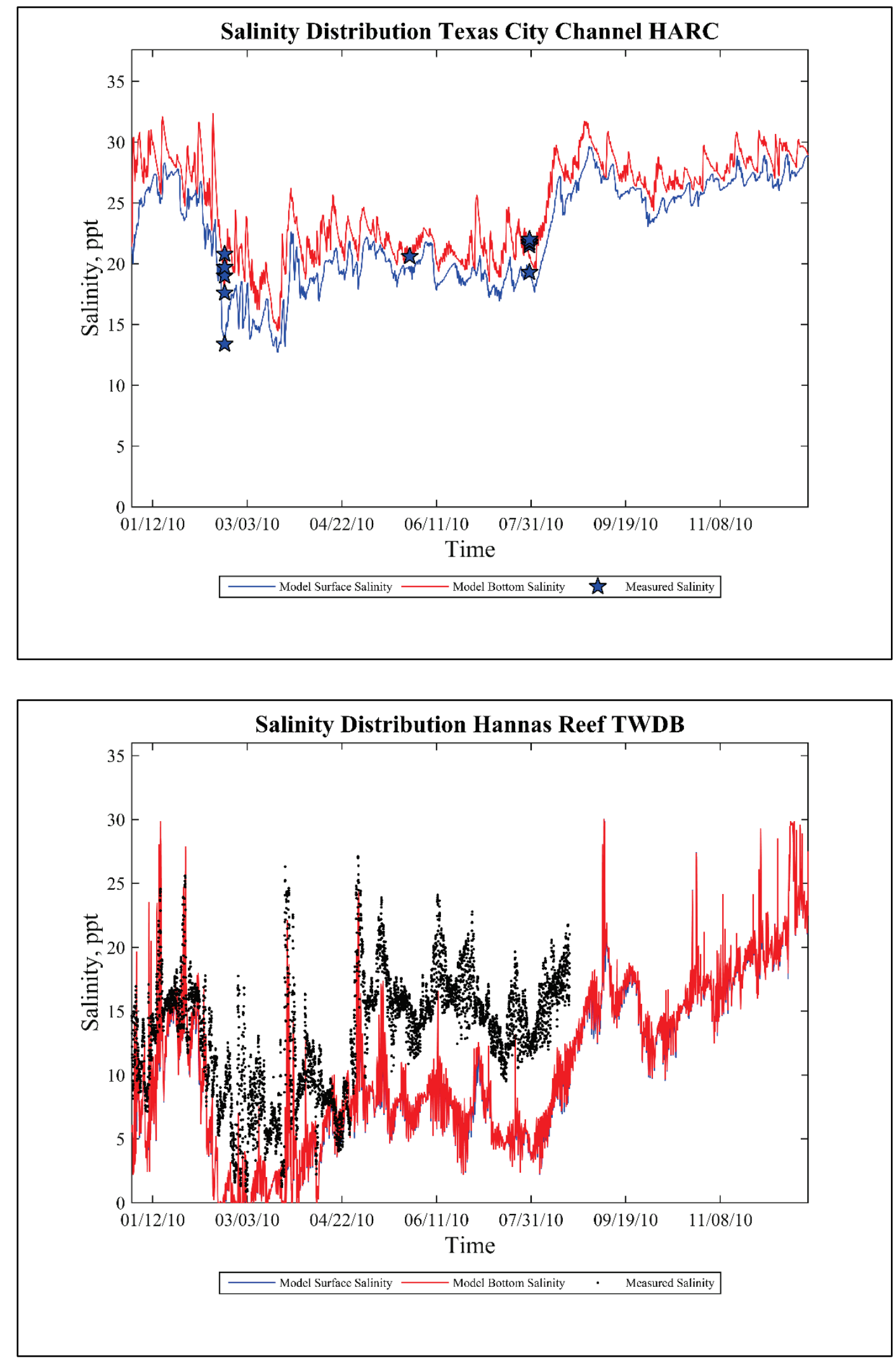

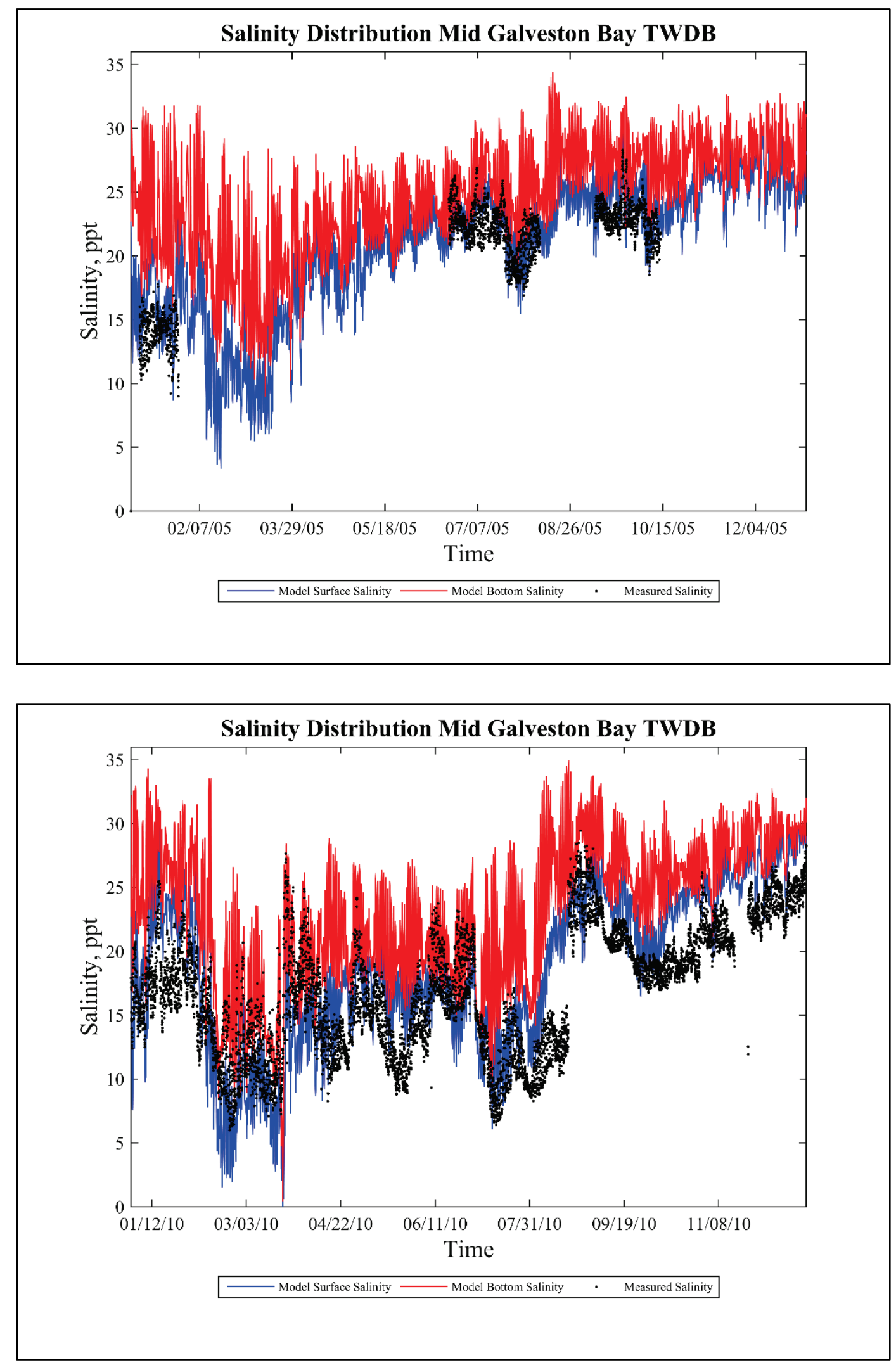

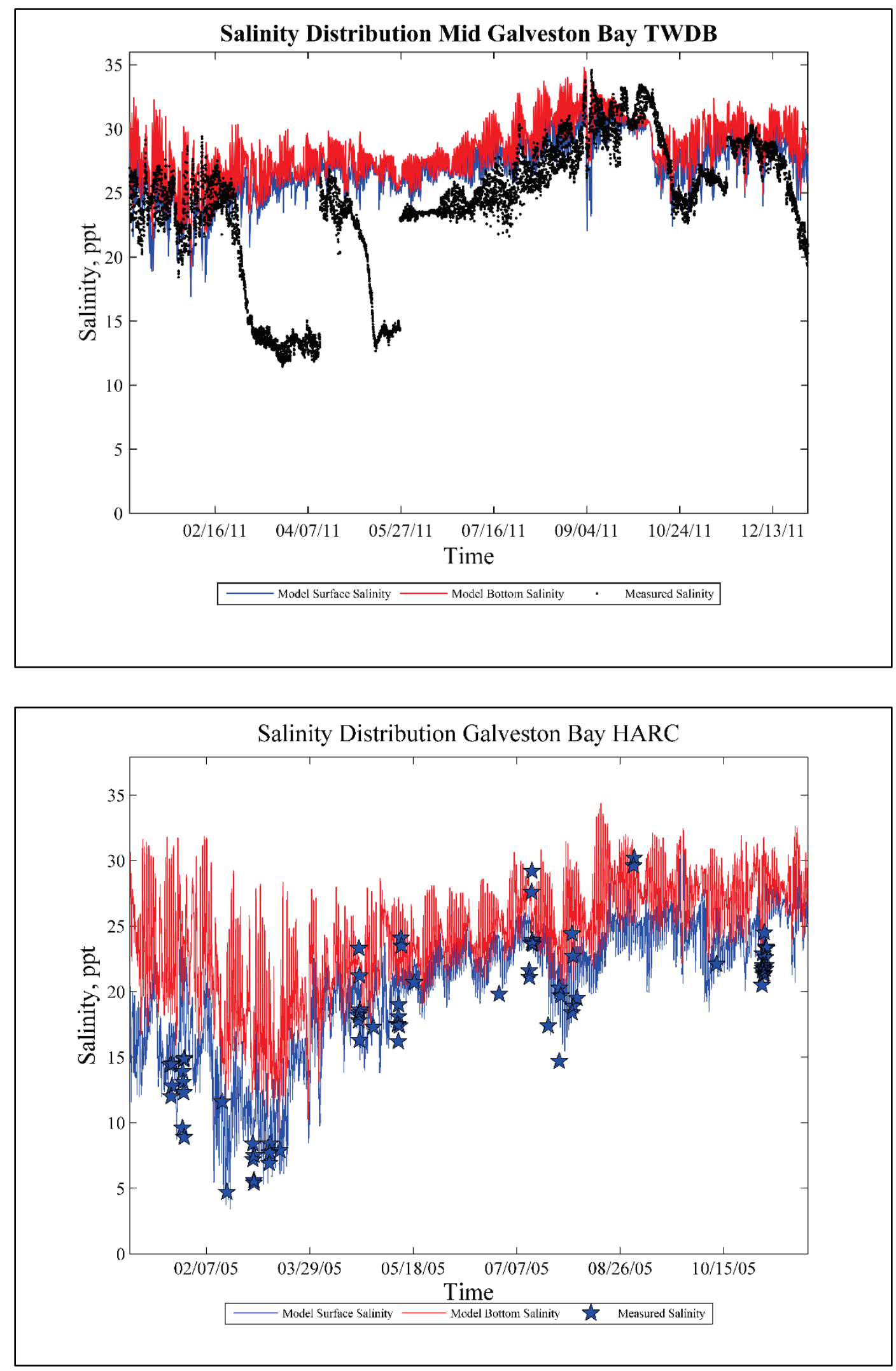


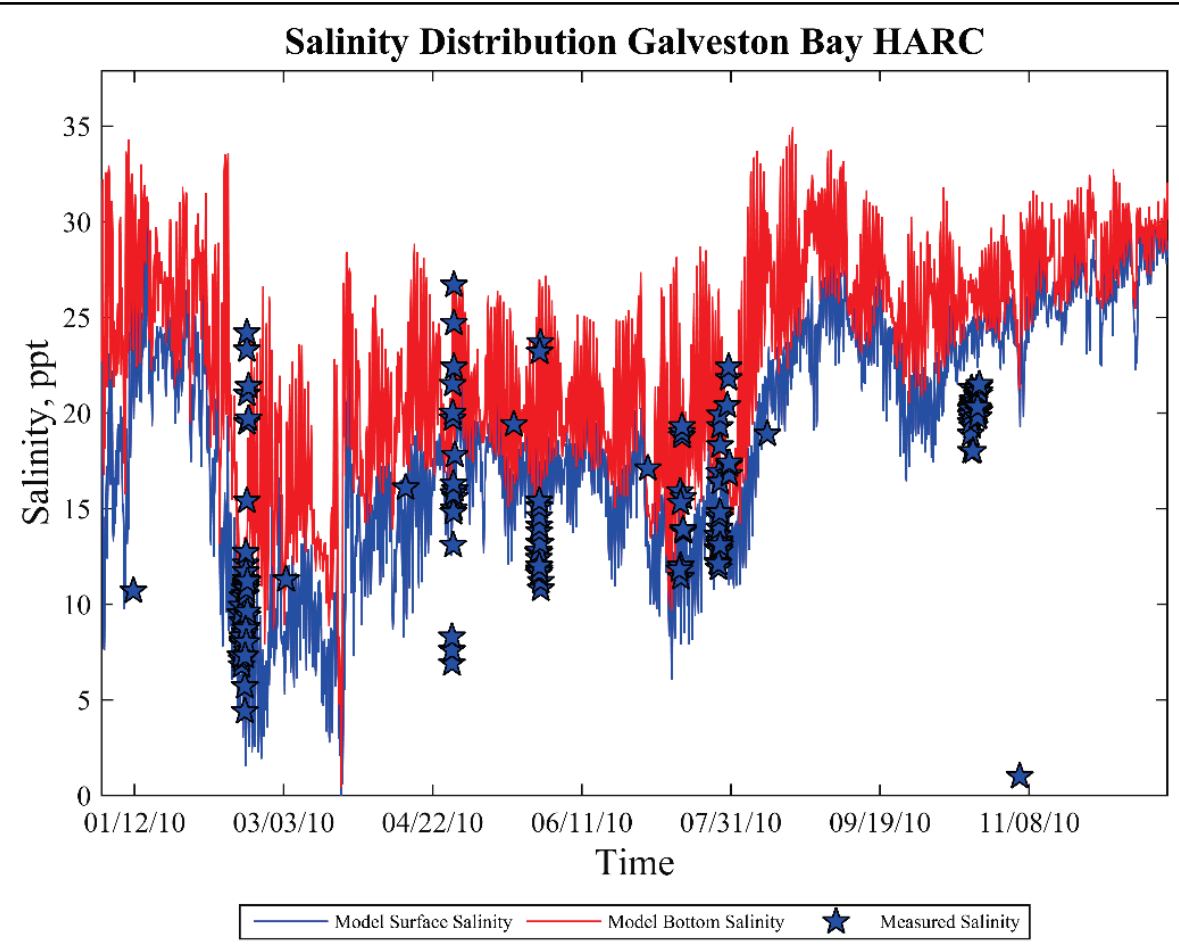

Salinity Distribution Clear Creek HARC

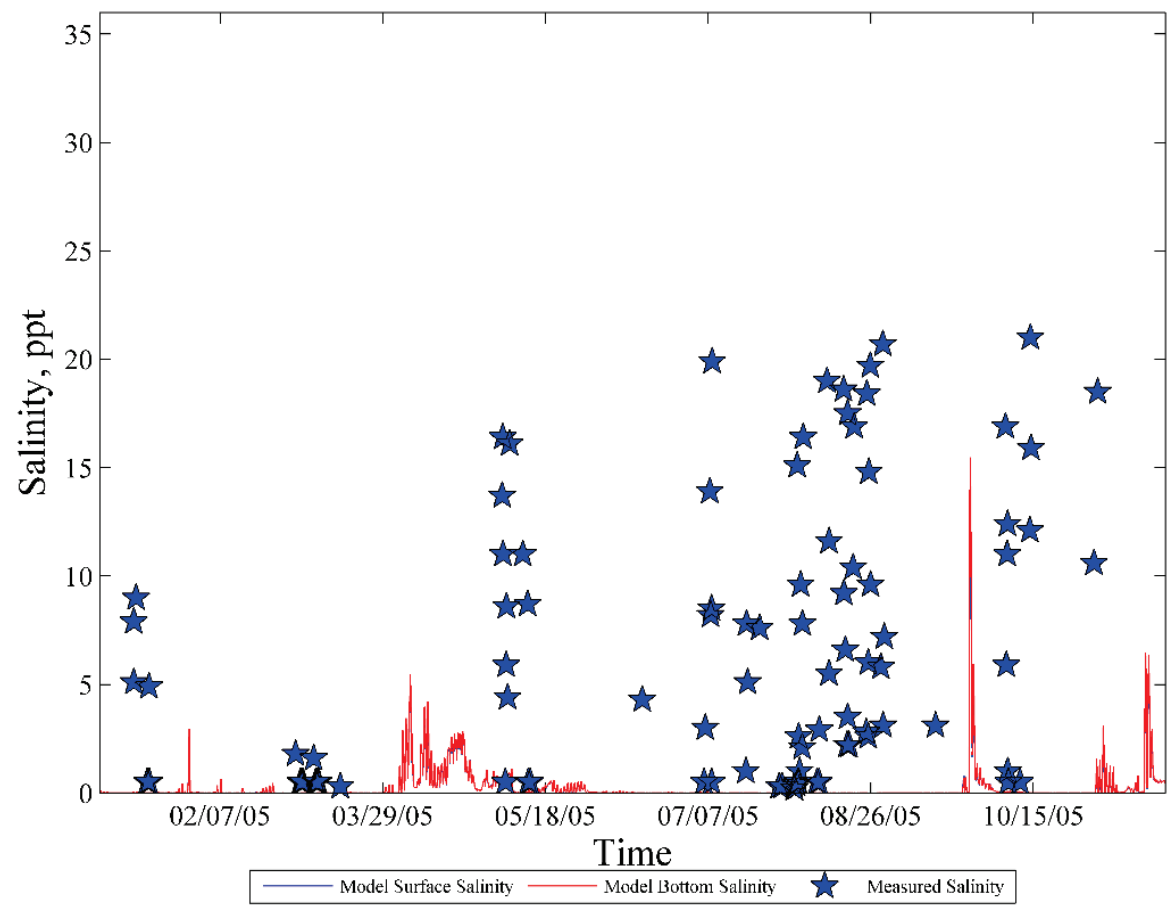



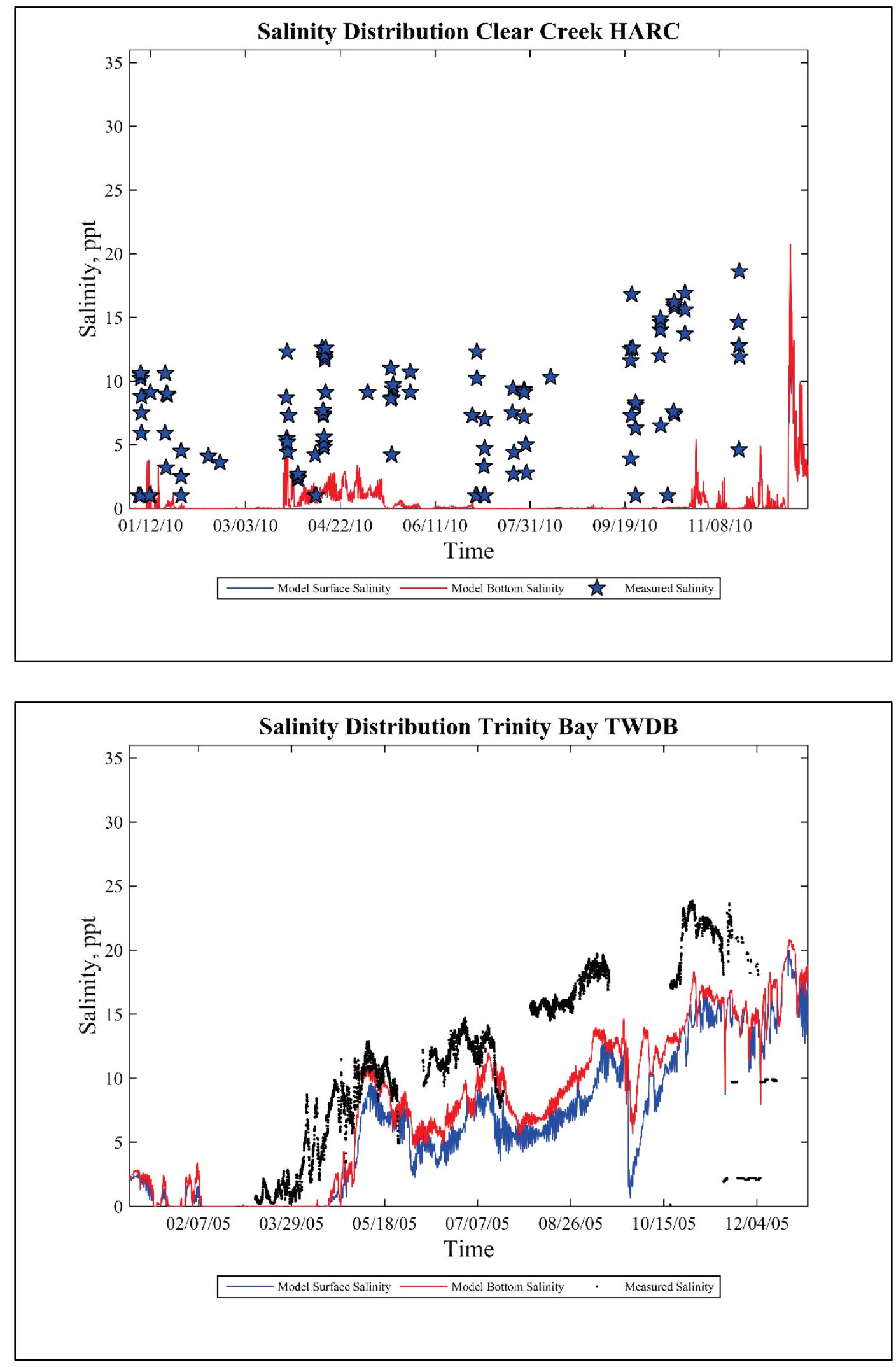

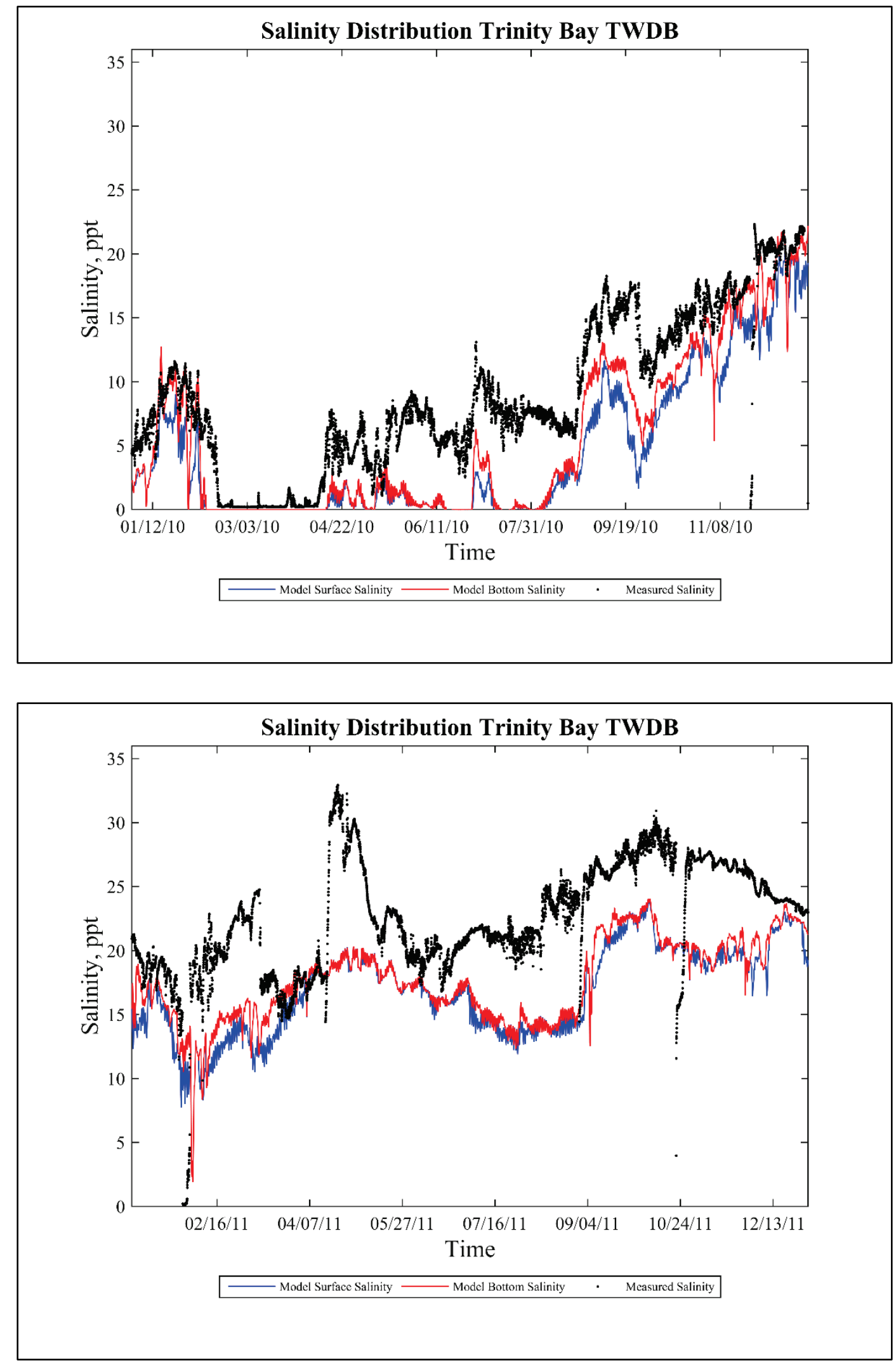

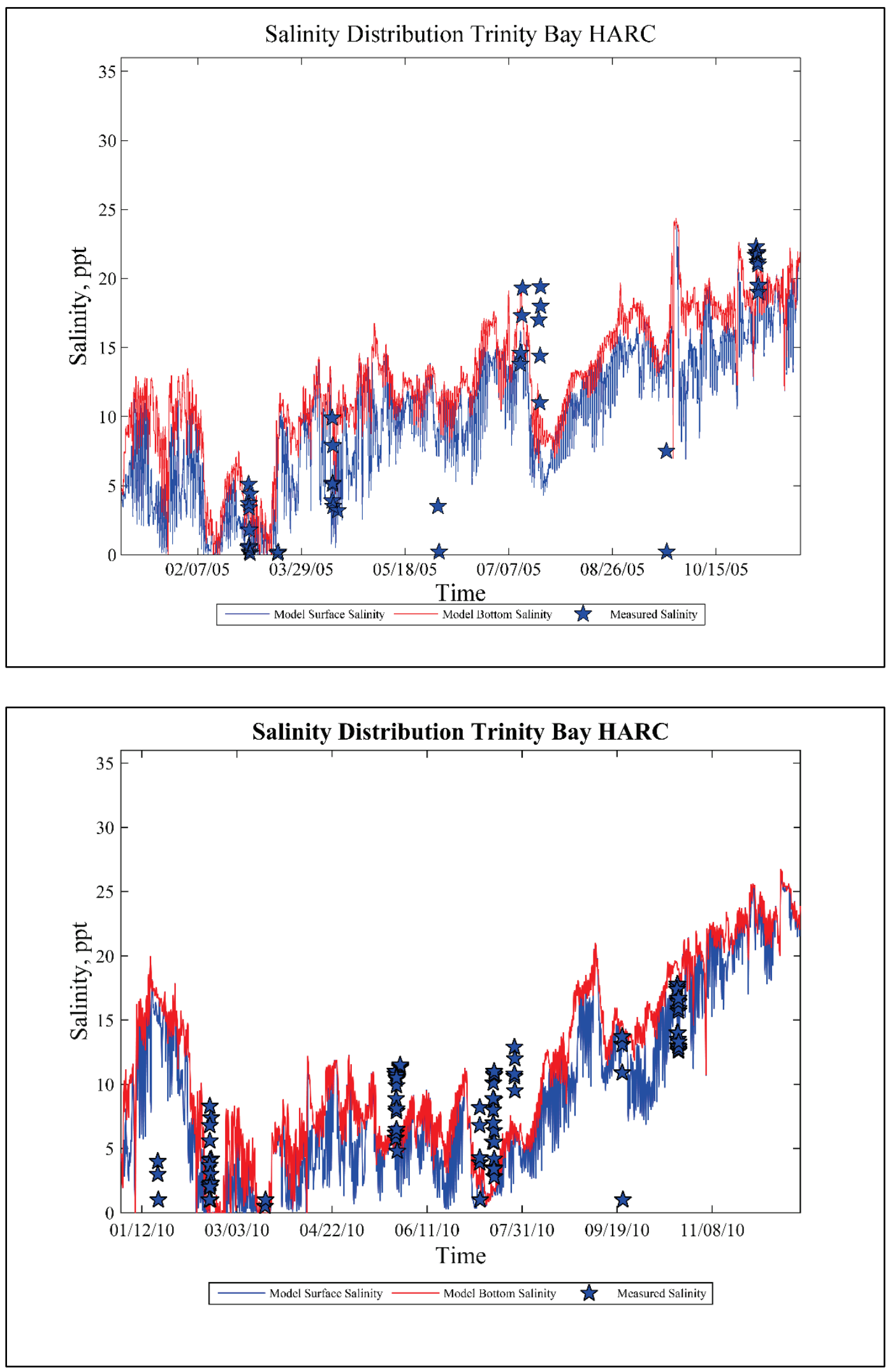

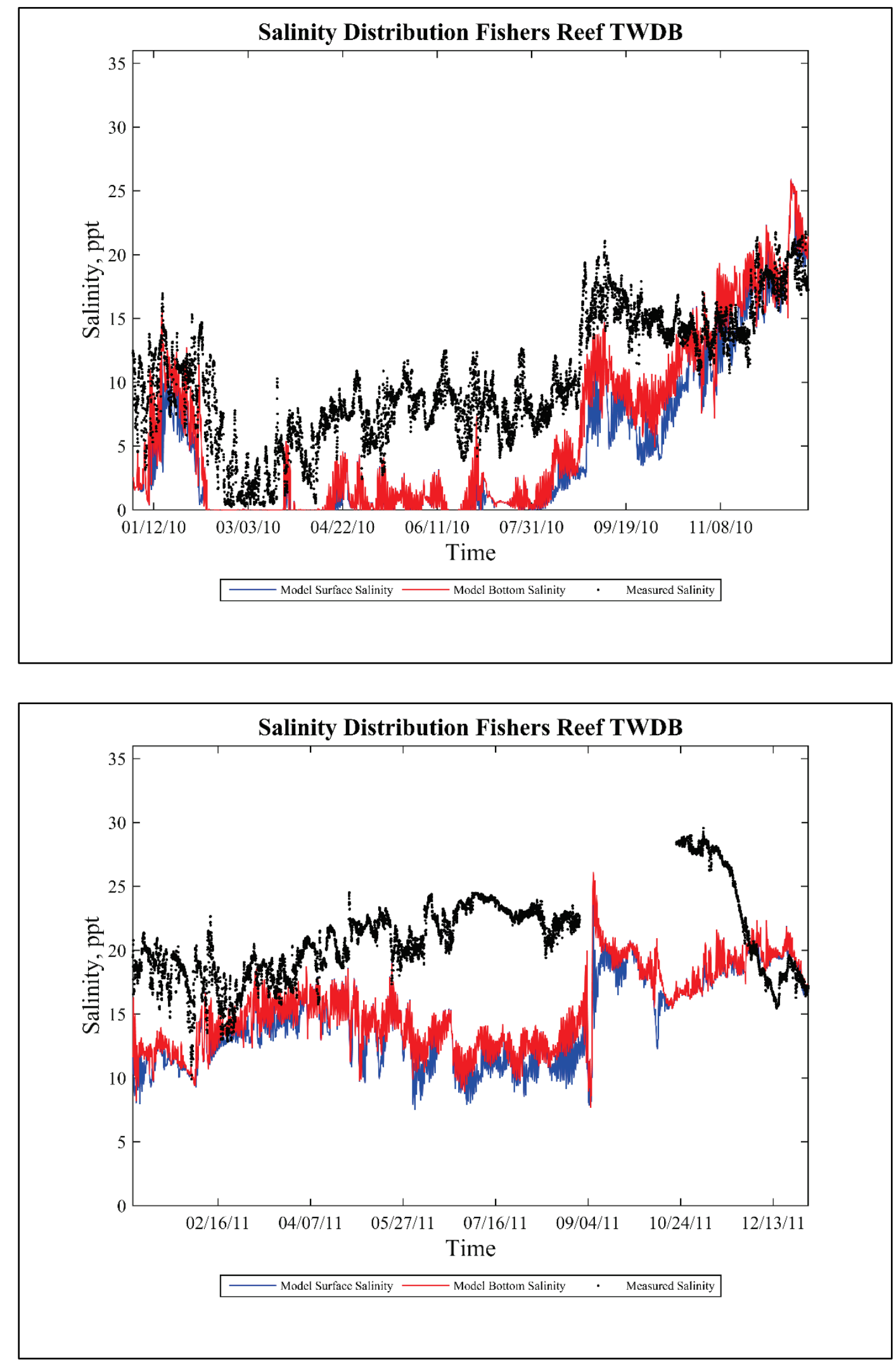

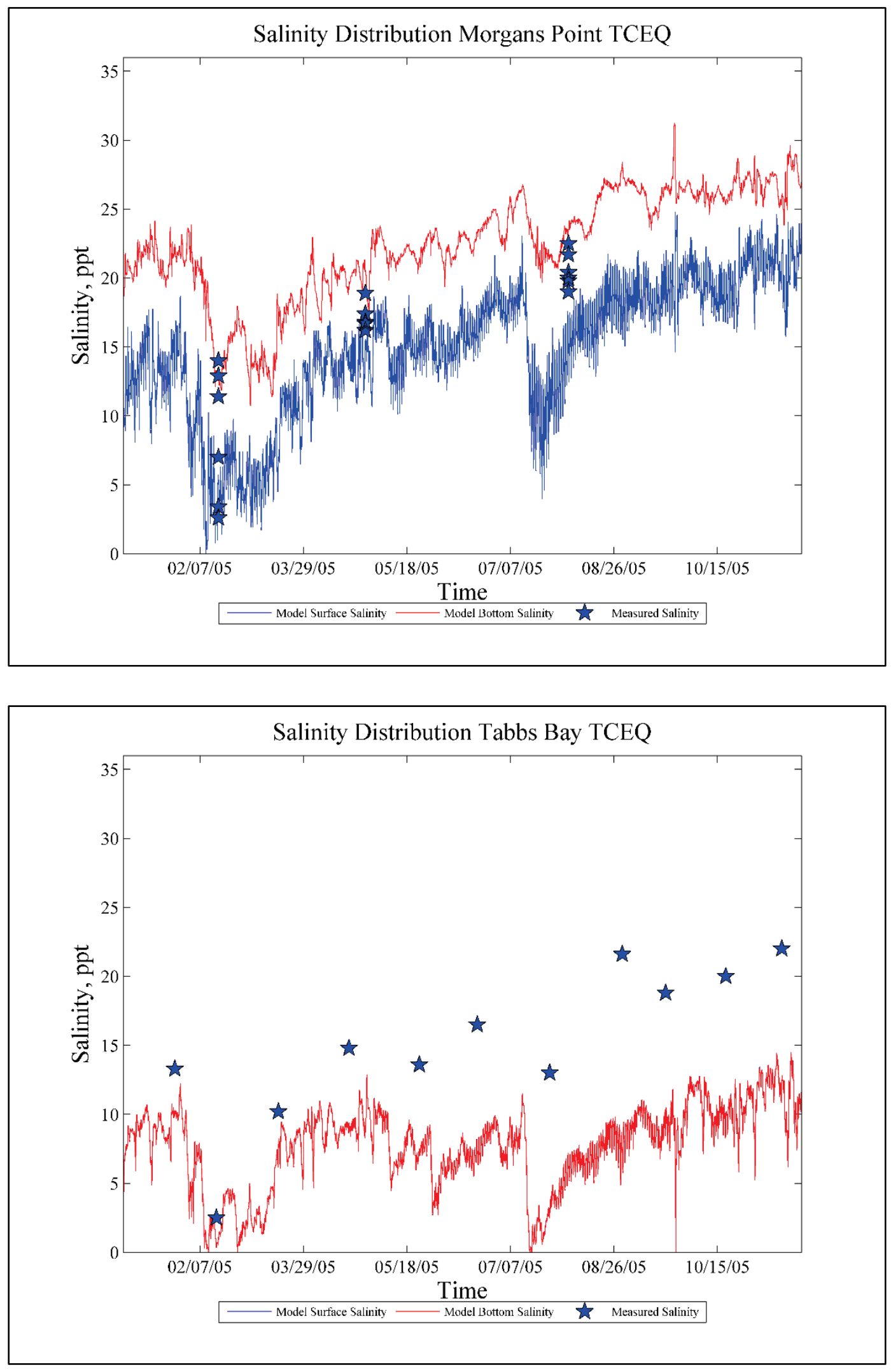

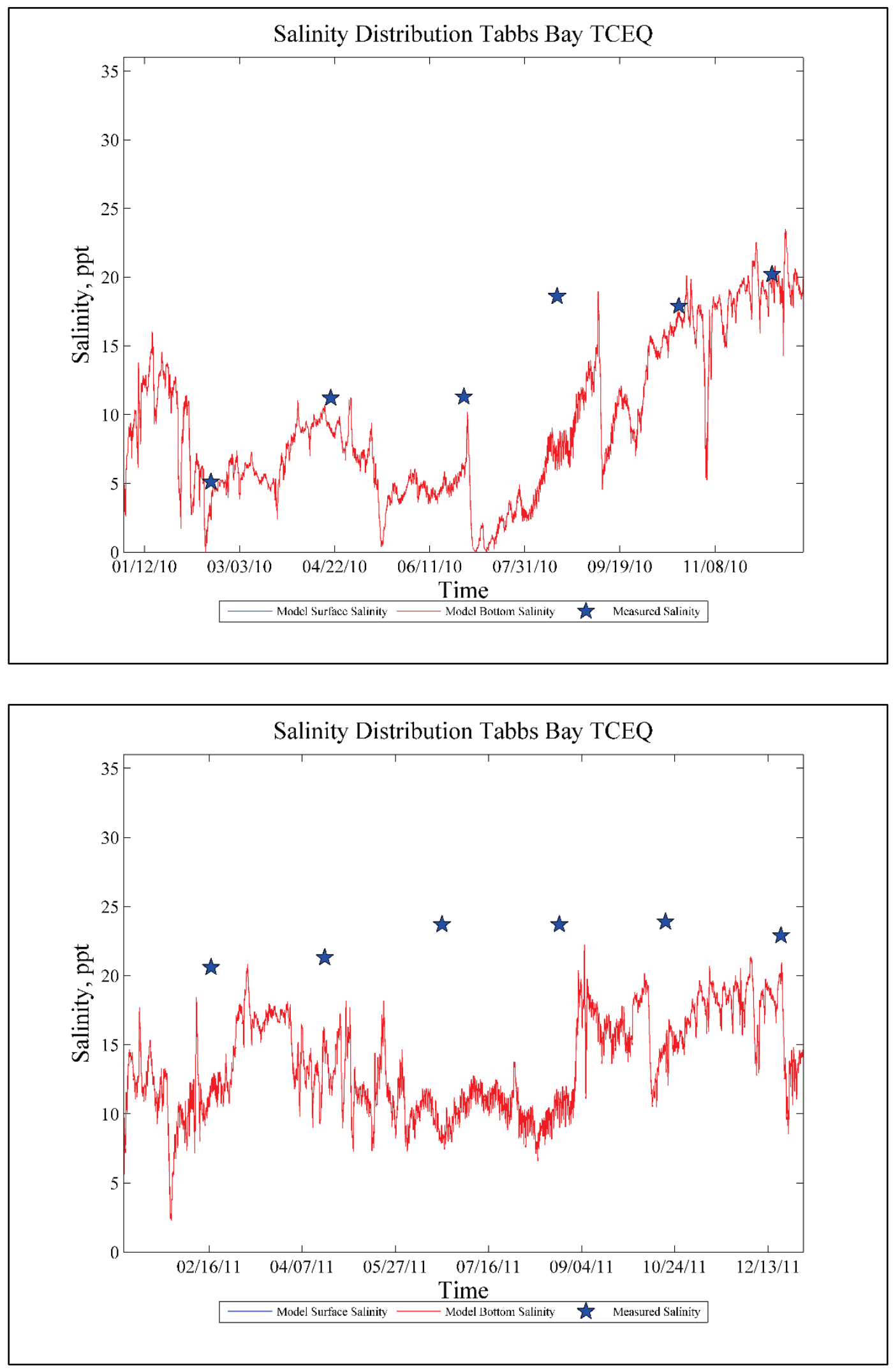

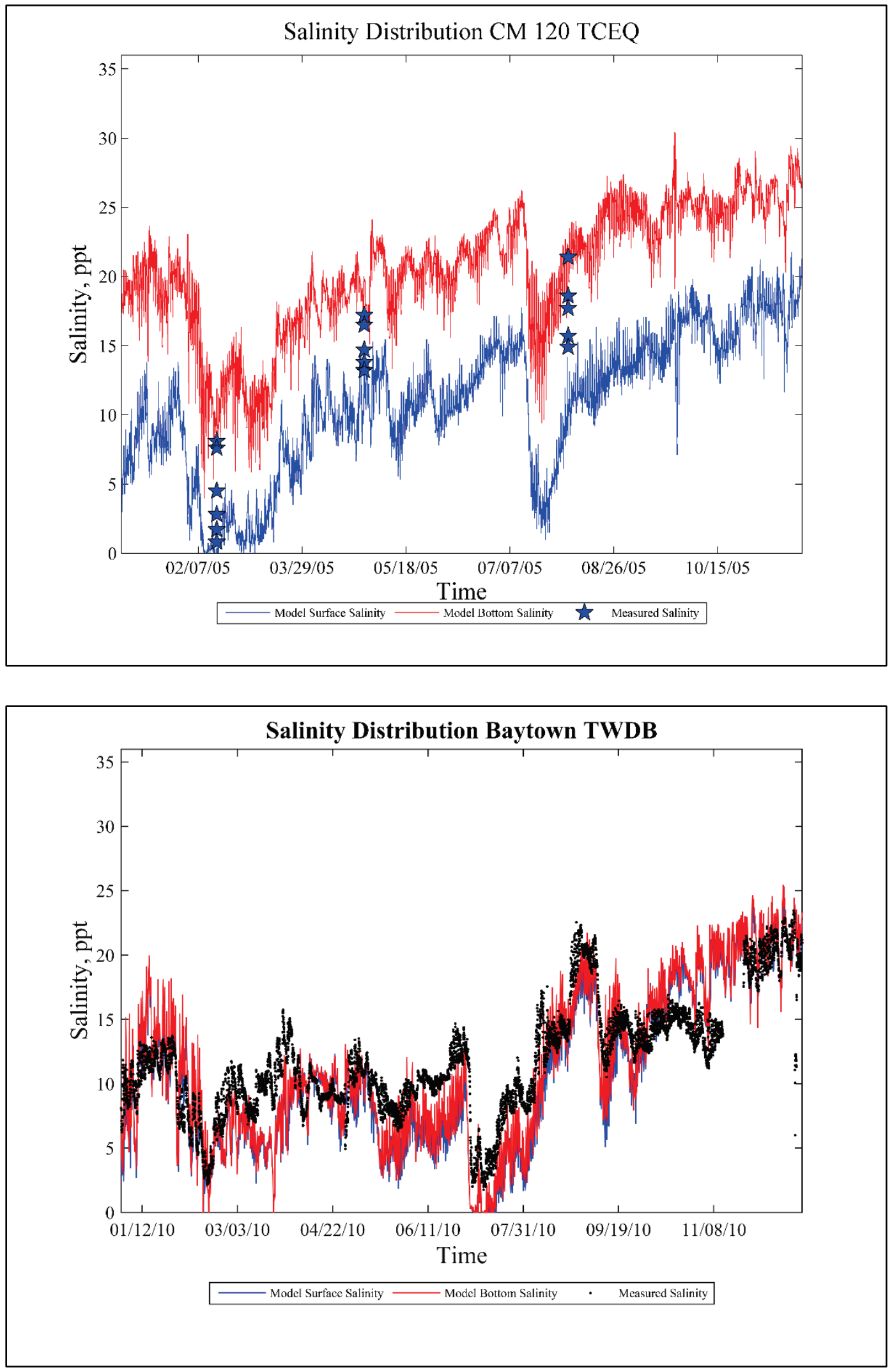

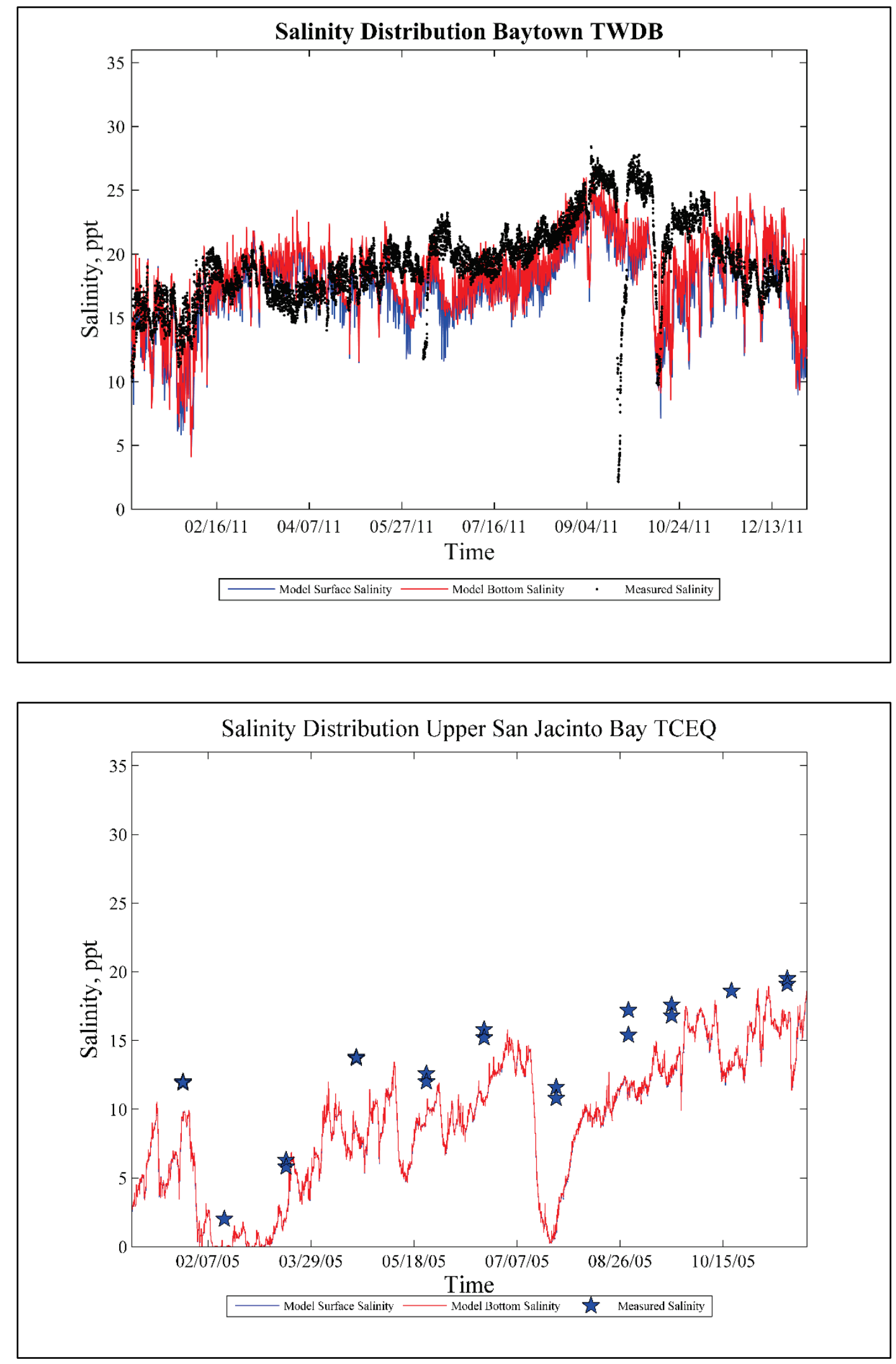

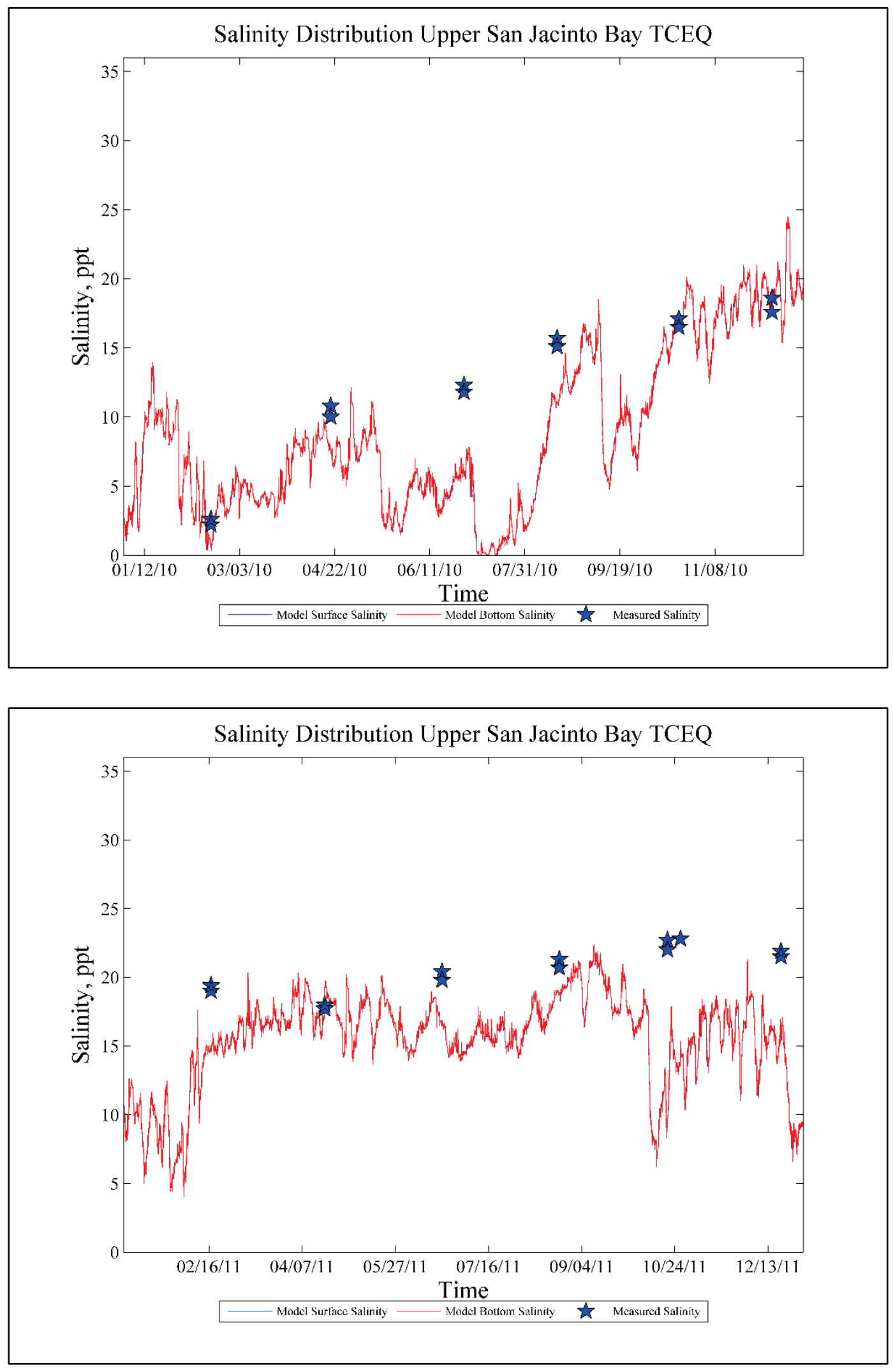

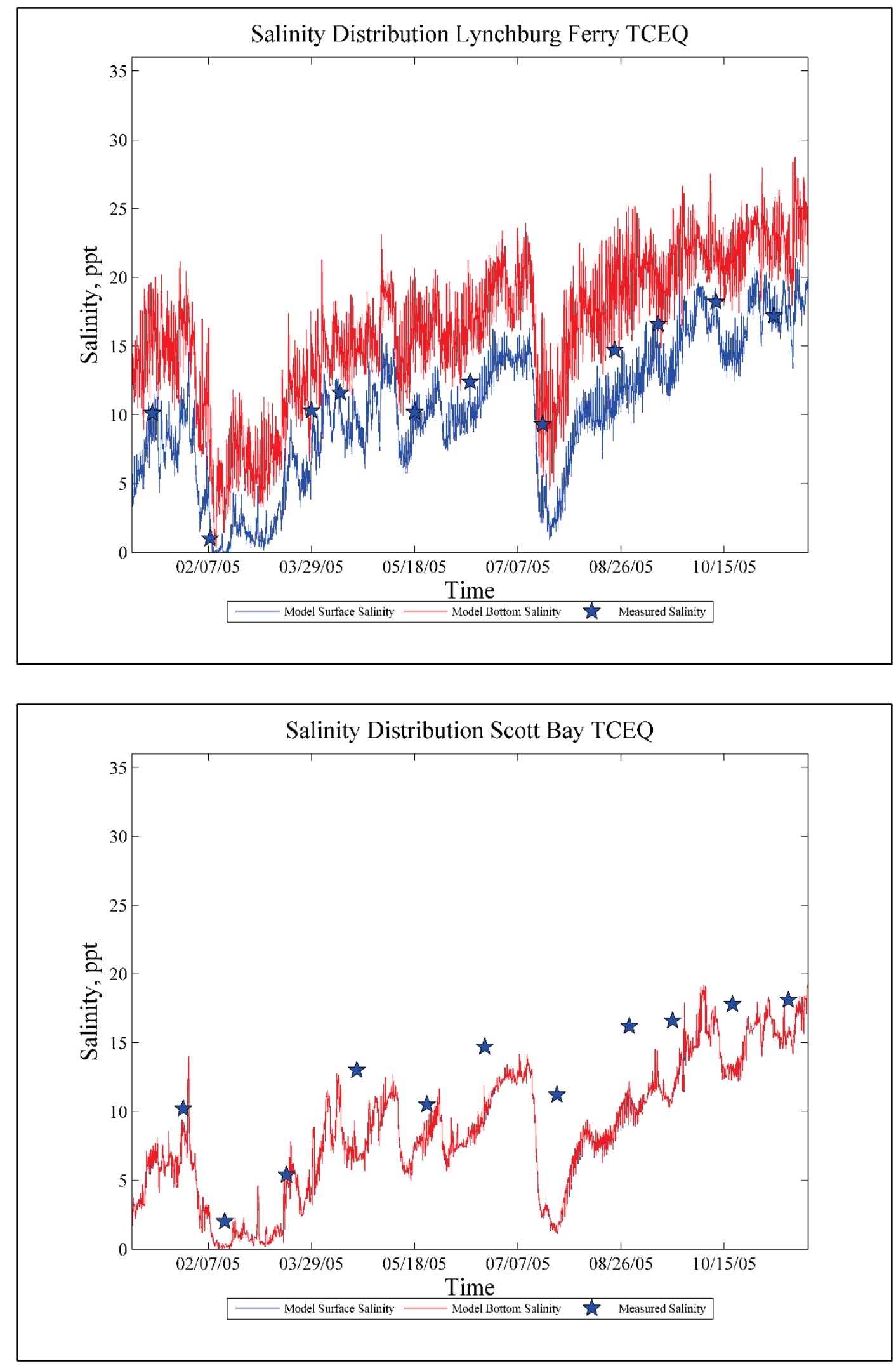

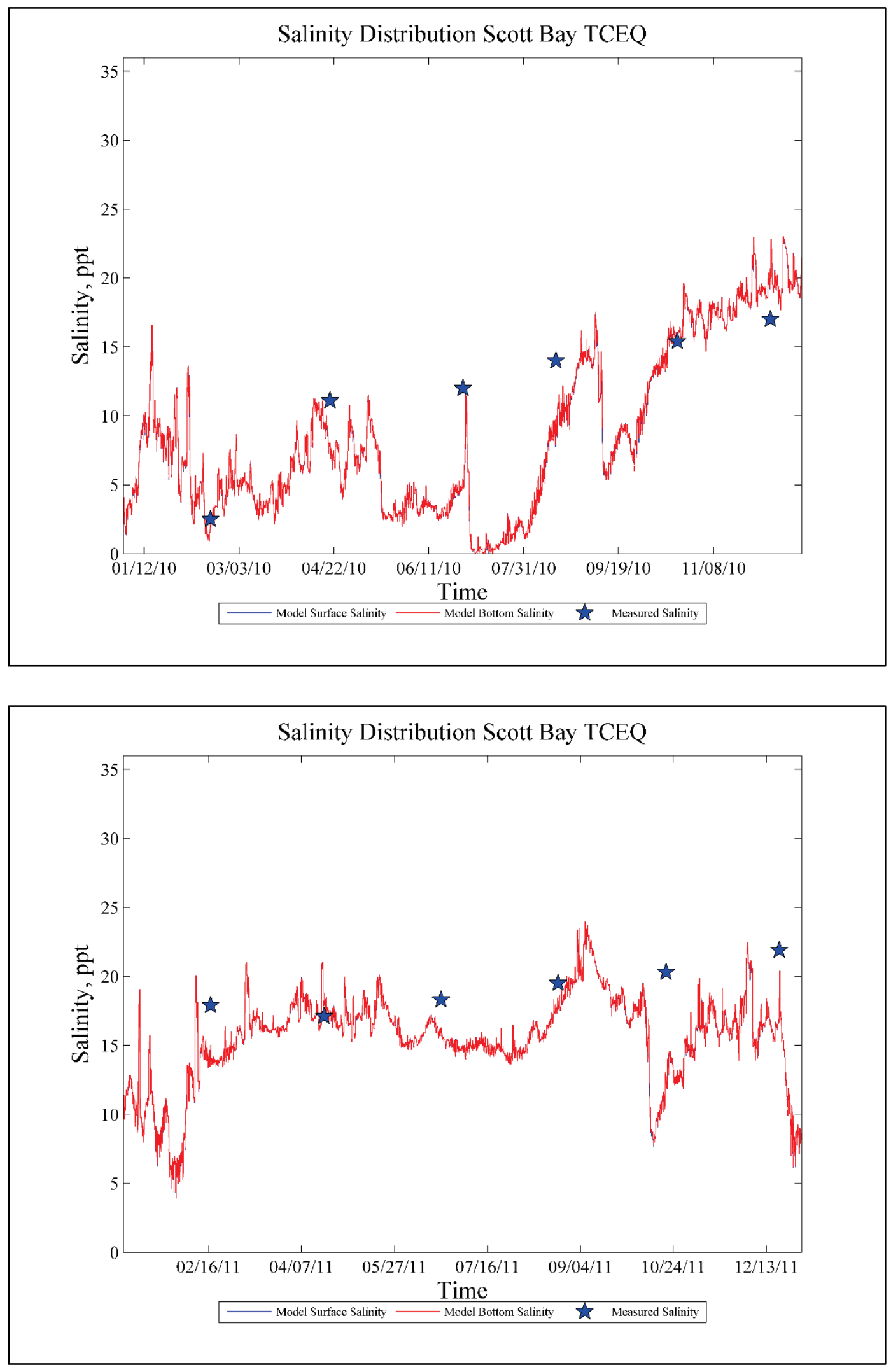

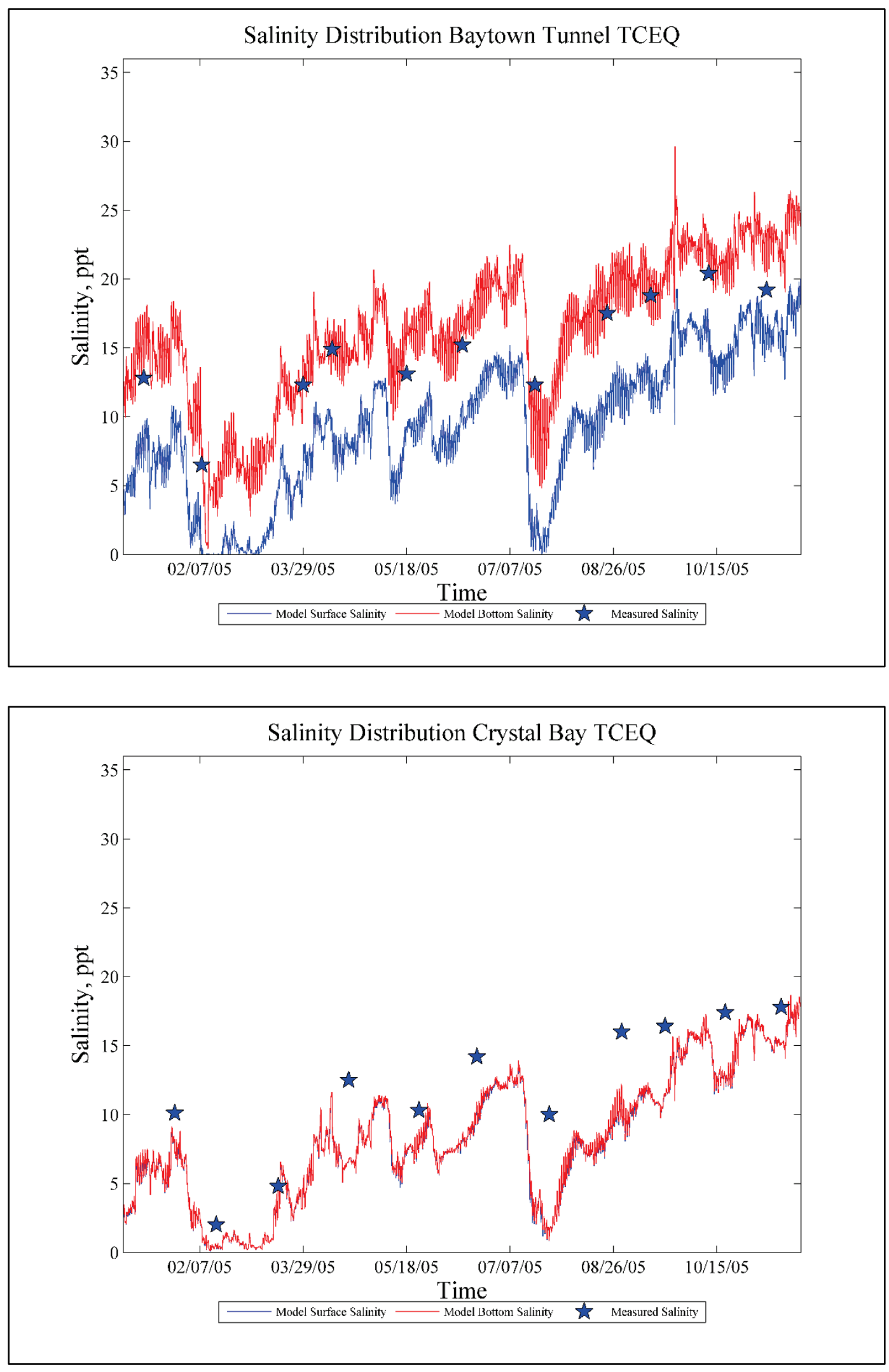

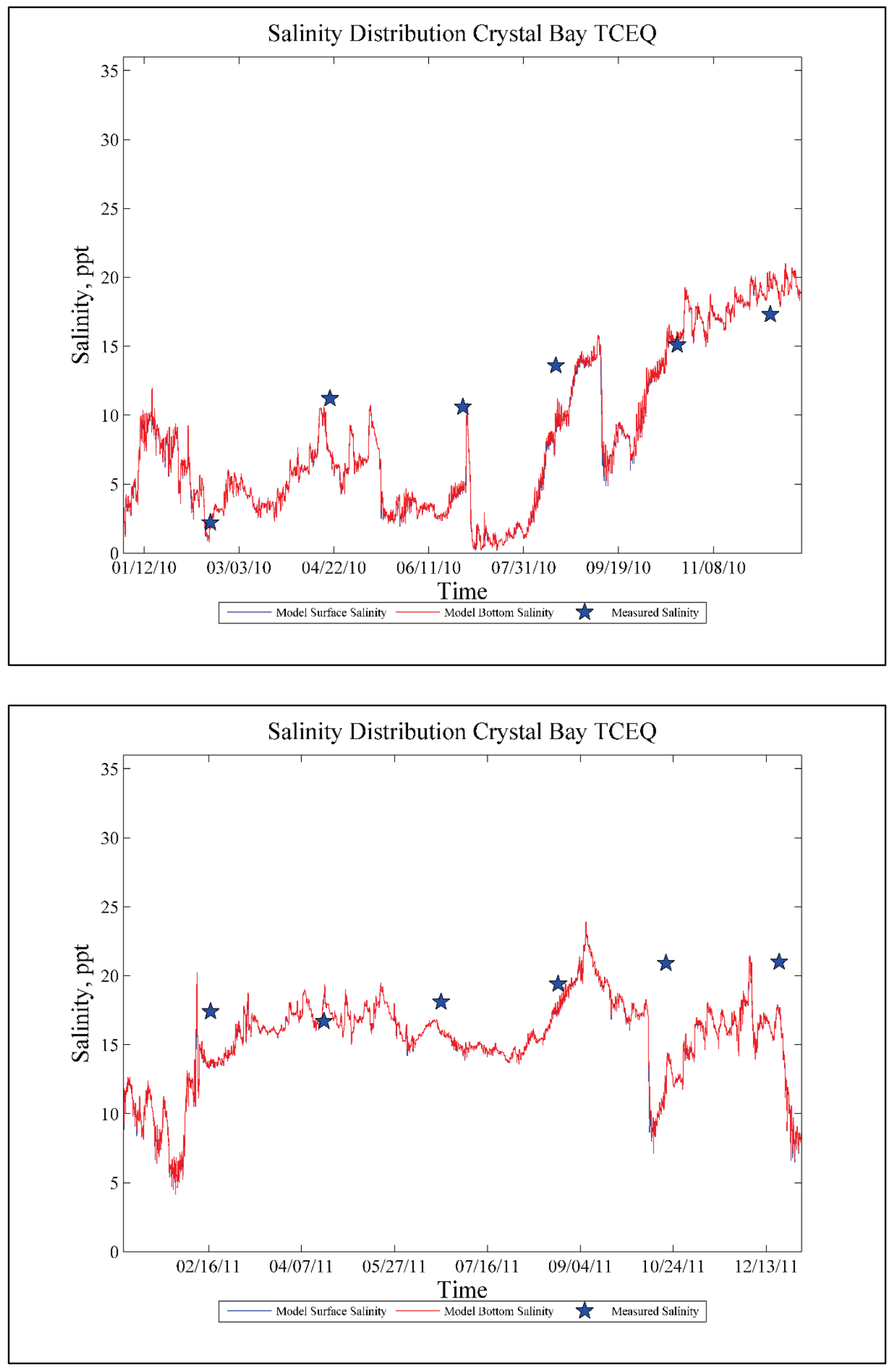

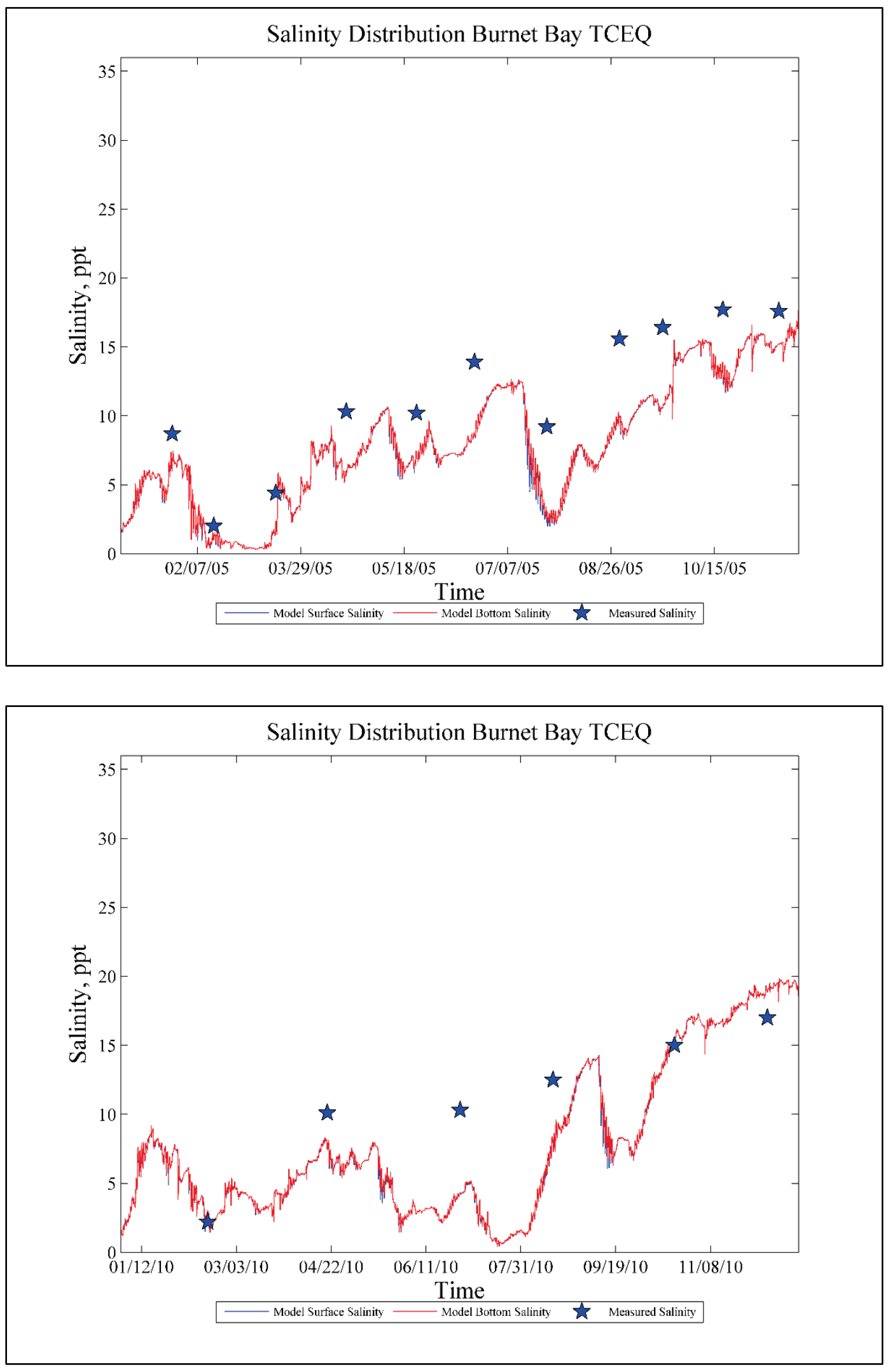

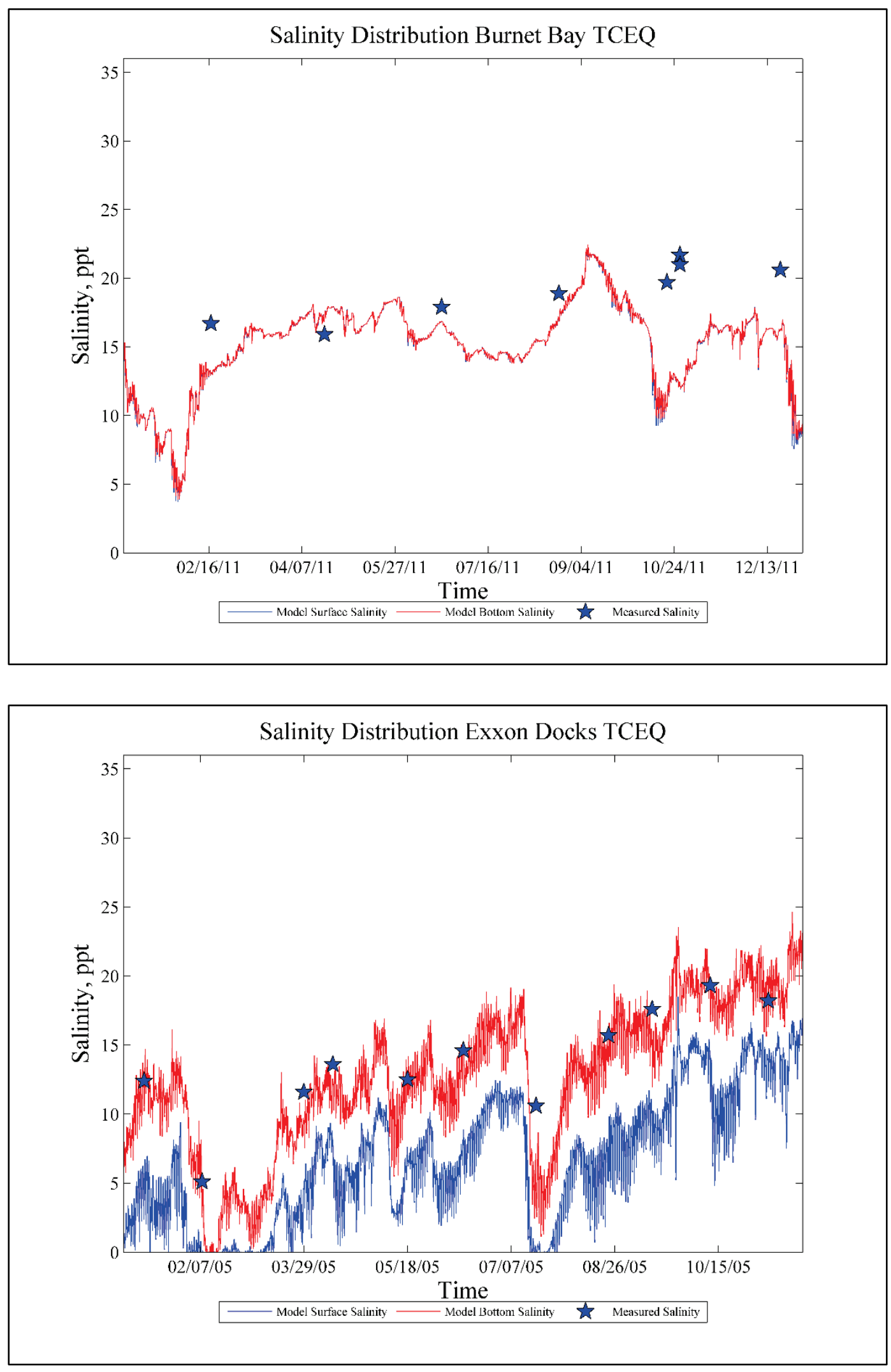

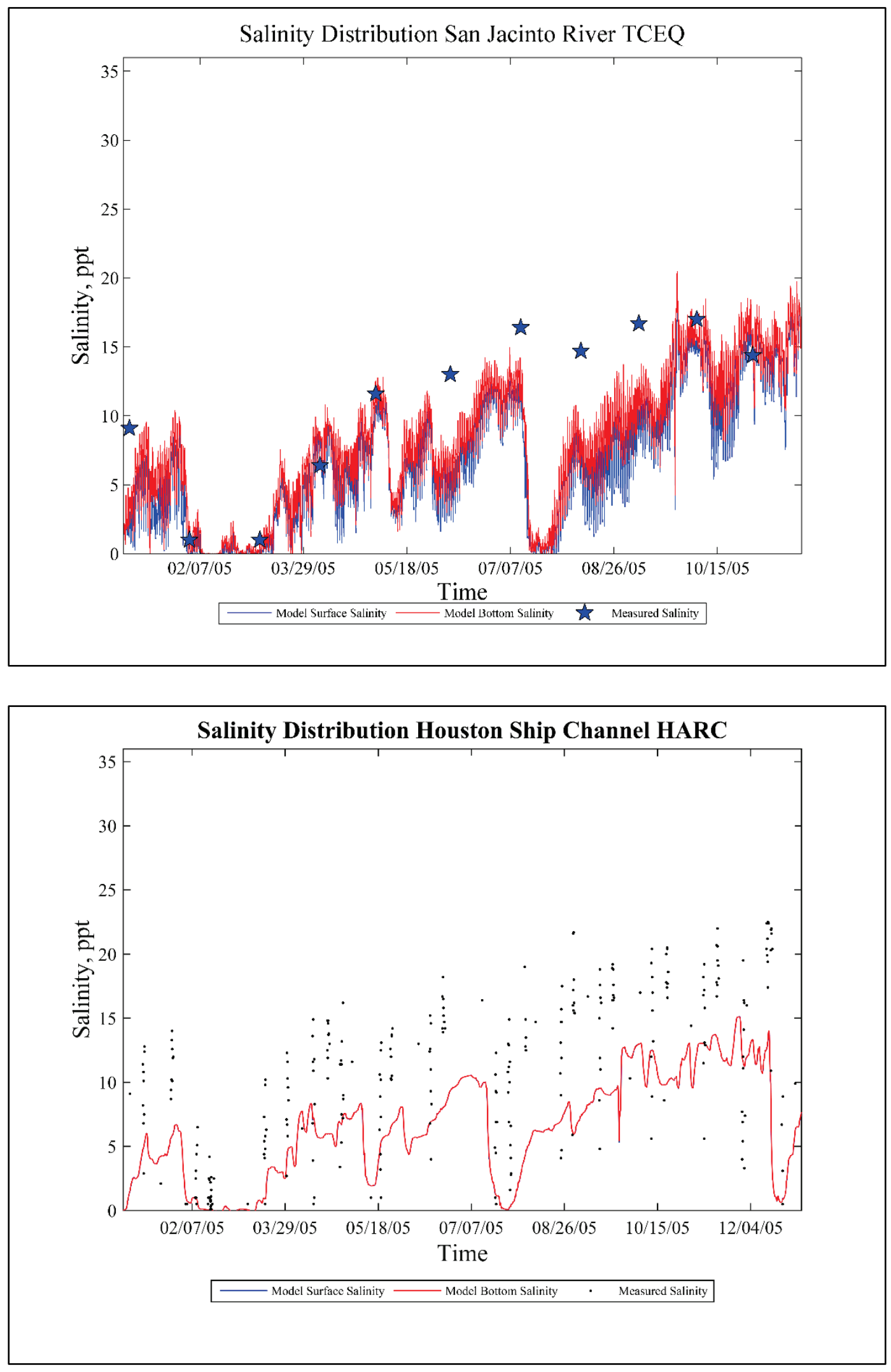


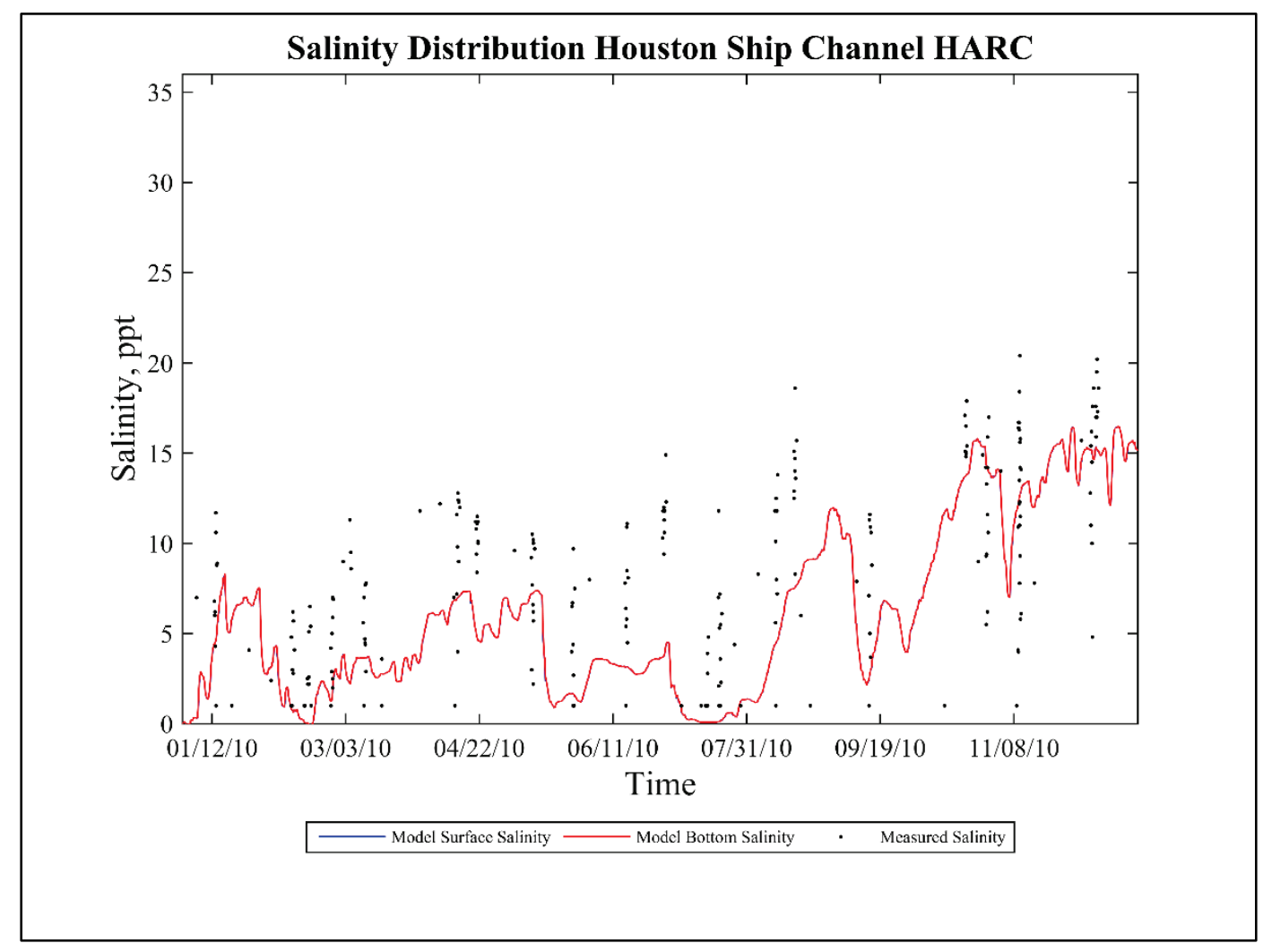




\section{Unit Conversion Factors}

\begin{tabular}{|l|l|l|}
\hline Multiply & By & To Obtain \\
\hline acres & $4,046.873$ & square meters \\
\hline acre-feet & $1,233.5$ & cubic meters \\
\hline cubic feet & 0.02831685 & cubic meters \\
\hline cubic inches & $1.6387064 \mathrm{E}-05$ & cubic meters \\
\hline cubic yards & 0.7645549 & cubic meters \\
\hline feet & 0.3048 & meters \\
\hline inches & 0.0254 & meters \\
\hline knots & 0.5144444 & meters per second \\
\hline miles (nautical) & 1,852 & meters \\
\hline miles (U.S. statute) & $1,609.347$ & meters \\
\hline square feet & 0.09290304 & square meters \\
\hline square yards & 0.8361274 & square meters \\
\hline yards & 0.9144 & meters \\
\hline
\end{tabular}




\section{List of Abbreviations}

\begin{tabular}{|c|c|}
\hline $\mathrm{AdH}$ & Adaptive Hydraulics \\
\hline AGU & American Geophysical Union \\
\hline AWAC & Acoustic Wave and Current Profiler \\
\hline CTR1 & Coastal Texas Region 1 \\
\hline ERDC-CHL & $\begin{array}{l}\text { Engineer Research and Development Center, } \\
\text { Coastal and Hydraulics Laboratory }\end{array}$ \\
\hline FWP & Future With Project \\
\hline FWOP & Future Without Project \\
\hline GERG & Geochemical and Environmental Research Group \\
\hline HARC & Houston Advanced Research Center \\
\hline HSC & Houston Ship Channel \\
\hline MLLW & Mean Lower Low Water \\
\hline NAVD88 & North American Vertical Datum 1988 \\
\hline NOAA & National Oceanic and Atmospheric Administration \\
\hline PWP & Present With Project \\
\hline PWOP & Present Without Project \\
\hline SLR & Sea Level Rise \\
\hline SMS & Surface Water Modeling System \\
\hline SWG & US Army Engineer District, Galveston \\
\hline TABS & Texas Automated Buoy System \\
\hline TCEQ & Texas Commission on Environmental Quality \\
\hline TSP & Tentatively selected plan \\
\hline TWDB & Texas Water Development Board \\
\hline TxRR & Texas Rainfall Runoff Model \\
\hline USACE & U.S. Army Corps of Engineers \\
\hline USGS & U.S. Geological Survey \\
\hline UTM & Universal Transverse Mercator \\
\hline WIS & Wave Information Studies \\
\hline $2 \mathrm{D}$ & Two-dimensional \\
\hline $3 D$ & Three-dimensional \\
\hline
\end{tabular}




\section{List of Unit Abbreviations}

\begin{tabular}{|l|l|}
\hline $\mathrm{ft}$ & feet \\
\hline $\mathrm{m}$ & meters \\
\hline $\mathrm{m}^{3}$ & cubic meters \\
\hline $\mathrm{cms}$ & cubic meters per second \\
\hline $\mathrm{m} / \mathrm{s}$ & meters per second \\
\hline $\mathrm{mg} / \mathrm{l}$ & milligrams per liter \\
\hline $\mathrm{ppt}$ & parts per thousand \\
\hline
\end{tabular}


The public reporting burden for this collection of information is estimated to average 1 hour per response, including the time for reviewing instructions, searching existing data sources, gathering and maintaining the data needed, and completing and reviewing the collection of information. Send comments regarding this burden estimate or any other aspect of this collection of information, including suggestions for reducing the burden, to Department of Defense, Washington Headquarters Services, Directorate for Information Operations and Reports (0704-0188), 1215 Jefferson Davis Highway, Suite 1204, Arlington, VA 22202-4302. Respondents should be aware that notwithstanding any other provision of law, no person shall be subject to any penalty for failing to comply with a collection of information if it does not display a currently valid OMB control number.

PLEASE DO NOT RETURN YOUR FORM TO THE ABOVE ADDRESS.

\begin{tabular}{|l|l|l}
\hline 1. REPORT DATE & 2. REPORT TYPE & 3. DATES COVERED (FrOm - To)
\end{tabular}

June 2019

Final Report

\section{TITLE AND SUBTITLE}

Houston Ship Channel and Vicinity Three-Dimensional Adaptive Hydraulics (AdH)

Numerical Model Calibration/Validation Report

5a. CONTRACT NUMBER

5b. GRANT NUMBER

5c. PROGRAM ELEMENT NUMBER

Jennifer McAlpin, Cassandra Ross, and Jared McKnight

\section{5d. PROJECT NUMBER}

5e. TASK NUMBER

5f. WORK UNIT NUMBER

$145745 \& 451902$

8. PERFORMING ORGANIZATION REPORT NUMBER

ERDC/CHL TR-19-10

10. SPONSOR/MONITOR'S ACRONYM(S)

USACE SWG

11. SPONSOR/MONITOR'S REPORT NUMBER(S)

\section{DISTRIBUTION/AVAILABILITY STATEMENT}

Approved for public release; distribution is unlimited.

\section{SUPPLEMENTARY NOTES}

\section{ABSTRACT}

The Houston Ship Channel is one of the busiest deep-draft navigation channels in the United States and must be able to accommodate larger vessels as needed. The U.S. Army Engineer District, Galveston, requested the U.S. Army Engineer Research and Development Center, Coastal and Hydraulics Laboratory, perform hydrodynamic, salinity, and sediment transport modeling of proposed modifications along the Houston Ship Channel from its connection to the Gulf of Mexico to the Port of Houston as well as alterations for storm protection. The modeling results are necessary to provide data for salinity and sediment transport analysis as well as a ship simulation investigation to determine the navigational impacts of the proposed alternatives. The model setup and validation are presented in this report. The model proved to match field data for water surface elevation, velocity, and shoaling in the ship channel over three simulation years - 2005, 2010, and 2011.

\section{SUBJECT TERMS}

Coastal engineering-Numerical, Houston Ship Channel (Tex.), Inland navigation, Hydrodynamics, Salinity, Sedimentation and deposition, Sediment transport

16. SECURITY CLASSIFICATION OF:

\begin{tabular}{|l|c|c|r|}
\hline a. REPORT & b. ABSTRACT & c. THIS PAGE & ABSTRACT \\
Unclassified & Unclassified & Unclassified & SAR \\
\end{tabular}

18. NUMBER OF PAGES

133 19a. NAME OF RESPONSIBLE PERSON

S

19b. TELEPHONE NUMBER (Include area code) 601-634-2511 